


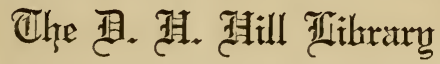

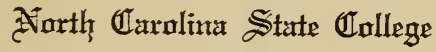

$$
\begin{array}{r}
\text { SF95 } \\
\text { K55 }
\end{array}
$$




\section{Date Due}

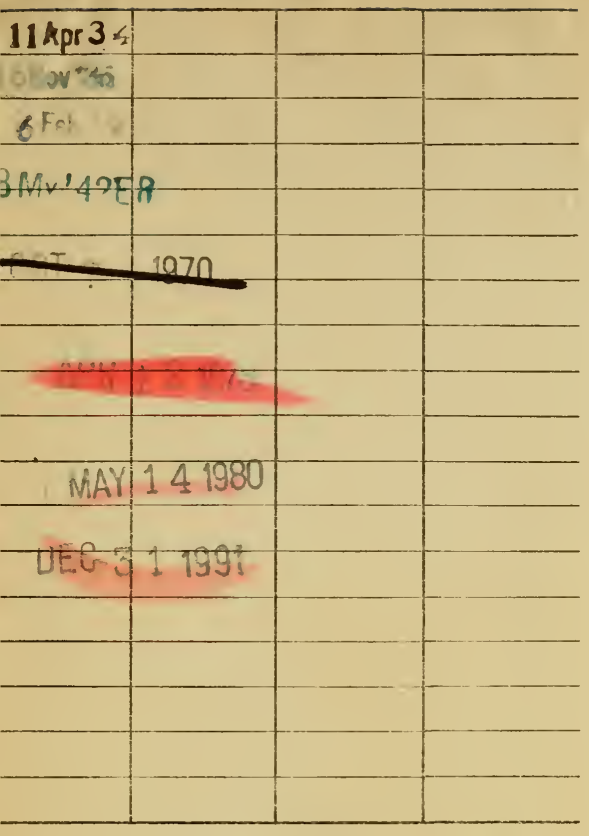

L. B. Cat. No. 1137 




\title{
SCIENTIFIC FEEDING
}

OF THE

\section{DOMESTIC ANIMALS}

by

\author{
Dr. Martin Klimmer, Ph.D., D.M.V.
}

Professor of Hygiene and Feeding, and Director of the Hygienic

Institute of the Veterinary College of Dresden

Third Revised and Enlarged Edition

94 Illustrations

Authorized Translation by

Paul Fischer, B.S.A., D.V.M.

Formerly Professor of Pathological Anatomy in the Ohio State University. College of Veterinary Medicine, State Veterinarian of Ohio, etc.

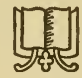

Chicago, U. S. A.

ALEXANDER EGER, PUBLISHER 
Copyright,

1923,

by

Alexander Eger 


\section{TRANSLATOR'S PREFACE}

The translation of Klimmer's admirable work on Veterinary $\mathrm{Hy}$ giene and Scientific Feeding of Animals was undertaken at the suggestion of the publisher, Mr. Alexander Eger, with the hope and belief that in doing so the translator was rendering a real service.

While some of the ideas and practices outlined in this work do not entirely fit into the economy of our own country and many changes and adaptations might have been made and served a useful purpose, the translator believed that a practically literal translation of the work as offered by the author would be not only more interesting to the American student but really more instructive.

A comparison of the careful and painstaking methods of the German people and their continual efforts to economize, with our own characteristically wasteful practices, even though conditions prevailing with us are entirely different, cannot fail to have a wholesome influence.

The translator has therefore confined himself to adding only here and there a few words of explanation which he believed necessary for clearness, either in the form of footnotes or remarks in parentheses in the text.

The translator wishes to express his sincere thanks to his friend, Dr. J. R. Mohler, Chief of the United States Bureau of Animal Industry, for reading the manuscript before its submission to the printer: making valuable suggestions in the arrangement of the text and adding instructive footnotes. Dr. Mohler's suggestion that the extensive references to technical literature which are appended to most chapters in the original German edition, be omitted, was also followed. It was mutually agreed that since this would be of value only to students familiar with the German language the original work of Dr. Klimmer would be available to them for such references.

The translator wishes further to express his appreciation to the publisher, Mr. Eger, for his patience in overlooking the many annoying but unavoidable delays in preparing the manuscript and reading the final proof of this translation.

Paul Fischer.

Bartow, Florida.

February 10, 1923. 



\section{ABSTRACT FROM THE PREFACE TO THE FIRST EDITION}

In accordance with the great practical importance of a knowledge of feeding and of injurious feed admixtures I have devoted liberal space to this department of veterinary hygiene. The principles of feeding as elaborated in this work have been based upon the epoch making labors of Kellner who has directed the study of this science into new channels. The kindness and obligingness of Prof. Dr. Kellner and of the Publishing House of Paul Parey has made it possible to include the tables on the composition, digestibility and starch value of feeding stuffs to which I have added for the sake of handy reference the digestible albumen and starch value ratios as well as the table of condensed feeding standards. I consider it a pleasant duty to express my sincere thanks for the kind permission granted to publish these tables.

Dresden, in the fall of 1917.

\section{ABSTRACT FROM THE PREFACE TO THE SECOND EDITION}

In revising this work it has been my endeavor to correct any existing shortcomings of the first edition which have been kindly pointed out by my critics, and further, to make such changes and additions as recent investigations and discoveries demanded.

Dresden, November, 1913.

\section{PREFACE TO THE THIRD EDITION}

The recent decision in favor of the separate consideration of the study of feeding and veterinary hygiene in the college courses of veterinary medicine and in state examinations has been the motive for the publication in two separate volumes, "Veterinary Hygiene" and "Scientific Feeding of Animals," of my former work which was published under the common title of "Veterinary Hygiene."* Whether this division and separate consideration of the subjects was practical and necessary is a matter concerning which differences of opinion may well exist. I regret it.

The fact remains that animal nutrition is one of the most important branches of the study of veterinary hygiene. A sharp distinction between these two divisions is not always possible.

*Note. First Volume. Hygiene of the Domesticated Animals. Third revised and enlarged edition. With 270 illustrations. About 440 pages. Berlin. 1921. 
Important sections as for instance those on injurious feed admixtures and pasturage, which to this day are considered as coming properly under the subject of veterinary hygiene, constitute an intimate connecting link between hygiene and feeding. Furthermore, I do not consider it wise that a comparatively restricted field of study which is practically complete in itself (Veterinary Hygiene) should be artificially subdivided into two dependent halves (hygiene and feeding). Not even the temporary interests of the student would justify such unwarranted proceedings. On the contrary, pedagogic interests would be served by dealing with related subjects under as few heads as possible instead of an indefinite splitting up of subjects into every possible kind of specialty.

Notwithstanding my objections to this division of veterinary hygiene into separate sciences I have submitted to the trend of the times and published my "Veterinary Hygiene" in two parts, "The Science of Feeding" and "Hygiene of Domesticated Animals." As long as the entire work was published in one volume, objections were not so serious because the whole subject was always at hand for reference. But this no longer holds since the increased bulk of the work made its publication in two volumes almost necessary.

In the revision of the work numerous additions were called for in every part, thus the enlargement of the chapter on the conservation and preparation of feeding stuffs, the preparation of a key for the determination of the most important meadow grasses and descriptions of the same, the sections of feed for goats, dogs, poultry, ducks, geese, rabbits and fish. Discussions of several new feeding stuffs and substitute feeding stuffs have also been added and the chapters on examination of feeding stuffs and contaminations have been enlarged. Individual and group feeding have also received additional discussion. To conform with modern efforts to feed for economic production. The addition of 58 new cuts is believed to be a decided help in the study of this work.

In the revision of this work the extraordinary practical importance of the subject of "feeding" to the veterinary and agricultural interests has been kept constantly in mind.

My sincerest thanks are extended to Dr. Haupt and to Dr. Schadowsky for the laborious work of correcting the proof, and to the publishing house of Paul Parey for its ready compliance with all my requests.

May the revised third edition in its new form meet with the same kindly reception by its readers and critics as was the fate of its predecessors.

M. Klimmer.

Dresden, Fall of 1920. 


\section{CONTENTS}

\section{INTRODUCTION}

Politico-economical Considerations on Animal Husbandry and Feeding . 1

SECTION I

\section{Feeding Stuffs}

A. General Matter.

a. Chemical Composition of Feeding Stuffs : : $2_{2}^{2}$

Nutrients and Condimental Substances . . . . . . . 2

I. Water and dry matter . . . . . . . . . . . 3

II. Salts . . . . . . . . . . . . . . . . . 4

III. Albumens

Appendix: Ferments (enzymes) and Vitamins . . 7

Nitrogenous compounds, not belonging to the albumens (amidocompounds, nitrogen-containing glycosids, alkaloids, salts of ammonia and nitric acid . . . . . . . . . . . . 8

IV. Fats

V. Carbohydrates . . . . . . . . . . . 11

1. Crude fiber (cellulose, pentosanes) . . . . 11

2. Nitrogen-free extractives (easily digestible carbo-hydrates), (starch, cellulose, dextrine, sugars, pectin substances, pentosanes and pentoses), organic acids (lactic, formic, acetic, butyric, malic, tartaric, citric and tannic acids), nitrogen free glycosids and bitter principles . . . . . . 12

b. The Conservation and Preparation of Feeding Stuffs . . . 16

I. Conservation . . . . . . . . . . . . . 16

1. Storage . . . . . . . . . . 16

2. Drying

a. Hay Making . . . . . . . . . . . 19

b. Artificial drying : . . . . . 21

3. The Conservation of Feeding Stuffs by means of Fermentation . . . . . . . . . . . . . . 23

a. Baked hay . . . . . . . . . . . 23

b. Brown hay : . . . . . . . . . 23

c. Sweet Silage . . . . . . . . . . . 24

d. Sour Silage. . . . . . . . 27

II. The Preparation of Feeding Stuffs . . . . . . . 28

1. The reduction of coarse material into fine particles . . . 28

2. Moistening and Soaking . . . . . . . . . . 28

3 . Cooking, scalding and steaming . . . . . . . . . 28

4. Roasting . . . . . . . . . . . . . . 28

5. Leaching : . . . . . . . : 28

6. Fermenting . . . . . 28

7. The Conversion of Indigestible into Digestible Matter . 28

8. Predigestion . . . . . . . . . . . . . . 28

9. Baking . . . . . . . . 28

B. The Most Important Feeding Stuffs . . . . . . . . . . . 34

I. Green Forage . . . . . . . . 35

Botanical Matters relating to pastures and Pasture Grasses . 35

Sweet Grasses. Key for their Determination . . . . . : 36

Sour grasses. Scouring Rushes . . . . . . . . . . 43

Herbaceous Meadow plants . . . . . . . . . . . . 44

Chemical Study of Pasture Grasses : . : . . . 44 
Affect of Age of Plants, Soil, Fertilization, Weather and Climate on Composition of Plants . . . . . . 45 Hygienic Matter. Advantages and Disadvantages of Soiling . 45 Diseases, effect upon milk. . . . . . . . . . 46 Uses of Green Forages . . . . . . . . . . . . 47 Green Rye, Wheat, Barley, Indian Corn, Sorghum . . . . 47 Varieties of Clovers, Nutritive Value, Disadvantages . . . . 49 Lupines, Clovers, Kidney Vetch, Esparcet, Serradella, etc. . . 50 Leaves of Beets, Chicory, Comfrey, Potato tops, Thistles . . 56 Prickly Dyer's Broom, Fungi . . . . . . . . . 56

II. Roughage . . . . . . . . . . . . . . . 57

1. Hay . . . . . . . . . . . . 57

a. Meadow Hay and Aftermath . . . . . . 57

Judging the Value of Hay $: 58$

Irrigated Meadows, Woodland, Alpine and Salt Marsh Hay . . . . . . . . . . 59

Hygienic Requirements and Uses of Various Kinds of Hay . . . . . . . . . 61

Sweet Silage and Sour Ensilage . . . . . . 62

b. Clover Hay, Lupine Hay, Leaf Hay and Twig Hay : 63

2. Straw

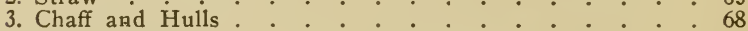

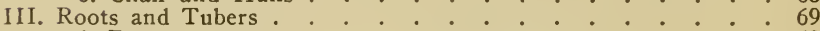

1. Potatoes . . . . . . . . . . . . . 69

2. Artichokes . . . . . . . . . . . . . . 73

3. Beets . . . . . . . . . . . . . 74

IV. Cereal Grains, Legume Seeds : . . . . . . . 76

1. The Cereal Grains . . . . . . . . . . . 76

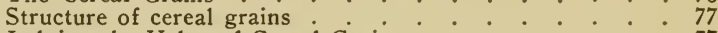

Judging the Value of Cereal Grains . . . . . . . 77

Requirements for Soundness . . . . . . . . . 77

a. Oats . . . . . . . . . . . 81

Varieties of Oats $: \div \quad \div \quad \div \quad \div$

The grain of the Oat, the oat hull, chemical composition 81

Digestibility and Agreeability, Judging the Value of the 83

Oat Grain, Uses and Substitutes . . . . . . 86

b. Barley . . . . . . . . . 87

c. Rye and Wheat $:$. . . . . . 99

d. Indian Corn . . . . . . . . . . . . . . 91

e. Millet and Rice. . . . . . . . . . . . . 92

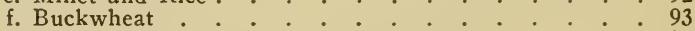

2. The Seeds of Legumes : . . . . . 93

a. Field bean, Peas, Vetches and Serradella . . 93

b. Lupines . . . . . . . . . . . . . 96

c. Soybean $: \div \quad \div \quad \div \quad \div \quad \div \quad \div$

Miscellaneous Seeds. Field Spurry, Flax Seed, Rape, Turnip seed, Hemp seed, Buck wheat, Acorns, Buckeyes and Beechnuts . . . . . . . . . . . . 98

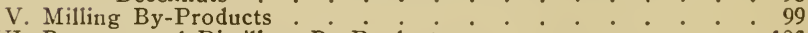

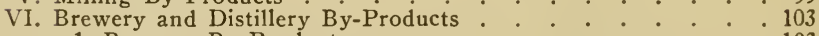

1. Brewery By-Products . . . . . . . . . . . 103

2. Distillery Wastes or By-Products . . . . . . 105

3. By-Products of Wineries and Ciderpresses : . . . 107

VII. Sugar Refinery By-Products . . . . . . . . . . . 107

VIII. Starch Factory By-Products . . . . . . . . . . . 111

IX. By-Products of Oil Production . . . . . . . . . . 112

X. Feeding Stuffs of Animal Origin . . . . . . . . . . 124

XI. Substitute Feeding Stuffs . . . . . . . . . . . . 128

XII. Calculation of the Money, Value of Feeding Stuffs . . . . 129

XIII. Examination or Inspection of Feeding Stuffs . . . . . . 131

C. General Rules for the Purchase of Commercial Feeding Stuffs . . . . 131

Hygienic Examination of Feeding Stuffs . . . . . . . 133 
Page

1. Chemical Examination . . . . . . . . 134

a. Determination of Albumen, Fat, Nitrogen-free Extract, Crude Fiber, Salts and Water

b. Determination of Sand, Lime, Infusorial Earth, Barite and other minerals.

c. Determination of Corn cockle, Ergot, etc., in Neals by means of Vogl's Reagent . . . . . . . . 134

d. Iodin-Starch Reaction . . . . . . . . . . 134

e. Testing Spoiled Feeding Stuffs . : . : : : 134

2. Biological (serological) Examination . . . . . . . 135

3. Microscopical Examination . . . . . • . 136 Preparation of Feeding Stuffs for Microscopical Examination 136 Examination for Starch Grains . . . . . . . 137 Examination of By-Products Containing Shells, Hulls, Skins, etc. a. Meals, and Brans of Rye, Wheat, Barley, Corn and Oats 142

b. By-Products of Oil Production . . . . . . . 143

c. Leguminosae . . . . . . . . . . . 144

d. Adulterations (rice chaff, stone fruit pits, saw dust, screenings, seeds of weeds, corn cockle, castor beans, etc.)

4. Bacteriological Examination

\section{CONTENTS}

\section{SECTION II}

\section{Principles of Nutrition and Feeding}

A. General Matter

Insufficient Nutriment, Overfeeding, Complete Feeding Stuffs, Basal Feeding Stuffs, Supplemental Feeding Stuffs and By-Feeds •. 148

Concentrates, Roughages, Organic Feeding Stuffs, Combustibles and Fuel Value, Maintenance and Production Rations, Assimilation and Utilization

I. Nutrient Requirements . . . . . . . . . . 150

1. Assimilation and Utilization . . . . . . . . . 150

2. Organic Nutrients . . . . . . . . . . 151

3. Inorganic Nutrients . . . . . . . . . . . 154

4. Testing Feed Utilization and Assimilation . . . . 161

II. Calculation of Feeding Rations and Feeding . . . . . 164

B. Special Feeding . . . . . . . 173

I. Maintenance Feed (For Oxen and Wool-producing Sheep) . 173

II. Rations for Work Animals . . . . . . . . . . . 175

1. For Oxen . . . . . . . . . . . 176

2. For Horses

III. Rations for Growing Animals . . . . . . . . . 179

1. Rations for Colts . . . . . . . . . . . . 182

2. Rations for Calves . . . . . . . . 183

3. Rations for Lambs . . . . . . . . . . . 188

4. Rations for Pigs . . . . . . . . . . 190

IV. Fattening Rations for Mature Animals : . . . . . 193

1. Fattening Rations for Mature Ruminants . . . . . 194

2. Fattening Rations for Mature Swine . . . . . 198

V. Rations for Dairy Animals . . . . . . . . . . . 198

1. The Influence of Feed on Milk Secretion . . . . 199

2. Standardization of Rations for Cows . . . . . . 201

3. Rations for Goats . . . . . . . . . . 204

VI. Rations for Dogs . . . . . . . . . . . . . 205

VII. Poultry Feed . . . . . . . . . . . . . . 207

1. Feeding Chickens . . . . . . . . . 207

2. Feeding Ducks . . . . . . . . . . . 212 
3. Feeding Geese Page

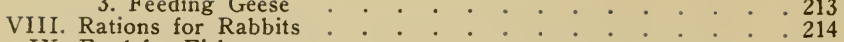

IX. Feed for Fish . . . . . . . . . . . . . 215

A. Fertilization : . . . : : : : : 215

B. Artificial Feeding . . . . . . . . . 221

Appendix. Dietetic Feed Mixtures . . . . . 223

Table I. The Composition, Value, Digestible Albumen Content, Starch Value, and Albumen-Starch-Value Ratio of Feeding Stuffs 225

Table II. The Composition of the Salts in Feeding Stuffs . . . 228

Index . . . . . . . . . . . . . . . . . .233 


\section{Introduction}

Scientific feeding may be defined as the conversion of elementary feeding stuffs into animal product or performance. Since domestic animals are not kept for their own sake, but for the profit of their owners, they must be kept and fed upon a purely economic basis. With due attention to the question of health, our every effort should be directed to maximum production at minimum expense. The cost of feed alone represents a very considerable item in the expense of growing or keeping an animal. Important economies may be practiced in the selection of feeding stuffs by substituting the less expensive for higher priced material of the same feeding value. In connection with the problem of feeding for production or gain, that of maintenance during certain unproductive intervals, as, for example, dry milk cows, or work horses in the idle season, is of equal importance.

The actual cost of the feed which enters into production expense will be discussed more in detail in the sections on the money value of feeding stuffs and the testing of feed-utilization. In passing it may be remarked, however, that the cost of production very frequently is altogether out of proportion to the actual gain secured, whether this be due to the presence of so-called passive animals or to the selection of unnecessarily highpriced feeding stuffs when equally good material at a lower market price might have been available. Thus the use of comparatively high-priced oats for horses, high-priced bran for milk cows and high priced barley for swine is not economical when cheaper feeding stuffs, such as potatoes, dry yeast, oil cake, etc., of equal feeding value, can be obtained and substituted. The Paris Omnibus Company with its 12,000 horses in this manner reduced the feeding expense of its horses by nearly 20 per cent. The animals thrived under the new conditions and continued to perform satisfactorily. In this respect the late war taught us many valuable lessons.

In feeding for profit not only the market value of the feed but, in no less degree, the resulting animal product and service must be taken into consideration.

Feeding must be conducted upon an individual basis. Fattening a draft horse is just as injudicious as starving a milk cow at the expense of reduced milk secretion.

In most agricultural and industrial establishments rational feeding has not yet received the attention which, in the present depressed economic conditions, is demanded more than ever before. Modern feeding technic can be the means of adding enormously to the national wealth. To accomplish this end we must use more arithmetic. Our farmers should be 
continually reminded of this fact. In herds of thirty cows an annual saving of 1,000 marks $(\$ 250)$ is in many cases easily possible. Economies of this kind are no more important to the agriculturist than to the country in general. The enormous sums of money that are expended for commercial feeding stuffs go for the most part to foreign countries. During the last pre-war years about $800,000,000$ marks $(\$ 200,000,000)$ were thus exported to foreign countries.

The science of feeding may be divided into: 1 . The study of feeding stuffs. This treats of origin, characteristics, composition, digestibility, palatability, advantages and disadvantages, impurities and adulterations, judging and using the various feeding stuffs, and their feeding value.

2. The study of the laws of feeding and nutrition. These treat above all of the food demands of animals for the varied economic purposes, the practical meeting of these demands by feeding and the principles underlying them.

The study of injurious or unwholesome qualities or ingredients of feeds is most intimately associated with the study of feeding and with that of feeding stuffs in particular. A sharp distinction is therefore not always possible. In spite of this intimate relationship the subject is not covered in this work, but in conformity to accepted custom is included in and treated with the subjects grouped under the term "hygiene."

\section{Section I \\ Feeding Stuffs}

The term "feeding stuffs" is applied to organic or inorganic food material of any character that will serve as nourishment for domestic animals and at the same time, when fed within practical limits, will not injure the health. Indigestible (muck, rice hulls, etc.) or poisonous substances (poisonous plants, etc.) are not included in this term.

\section{A. Chemical Constituents}

Feeding stuffs, as a rule, consist of a combination of several basic components-mutrient elements or nutrients. In addition they of ten contain so-called condimental or flavoring elements. The term nutricnt includes all those component parts of feeding stuffs which, after digestion and absorption, serve to produce heat and energy (combustibles), or the building of tissue (organogenic substances) or which are necessary in any other normal function of the body.

Nutrients are classified as follows:

I. Inorganic. (1) Water. (2) Salts, mineral matter or ash.

II. Organic. (a) Nitrogen-containing, or (3) albuminous substances or protein.

(b) Nitrogen-free, or (4) fats and (5) carbohydrates. 
Thus the five groups of nutrients may be divided or classified as water, salts, albuminous substances, fats and carbohydrates.

APPETIZERS are substances which, though possessing no nutritive value, have the effect of stimulating the appetite and secretion of digestive fluids. In addition there should be recognized certain salts, ethereal oils, bitter principles, vegetable acids and alkaloids (in small quantities).

\section{Water and Dry Matter}

The term "water" is in a general way applied to that constituent of feeding stuffs which evaporates upon drying at a temperature of $102^{\circ} \mathrm{C}$. $\left(215.6^{\circ} \mathrm{F}.\right)$. Loss from evaporation is not always limited to pure water, but includes ethereal oils, as well as products of decomposition, such as lactic acid, butyric acid, acetic acid, ammonia, etc., which should properly be added to the residue. The residue represents the "dry matter."

Feeding stuffs having a perfectly dry appearance, so-called air-dried feeding stuffs, as grain, bran, meal, oil cake, hay and straw, contain a certain amount of water, on an average 10 to 15 per cent.

All green forages contain a high percentage of water, averaging from 75 to 90 per cent. The same is true of root crops and potatoes and their factory waste products. Potatoes contain 70 to 75 per cent of water, beets 80 to 85 per cent, beet pulp 90 per cent, distillery slop 94 per cent. etc.

The relative proportion of dry matter and water in the food requirements of different species of animals varies thus: Horse, 1 to 2 or 3 : ox, 1 to 4 or 5 ; sheep, 1 to 2 ; swine, 1 to 6 or 7 . It is thus evident that swine thrive best on the more succulent feeds, horses and sheep on comparatively dry feeds, and cattle on intermediate combinations. Feeds too rich in water should be avoided.

The water content of feeding stuffs affects their feeding value. Succulent plants are less nutritious, or contain less nutrient material, than less succulent or dry plants of the same species. Grasses from meadows or pastures that were too wet (too much rain or irrigation) during the growing season contain more water and less dry matter and are consequently less nutritious than when grown under opposite conditions. Forage plants grown in the shade of trees or in other protected places usually contain proportionately less dry matter than in the same species grown under more natural conditions.

A knowledge of the water content of feeding stuffs is important also with reference to their keeping qualities. Feeding stuffs rich in water spoil easily (slop and beet and potato pulp). Meals and oil cakes are subject to decomposition and molding when they contain an excess of water (over 14 per cent).

Mold fungi predominate when the water content is between 15 and 30 per cent, while decomposition bacteria predominate when the moisture exceeds 30 per cent.

Determination of moisture content.-The substance to be analyzed should first be finely ground in a small mill. Five or ten grams of the powdered product are 
placed in a drying glass (Erlenmeyer flask) and dried at 102 to $105^{\circ} \mathrm{C}$. until the weight has become constant. This usually requires from three to five hours. The loss in weight represents the moisture content. In the case of succulent material, carefully weighed portions may be cut into small pieces, thoroughly dried, then ground in a mill, as above, and desiccated in the same manner.

\section{Salts, Mineral Matter, or Ash}

The mineral matter (salts, ash or inorganic matter) is what remains after destruction of the dry organic matter by burning.

The ash obtained from the weighed portion of the air-dried substance by the usual method of burning does not, however, represent the exact amount of mineral matter. On the one hand, small quantities of inorganic combinations of chlorin and sulphur are lost by volatilization; on the other hand carbonic, sulphuric and phosphoric acids are formed from the organic substance (e.g., the albuminous portions) during the process of combustion, combine chemically with potassium, sodium, lime and magnesia, and remain as a residue in the ash. Thus, when absolute accuracy is not essential, we merely determine the weight of the white (crude) ash, which may contain besides carbon dioxid, small amounts of charcoal and silica (or sand). For accurate results it is necessary to determine the amount of $\mathrm{CO}_{2}$ which entered into combination with mineral matter during combustion, and subtract the amount, with that of the silica, from the weight of the ash. (For further details see Beythien, Hartwig and Klimmer).

The principal mineral constituents of feeding stuffs are potash, sodium, calcium, magnesium, iron, aluminum, manganese, phosphoric acid, sulphuric acid, silicic acid and chlorin. In addition to these there are present occasionally and in small quantities or traces lithium, barium, rubidium, cæsium, iodin, bromin, etc. Under exceptional conditions there may be present lead, copper, arsenic, zinc. With reference to these poisonous mineral constituents, see Klimmer, Veterinary Hygiene. The mineral elements appear in the composition of plants, in part as inorganic salts, in part as organic combinations. The latter are especially valuable and important in the process of nutrition on account of the facility with which they are absorbed into the tissues.

The amount and character of the mineral matter in the different feeding stuffs varies according to the species of plant, the part of the plant in question, as well as soil, fertility and weather conditions. Methods of curing and commercial processes often affect the proportion to a considerable extent. The importance of salts or mineral matter in nutrition as well as in the conservation of health and efficiency of our domestic animals is frequently not sufficiently appreciated. Special consideration should be given to the mineral constituents of feeding rations, especially where the feeding is more or less artificial. Feeding stuffs do not always contain a sufficient amount of mineral matter, especially of lime, phosphoric acid and sodium chlorid. Less frequently they are deficient in potash. In dry seasons plants take up less mineral matter than in wet seasons for the reason that the necessary solvent, water, is absent. Soils deficient in these salts produce plants similarly deficient, etc.

In regard to the occurrence of the nutrient salts in feeding stuffs, the following should be noted:

Potash is abundant in so-called root croops (potatoes, artichokes, beets and beet molasses), in the seeds and straw of leguminous plants (excepting lupines), also in the hulls of beans, in young forage plants (aftermath), 
in wheat bran, rye bran, malt sprouts, and in most oily seeds (flax seed), and oil cakes; in animal feeding stuffs like skim milk, whey, meat, cock chafer or May bug, in most vegetables, and in all spices (seeds). Sour grasses (reeds and sedges) corn cobs, and all leached feeding stuffs, such as.hay and roughage that have been wet with rain, beet and potato pulp, brewers' grains and American meat meal (tankage), are deficient in potash salts.

Most feeding stuffs contain a very low percentage of sodium salts, hence the desirability of adding common salt to rations. Sodium salts are more abundant in certain tubers and roots as well as in the young growth of forage plants or hay. The same may be said of chlorin.

All clovers are usually rich in lime salts, which is true also of the better sorts of meadow grasses, the straw of legumes and the hulls of buckwheat. On the other hand, the straw of the various species of grains and chaff, all root crops, distillery slops, the cereals, legume seeds and malt sprouts are deficient in lime salts.

Magnesium salts are abundant in the grains, grasses and clovers. Most other feeding stuffs contain magnesium salts in sufficient quantity. The salts of iron are usually present in sufficient quantity in most feeding stuffs.

The following are usually rich in phosphoric acid: Good green forage and hay, all seeds, bran and malt sprouts, some oil cakes, also milk and meat. Phosphoric acid occurs chiefly in organic compounds. Other feeding stuffs, and especially straw and flour made from the various grains, beets and beet pulp, contain little phosphoric acid.

\section{Albuminous Substances; Protein}

The combustible portion of the dry matter, the organic material, includes the proteids, fats and carbohydrates. According to their properties and their physiological action these are divided into two groups, the nitrogenous bodies or albuminous substances and the fats and carbohydrates which latter contains no nitrogen. Fats and carbyhydrates are composed entirely of carbon, hydrogen and oxygen. They therefore contain no nitrogen whatever. They have similar physiological actions and may be substituted for each other. The proteids, on the other hand, contain nitrogen in addition to carbon, hydrogen and oxygen. The proteids may take the place of carbohydrates, but the latter cannot be substituted for the proteids.

Since nitrogen occurs only in the proteids, but not in the fats and carbohydrates, and since it is present in more or less constant proportions (average 16 per cent), it is used in the quantitative determination of proteids in feeding stuffs. Kjeldal's method for the determination of proteids is used almost exclusively at the present time and is as follows:

Place one or two grams of dry feeding stuff (10 to 20 grams of fluid material) in a combustion flask (Fig. 1) of high fusibility, add $20 \mathrm{cc}$. of concentrated sulphuric acid (to which there should usually have been added 200 to $250 \mathrm{gm}$. of phosphoric anhydrid per liter) and one drop of mercury, as oxygen carrier. The flask, set at an angle, is heated until the solution has become completely colorless. Combustion is usually complete in the course of three hours. The nitrogen which is present 
in chemical combination in the feeding stuffs is thereby converted into ammonia which combines with the sulphuric acid.

After completion of combustion the mass is allowed to cool, and the residue is diluted by the addition of $20 \mathrm{cc}$. of water. After cooling, add $80 \mathrm{cc}$. of a solution of caustic soda (free from nitric acid) and sp. gr. $1.35 ; 25$ cc. of 4 percent potassium sulphid solution (to precipitate the mercury) and a few granules of zinc, and connect immediately with distillation tube (Fig. 2). The latter terminates with its distal end in an Erlenmeyer flask (condenser) which contains 10 to $20 \mathrm{~cm}$. normal sulphuric acid and sufficient water so that the end of the distillation tube dips into the fluid. After about $100 \mathrm{cc}$. of the fluid has been evaporated and the reaction as determined by test paper in the distillation tube is still neutral, the excess sulphuric acid in the condenser is titrated back with one-quarter normal caustic soda solution to which has been added cochineal tincture or Congo red as an indicator. The nitrogen is then calculated from the ammonia which has been distilled over (17 parts of ammonia represent 14 parts of nitrogen). (For further details see Beythien, Hartwich and Klimmer).

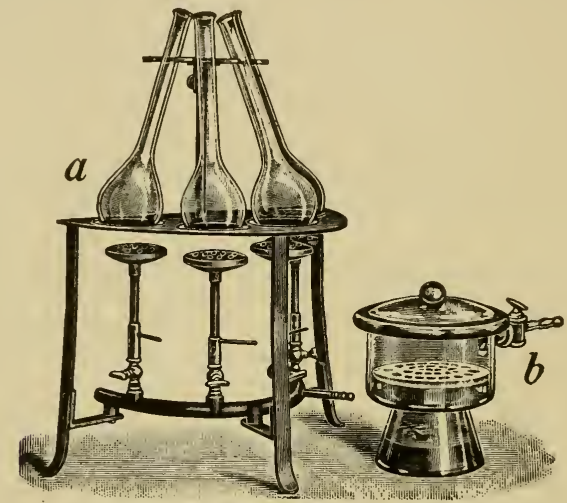

Fig. 1. Determination of nitrogen by Kjedahl's method. $a$, Combustion flasks. $b$, exsiccator.

The weight of nitrogen thus obtained is multiplied by 6.25 to obtain the weight of crude protein (6.25 parts protein contain one part nitrogen by weight).

The amount of crude protein thus indicated corresponds only approximately to the albumins present, since the actual nitrogen content of albumins is not always exactly 16 percent but varies between 15 and 19 percent. And again, feeding stuffs contain other nitrogen compounds besides proteids (amids, alkaloids, ammonia, nitric acid, etc.-( see pp. 8 and 9). Both of these sources of error, however, are small in most feeding stuffs, are partly compensating, and may therefore be ignored for practical purposes. In certain feeding stuffs, however, considerable quantities of nitrogen-containing compounds, besides the proteins, are present, e. g., beets and the leaves of cabbage, and these must be removed from the proteids before combustion.

This is usually done according to Stutzer's method. Place $2 \mathrm{gm}$. of the finely pulverized material into a breaker, add $100 \mathrm{cc}$. of water and heat to boiling temperature, treat with $0.4 \mathrm{gm}$. cupric hydroxid (in case of substances rich in phosphoric acid add, in addition, a few cubic centimeters of alum solution). Filter when cool, wash the residue and use for the determination of nitrogen. The nitrogen thus obtained indicates protein nitrogen, and the amount of pure protein may be obtained by multiplying by 6.25 .

Soil, fertility and meteorological conditions exert no inconsiderable influence on the protein content of feeding stuffs or forage plants. The seeds of the Leguminosæ, oil cakes, malt sprouts, young green forage, 
especially clovers, the endosperms of grains, industrial waste products of animal and vegetable origin (bran, brewers' grains, meat meal and blood meal) are all relatively rich in protein. On the other hand, old or woody green forage, the straw of the various grains, root crops and tubers, the interior portion of the grains (hence also flour) are relatively poor in protein.

\section{Ferments and Vitamines}

In connection with the proteids mention should also be made of the ferments and vitamins. The ferments (enzymes) possess the property of producing chemical changes in other compounds (within certain tem-

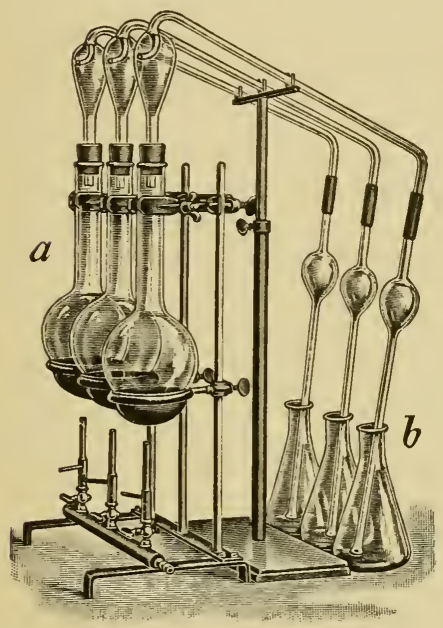

Fig. 2. Determination of nitrogen according to Kjeldahl. a, Distillation flasks with bulb tube; $b$, condenser.

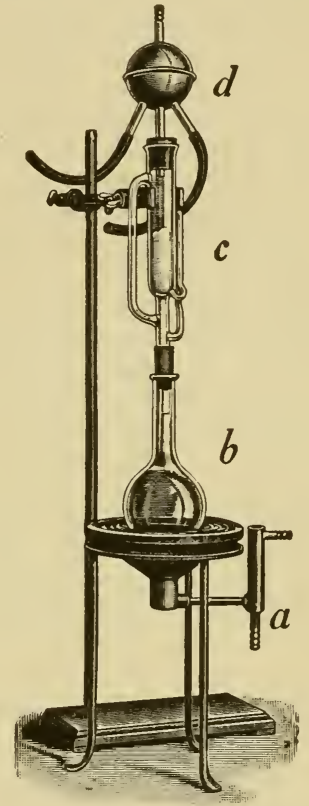

Fig. 3. Apparatus for fat extraction. a, Water bath; $b$, flask with ether; $c$, extraction apparatus; $d$, globe cooler.

perature limits) without themselves undergoing any appreciable change. They have been demonstrated to be widely prevalent in the tissues of plants and animals. These ferments include diastase, proteolytic ferments, lipase, oxydase, etc. There is little doubt that the ferments contained in feeding stuffs have certain functions in the process of digestion. In ruminants they probably begin to play a part in predigestion in the rumen. 
The term vitamin is applied to nitrogenous compounds, essential to the support of life but as yet little understood. Some of these substances are stable on heating and soluble in ether (A vitamins) and occur in the yolk of eggs, in milk, butter, kidney fat of the pig (but not in ordinary lard), cod-liver oil, meat, portions of beef tallow with low melting point, (hence oelomargarine), traces in flaxseed and grains. They are not found in the oil of sunflower seed, olives, almonds or cottonseed.

Other vitamins are also stable on heating and soluble in water and alcohol. (B vitamins). They occur in yeast, eggs, milk, meat, vegetables, the germs of seeds, Indian corn etc., but are absent in degerminated polished rice.

When vitamin-containing food is witheld from animals for a certain time, diseases which are designated by the generic name of avitaminoses make their appearance. This group includes beriberi, scorbutus, pellagra, rachitis (man), morbus Barlowi and polyneuritis gallinarum.

Harmful effects, as a result of deficiency in vitamins, occur now and then, but only in certain species of animals. Thus rabbits are affected when fed exclusively on Indian corn, while pigeons are not. Guinea-pigs are affected after exclusive feeding on dried peas, while pigeons and rabbits are not affected.

Cooper and Funk demonstrated that an alcoholic extract made from the glumes or chaff of rice acts therapeutically. The active element in this extract is thought to be a crystalline substance (nonphosphorous) of the pyrimidin group ${ }^{1}$, or vitamin $\mathrm{C}_{17} \mathrm{H}_{19} \mathrm{O}_{7} \mathrm{~N}_{2}$. A few milligrams are said to be sufficient to effect a cure. A similar action is possessed by torulin, prepared from yeast by Edie, Evans, Moore and others, and by lysin, arginin and tryptophan prepared by Roehmann. The latter, with other compounds, are present also in the aleurone layer and the pericarpium of rice. The following also have a therapeutic effect: Rice chaff, raw meat (the latter loses its therapeutic effect when heated to $120^{\circ} \mathrm{C}$.) Katjang nijdjoe (Phaseolus radiatus) is also effective in this respect. Hulshoff Pol prepared an effective, slightly acid, crystalline substance, "X-acid," from the latter.

\section{Nonproteid Nitrogenous Compounds}

Non-proteid nitrogenous compounds ${ }^{2}$ occur as follows:

1. In the young growth of plants (germs, buds, young leaves).

1The pyrimidin group or metadiazins are derived from pyrimidin $\mathrm{CH} / \mathrm{CH}-\mathrm{N}=\mathrm{CH}$

2For each 100 parts of nitrogen there are present nitrogenous bodies of nonproteid character as follows:

Very young meadow hay $\ldots \ldots \ldots \ldots .22 \%$

Meadow hay at cutting period.......... $15 \%$

Overseasoned hay .................. $7.5 \%$

Very young red clover ................. $31.5 \%$

Red clover in bloom .................. $19 \%$

Potatoes ......................... $43 \%$

Well-manured field beets............ $76.5 \%$

Normal field beets............... $57.5 \%$

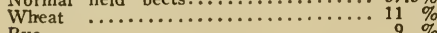

Rye
Oats $\ldots \ldots \ldots \ldots \ldots \ldots \ldots \ldots \ldots \ldots \ldots \ldots \ldots \ldots \ldots \ldots \ldots \ldots \ldots \ldots \ldots$

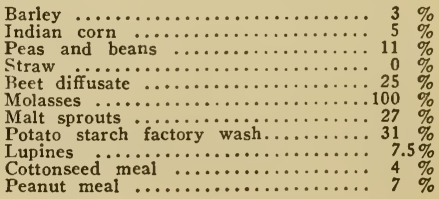


2. In succulent parts of plants (roots, tubers, pumpkins, squash).

3. In fermented feed (silage) and in feeding stuffs decomposed by molds and bacteria.

The nonproteid nitrogenous compounds include:

1. Amido compounds which occur in plants, in part as proteids in process of formation, in part as cleavage products of reserve proteids. These include: Asparagin (in young green forage, malt sprouts; in potatoes half of the nitrogenous matter consists of asparagin), glutamin (in beets, beet leaves, spurry [Spurgula arvensis]), leucin, tyrosin and xanthin (in various plant juices), hypoxanthin (in bran, potato juice, mustard seed), vernin (in vetches, red clover leaves), guanin (in young shoots), guanidin (in freshly germinated vetches), allantoin (in the leaves of trees), and finally adenin, caffein, theobromin (in tea, coffee, cocoa).

The amid compounds are all readily soluble and digestible. In rations rich in carbohydrates and crude fiber and very deficient in proteids (ratio of 1 to 19 or 20) fed to ruminants, they (especially asparagin) conserve the proteids and to a certain extent take their place (Kellner, Zuntz, etc.). This action or property of the amid compounds is of limited practical importance, since rations of this character would be fed to domestic animals only in years of extreme famine. Their effect is not noticeable in ratios of 1 to 15 . In the usual feeding operations the amids are oxidized directly into carbonic acid and water. The slight amount of heat produced in this process is of little significance even in mere subsistence rations.

Special methods for the determination of amids do not exist. By tacit consent, the difference between pure and crude protein is assumed to represent amid compounds.

2. The nitrogenous glycosids (amygdalin in vetch seed, linamarin in flax seed and linseed cake, solanin and solanidin in the sprouts, seeds and tops of potatoes, sinigrin and sinalbin in rape and mustard seed) in large doses act as irritants and even as poisons (mustard seed). In very small doses they act as stimulants.

3. The organic bases (alkaloids) such as betain (mangolds, vetch seeds, barley and wheat sprouts, molasses, cottonseed meal), cirsin (thistles), cholin (vetches, peas, peanuts, sesame and cottonseed, cocoanut, palm seeds, etc.), lupin alkaloids (lupines), occurring in minimal quantities as they do, probably act as slight stimulants to digestion, or as appetizers. In larger doses (sometimes in lupines and certain poisonous plants like hemlock, colchicum, hellebore, nightshade, stramonium henbane, aconite, etc.) they act as active poison. Cholin, which is a constituent of many tonic foods, may, through the agency of microorganisms, be converted into neurin, which is very poisonous. This fact may possibly explain the toxic action of certain feeding stuffs, such as cotton seed cake and meal, which manifests itself under certain conditions.

4. Salts of ammonia and nitric acid. Among the feeding stuffs in common use nitrates in any quantity are found in beets only (in exceptional 
cases to the extent of 44 per cent of the total nitrogen content). The salts of ammonia occur in fermented feeding stuffs (silage and so-called brown hay). Traces are also found in natural feeding stuffs. The physiological action of these salts in small quantities probably resembles that of the amids. (Zuntz, Morgen, Kellner). Large quantities are diuretic and even toxic (nitrates).

\section{The Fats}

The fats, with the carbohydrates, constitute the group of nitrogen-free organic substances.

The fats are esters of glycerin $\mathrm{C}_{3} \mathrm{H}_{5}(\mathrm{OH})_{3}$, and of several fatty acids, among which palmatin $\mathrm{C}_{18} \mathrm{H}_{32} \mathrm{O}_{2}$, stearin $\mathrm{C}_{18} \mathrm{H}_{36} \mathrm{O}_{2}$, and oleic acid $\mathrm{C}_{18}$ $\mathrm{H}_{34} \mathrm{O}_{2}$ are the most common. When the first two acids named are in excess the fat is firm (tallow); when oleic acid is in excess the fat is fluid (oils). Free fatty acids make their appearance in the seeds of oil-producing plants, harvested before maturity, or in sprouted seeds of the latter, as well as in feeding stuffs rich in fat and stored in damp places (oil cake, etc.), imparting a sour odor and an acid taste. Further decomposition produces rancidity.

The amount of fat in vegetable feeding stuffs, as compared with other carbohydrates is comparatively small. Comparatively few seeds are rich in fat (oil-producing seeds, up to 50 per cent; oats and corn, 6 to 7 per cent; wheat and rye bran, 3 to 4 per cent, some legumes; (peas, 3 per cent ; lupines, 6 to 7 per cent); oil cakes had 8 to 12 per cent ; meat meal, 10 to 15 per cent. Green fodder and roughage and all tuber and root crops are decidedly poor in fat content. In the animal body, on the other hand, the fats are far in excess of the other nitrogen-free compounds (carbohydrates).

The fat content is usually ascertained by extracting it from the feeding stuff with ether or petroleum ether, evaporating the ether and weighing the residue, (Fig. 3 ).

The crude fat thus obtained contains in admixture other ether-soluble substances like cholesterins, lecithins, vegetable wax, chlorophyl, ethereal oils, resins, etc., which are occasionally present in considerable quantity. Thus the crude fat of the rough forages contain no less than 60 per cent of these ether-soluble nonfatty substances.

Among the ether-soluble nonfatty substances the phosphorus-containing lecithins are valuable nutritive substances. The cholesterins are less valuable, and the resins probably possess no value at all. The lecithin content of the chemical dry matter of vetches amounts to 1.1 per cent; peas, 1 per cent; hulled yellow lupines, 2.2 per cent; wheat, 0.4 per cent; barley, 0.5 per cent ; Indian corn, 0.25 per cent ; flaxseed, 0.7 per cent; hempseed, 0.85 per cent; peanut cake, 0.2 to 0.4 per cent; sesame cake, 0.5 per cent; linseed cake, 0.44 per cent ; cocoanut cake, 0.3 per cent; cottonseed cake, 0.5 per cent. Most ethereal oils possess bactericidal properties. Thus the oil of mustard checks the growth of bacteria in solutions of 1 to 3,000 . The ethereal oils are widely prevalent in the seeds of Cruciferæ, 
especially of rape, turnips and mustard, also in the Umbelliferæ (caraway, fennel, anise, coriander), in juniper berries and in the following: Common milfoil or yarrow, parsnip, garden sage, artemisia or mugwort, calamus, gill-over-the-ground, cow parsnip, tansy (suitable for sheep only), etc.

\section{The Carbohydrates}

The carbohydrates are combinations of carbon, hydrogen and oxygen, in which the last two elements are present in the proportion of 2 to 1 , as in water, $\mathrm{H}_{2} \mathrm{O}$.

The carbohydrates with which we are concerned here usually contain 6 or a multiple of 6 carbon atoms (hexones), although a few contain only five atoms of carbon (pentones).

From a chemical standpoint the hexones are divided into:

1. Monosaccharids (grape-sugar group) $\mathrm{C}_{6} \mathrm{H}_{12} \mathrm{O}_{6}$, represented mainly by grape sugar (glycose or dextrose); fruit sugar (fructose or levulose), and galactose.

2. Disaccharids, $\mathrm{C}_{12} \mathrm{H}_{22} \mathrm{O}_{11}$ (cane-sugar group): Cane sugar (saccharose), milk sugar (lactose), malt sugar (maltose), and raffinose.

3. Polysaccharids $\left(\mathrm{C}_{6} \mathrm{H}_{10} \mathrm{O}_{5}\right)$ (cellulose or starch group): Cellulose, starch, dextrin, glycogen, inulin, gum, vegetable mucilage, etc.

This division, however, is not strictly followed in the study of practical feeding. According to their digestibility we distinguish merely between two groups-crude fiber and nitrogen-free extract.

\section{Crude Fiber}

The term "crude fiber" is applied to all organic nitrogen-free constituents of feeding stuffs which remain undissolved after heating the substance in question in a 1.25 per cent solution of sulphuric acid and 1.25 per cent solution of caustic potash for one-half hour and extracting with water, alcohol and ether (Henneberg and Weender method). It was formerly believed that the entire cell structure (cellulose together with all ligniform substances) was included in the residue. This supposition was not, however, founded on fact. Thus, only 30 per cent of the organic nitrogen-free cell-wall substance of wheat bran remains undissolved after this treatment, and hulled lupine seed leaves only 6 per cent of crude fiber. The rest is dissolved and is estimated as nitrogen-free extract.

Crude fiber obtained as above, contains-

a. Cellulose $\left(\mathrm{C}_{6} \mathrm{H}_{10} \mathrm{O}_{5}\right) \times 1$, which is admixed (incrustated) and possibly, in part, chemically combined with lignin (woody substance), suberin (corky substance), cutin, inorganic salts (especially silicic acid), as well as with nitrogen-containing substances. It is present in the woody parts of plants and in all rough forage (straw, hay, etc.).

b. Pentosanes. Like cellulose, with which they are frequently admixed, the pentosanes are incrustated with other substances. Chemically the pentosanes $\left(\mathrm{C}_{5} \mathrm{H}_{8} \mathrm{O}_{4}\right) \mathrm{x}$ are regarded as anhydrids of the pentones, as, for example, xylose and arabinose $\left(\mathrm{C}_{5} \mathrm{H}_{10} \mathrm{O}_{5}\right)$, just as cellulose, $\left(\mathrm{C}_{6} \mathrm{H}_{10} \mathrm{O}_{5}\right) \mathrm{x}$, is an anhydrid-like combination of a hexone (e. g., grape sugar $\mathrm{C}_{6} \mathrm{H}_{12} \mathrm{O}_{6}$ ). Externally the pentosanes resemble cellulose, but they 
are easily differentiated from the latter by a number of reactions. The amount of pentosanes in crude fiber is on the average from 5 to $10 \mathrm{per}$ cent, in meadow hay 5.2 per cent, rye straw 11.0 per cent, clover hay and lupine straw 6.2 per cent.

The total crude fiber content of straw is from 20 to 55 per cent, meadow hay and young forage plants 16 to 40 per cent, grains 0.5 to 17 per cent, root crops slightly above 1 per cent.

The function of crude fiber may be regarded primarily as that of nonnutrient ballast, and in the calculation of rations crude fiber is recognized as an important part of the dry matter. It is important because it imparts volume and texture to the feeding stuff and thus serves to fill the voluminous spaces of the digestive canal. It also exerts a mechanical effect on the mucous membranes of the digestive canal and, in a reflex manner, excites the secretion of the digestive fluids and the movements of the bowels. However, care must be observed in the use of feeding stuffs rich in crude fiber, because on the one hand they are deficient in nutrient substances and on the other hand require undue effort in mastication and digestion.

As far as the nutrient value or nutrient action of crude fiber is concerned, experiments have shown that the actual digestion of 57 per cent of the crude fiber results in neither gain nor loss to the animal. If less than 57 per cent is digested, there is an actual loss at the expense of the other nutrients. This loss is due to undue effort on the part of the organs of digestion (mastication muscular effort in moving the contents of the intestinal canal, secretion of the necessary digestive fluids, etc.). On the other hand, if an excess over 57 per cent of the raw fiber administered is digested, there is a proportionate gain, the value of the excess digested being the same as that of starch, in equal amount.

\section{Nitrogen-Free Extracts}

The group of nitrogen-free extracts includes all nitrogen-free organic substances which are not classified with the crude fat nor crude fiber. They consist, therefore, of those nitrogen-free substances which are dissolved in the determination of the crude fiber. Their amount is determined mathematically by deducting or substracting the total percentage of water, crude protein, crude fiber, crude fat and mineral matter from 100. This gives the percentage of nitrogen-free extract.

The digestibility of nitrogen-free extract varies with the species of animal and according to the plant or feeding stuff from which it is obtained, as indicated in the following table:

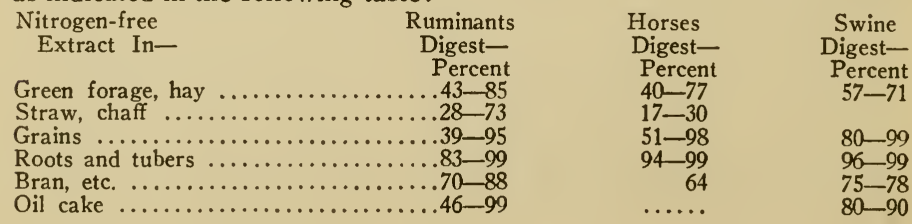


The nitrogen-free extracts include:

(a) The carbohydrates, not including crude fiber but only the readily digestible carbohydrates. They are by far the most important nitrogenfree extractives. The other groups may in this respect be practically ignored. Among the carbohydrates should be mentioned starch, nonwoody cellulose and pentosanes, dextrin, grape sugar, fruit sugar, cane sugar, milk sugar, malt sugar, etc.

(b) Several organic acids.

(c) Nitrogen-free glycosids.

(d) Bitter principles.

Nitrogen-free extracts play a most important rôle in the nutrition of domestic animals. They are the chief nutrient in vegetable feeding stuffs. They constitute the principal and the cheapest source of animal heat, mechanical energy and fat formation.

\section{a. Carbohydrates}

Starch $\left[\left(\mathrm{C}_{6} \mathrm{H}_{10} \mathrm{O}_{5}\right) \mathrm{x}\right]$ is present in practically all vegetables feeding stuffs. The various grains are especially rich in this nutrient (55 to 75 per cent), many Leguminous seeds ( 45 to 50 per cent) and potatoes (12 to 25 per cent; dry, 75 per cent). The starch grains themselves have different forms and structures according to their origin. They take a blue stain with iodin.

The structure of the starch grains consists of easily digestible granulose (starch proper) and starch cellulose. Starch is characterized by its easy and perfect digestibility. It is used as the standard of feed value in feeding stuffs.

Celluluse $\left(\mathrm{C}_{6} \mathrm{H}_{10} \mathrm{O}_{5}\right) \mathrm{x}$ is in part very easily digested; thus, the cellulose of paper and lint, 70 to 80 per cent; of hay, 60 to 70 per cent; of straw and poplar wood, 40 to 50 per cent; pine wood, 30 to 40 per cent. The ability to digest cellulose varies with the species, being greatest in the ox (30-70 per cent), followed by the sheep ( 50 per cent), horse (3040 per cent), and pig (20-50 per cent). In man and in the dog it is practically nil. The more nutritious any particular feed happens to be, the less cellulose is digested of that particular feeding stuff.

Dextrins $\left(\mathrm{C}_{12} \mathrm{H}_{20} \mathrm{O}_{10}\right)_{3}$, are found in the juices of all young plants, in many seeds, in distillery slops and in feedstuffs rich in starch (potatoes, grains). The dextrins are primary starches and reappear in the digestion of starch as inversion products. Iodin does not stain them a blue color like the starches. Erythrodextrin is stained red with iodin. Fehling's solution (metallic copper salts in alkaline solution) is not reduced by their addition (colored red).

Grape sugar $\left(\mathrm{C}_{6} \mathrm{H}_{12} \mathrm{O}_{6}\right)$ is only rarely found in feeding stuffs. Fruit sugar $\left(\mathrm{C}_{6} \mathrm{H}_{12} \mathrm{O}_{6}\right)$ is more widely prevalent, found in sweet plant juices, green rye, etc. Grape sugar (dextrose, glucose) occurs in feeding stuffs as primary cane sugar and primary starch, and during the digestion of the 
latter reappears as a cleavage product. Not affected by iodin. Reduces Fehling's solution in the presence of heat (red precipitate).

Cane sugar $\left(\mathrm{C}_{12} \mathrm{H}_{22} \mathrm{O}_{11}\right)$ occurs in quantity in sugar cane and sugar beets. Many other plants contain small quantities (green rye, sweet corn, sweet millet, meadow grasses, vetches, potato tops and immature potatoes). Also in the grains and other seeds, in seed hulls and in sweet fruits. When broken down in the process of digestion it forms grape sugar and fruit sugar.

Milk sugar $\left(\mathrm{C}_{12} \mathrm{H}_{22} \mathrm{O}_{11}\right)$ (lactose) under the influence of enzymes (diastase) and the absorption of water is split up into galactose and glycose, Occurs in milk but not in vegetable feeding stuffs. The latter, however, are often rich in galactose-producing substances (galactan, paragalactan, seminin, lactorin). Thus sugar beets contain galactan; beans, peas, vetches, palm cake, cocoanut cake contain paragalactan and seminin. Vegetable substances containing galactose appear in plants as mucilages, pectin substances and gums. According to Muntz they are always present in these substances in sufficient quantity to serve as raw material for the production of milk sugar.

The following carbohydrates have also been demonstrated in plants: Malt sugar $\left[\left(\mathrm{C}_{12} \mathrm{H}_{22} \mathrm{O}_{11}\right)\right.$ malt]; raffinose $\left(\mathrm{C}_{18} \mathrm{H}_{32} \mathrm{O}_{16}\right)$ in cotton seed and sugar beets; inulin (a form of starch which, however, does not stain blue with fuchsin) in fleshy tubers and roots-topinambur (artichoke), arabin (a vegetable gum) and sinistrin (grain of barley) and vegetable mucilages (in various seeds and tubers).

Pectin substances are a mixture of pentoses (beets, etc., fleshy fruits).

The pentosanes occur as wood gum (xylan), are widely prevalent and frequently in great abundance (brewers grains contain 29 per cent, slops from distilled rye 16 per cent, straw 25 per cent, meadow hay 18 per cent, clover hay 10 per cent, corn cobs 34 per cent, of the dry matter). Cattle digest 62 per cent of the pentosanes, sheep 55, horses 40 , swine 45 and poultry 25 per cent. The digestibility of the pentosanes diminishes as the starch content of the food increases.

\section{b. Organic Acids}

Lactic acid $\left(\mathrm{C}_{3} \mathrm{H}_{6} \mathrm{O}_{3}\right)$ occurs in germinating seeds, distillery slops and particularly in ensilaged or otherwise fermented vegetable feeding stuffs, in quantities exceeding 3 per cent. In moderate quantities lactic acid aids digestion and is said to favor milk secretion (Pott). When fed in large amounts, injurious effects may follow, especially if the fermentative processes were not properly regulated or controlled and other acids (acetic, propionic, valerianic, capronic) are present.

These latter are very apt to cause digestive disturbances, influence milk secretion and impart a bitter taste to the milk, which latter is ascribed to the fact that fermentative micro-organisms are discharged from the aliamentary canal and through carelessness or other causes contaminate the 
milk after it is drawn from the udder, multiply therein, cause chemical changes and affect the taste of the milk.

Oxalic acid $\left(\mathrm{C}_{2} \mathrm{H}_{2} \mathrm{O}_{4}\right)$ is found in the juices of many plants either as free acid or combined with alkalies or lime (oxalis, rumex, beet leaves 2-10 per cent of the dry matter) and in many spoiled feeding stuffs. Occasionally taken in small quantities it stimulates the appetite; larger quantities are laxative, and toxic doses produce acute gastrointestinal inflammation. After continued consumption of moderate amounts kidney, heart and bone affections may result. The latter are due to the circumstance that the oxalic acid precipitates the lime salts in the food and prevents their absorption. The result is lime starvation under which the bones suffer most and become subject to various forms of disease (softening, brittleness, etc.). The effect of the oxalic acid depends to a great extent upon the form in which it is taken into the body. While sodium oxalate, readily soluble, produces injurious effects even when taken in small quantities, oxalate of lime, insoluble in water, may be taken in large amounts with hardly any harmful results whatever. The injurious effects of continued feeding of substances rich in oxalic acid may to a great extent be avoided by the simultaneous administration of carbonate of lime. Swine and rabbits are much more susceptible to the effects of oxalates in feedstuffs than ruminants. In the latter the oxalic acid is destroyed by the fermentative processes that occur in the paunch. The oxalic acid absorbed into the system is excreted with the urine, unchanged.

Acetic acid is a constituent of many plant juices. It occurs also, in conjunction with butyric and lactic acids, etc., in ensilaged and fermented feeding stuffs (distillery slops in poorly conducted distilleries). Minimum quantities of acetic acid promote the digestive processes; larger amounts are injurious, retarding digestion and destroying the red blood corpuscles.

Formic acid occurs principally in dried pine needles and in nettles (which latter are a popular remedy for digestive disorders of ruminants).

Butyric acid occurs primarily in poorly fermented feeding stuffs, to which it imparts a disagreeable odor and a sharp or biting taste. In large quantities butyric acid is injurious.

Malic, tartaric and citric acids occur in the juices of many so-called acid fruits, in the refuse of the wine and cider presses and in various growing plants. Citric acid also occurs in milk, in the seeds of Leguminosæ and in the common beet. All of these acids aid the digestive processes; they promote the digestion of albumin, and in the presence of sugar influence the solubility and absorption of certain phosphates and salts of the alkaline earths which are insoluble in their absence. Their stimulating and refreshing effect is well known.

Tannic acid is found in limited quantities in many plants. Feeds rich in tannic acid (kidney vetch, other species of vetch, the leaves of oaks and willows, acorns) retard the digestion of albumins, affect the secretion of milk and cause constipation. 


\section{c. Nitrogen-Free Glycosids}

Prominent among the nitrogen-free glycosids is the poisonous principle of the seeds of corncockle, githagin. Thistles and nettles contain very small quantities of glucosids. The latter are the basis of the tonic effects of these plants on digestion and milk secretion. Hence the custom of feeding them to horses in the spring of the year.

\section{d. Bitter Principles}

Absinthin, derived from wormwood (Artimesia absinthium), gentiopicrin, derived from gentian root, and angelicin, derived from the carrot. In small quantities they stimulate the appetite and promote the secretion of gastric juice and the muscular movements of the stomach.

\section{B. The Conservation and Preparation of Feeding Stuffs}

\section{Conservation}

The varied methods of feeding stuff conservation may be loosely summed up under the following heads:

1. Storage (in cellars or pits).

2. Curing or drying.

3. Fermentation.

The nature of the feeding stuff, economic conditions, weather and climatic conditions, determine the method of conservation.

\section{Storage}

The object of storage in cellars or in mounds of earth or pits (pitting) is to protect feeding stuffs from external influences and keep them in a fresh and live state. This method of conservation is adapted for root crops $^{3}$, potatoes, beets, carrots, turnips, etc., during the cold season only.

Losses from storage.-The root crops are living feeding stuffs. They manifest a certain amount of vital activity (respiration-take in oxygen and give off carbon dioxide), and thus consume a certain amount of food. This loss affects mainly the carbohydrates. Starch and cane sugar, through processes of fermentation, are split up into grape sugar, and the latter is oxidized in the act of respiration. The degree of loss, in potatoes, depends on variety, temperature and moisture conditions. According to Baessler, De Wet variety lost 2.5 per cent during five months' storage, and the "Up to Date" variety 16.3 per cent under the same conditions. In the experiments of Von Feilitzen, among 46 varieties of potatoes tested, the loss ranged between 4 and 25 per cent. According to Nobbe, six months' storage under damp and warm conditions resulted in a loss of 47 per cent, while under cool and dry conditions the loss was only 12 per cent. Sugar beets when stored in a cool place suffer a daily loss of 0.01 to 0.02 per cent of the sugar content. In beets the loss during the whole

\footnotetext{
3The hardy artichoke is usually left in the ground over winter and dug up and fed fresh in the spring of the year.
} 
winter storage season amounts to 10 per cent of the dry matter (principally digestible carbohydrates).

Germination or sprouting entail considerably greater losses. According to Kramer the loss in sprouting potatoes with sprouts 1 to $2 \mathrm{~cm}$ long amounts to 3 per cent of the starch; 2 to $3 \mathrm{~cm}$., 5 per cent; 3 to $4 \mathrm{~cm}$., 10 per cent.

Prevention of loss.-To avoid deterioration and consequent depreciation in value, root crops and tubers should be stored in a cool place. In this respect the external temperature is of minor importance, because root crops are usually harvested in the cooler season of the year (this applies more particularly to the climate of Northern Europe than to that of the Northern and Middle United States). It is much more important to consider the heat generated by the processes of respiration and of decomposition and decay. Since moisture favors the latter, as well as freezing, root crops should be buried, or stored in cellars, in as dry condition and sound as possible.

On the other hand, these living feeding stuffs must be protected from the action of frost. Freezing temperatures destroy the life of these plants, cause them to rot after thawing, and by contact with healthy plants the infection is spread.

Potatoes freeze at a temperature of approximately $26^{\circ} \mathrm{F}$., beets at about $30^{\circ} \mathrm{F}$.

Before all vitality is destroyed in potatoes by freezing, they "turn sweet," which is caused by the conversion of starch into sugar. The sweet taste can be detected when the amount of sugar reaches 0.8 per cent. When the amount of sugar reaches 2 per cent the potatoes are no longer considered fit for food. Sugar formation begins at a temperature of about $43^{\circ} \mathrm{F}$., doubles in rapidity at $37^{\circ} \mathrm{F}$., and at $32^{\circ} \mathrm{F}$. is six times as intensive as at $43^{\circ} \mathrm{F}$. (Appel).

At $32^{\circ} \mathrm{F}$., 0.8 per cent of sugar is formed in 3 weeks, 2 per cent in 4 weeks and 3 per cent in 8 weeks (Mueller-Thurgau).

The "sweetening of potatoes" is due to the conversion of the starch into sugar by the continued action of the ferments (enzymes) and prevention of the further decomposition or splitting up of the sugar by the reduced or inhibited respiration due to low temperature. As the temperature rises $\left(50^{\circ} \mathrm{F}\right.$.) respiration is resumed or increased and the excess of sugar disappears (in the course of 8 to 11 days at $68^{\circ} \mathrm{F}$.).

Food potatoes and potatoes intended for the manufacture of starch should never be exposed (except very temporarily) to temperatures below $40^{\circ} \mathrm{F}$.

A portion of all root crops is spoiled by disease (Phytophthora) during storage, and by decomposition, which also affects their food value and wholesomeness. Losses due to these causes under reasonably favorable conditions amount to 8 per cent in the course of four or five months. When storing potatoes in the ground (pits) care should be observed in 
the selection of a suitable place, easily accessible, protected from prevailing winds, dry subsoil and cover soil not too light.

Methods of storing in pits vary in different localities. Fig. 4, representing the method of Appel, is offered merely as one of many possible methods.

The bottom of the pit should be not more than about 6 inches below the level of the surrounding ground, except in very cold climates, where it may be sunk as low as 2 feet. Deep pits may have a diameter of 20 to 30 inches at the base, shallow pits 40 to 60 inches, and where the base is on a level with the ground it may be made as wide as 6 to 8 feet. The length of the pit is a matter of taste or convenience.

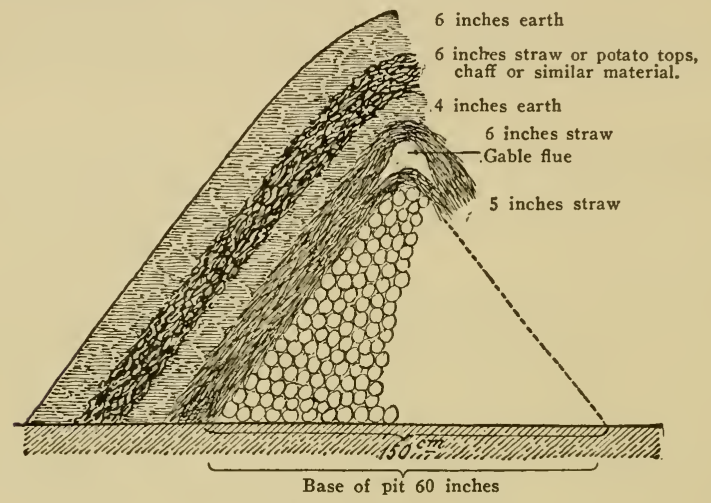

Fig. 4. Cross section of potato pit.

Shallow pits need proportionately more top or cover protection than deeper ones. It is a bad practice to store potatoes in excessively large piles or bins (violent sweating or curing process).

The covering should consist of a 4 to 6 inch layer of stiff straw (in Northern Germany the twigs of juniper trees are frequently used for this purpose) applied directly to the potatoes and this covered with a layer of earth about 18 inches thick. The use of potato tops in lieu of straw for covering the potatoes is objectionable on account of the danger of infection with potato rot (Phytophthora). Where the base of the storage cavity is on a level with the ground it is advisable to provide additional protection by dividing the earth layer and inserting a second layer of straw, chaff, or similar material. Potato tops would not be objectionable in this layer.

Ventilation is best provided by means of a gable flue, provided by inserting a cylindrical pole, or half round, when placing the first layer of straw, and withdrawing the same after completion of the mound. (See Fig. 4.) 
With the approach of warm weather in the spring, when the temperature in the pit reaches $59^{\circ} \mathrm{F}$., the covering of the pit must be removed to prevent decomposition of the potatoes.

For further information see Albert, Konservierung der Futterpflanzen (Thaerbibliothek), and publications of the United States Department of Agriculture.

\section{Curing or Drying}

Feeding stuffs are cured or dried in order to preserve them throughout all the seasons of the year without loss of feeding value or palatability.

Conservation by dry curing is practiced chiefly with the forage plants, grasses, etc., but is also applicable to potatoes, brewers' grains, distillery slops, beet pulp, etc. While the curing of hay and other forage plants is accomplished by the aid of natural means (sun, air and wind), the other classes of feeding stuffs mentioned are subjected to artificial processes of desiccation.

\section{a. The Preparation of Hay}

In the preparation of hay the green plants of field and forest (trees, grasses and herbs) should be cured with a view to preventing every possible loss during the process.

The preparation or "making" of hay consists usually of the simple procedure of exposing the green forage after it has been cut, to the action of the sun's rays and the circulating air, until the coarse stems lose their elasticity and break when bent. In this condition the dried vegetation has a water content of 13 to 16 per cent. The usual custom is to expose the mowed grass to the action of the sun's rays and supplement this by one or more teddings to expedite drying. Toward evening it is collected into small cocks and on the following morning spread out again, and so on until the drying process is completed. This is the customary procedure, but is practicable only under favorable weather conditions. This method of making hay is referred to as "sun curing," as distinguished from "air curing" in which the drying process is accomplished by currents of air. The plants or grasses are gathered into sheaves, either immediately after being cut or after having been exposed to the air or sun for a longer or shorter period, and set up in various forms of shocks or cocks, or supported on specially constructed racks, poles with cross bars, trusses, etc. (Figs 5 and 6 ). The advantage of these various devices consists in keeping the forage off of the wet ground, an indispensable condition in the mountainous regions of Europe and some of the Southern States where wet seasons are the rule and haying by methods practiced in dryer climates is out of the question. When thus suspended the water from the rains is readily shed, the forage will not rot as fast as it would if resting directly on the ground, and it may be left thus suspended for a week or ten days during rainy weather without spoiling.

The losses suffered in the sun-curing process of hay making, even in favorable seasons, are not inconsiderable. Raking, tedding, cocking, and 
the possible repetition of these processes, cause loss of the more delicate portions of the plants (blossoms, leaflets, tips), the most valuable parts. Under favorable harvest conditions this loss is equal to about 10 per cent of the available nutrients, especially crude protein and nitrogen-free extractives (Falke). In the second place the loss of the more tender or delicate portions of the plants reduces the digestibility of the forage. This - in itself amounts to a loss equal to 15 per cent of the entire food value of

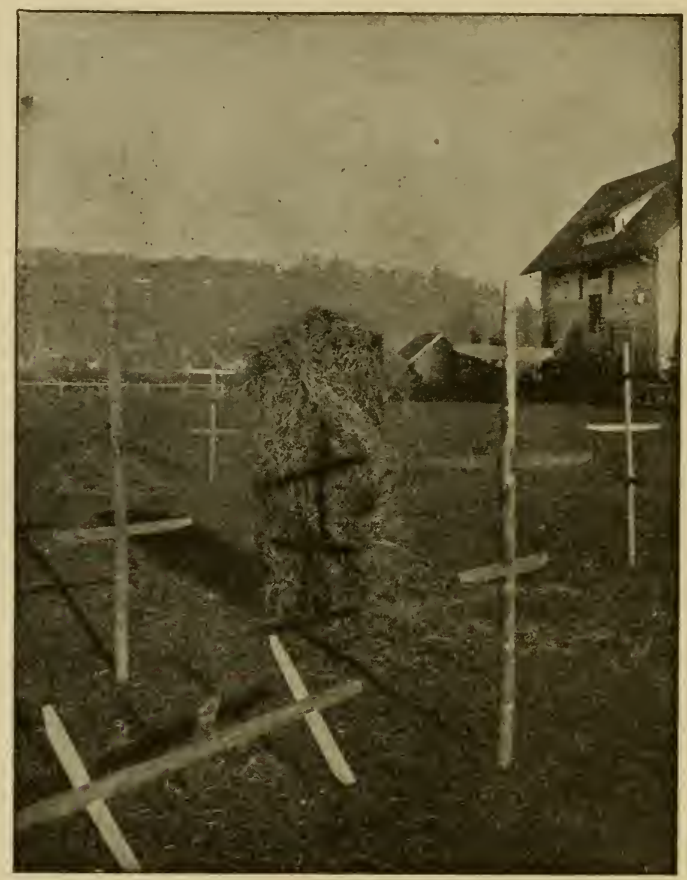

Fig. 5. Racks for curing hay in the mountainous country of southern Germany.

the plant (Kellner). The total losses sustained by the usual process of sun-drying or sun-curing hay under the most favorable conditions are therefore 25 per cent of the total value of the forage. One-fourth of the entire crop! In the air-curing methods the losses caused by breaking of the delicate structures of the plant can be almost wholly avoided. In this method the plants remain undisturbed on the drying racks until cured. The minimum loss is suffered when the plants are harvested and fed in their fresh or green state (soiling). 
Under unfavorable weather conditions the losses sustained from the sun-curing method are still greater-leaching, loss of leaves, etc., and decomposition. The extent of the loss sustained under these conditions is shown by the investigations of Emmerling and others. Hay lying exposed to the action of the elements for ten days and receiving $47 \mathrm{~mm}$. (approximately 2 inches) of rain and another lot, exposed for 20 days and receiving $93 \mathrm{~mm}$. (approximately 4 inches) of rain, showed losses as follows, as compared with hay harvested under the most favorable weather conditions :

\begin{tabular}{|c|c|c|c|c|c|c|}
\hline $\begin{array}{l}\text { Duration of } \\
\text { exposure }\end{array}$ & $\begin{array}{c}\text { Dry } \\
\text { matter }\end{array}$ & $\begin{array}{l}\text { Crude } \\
\text { protein }\end{array}$ & $\begin{array}{l}\text { Crude } \\
\text { fat }\end{array}$ & $\begin{array}{l}\text { Nitrogen-free } \\
\text { extract }\end{array}$ & $\begin{array}{l}\text { Crude } \\
\text { fiber }\end{array}$ & $\begin{array}{l}\text { Mine } \\
\text { mat }\end{array}$ \\
\hline & $\begin{array}{l}\text { Perce } \\
.13 .5 \\
.461\end{array}$ & $\begin{array}{c}\text { Percent } \\
9.9 \\
45.9\end{array}$ & $\begin{array}{c}\text { Percent } \\
49.5 \\
72.9\end{array}$ & $\begin{array}{c}\text { Percent } \\
16.3 \\
46.6\end{array}$ & $\begin{array}{c}\text { Percent } \\
2.5 \\
27.7\end{array}$ & $\begin{array}{r}\text { Percent } \\
12.8\end{array}$ \\
\hline
\end{tabular}

Exposure to rain also affects the digestibility of the nutrients in the hay. According to Behrend the percentage of protein that is digested in hay is as follows:

Per cent.

Properly cured hay $\ldots \ldots \ldots \ldots \ldots \ldots \ldots \ldots \ldots \ldots \ldots . . \ldots \ldots$

Rain-soaked hay ............................ 46.0

Hay exposed to rain to the point of spoiling..........4 40.4

These losses are considerably less in air-cured hay. According to Falke these losses in sun-cured hay (ordinary weather) amounted to 23 per cent, in bad weather 50 per cent, while it was only 18 per cent in air-cured hay under the same conditions.

To get the best results, no more grass should be cut at a time than can be taken care of and harvested in the course of one or two days, irrespective of weather conditions.

Sun curing is suitable for grasses under favorable weather conditions, but not for clovers, on account of the loss of leaflets, buds, blossoms, etc., when handled in a dry and brittle condition. Clovers, to obtain most profitable results, should be air cured, which is recommended also for all other green forages.

Hay should be thoroughly dry before being stored in barns or sheds. Hay stored in a damp condition will become heated and even charred or will actually ignite.

\section{b. Artificial Drying}

A number of watery feedstuffs, in order that they may be preserved without loss of valuable nutrients, are subjected to artificial desiccation (potatoes, sugar beets, distillery wastes, pulps, brewers' grains, beet pulp, etc.)

Desiccation has the further advantage of reducing bulk and weight and consequently transportation expense. The apparatus and technique employed are quite variable. 
Desiccated potatoes are prepared as follows:

1. The raw potatoes are reduced to slices, shavings or flakes and then subjected to the action of heated air, combustion gases or steam.

2. Previously steamed potatoes are dried in oil-heated or steam-heated drums at a temperature of $266^{\circ}$ to $284^{\circ} \mathrm{F}$. The portions adhering to the surface of the drums are almost immediately reduced to a $12-15$ per cent water content and then removed by means of special knives, in the form of flakes.

3. The potatoes are subjected to pressure to remove the excess water and then dried. The potato cake thus obtained consists of a rather dark,

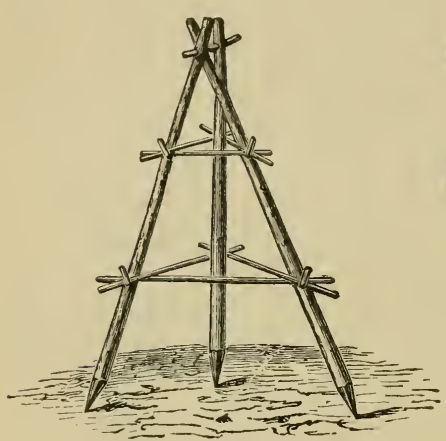

Fig. 6. Clover horse.
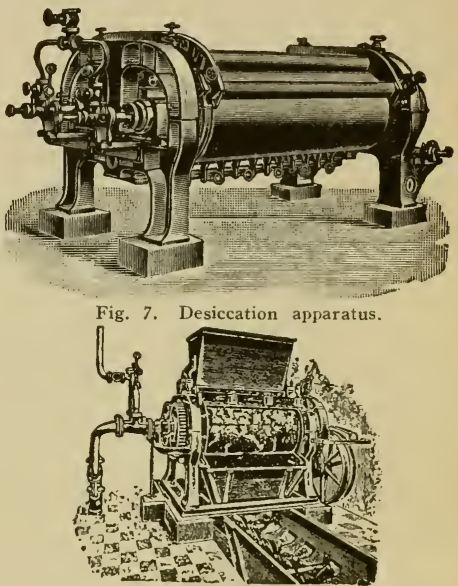

Fig. 8. Apparatus for preparing dried potato flakes.

crumbly mass of pleasing odor resembling that of fresh bread. Potato cake contains less proteids than other preparations.

Figs. 7 and 8 illustrate potato drying apparatus.

The potatoes are first cleaned, steamed (for other apparatus it is necessary to reduce them to small pieces) and then dried. The steamed potatoes are fed into the machine, crushed between rollers, pressed against the heated walls of the drums and dried. They are then automatically scraped off with knives and mixed in bins.

Distillery wastes are dried in a similar manner.

The desiccation of beet leaves, which is practically impossible by natural methods during cool and damp fall weather, is similarly accomplished.

Beet pulp, brewers' grains and other pulps are first subjected to pressure to remove most of the water, then dried. For drying, filtered furnace gases and high pressure steam (or exhaust steam) are utilized. The temperature therefore necessarily varies. 
Artificial desiccation affects the digestibility of feeding stuffs to a certain extent, especially when high temperatures are used.

The cost of desiccation is about 5 cents per cwt. (in Germany).

\section{Fermentation}

The process of fermentation is applicable in-

a. The production of so-called "baked hay."

b. The production of so-called "brown hay."

c. The production of sweet silage.

d. The production of sour feeding stuffs or silage.

"Baked hay," according to Klappmeyer, is prepared as follows:

\section{a. "Baked Hay"}

The freshly mown grass, free from dew, is stacked in cocks 10 feet high, and after one to three days scattered again. In favorable weather it will then dry sufficiently in about five hours. This method is no longer

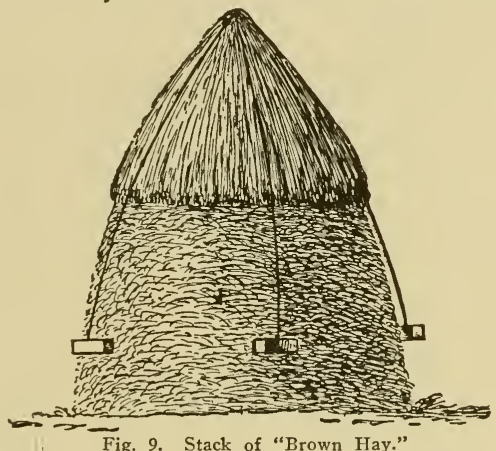

in common use, the results being too uncertain. While in the cocks the temperature of the hay reaches about $160^{\circ} \mathrm{F}$., which favors the drying process when the hay is scattered. When carried out under favorable weather conditions the losses in nutrients are negligible.

\section{b. "Brown Hay"}

The production of "brown hay" has been practiced for a long time in regions where climatic conditions are unfavorable for hay production by ordinary methods. It is especially practicable in the curing of second growth or aftermath. The grass or clover is cut and immediately put up into small cocks and left for 24 to 36 hours. In this wilted condition it is then built up in layers into stacks 10 to 20 feet high (Fig. 9).

Thus prepared, it undergoes a process of fermentation through the action of Bacillus coli, Bacillus calfactor, Oidium lactis, Actinomyces thermophilus, Thermomyces, Thermoascus, species of Aspergillus and Muco- 
$r d 4 s$, etc. At the expiration of six weeks the fermentation and drying process is completed and the product is an air-dried, aromatic, compact mass, of light brown color, pungent odor and good keeping qualities (socalled brown hay), which is relished by animals.

The losses of nutrients occurring in this mode of preparing hay amount to 15 to 30 per cent. They are confined chiefly to the carbohydrates (as high as 45 per cent of these) and to some extent the crude proteins and fats. In addition to this loss, the digestibility of the proteins is impaired. The extent of the losses depend in a measure on the size of the stacks. The losses are considerably less in the stacks customarily built in northern Germany (about 10 or 12 feet in diameter) than in those of southern Germany, where they are made twice this diameter. The digestibility of the albumins is also impaired. The plant tissues in this form of hay are very friable and easily crushed between the fingers.

\section{c. Sweet Silage}

The term "sweet silage" is applied to succulent forage that has undergone a process of autofermentation and heating to a marked degree. Any green succulent forage plants are suitable for the preparation of sweet silage; e. g., grass, clover, Indian corn, beet leaves and tops, carrots and turnips.

The character of the products of fermentation is dependent upon the temperature at which the latter takes place.

1. Acetic acid fermentation takes place at a temperature of $65^{\circ}$ to $95^{\circ}$ $\mathrm{F}$. In the production of sour ensilage this form of fermentation is usually not unimportant in its effects. The acetic acid bacteria are destroyed at a temperature of $122^{\circ} \mathrm{F}$.

2. Butyric acid fermentation occurs at temperatures between $95^{\circ}$ and $98.6^{\circ} \mathrm{F}$., under anaerobic conditions (absence of oxygen). The spores of these bacteria are very resistant to the action of heat. Butyric and other volatile fatty acids are easily recognized by their disagreeable rancid odor.

3. Lactic acid fermentation takes place at temperatures between $86^{\circ}$ and $149^{\circ} \mathrm{F}$. This is the character of fermentation most desirable in all feeding stuff fermentations. In order that this form of fermentation may take place without interference by those less desirable, it should take place between $122^{\circ}$ and $149^{\circ} \mathrm{F}$. Compared with the sour odor of acetic acid and the rancid smell of butyric acid, lactic acid is practically odorless. The most important lactic acid bacteria are Bacillus delbruecki (warm milk lactic-acid bacillus) and B. cucumeris fermentati and Bacterium lactis acidi (cold milk lactic-acid bacteria I and II).

In the production of sour silage (common silage) not only lactic acid but a large amount of acetic acid is formed. This is the cause of the sour smell of ordinary silage, hence its name. When the preparation of sweet silage is properly conducted, no acetic nor butyric acids are formed, but only lactic acid. Sweet silage therefore has no sour smell, but rather a 
sweet or honey-like odor. For these reasons the two varieties, sweet and sour silage, are distinguished. From a chemical point of view, of course, sweet silage, on account of the lactic acid it contains, is also a sour (acid) silage.

According to Von Wenckstern, Heinerle and Richardsen, sweet silage production as compared with ordinary haymaking is a marked advance in forage conservation, on account of its decidedly greater economy.

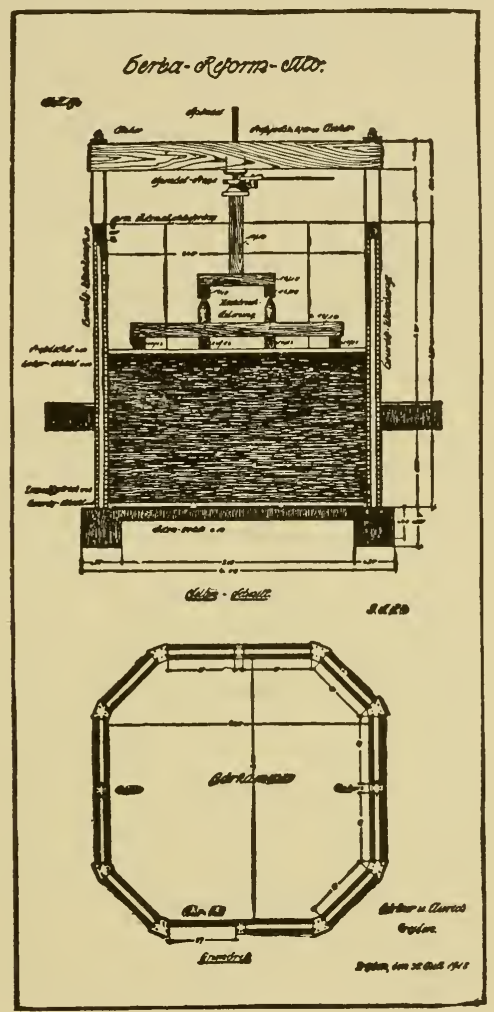

Fig. 10. Herba Reform Silo for Sweet Silage.

The foundation of our present methods of sweet silage production we owe to the efforts of Graf. The latter placed slightly wilted grass in masses 3 to 6 feet thick and subjected them to high pressure in a hay press. This caused the mass to heat to a temperature of $122^{\circ} \mathrm{F}$. The result was a juicy sweet feed, greedily eaten by cattle and other animals. 
Since the air had free access to the edges of these compressed masses, much of the material was destroyed or lost by decomposition or decay. To avoid these losses Messmer and Sonderegger put the grasses in the wilted stage into sealed cement reservoirs (or silos) and a Swiss firm has manufactured a patented mechanical press for the purpose (Fig. 10).

The present-day method is as follows: The grass, freshly mowed, or in a slightly wilted or partially dried condition, is loosely but evenly packed, or layered, into specially constructed silos, having walls of double layers of hollow tile, cement-lined on the inside. The grass is thus piled up from $3 \mathrm{r} / 2$ to 5 feet high. Within 24 hours the temperature of this mass rises to $122^{\circ} \mathrm{F}$. (to be determined by aid of thermometer).

As already explained, it is important that this temperature be attained, otherwise, at lower temperatures (under $109^{\circ} \mathrm{F}$ ) acetic and butyric acid fermentation will be in excess, and spoil the product. Lactic acid fermentation does not occur except at temperatures above $109^{\circ} \mathrm{F}$. This has a sterilizing effect upon the feed and a favorable dietetic effect.

As a result of oxydation processes (combustion) which occur during fermentation, the mass becomes heated. The amount of heat generated is dependent upon the amount of air that has access, and this can be regulated by compression of the mass. Increased compression checks oxydation and reduces the temperature by shutting off the air, and vice versa.

When the temperature reaches $122^{\circ} \mathrm{F}$. another layer of equal thickness ( $3 \mathrm{r} / 2$ to 5 feet) is added loosely, treated as before, and so on until the silo is filled. The topmost layer is then covered with planks and the entire contents of the silo subjected to the pressure of a mechanical hand press. After 4 to 6 weeks the process is completed and the feed is "done," although it may be used for feeding purposes before this time. It will keep for one year. If the process of filling the silo is interrupted, the last layer put in should be pressed as above explained, as soon as properly heated.

Successfully prepared sweet silage or "press feed" has a light green to brown color. Very light green color indicates low temperatures during the process of curing and is attended with the presence of more volatile acids (which is undesirable). The darker the color, the higher the temperatures during the curing stage. Too much heating reduces the nutritive value of the feed. An olive green color is the most desirable.

The smell should be neither sour (volatile acids, too low temperatures during fermentation) nor putrid, nor musty (decay and moldiness), nor should it be that of brown hay (from too high temperatures). The odor of good press feed should remind one of that of dried or baked plums! The taste should be only slightly acid.

The structure of the plants should be preserved. The botanical character of the grasses should still be clearly recognizable, and in contrast to ordinary hay, they should retain all of the smaller and more delicate organs and appendages of the stem and leaves. If the plants are easily broken or crushed the curing temperatures were too high.

Physically, sweet silage or "press feed" is moist or clammy to the touch and contains about 66 per cent of water and 34 per cent dry matter. The latter is composed of crude protein, 5.25 per cent, of which 2.6 per cent 
is digestible (practically equal parts of pure albumin and amids), 1.3 per cent crude fat, 13.5 per cent nitrogen-free extract, 9.5 per cent crude fibre, and 3.5 per cent crude ash or mineral matter. There is present also 1.24 per cent of lactic acid (according to Liechti 1.6 to 4.1 per cent) and only 0.14 per cent of undesirable volatile acids.

The chief advantages of this method of preserving feeding stuffs are, according to Wenckstern:

1. Increased food value.

2. Favorable effect on milk secretion.

3. Saving of labor.

4. Independence of weather conditions.

5. Saving of storage room.

Final judgment on the value of this form of feeding stuff can not, however, be pronounced at this time. According to the investigations of the agricultural experiment station of Bern-Liebefeld, neither press feeds (sweet silage) nor the ordinary sour silage possess any advantage over ordinary dry hay in feeding for milk production. On the contrary, the taste and flavor or odor of the milk are said to be unfavorably affected, and even made unfit for the production of Emmental cheese.

According to Liechti, the loss in dry matter in this process is comparatively slight, 5-9 per cent as compared with 15-25 per cent in sun-dried or air-dried hay (including the mechanical loss of 5-10 per cent in handling in the field). The losses are confined mainly to the nitrogen-free extract (11-18 per cent) and pure albumin, which is partly converted into ammonia and otherwise loses 50 per cent in digestibility. Of 100 parts of digestible crude protein only 45 parts remain in the completed sweet silage.

\section{d. Ordinary or Sour Silage}

The method of producing sour silage is suitable for succulent or fleshy feeding stuffs, which can not be air dried, e. g., leafy forage, beet tops, green Indian corn, beet and potato pulp, etc. Under unfavorable weather conditions the method is also resorted to for the preservation of grass, clover, alfalfa or lucerne, esparset, vetches, mixed forage, etc.

Ensilaging is also specially adapted for preserving the less palatable feeding stuffs like potato tops and lupines (Stutzer). As a rule these materials (beets and potatoes) are previously reduced to small pieces or the interstices are filled with beet or potato pulp.

This material is stored in pits, 10 feet wide and 6 or 7 feet deep, with clay or cement bottom, or in regular silos. It is thoroughly compressed and then covered with a one-inch or one-and-a-half-inch layer of chaff or leaves. When the mass has become heated to $95^{\circ}$ to $104^{\circ} \mathrm{F}$. it is covered with a layer of earth 3 feet thick, well tamped down, or with a layer of planks well weighted. In this condition the feeding stuffs undergo a lactic acid fermentation. The fermentation is complete after the lapse of 6 to 8 weeks and the silage is ready for use. It has characteristics resembling those of cooked feed, a sour odor and taste, and may contain 
as high as 29 per cent free acid (two-thirds lactic and one-third acetic acid and under unfavorable conditions quantities of butyric acid) (estimates for the dry matter-Morgen).

In good silos silage will keep almost indefinitely (one year), but it quickly spoils when exposed to the air. The process of silage preparation causes a loss of about 20 to 35 per cent of the dry matter. The crude protein suffers most, being converted into ammonia and nitrogen-free extract with formation of organic acids. On account of the great losses inevitable in the preparation of silage, this method should not be practiced when other means of preservation are possible and successful.

The usual method of silage preparation is attended with the development of great numbers of different species of microorganisms (bacteria, mold and yeast fungi) (Henneberg) which cause desirable as well as undesirable fermentations and decompositions. Henneberg recommends inoculation with pure cultures of desirable species of bacteria in order to control the character of the product.

Inoculation gives the best results with feeding stuffs comparatively free from bacteria, like steamed or sterilized shredded beets, potatoes, etc. Whether inoculation would be of any advantage for feeding stuffs comparatively rich in a bacterial flora, like grass, beets and beet tops, etc., is still an unsettled question.

\section{The Preparation of Feeding Stuffs}

This subject will be discussed under the following heads:

1. The reduction of coarse material into fine particles.

2. Moistening and soaking.

3. Cooking, scalding and steaming.

4. Roasting.

5. Leaching.

6. Fermenting.

7. The conversion of indigestible into digestible matter.

8. Predigestion.

9. Baking.

1. The reduction of coarse feed particles to smaller size (especially the roughages) saves energy by assisting or supplementing mastication. The usual method consists of culting or chaffing. Chaffed straw for cattle is usually cut about one or one and one-half inches in length; for horses about four-fifths of an inch; for sheep one-half to one inch. Green forage or hay is usually cut a little longer.

Digestibility is not affected by this process, nor by grinding. It only aids mastication, which, in the case of straw, is not even always desirable.

Root crops (potatoes, beets, etc.) are cut or chopped for hygienic reasons (to prevent choking) and to facilitate mixing with less palatable feeding stuffs, or they may be cooked and crushed. Chopped root crops are subject to spoiling and should therefore be fed the same day they are prepared. 
The grains are frequently ground, cracked or "rolled" so that the contained nutrients may be the better utilized in the various digestive processes. "Rolling" breaks the skin or shell of the grain but the crushed contents remain intact. "Cracking" serves to reduce the grain to smaller but coarse particles. Grinding reduces it to a powder form.

These processes all serve to increase digestibility to some extent, about 1 to 2 per cent for oats fed to healthy horses, and 5 to 10 per cent for swine. In case of the hard grains (corn, rye, beans and peas) the advantages are still more marked (Jordan and Hall, Gay, Henry). For these reasons the moderately soft grains are usually fed whole to horses and swine, while the hard grains give better results when rolled, crushed or ground and fed with cut feed. Swine should never receive whole grain for most economical results.

2. Moistening and soaking assist or facilitate prehension, prevent blowing away or inhalation of finely divided or dusty particles, and facilitate mixing. According to Kuehn it has no appreciably favorable effect on digestion. It is usually practiced in cattle feeding and avoided for horses and sheep. In more recent times the moistening or soaking of the concentrates is usually dispensed with as serving no special end, except in swine, when liberal additions of water are frequently made.

For cattle and even for swine dry feeding is now being practiced more and more. Dry feed is consumed more slowly, masticated more thoroughly, mixed better with the saliva, and consequently, in all probability, is more thoroughly utilized by the body.

In general, long-continued soaking has not proved of advantage. It is still resorted to chiefly for hard grains that for certain reasons it may not be practicable to crack or grind, and for dried pulp, etc.

3. Cooking, scalding and steaming save energy in aiding mastication, increase palatability, destroy injurious microorganisms, animal parasites and chemical poisons (lupines), but they also destroy the enzymes which happen to be present in the feeding stuffs so treated. The digestibility of the crude protein is reduced or impaired by cooking, etc.

In general, it is not advisable either to cook, scald or steam pure or unspoiled feeding stuffs that are easily digestible in the raw state. The practice is rather to be limited to feeding stuffs that would otherwise not be completely utilized and to such as require the application of heat to remove certain injurious properties.

The cooking or steaming of potatoes has become quite customary and there is no doubt that their digestibility and palatability are improved in this way. Cooking and steaming are also resorted to for the removal of the toxic substances in lupines.

According to the method of Kellner, the lupine seeds are soaked in cold or in lukewarm water for 24 to 36 hours, then boiled for one hour, or steamed (without pressure) and then leached with cold water to remove their bitier taste. The leaching process requires about 48 hours and may be conducted with flowing water or by changing the standing water every 
6 to 12 hours. This makes the grains "slippery," and subsequent crushing before feeding is therefore advisable. The losses occasioned by this process amount to 3 to 5 per cent of the pure albumin, 20 to 40 per cent of the nitrogen-free extract and 50 to 60 per cent of the mineral matter. The process, however, also removes all the bitter principles and thus fits the product for feed for milk cows.

The feeding of wet or soaked feed calls for scrupulous cleanliness of the mangers or feed troughs.

4. Roasting is always attended with considerable loss of digestible nutrients and is therefore rarely resorted to. It may serve to remove certain unpalatable constituents of certain feeding stuffs (buckeyes and lupines) and to destroy certain injurious microorganisms and their products. It is therefore applicable to moldy or otherwise partially spoiled feeding stuffs, or, for dietetic purposes (roasted oats, etc.), to check diarrhea.

5. Leaching serves to remove soluble injurious substances, but is attended with loss of nutrients. It is applicable, above all, for the removal of the bitter principles and the toxic substances in lupines. This is the principle made use of when lupine hay is left on the ground, exposed to the rains, until late in the season or even winter. The seeds are treated by more artificial methods. Common salt, sulphuric acid or lactic acid, soda, ammonia, milk of lime or chlorid of lime are used as solvents and extraction fluids, followed by the use of soda or hydrochloric acid (as the case may be) for neutralization of the product, by washing (Steiner). The leaching of cooked and steamed lupines should be mentioned in this connection.

The leaching of sliced potatoes is also practiced for the purpose of removing acrid and bitter principles ( 6 to 12 hours). The losses are slight ( 3 per cent). Leached potatoes may be fed in larger quantities than the unleached tubers.

6. Fermentation is frequently practiced with mixed cut hay and straw, chaff, green forage, cut or chopped root crops, distillery wastes, even molasses, etc. Common salt is usually added to the mixture. The mass is placed in layers in troughs or wooden boxes or thoroughly mixed and placed in piles about two feet high. The mass should be thoroughly wet, but not sufficiently so to cause water to drip or drain off. Sliced or shredded potatoes or beets should be covered, because direct contact with air imparts a bad taste to them. At ordinary temperatures fermentation and heating soon set in under formation of lactic and acetic acids, as well as other substances with fruity and winelike odor. The mass is ready to feed in the course of 48 hours.

The object of this method of fermentation is to improve the palatability of the feed, to enable one to feed potatoes in larger quantities in the raw state, and to remove their acrid taste without making them too insipid. The losses occurring in the feeding stuffs mentioned amount to about 4 per cent. In feeding stuffs rich in nutrients the losses are considerably 
greater (bran, meal, oil cake, etc.). It is best, therefore, to make use of the fermentation process just described, for the roughages only, and to feed the concentrates separately or mix them with the fermented roughages immediately before feeding.

This character of feed is suitable for the coarser breeds of cattle and sheep, less so for young stock and horses, and for swine only when it is composed of root crops and, at most, minimal quantities of finely cut roughage.

7. Conversion. This chemical term is used to designate a process by means of which woody feeding stuffs (straw, sawdust) are converted into digestible substances. The microscopical incrustations of the nutrient ingredients, which prevent digestion, are removed by this process. A certain degree of conversion occurs in the ordinary process of fermentation. To convert straw more completely, more effective means are necessary, above all, treatment with strong bases (lye and unslaked lime).

It is to Kellner that we owe our knowledge of the scientific principle underlying the conversion of straw. Lehmann, of Goettingen, however, applied the principle in a broad and practical manner in his work which covered a period of more than twenty years. But it was the pressing necessity of the late World War that led to its general adoption. Oexmann deserves the credit for having first directed attention to a method for ultilizing the straw pulp of paper mills as a feeding stuff. This pulp is treated with mollasses (straw concentrate II), followed by treatment with yeast or gluten concentrate (albuminous straw concentrate I).

Colsman invented a process of converting straw that could be conducted at home, on the farm. The straw is cooked in 8 per cent sodium lye, in open kettles set in masonry. The superfluous water is then expressed. After being washed to remove the excess lye, the matrial is ready for feeding.

Beckman demonstrated that conversion is possible and practicable without the use of heat and that the lye solution can be used a second and a third time providing it is reinforced to the extent of the used fraction. This simplifies the process and reduces the expense materially. An additional advantage for the Beckman process is that many of the nutrients that are destroyed by heat are retained. The available product is increased in this manner from 55 or 58 per cent to 75 or 80 per cent. The digestibility of straw concentrate is about 70 to 75 per cent as compared with 35 per cent of the untreated or unconverted straw.

Milk of lime exercises a converting effect upon straw similar to that of sodium lye. The solution of the silicic acid and the lignins (to the presence of which the indigestibility of straw is due) is less complete, however, while the desired destructive action of cellulose and of the pentosanes is the same as that of sodium lye. Thus the food value of straw treated with lime is less than that of the same material treated with sodium lye. The action of soda (sodium carbonate) is similar to that of lime. 
For practical purposes, on the farm, straw conversion is conducted as follows :

\section{Lehmann's Method (Goettingen)}

(a) Boil 6 to 8 hours in sodium lye in open iron kettles.

(b) Boil 6 to 8 hours in closed tanks in sodium lye under pressure of 5 to 6 atmospheres.

The first method is not followed by washing; the second is followed by washing. Yield, 53 per cent; loss, 47 per cent.

2. Colsmann's Method (Lindenberg)

Boiling $5 \mathrm{r} / 2$ hours in 8 per cent sodium lye in open kettles set in masonry. Yield, 58 per cent; loss, 42 per cent.

\section{Beckmann's Method}

Treating with 12 per cent sodium hydroxid solution in wooden tubs, ordinary temperature, etc. Yield, 73 to 80 per cent.

In methods 1 and 2 the straw is first run through a cutting machine and chaffed. For each $100 \mathrm{lbs}$. of straw $200 \mathrm{lbs}$. of water and $10 \mathrm{lbs}$. of sodium lye are added; the mixture is then boiled, and after the mass has been thoroughly drained the excess lye is washed out with fresh water This, of course, entails loss of nutrients, to avoid which Thomann recommends dispensing with the washing and neutralizing the mass by the addition of sour whey or fermented slops, sour ensilage, etc., and testing product with litmus paper. The high lye content of the straw mass and the low acid content of the neutralizing feeding stuffs necessitates the addition of very considerable amounts of the latter to effect neutralization. The product thus obtained is greedily eaten even by horses and swine. Swine receive 3 lbs., horses 4.5 lbs., cattle 30 lbs.

Converted straw, after the customary process of expressing the superfluous water, still has a moisture content of 70 to 75 per cent.

The dry matter has the following composition:

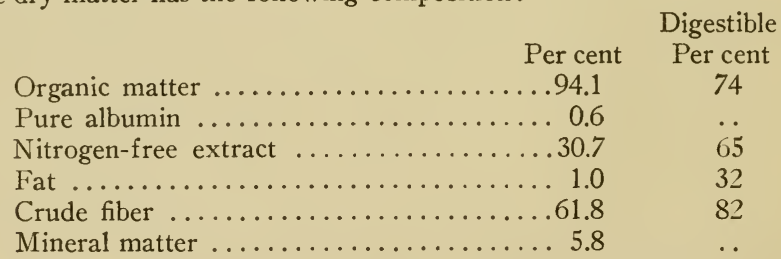

The digestible crude fiber is digested and assimilated as thoroughly and completely as starch.

The starch value in the dry matter is as follows:

Per cent

Ordinary straw $\ldots \ldots \ldots \ldots \ldots \ldots \ldots \ldots \ldots . . . \ldots \ldots$

Completely converted straw $\ldots \ldots \ldots \ldots \ldots \ldots .6 .0$

High-grade converted straw ...........65.0 to 70

Moderately converted straw ........... 50.0 to 60 
If the losses occurring in the process of conversion are included in the calculation, the starch values with reference to the original material are as follows:

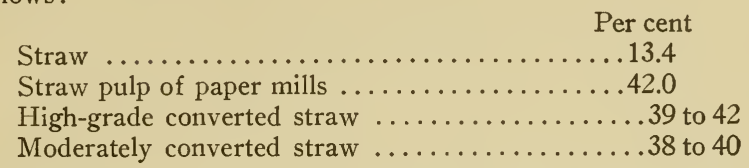

Whether the conversion of straw as practiced by present methods will continue to be practiced after the return to normal conditions remains to be seen. The Lehmann and Colsmann methods are undoubtedly too expensive (necessary apparatus, etc.). Beckmann's method may survive, but much will depend upon the condition of the grain and feed market. From a national economic point of view it would undoubtedly be a blessing if the enormous straw product of the country could be more profitably utilized than in the past.

Animals must be accustomed gradually to the use of wet "straw concentrate." At first three to five pounds are given daily, divided into three feeds and mixed with other material. If oats are added they should first be crushed.

Pea, rape and turnip straw have thus far proved rather refractory to the conversion processes.

The conversion of wood meal, or sawdust, by treatment with hydrochloric acid or with sodium or sulphite lye has not as yet given encouraging results. The digestibility and palatability depend upon the species of the wood as well as upon the part of the plant or tree furnishing the same (base or trunk, branches, etc.), whether the sawdust is the product of cross-cut or longitudinal sawing, the method of conversion employed, etc. The variation in this respect is quite marked. Ether-soluble constituents (resins, turpentines, etc.) affect digestibility and palatability unfavorably. The admissible maximum of these substances varies between 0.6 and 0.8 per cent. These substances are not present in sulphite and sodium cellulose.

Converted fir-tree sawdust or meal, highly saccharinated pine wood meal and sulphite cellulose have the following composition (Ellenberger and Waentig):

\section{Material}

Water

Crude

Crude Nit.-free

Crude

Percent

Fir wood, sawdust or meal....9.3

Pine wood, sawdust or meal...7.4

Sulphite cellulose ..........8.9

Ash Protein

Fat

Extract

Fiber

Percent Percent Percent Percent Percent

$\begin{array}{llllr}1.7 & 1.12 & 0.8 & 28.6 & 58.4\end{array}$

$\begin{array}{lllll}2.6 & 1.25 & 0.6 & 30.9 & 57.0\end{array}$

$\begin{array}{lllll}1.3 & \cdots & 0.4 & 17.0 & 72.5\end{array}$

The digestibility of straw pulp, according to Kellner and Fingerling, is 89 per cent in cattle and swine, sheep 83 per cent, while that of highgrade converted straw is 68 to 70 per cent, low-grade converted straw 60 to 65 per cent, surphite cellulose or wood cellulose 79 per cent, sodium 
cellulose of the fir 84 per cent and sodium cellulose of the pine, 28 per cent.

The extreme degree of pulverization required for the conversion of wood, as well as the comparative scarcity of raw material even for necessary paper manufacture, makes it improbable that this method of obtaining or cheapening feeding stuffs will be of immediate economic importance.

8. Predigestion. We distinguish (a) saccharification, preparation of sweet mashes, and (b) peptonization.

(a) Saccharafication, or the preparation of sweet mashes, is accomplished with the aid of ferments contained in sprouted barley (malt). Crushed cooked potatoes constitute the raw material. One hundred pounds of potatoes are treated with 0.3 to $0.5 \mathrm{lbs}$. of malt at a temperature of $122^{\circ}$ to $131^{\circ} \mathrm{F}$. The sweet mash thus obtained may be kept from 10 to 14 hours longer in order to permit the lactic acid fermentation which follows to make the mass more palatable. This, however, is not recommended.

Saccharification is also made use of in calf feeding. In order to utilize more perfectly the starchy feeding stuffs, it has been recommended to treat the starch with diastase before feeding (diastasolin), or, what is more economical, to convert the starch into sugar with barley malt. Animals relish "saccharinated starch" and digest and assimmilate it well, and its use reduces the cost of calf feeding 33 per cent (Hansen, Schneider, Schmidt, Pflugrath, Haselhoff). The meal (ground wheat, starch, potato flour, etc.) is cooked in water or skim milk (about $11 / 4$ ounces to the quart), treated with crushed malt, kept in a warm place for half an hour, again raised to the boiling point, strained and immediately fed.

(b) Peptonization is brought about with gastric juice in acid-reacting, and with pancreatic extract in alkaline reacting feeding stuffs. It is practiced with meat meal, blood meal, milk and dairy waste products. No real necessity exists for this practice and it is therefore not in common use.

9. Baking. The raw material used may be meal, cracked grains and leguminous seeds, bran, meat and fish meal, blood meal, potatoes, chaff, cut hay or straw, molasses, slops, dairy waste products, etc. Salt and occasionally yeast or leaven are added, also sufficient water to make a dough, and the mixed product is baked. Bread or biscuits of this nature are serviceable as dog and horse feed.

\section{The Most Important Feeding Stuffs}

The feeding stuffs used for domestic animals are usually classified in the following manner:

1. Green forage.

2. Roughage.

3. Tubers and root crops.

4. Grains or cereals, and beans and peas. 
5-9. Commercial waste products (from milling, brewing and distilling, sugar, starch and oil production).

10. Animal feeding stuffs.

\section{Green Forage}

The term "green forage" is applied collectively to all feeding stuffs that are used or fed in the green or fresh state. The term is applied in particular to the leaves and stems of the grasses (Gramineæ), clovers, a few other Leguminosæ (esparcet, alfalfa or lucerne, serradella, hop trefoil) (Medicago lupulina), kidney vetch (Anthyllis vulneraria), white or Dutch clover, vetches, sow beans, field peas, spurry (Spergula arvensis), buckwheat, beets, turnips, etc.

Botanical. The main representatives of the meadow or pasture grasses are the socalled true meadow grasses or sweet grasses. They may be recognized by their round, hollow, nodose stems, the split sheathes of
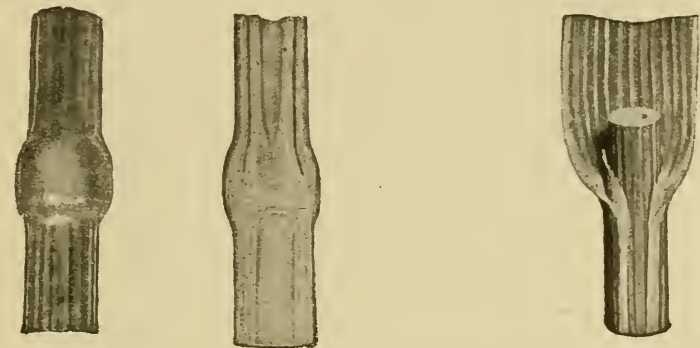

Fig. 11. Stem of grass. b, longitudinal section. Fig. 12. Stem of grass, surrounded by leaf $a$, External view; sheath, ligule and leaf.

the leaf bases and the ligule (Figs. 11 and 12), and are thus distinguished from the reeds and sedges or sour grasses.

The sedges are characterized by a triangular solid stem, without nodes, and leaves with closed sheathes. These so-called sour grasses grow in damp, swampy meadows that are poorly drained and in which free humic acid is formed by the conversion of the humus in the soil. The principal representatives of the sour grasses are the Juncacex (rushes), Cyperaceæ (reeds) and, above all the most common, the genus Carex or the sedges.

With reference to the different species of grasses under consideration, the following groups are distinguished:

1. Sweet grasses.

2. Sour grasses.

3. Scouring rushes.

4. Herbaceous plants.

Below is given a short guide for the determination, and a description, of the more important meadow grasses: 


\section{Key}

A. Spike grasses including false spike grasses (spikelets sessile or shortstemmed on the unbranched rachis):

(a) Spike symmetrically arranged around the rachis;

I. Pales awned:

1. Only one awn: Alopecurus.

2. With two awns: Anthoxanthum.

II. Pales not awned, glumes mucronate: Phleum.

(b) Spike prismatic, fourth side of rachis naked: Cynosurus.

(c) Spike bilateral, the other two sides of the rachis naked, spikelets alternate.

I. Spikelets short-stemmed: Brachypodium.

II. Spikelets sessile:

1. Spikelets with the wide side toward the rachis: Triticum.

2. Spikelets with the narrow side toward the rachis: Lolium.

(d) Spike unilateral, the three other sides naked: Nardus.

B. Meadow grasses ( $P o a s p$. ), (spikelets distinctly stipitate, rachis branched: $P o a$.

(a) Spikelets one-flowered (or apparently so): Agrostis.

(b) Spikelets two or more flowered:

I. Glumes as long as the spikelets:

1. Spikelets and pales arched: Avena.

2. Spikelets and pales compressed, carinated: Holcus.

II. Glumes shorter than the spikelets:

1. Spikelets and pales carinated:

(a) Spikelets glomerulate, compressed with rachis: Dactylis.

(b) Spikelets solitary: Poa.

2. (Spikelets and) pales arched:

(a) Pales usually awned at tip; stigma inserted at tip of ovary: Festuca.

(b) Pales awned below the tip or naked; stigma inserted below the tip of the ovary: Bromus.

Alopecurus, foxtail. Cylindrical, soft, false spike, resembling Phleum. Spikelets of Alopecurus at all times readily stripped from above upward, while those of Phleum can be stripped only in maturity and then with difficulty. Glumes of Alopecurus connate, long, pointed densely ciliated, floral glumes (pales) with long awns; spike resembling fox's tail. Glumes in Phleum not connate, resembling bootjack.

Alopecurus pratensis, meadow foxtail (Fig. 13). Good forage grass, on meadows. Alopecurus geniculatus, jointed foxtail. Good pasture grass but short lived. Anthers yellowish white, leaves somewhat bluish green.

Anthoxanthum odoratum, common spring grass. Of little value. Rather loose false spike, distinctly pedunculated spikelets when in bloom (panicled spike).

Phleum pratense, meadow grass, Herd's grass, timothy grass (cf. Alopecurus). Valuable. Dense, stiff, cylindrical, false spike (Fig. 14).

Lolium italicum and L. perenne, Italian and English rye grass. Highly prized 
meadow and pasture grasses (Fig. 15). In L. italicum floral glumes (pales) usually distinctly awned, in L. perenne glumes naked or bluntly acuminate.

Cynosurus cristatus, common dog's-tail grass. False spike, prismatic, fourth side of the rachis naked. Culm rigid, upright, leaves narrow. Cristate glumes at base of each spikelet (sterile florets). Good grass of medium feeding value.

Nardus stricta, nardus or bristle grass. Low grass with bristly leaves. No value. Agrostis alba, bent grass, bonnet grass, florin grass. Panicle pointed when in

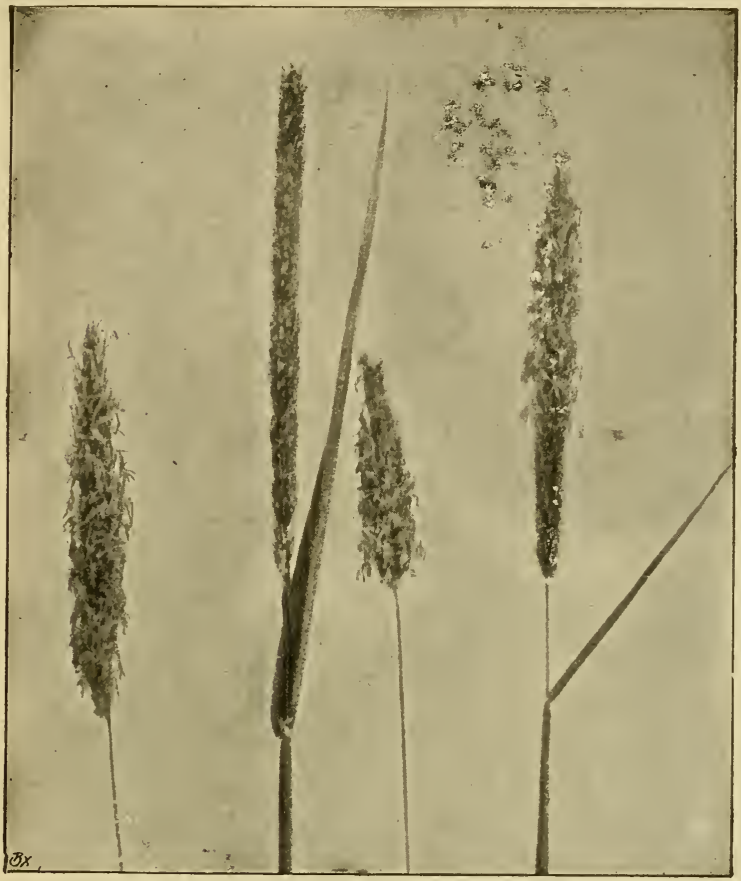

Fig. 13. Meadow Foxtail (Alopecurus pratensis).

bloom; conical; contracted after blossom period; cespitose. Forms stolons. Valuable.

Agrostis vulgaris, redtop, dew grass, Herd's grass of the Southern States. Panicle purple, oblong, with short, spreading, or divaricate roughish branches. Leaves linear with very short ligules, sometimes the upper one elongated. A common and valuable grass in old fields and drained swamps. It is quite variable in aspect (Wood).

Avena elatior, high meadow oats, French rye grass. Very tall, culm 2 to 4 feet high, geniculate, smooth. Panicle loose, equal, nodding; branches in pairs or terminate. Spikelets bluish violet, becoming straw colored. Excellent forage grass.

Avena pubescens, downy oatgrass. Leaves downy on both sides.

- Avena pratensis, meadow oats. 
Avena s. Trisitum flavescens, golden oats. Culm often hairy on lower internodes; panicle wide; golden iridescense when in bloom; panicle delicately branched, rough; upper blossoms long awned. (Fig. 17).

Holcus lanatus, woolly honeygrass, soft grass. Hoary pubescent; awns recurved shorter than glumes; spikelets whitish or reddish. Of indifferent food value.

Holcus mollis, soft honeygrass. Smooth, naked; awns straight, longer than the glumes (Fig. 18).

Dactylis glomerata, orchard grass. Spikelets numerous, aggregated, compressed; spike unilateral. (Fig. 19). Excellent grass.

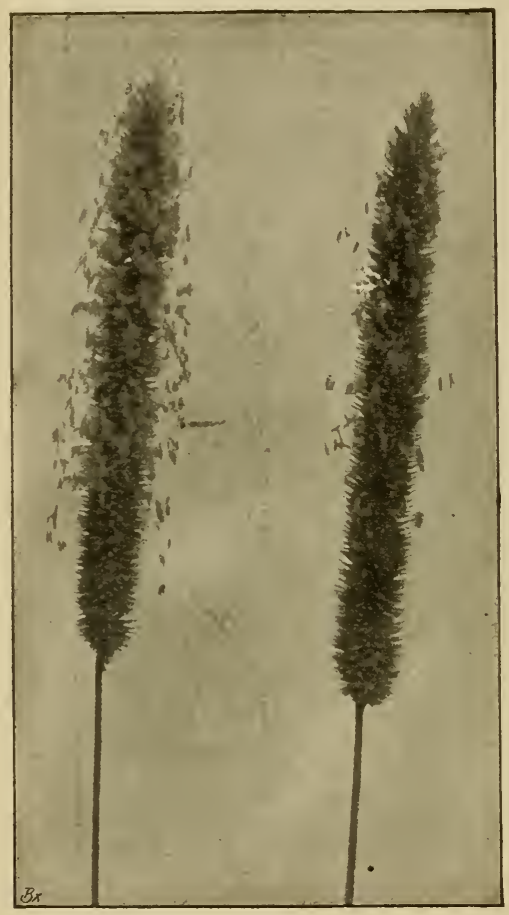

Fig. 14. Timothy (Phleum pratense).

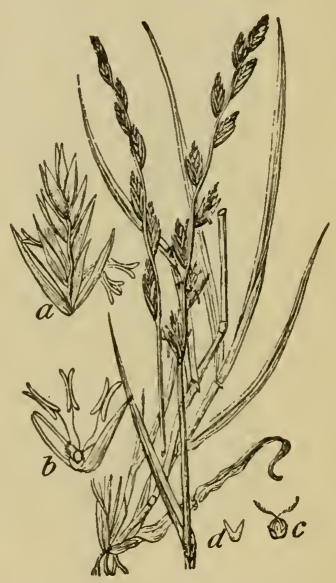

Fig. 15. English rye grass (Lolium perenne).

Poa pratensis, spear grass, June grass. Culm terete, smooth, panicle contracted before bloom, then spreading; blue, violet or brownish hue. Branches rough; blossom glumes covered with short down; forms matted stolons. (Fig. 20).

Poa trivialis, common or rough meadow grass. Culm and leaf sheaths rough.

Poa serotina, meadow redtop, foul meadow. Culm erect, weak, leaves narrowly linear, flat. Varies with the spikelets all two flowered and colored or all three or more flowered.

Poa nemoralis. Leaf shcaths shorter than the culm joints; nodes bare.

Poa annua, annual spear-grass. Very small, panicles usually unilateral.

Poa compressa, bluegrass. Culm decumbent and rooting at base, much com- 
pressed; leaves linear, short, bluish green; sheaths rather loose with a short, obtuse stipule. A valuable grass with sweet and nutritious herbage, propagating itself everywhere (Virginia and Tennessee northward) in woods, pastures and meadows. Wood's Botany.-Translator.

Festuca elatior s. pratensis, tall fescue grass. Rachis unilateral, spreading when in bloom, otherwise contracted; branches rough, usually in pairs, one short with one spike, the other long and raceme-like, with three or four spikelets. (Fig. 21).

Festuca arundinacea. Rachis large, nodding; branches rough, in pairs, each with 5 to 10 spikelets.

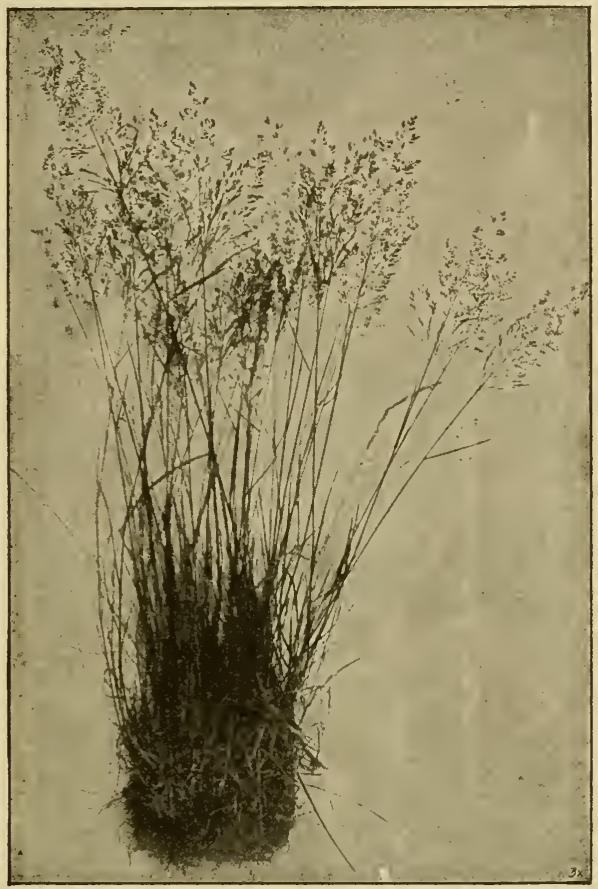

Fig. 16. Agrostis vulgaris.

Festuca heterophylla, F. ovina, F. rubra, sheep fescue and red fescue. Lower leaves folded, bristly.

Festuca gigantea, giant fescue. Leaves broad, long pointed, drooping, edges rough; awns twice as long as the pales; tortuous; woody when mature.

Bromus erectus s. pratensis, meadow chess. Lower leaves very narrow, edges ciliated; rachis erect, evenly spreading. (Fig. 22.)

Bromus mollis, downy chess. Grayish green; lower pale awned; leaf sheathes downy.

Bromus racemosus. Resembles $B$. mollis.

Bromus inermis, unarmed chess. Leaves and leaf sheathes naked; lower glume awnless. 

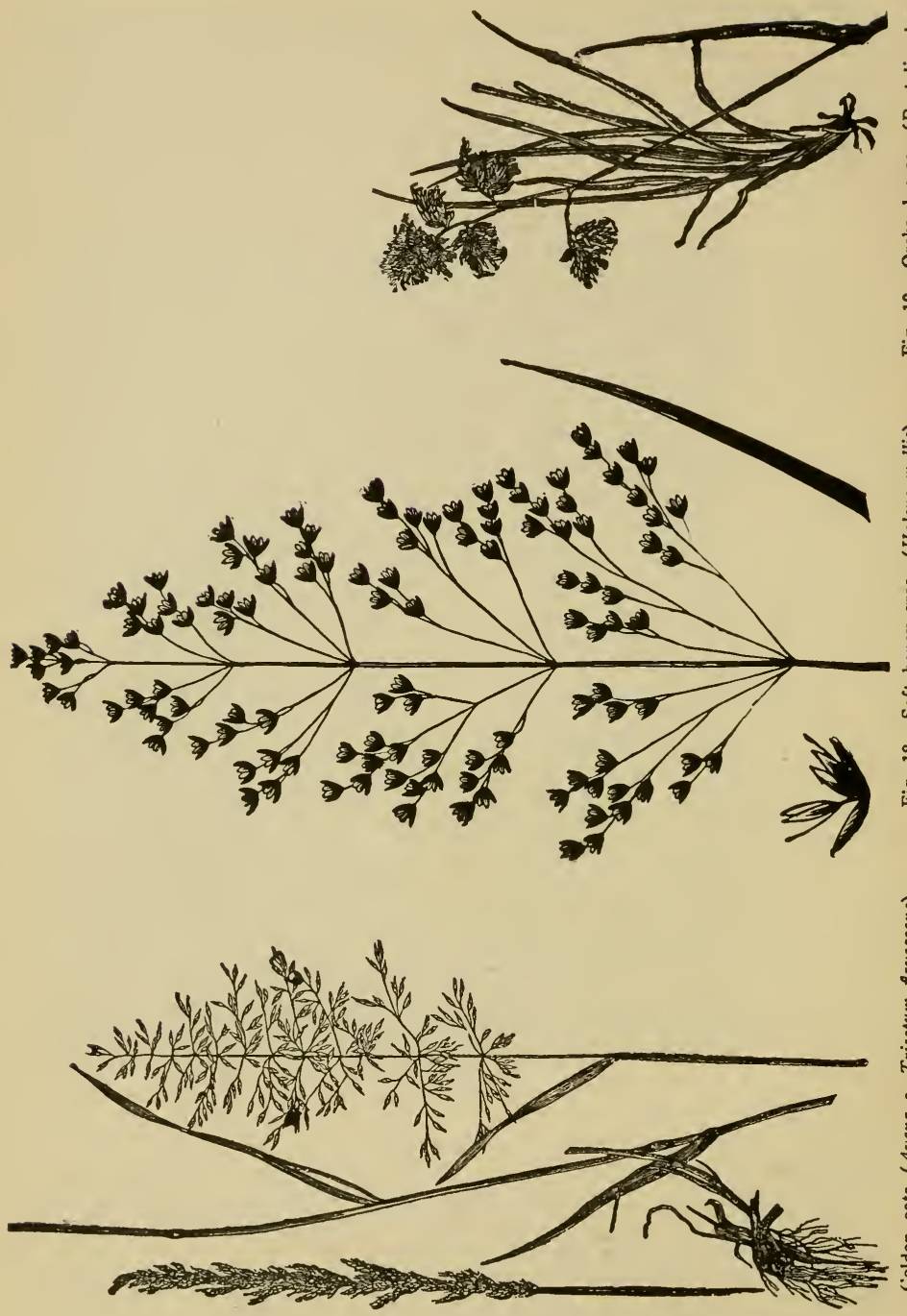
Glyceria fluitans, manna grass. Rachis unilateral; branches at right angles when in bloom, later compressed; spikelets very long, appressed. (Fig. 23.)

Glyceria aquatica s. spectabilis, water chess. Rachis symmetrically spread out, very branchy and spreading; culm thick, reed-like. (A large and handsome grass cultivated for hay in Europe.-Wood.)

Phalaris arundinacea, Canary grass. Leaves wide, grayish green; panicle branched in bloom, contracted at other times; spikelets in clusters. (Fig. 24.) Tall and reed-like.

According to nutritive value and palatability the sweet grasses are arranged in three classes as follows:

Grasses of the first rank: Meadow foxtail (Alopecurus pratensis), timothy grass (Phleum pratense), orchard grass (Dactylis glomerata), tall fescue grass (Festuca elatior), Italian rye grass (Lolium italicum), English rye grass (Lolium perenne),

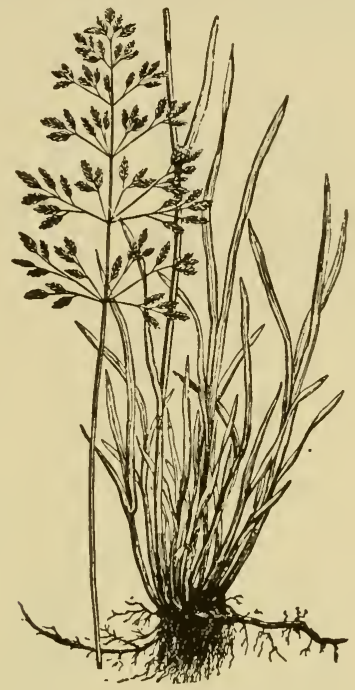

Fig. 20. Spear Grass (June Grass) (Poa Pratensis).

spear grass or June grass (Poa pratensis), rough meadow grass (Poa trivialis), golden oats (Avena flavescens-European species), meadow oats (Avena pratensis -European), so-called French rye grass (Avena elatior-European species, naturalized in United States), white or English bent grass (Agrostis alba s. stolonifera), manna grass (Glyceria fluitans).

Grasses of the second rank: True manna grass (Glyceria aquatica s. spectabilis), hairy oats (Avena pubescens), dog's-tail grass (Cynosurus cristatus), red fescue grass (Festuca rubra and F. heterophylla), Canary grass (Phalaris arundinaceae), the various species of chess (Bromus sp.), common redtop, dew grass, or Herd's grass of the Southern States (Agrostis vulgaris), annual spear-grass (Poa annua, $P$. serotina, $P$. compressa, $P$. nemoralis), quaking grass (Briza media), honeygrass or soft grass (Holcus lanatus), sweet-scented vernal grass (Anthoxanthum odoratum), and Brachypodium pinnatum and B. sylvaticum.

Grasses of the third rank: Aira fleuosa and $A$. càespitosa, tuft-like grasses of the United States, 1 to 2 feet and 18 to 30 inches high, respectively. The former is an erect, elegant grass, common. Bromus giganteus (giant cheat or chess). Agrostis spica (a species of bent grass). Calamagrostis epigea (a calamus-like Agrostis). 


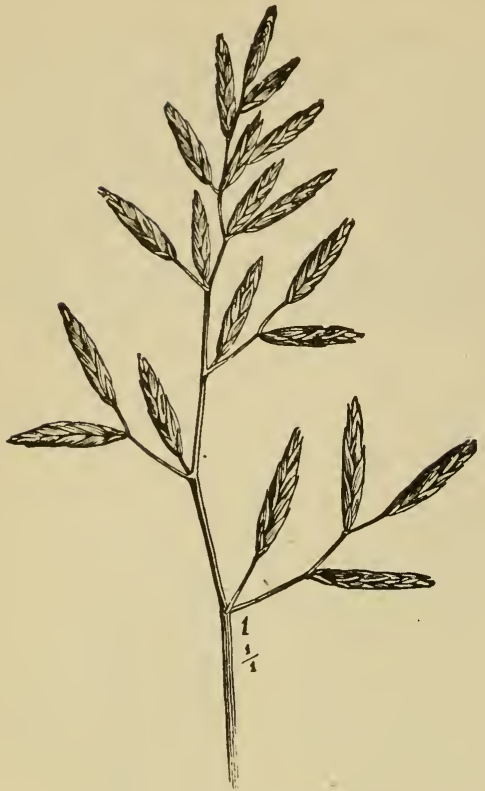

Fig. 21. Tall Meadow Fescue (Festuca elatior s. pratensis).

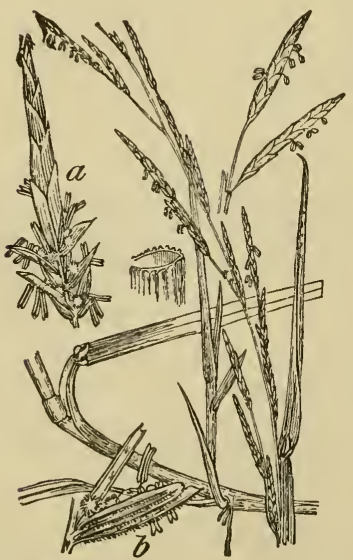

Fig. 23 Manna grass (Glyceria fluitans).

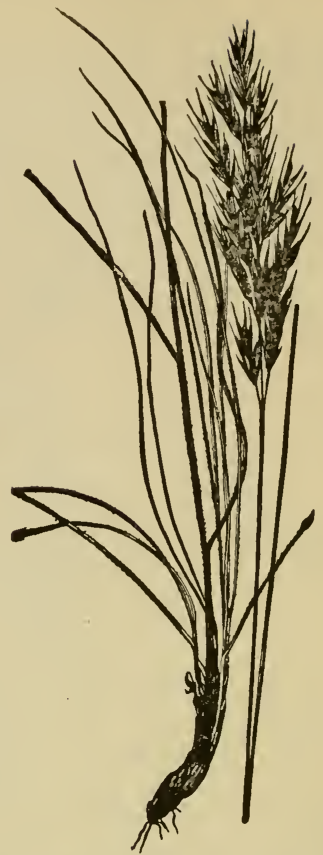

Fig. 22. Meadow Chess (Bromus erectus s. pratensis).

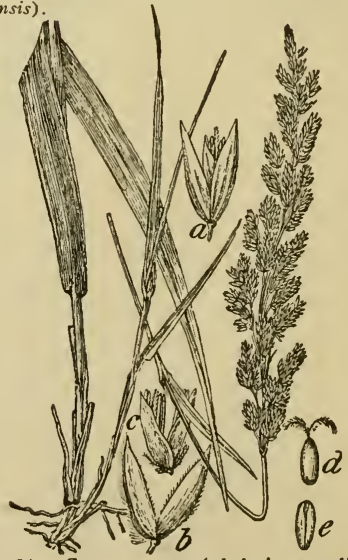

Fig. 24. Canary grass (phalaris arundina- 
Arundo phragmites (reeds). Aira s. Weingaertneria canescens (silver grassEurope). Molinia carulea (Europe). Nardus stricta (bristle grass-Europe). Ammophila s. Calamagrostis arenaria (mat grass or sand reed).

As compared with the meadow grasses, the so-called sour grasses have a very low feeding value, and when ingested in quantities are liable to affect the health, especially that of the digestive organs.

Organs-Koenig ascribes their injurious effect to the presence of nauseating volatile oil, but more recent investigations have shown that these co-called grasses contain large quantities of silicic acid in their tissues, even in the early stages of growth, and especially in the leaves, which owe their rough character to the presence of silica. The latter acts as a mechanical irritant to the mucous membranes of the digestive tract and leads to digestive disturbances and even active inflammation. Holy observed increased excretion of albumin in the urine and proteid substances in the fecal discharges. Under these conditions the tissues must suffer from albumin starvation. The incrustation of the sour grasses with silica also interferes with the action of the digestive fluids.

The various species of the sour grasses should not, however, be regarded as of equal inferiority. Some of them are indeed less inferior than some of the sweet grasses, especially the felty fruited Carex tomentosa; the millet sedge, $C$. Panicea; the dicecious sedge, $C$. dioca; the rush, Juncus botnicus; and the two species of Triglochin (arrow grass), $T$. maritimum and $T$. palustris ${ }^{4}$. The latter are regarded as first-class forages and are highly prized, especially as feed for milk cows. They contain only small quantities of silicic acid in the cell walls and comparatively few silicious spicules on the edges of the leaves. On the other hand there are sweet grasses which are provided with well-developed silicious spicules on the edges of the leaves and a needle-like pubesence on the leaf surfaces, making them just as objectionable as the sour grasses. Giant fescue grass is of this nature, as well as some other species. Among the sour grasses Carex canescens, $C$, pallescens and $C$. pilulifera (all European species) are considered of medium value as forage. Among the rushes (Juncaceæ) the species of the genus Luzula (wood and field rushes) have the same reputation. The latter are prevalent in the United States.

The horsetails (Equisetaceæ) are similar to the sour grasses in feeding value. They are found in damp, swampy and boggy meadows. The common swamp horsetail (Equisetum palustre) is a very inferior forage, and has, in addition, an unfavorable effect upon milk secretion, especially in horses. According to some authors it is said to have toxic qualities. On the other hand $E$. limosum (pipes) and $E$. heleocharis (often very abundant on the borders of ponds) are prized as good forage for milk cows (not for horses). E. limosum is common in the United States on borders of ponds and swamps and is greedily devoured by cattle and sheep.

Among the herbaceous meadow forage plants the Leguminosæ, and particularly the different species of clover and the vetches, Lathyrus

4All of these sour grasses seem to be European species, except $T$. maritimum and $T$. palustris, which are also indigenous in the United States, where cattle are fond of them, especially $T$. maritimum, which grows on salt marches and lake shores.-Translator. 
pratensis (meadow pea), Vicia cracca (tufted vetch) and $V$. sepium (fence vetch) are most highly prized as forage plants.

Other, mostly wild, herbaceous forage plants are pimpernel (Pimpinella saxifrage) wild burnet (Sanguisorba minor s. Poterium sanguisorba), scabiose (Centaurea scabiosa), plantain or ribwort (Plantago major) (most other species in United States worthless weeds), lady's mantle (Alchemilla vulgaris); aromatic plants-milfoil, yarrow or sneezewort (Achillea millifolium), caraway (Carum carvi) (not common in United States), thyme (Thymus serpyllum), marjoram (Origanum vulgare), mint (Mentha), and herbs with bitter principles like tansy (Tanecetum vulgare), wormwood (Artemisia), succory or chicory (Cichorium intybus), elecampane (Imula holenium) (esteemed as a tonic and expectorant), gentian wort (Erythraea centaurium), germander (Teucrium), etc. An admixture of these aromatic and bitter plants, in moderate amount, with other forage, is usually welcomed on account of their favorable dietetic action. The following are less desirable in this respect. Groundsel (Senecio), hawkweed (Hieraceum), knot grass and water pepper (Polygonum persecarum and $P$. hydropiper) cleavers and bed straw (Galium), bugloss and oxtongue (Anchusa), chervil (Charophyllum), cow parsnip (Heracleum lanatum), etc.

Among the worthless and injurious herbs that are common in meadows are the following: Dyer's broom or woad waxen (Genista tinctoria), thorny commock and rest harrow (Ononis spinosa), thistles (Cirsium s. Cnicus), sage (Salvia pratensis), swamp lousewort (Pedicularis palustris), marsh marigold (Caltha palustris), silver weed or goose grass (Potentilla anserina), water pepper (Polygonum hydropiper), knotgrass (Polygonum lapathifolium tomentosum), and, above all, the poisonous plants, among which may be mentioned crowfoot or buttercup (Ranunculus acer and R. sceleratus), aconite or wolf's-bane (Aconitum napellus), chervil (Charophyllum temulum), water hemlock (Cicuta virosa), spotted hemlock (Conium maculatum), hemlock, waterdrop wort or dead tongue (Enanthe crocata and Efistulosa), colchicum (Colchicum autumnale), hedge hissop (Gratiola officinalis), red foxglove (Digitalis purpurea), water plantain (Alisma plantago), poisonous darnel (Lolium temulentum), dog's mercury (Mercurialis perennis and $M$. annua), male fern (Aspidium filix-mas), and common brake (Pteris aquilina).

The chemical composition of the meadow grasses varies according to the species, age of plants, soil and fertilizer conditions, climate and location.

As the age of the plant advances the digestible substance diminishes and the crude fiber increases, as the following example will show:

Hay cut and dried at various times, but under otherwise identical conditions: 
Constituents

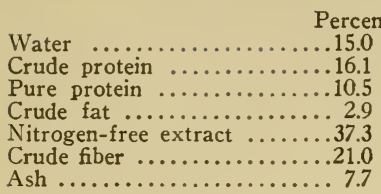

Near end of June

Percent
15.0
9.5
8.0
2.3
36.9
29.5
6.8

Near end of July

Percent

15.0

7.2

6.7

2.3

36.8

32.5

6.2

This shows the advantage in feeding meadow grasses when in the early stages of growth (before or at blossom time).

Soil and fertilizer conditions have a marked effect upon plants and their nutrient constituents. The seed itself has little or practically no effect (as far as feeding value is concerned) upon the character or composition of forage plants. On the other hand, cultivation, irrigation or drouth, liming, the application of phosphoric acid or potash, frequently have a marked influence in this respect. Climatic and meteorological conditions affect the mass and the composition of the forage harvested. An abundant water supply causes watery and coarse forage rich in crude fiber, deficient in nutrients and lacking in palatability. Prolonged drouth causes short, woody growth and deficiency in lime and phosphates. Wet meadows favor the growth of sour grasses. The latter can be avoided by proper drainage.

Meadow grasses contain on the average 75 per cent of water and 25 per cent of dry matter. Of the latter, 3 per cent consists of crude protein, 0.8 per cent crude fat, 13 per cent nitrogen-free extract, 6 per cent crude fiber and 2 per cent mineral matter ( 0.23 lime, $\mathrm{C}_{\mathrm{a}} \mathrm{O}$, and 0.15 per cent phosphoric acid, $\mathrm{P}_{2} \mathrm{O}_{5}$ ). Just before and during early bloom orchard grass contains 0.8 per cent digestible albumin; full bloom, same as timothy, 1.0 per cent; rye grass and the majority of meadow grasses, during bloom 1.3-1.5 per cent; grass from very rich pastures, up to 2.3 per cent. The starch content varies in a similar manner, between 10 and 14 per cent.

Advantages. Meadow grasses are relished by herbivora and are well digested and wholesome. They have a high dietetic value when fed green, in the succulent young stage, especially when admixed with aromatic plants of the same description. They stimulate the appetite and digestion and improve the "condition" of such animals in particular as are suffering from the effects of overexertion or disease. Meadow grasses are also slightly laxative. They are therefore of dietetic value in constipation, especially when the latter is of chronic nature, since they stimulate intestinal muscular activity. Their high content in salts, especially the bone-forming salts (lime and phosphates) makes them an excellent remedy for replenishing the depleted organism of animals long subjected to unnatural feeding conditions, or a preventive or even curative agent in halisteresis (salt starvation), especially of the bones, so-called osteomalacia and rachitis of ruminants. 
Disadvantages.-Under certain conditions the feeding of fresh meadow hay may lead to actual disease, especially when the change from dry feeding to green feeding (soiling) has been too abrupt. Among the disorders to be feared are tympanitis or bloat ${ }^{5}$, indigestion, colic, abortion, diarrhea. These unfortunate results are favored by dew or rain (on the grass), by "heating" of the grass before feeding, greedy feeding (especially after partial starvation), and by drinking water immediately after feeding.

By regulating these conditions serious consequences may be guarded against. In particular, sudden changes of feed should be avoided. This is best accomplished by mixing the green forage with hay or chaffed straw for a few days, or by feeding dry forage immediately before giving the animals access to the green. The green forage should be fed as fresh as possible and never more than 24 hours after cutting. When stored, even for this short period, it should be spread out in thin layers in a cool place, best on a raised lattice-work, to permit the circulation of air under and through it.

The following plants, when fed in quantity exert an unfavorable influence upon the secretion of milk and its quality:

(a) Chives (Allium ursinum), Sisymbrium alliaria s. Alliaria alliaria, germander (Teucrium scordium) and Thlaspi arvense. (All but the first named are European species.) All of the numerous species of Allium (garlic, the common onion, the wild onion, leek, etc.).

The above when eaten by cows impart the odor of onions or garlic to milk and its products.

(b) Wormwood (Artemisia absinthium), ragweed or hogweed (Ambrosia artimisiafolia), hedge hyssop (Gratiola officinalis), and tansy (Tanacetum vulgare) impart a bitter taste to milk.

(c) Rape (Brassica napus) and mustard (various species of Sinapis) impart a flavor of mustard.

(d) True chamomile (Matricaria chamomilla) imparts a nauseous aromatic taste.

(e) The common butterwort (Pinguicula vulgaris) produces slimy or viscous milk.

(f) Different species of Euphorbia (spurges) and madder (Rubia tinctor) cause a red coloration of the milk.

$(g)$ The sedges (Cyperace $)$ and scouring rushes and horsetails (Equisetaceæ) cause a diminution of the milk secretion (excepting the species already discussed).

Practical use.-The meadow grasses, like all green forages, are rich in water content and voluminous. Therefore unless supplemented by other feed they are not adapted to feeding horses, as they tend to distend the digestive canal unduly and interfere with normal respiration. In addition, the meadow grasses are not sufficiently nutritive. Horses subsisting upon them tire out and sweat easily. On the other hand, the meadow

5 The gases, or mixture of gases, which cause tympanitis, consist principally of $\mathrm{CO}_{2}$ up to 80 percent, methane up to 50 percent, and hydrogen. 
grasses are good maintenance or supporting feeds for mature horses as well as for horses two or three years of age; they produce a rounded out, smooth, thrifty appearance. The ration is 80 to $100 \mathrm{lbs}$. per day. All horses do well on small quantities admixed with other feeding stuffs. The amount to be fed depends upon the character of work performed by the animal. Care should be observed at all times in changing from one kind of forage to another.

For ruminants the green meadow grasses are an excellent forage under the most varied conditions, whether intended either for mere maintenance rations or for active production. Mature cattle require 100 to 160 lbs. per day, sheep 8 to 15 lbs. One hectare $(21 / 2$ acres) of the best quality bottom land pasture will support three cows, whereas the same area on poor soil will hardly suffice to support one.

The meadow grasses are not suitable as exclusive feed for swine. As a main ration, supplemented with some other feed, they are generally given to growing stock hogs, and as a rule with good results. As a supplementary feed they are excellent for swine in all conditions. Chaffing and cooking or steaming is advantageous.

The pasturing of meadows has a chemical as well as a botanical effect on plant growth as compared with that of meadows not pastured.

Various herbaceous plants, especially most species of clovers, are injured by the frequently repeated removal of their leaves and stems, gradually dying out and giving place to other species. Since the metabolic processes of plant life take place principally or entirely in the leaves (and all chlorophyl-bearing parts), their frequent removal prevents the full utilization of sunlight and heat as compared with plants that are deprived of these parts (or organs) by cutting only two or three times during the season. The latter have more time to develop "assimilating surfaces." This is the reason or explanation of the fact that the product from pastured meadows as measured in terms of total dry matter is reduced about 33 percent by the thorough and frequent removal of the leaves and green stems of the plants. On the other hand, the total weight of the green forage obtained is in excess of that obtained under other conditions, because of the richer water content of the young growth. Pasture grass furthermore differs from "harvested" grass in its greater content of mineral matter.

Pasture grass in general has a high water content ( 83 percent). The dry matter is rich in crude proteids, the latter including large amounts of nonalbuminous nitrogen-containing substances (amids). The crude fiber content is low and the fiber not woody. Lime and phosphoric acid are present in relatively large amounts.

Mowed or harvested meadow grass is rich in nitrogen-free extract and crude fiber and comparatively poor in crude protein.

The cultivated field grasses (rye grass, timothy, orchard grass and fescue, and also the millets and maba or Setaria italica) produce a less palatable (but equally nutritious) feed than the meadow grasses.

Green rye, oats, wheat and barley are sometimes used as green feeds. Rye and wheat are cut before the appearance of the heads, barley (on account of the objectionalle awns ${ }^{6}$ ) is cut at a still earlier stage. Oats

\footnotetext{
'Barley should therefore, if possible, be cut before the development of the awns, because the latter, according to investigations of Johne, Bostroem and others, are frequently the means of conveying the infection of Actinomyces bovis. Their peculiar structure makes these awns an ideal inoculating needle. They pierce the mucous membranes of the tongue, cheeks, phrarynx and esophagus and introduce the fungus in question into the tissues. Infection of this sharacter is most common in cattle and appears sporadically, or on rarer occasions enzootically (Western Prussia, Upper Palatinate, etc., also Western and Southwestern States of the U. S.). It most frequently attacks the maxillary bones and is then popularly known as lumpy jaw.
} 
may be cut at any time. They equal the sweet grasses in nutrient value but not in palatability. These forages are liable to cause tympanitis and should therefore be mixed with chaffed straw. Green Indian corn is not dangerous in this respect. It is an excellent supplementary feed for cows in milk, and is usually fed mixed with chaffed straw and oil cake. The best time for cutting is immediately before or during bloom. It is
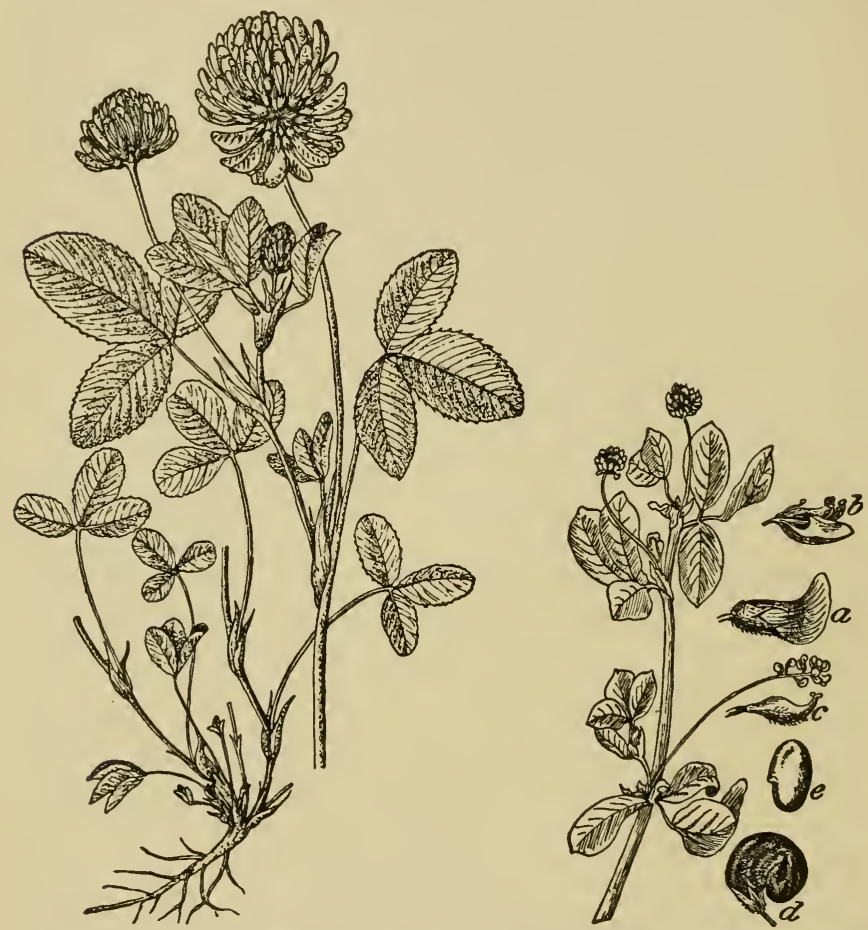

Fig. 25. Hybrid or bastard clover (Trifo.

Fig. 26. Nonesuch (Medicago lupulina) $a$, Flower; $b$, ovary; $c$, partly developed ovary; $d$, pod; $e$, seed (magnified).

then still succulent and soft and characterized by a high sugar content (4.6 percent). Among the different varieties of Indian corn the earlier maturing ones (Bavarian, Italian and Hungarian) are rather more nutritious, less woody and more palatable, contain 0.6 percent digestible albumen and possess a 9.1 percent starch value, as compared with American "horse corn" with 0.3 percent digestible albumen and a starch value of 7.3 per cent. American sweet corn probably has qualities similar to 
the first-named varieties. Henry and Morrison (Feeds and Feeding, 16th edition, 1916) give the following analyses: Flint corn fodder in milk: Dry matter, 15.0 per cent; crude protein, 0.9 per cent; starch, 8.9 per cent. Sweet corn fodder, roasting-ear stage or later: Dry matter, 20.3 per cent; crude protein, 1.2 per cent; starch, 12.0 per cent. They have the fat value 0.4 per cent., and practically the same nutritive ratio, $1: 10.9$ and $1: 10.8$ respectively.

Sorghum (Sorghum saccharatum) furnishes the source of a forage resembling that of Indian corn but with less coarse stems and higher

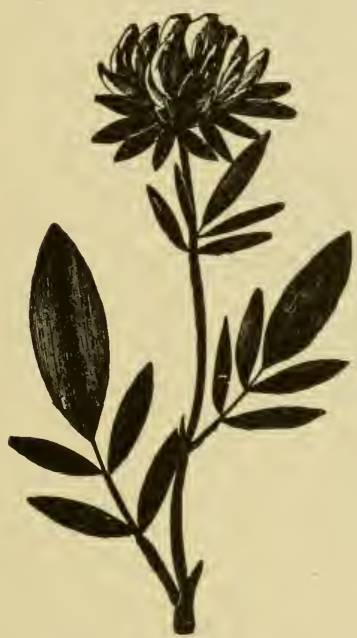

Fig. 27. Lady's finger or kidney vetch (Anthyllis vulneraria).

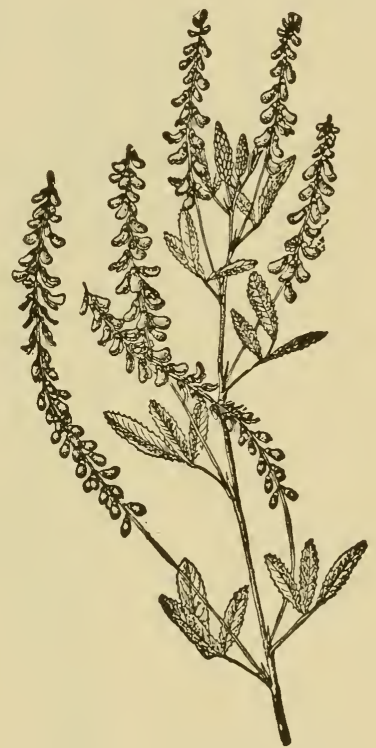

Fig. 28. Melilot (melilotus officinalis).

sugar content. Under favorable conditions several cuttings can be made. When fed in the early stages of growth violent poisoning has been observed to follow (prussic acid). This danger does not attend the feeding of the mature plant. The digestible albumen centent is 0.7 per cent, starch value, 8.1 per cent.

The most important species of clover are: First and above all, red clover (Trifolium pratense); white clover ( $T$. repens), crimson or carnation clover ( $T$. incarnatum, Italian species), bastard hybrid or Swedish clover ( $T$. hybridum, Fig. 25), to which should be added several other species of Leguminosæ, nonesuch (Medicago lupulina, Fig. 26), 
kidney vetch or lady's finger (Anthyllis vulneraria, Fig. 27), melilot (Melilotus officinalis, Fig. 28), esparcet (Onobrychis sativa, Fig. 29), serradella (Ornithopus sativus), lupines (Lupinus luteus, L. albus, L. angustifolius), field vetch (Vicia sativa), sand vetch ( $V$. villosa and its varieties), sow bean ( $V . f a b a)$ and field pea (Pisum sativum).

The nutritive value and digestibility (excepting crude fiber) of the foregoing Leguminosæ are higher than in the meadow grasses. The

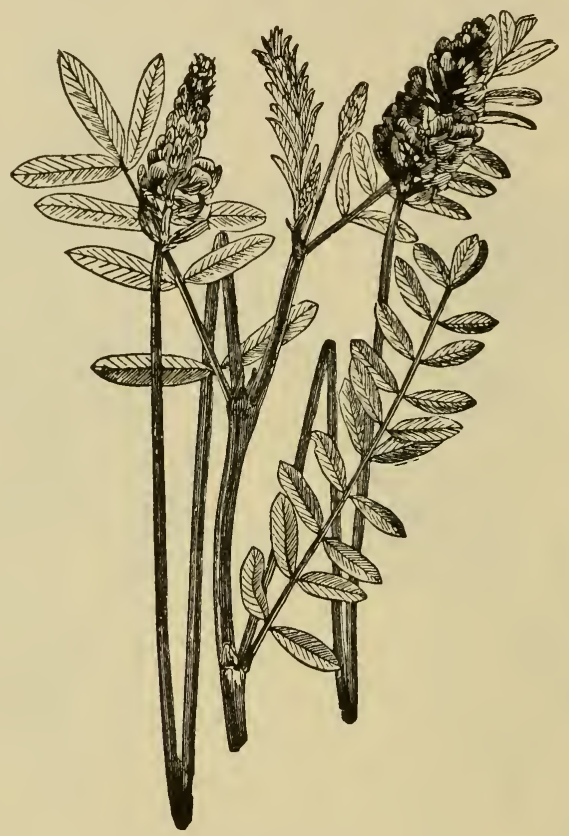

Fig. 29. Esparcet (Onobrychis sativa).

digestible albumen content is 1.3 to 1.9 per cent, the starch value 7.5 to 10 per cent. The dietetic effect on the digestive apparatus is somewhat less favorable than that of the meadow grasses, and their objectional characters are more pronounced (tympanitis, colic, abortion, diarrhea, cerebral effects). The precautions mentioned in connection with the feeding of the meadow grasses should therefore be observed in connection with the clovers and other Leguminosæ with redoubled vigilance. Young, rank-growing clover in particular is frequently the cause of violent and even fatal bloating. 
The formation of feed balls has been observed following the ingestion of wilted clover. Overfeeding with dry, woody clover, sow beans, field vetches or field peas may also be followed by serious consequences, especially when animals have not been accustomed to them. Red clover and alfalfa or lucerne, in the order named, are considered most dangerous in this respect and have the additional objection that they occasionally cause eczematous eruptions on the inside of the thighs in horses. Dammann states that vetches fed to horses in large quantity may cause wheezing and hard breathing (heaves) and paralysis of the muscles of the trunk. Again, melilot is rich in coumarin before blossom and should not be fed to sheep in quantities exceeding one-half normal rations, and not exceeding one-third normal ration for other animals. Hybrid clover, fed to horses, has been known to produce partial necrosis of the buccal mucous membrane, the conjunctiva, the white areas of the skin of the head and feet, and in less frequent cases hemorrhagic enteritis and colic. When fed in conjunction with lupines it has caused icterus, stupor, tottering gait, bloody urine, necrosis of small areas of the mucous membrane of the tongue, and death. The rate of mortality may reach 50 per cent. Cattle remain unaffected even where hybrid clover produced serious illness in horses. The inflammatory disturbances following the ingestion of hybrid clover were formerly believed to be due to parasitic infection of the food in question, as in case of alfalfa exanthema. More recently the cause is looked for in the photodynamic substances contained in these plants. It is possible also that these feeding exanthemata are anaphylactic phenomena, caused by the absorption of undigested albumen. This leads at first to sensitization (the formation of proteolytic antibodies) and after repeated ingestion is followed by anaphylaxis (feeding exanthema).

Recently Grammlich has reported mass affections following cloverfeeding (so-called clover disease). During the summer season 69 horses became affected, of which 31 died. The disease made its appearance following pasturing on rank-growing meadows (red and white clover) as well as after soiling with green clover, and could be reproduced experimentally. The symptoms were inflammation of the light-colored areas of the skin of the head and feet, exhaustion, swaying walk, symptoms of depression or raving, icterus, vesicles and ulcers of the mucous membrane of the mouth and, in severe cases, accelerated pulse, constipation and death. Postmortem examination revealed icterus, spotted inflammatory areas in the mucous membranes of the stomach and intestines, especially the large intestine, parenchymatous inflammation of the heart and liver, cloudy swelling of the kidneys, sometimes cystitis. The treatment consisted in withdrawal of the objectional feed, rest, saline purgatives, oatmeal soup, and symptomatic treatment. Hay made from these forage plants seems to be harmless.

To prevent the unpleasant tympanitic action of clover and alfalfa they may be mixed with grass (Italian rye grass) or better, with aromatic herbs (yarrow, caraway or gum succory). Where tympanitis is of 
common occurrence it is advisable to sow caraway (carum carvi), 8 to $10 \mathrm{lbs}$. to the hectare ( 3 to $4 \mathrm{lbs}$. to the acre) with the clover seed. (Probably not practicable in the United States.-Translator.) Since meadow caraway is a bienniel plant, it usually lasts just as long as the clover, and is a good forage plant.

The lupines, which, when dried, frequently cause serious losses among sheep, are attended with little danger when fed green (Dammann).

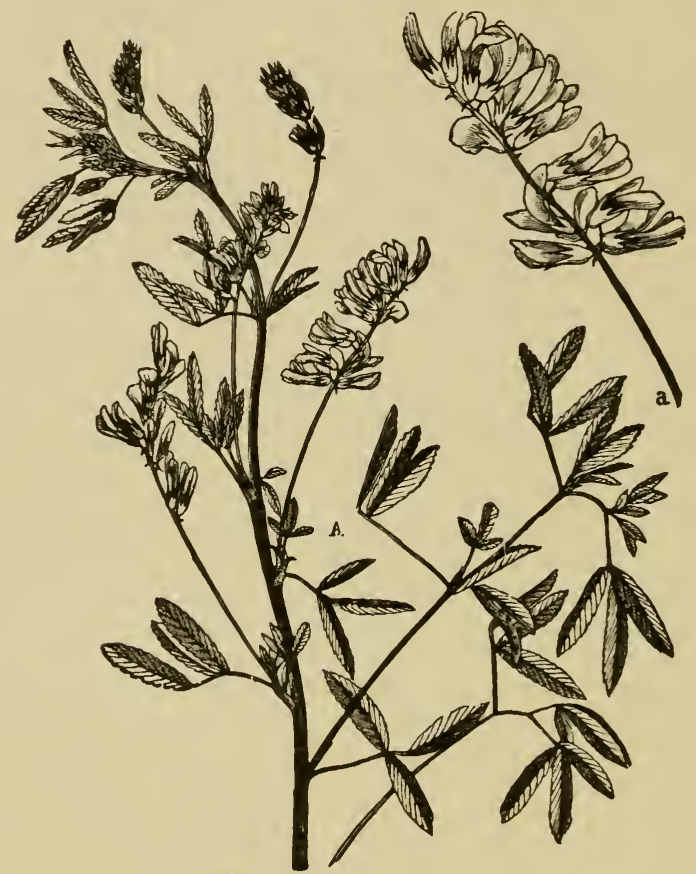

Fig. 30. Alfalfa or lucerne (Medicago sativa).

While the Leguminosæ in general are greedily eaten by all herbivora, the lupines, on account of their bitter taste, are not relished at first. However, sheep soon become accustomed to them, but not so with horses and cattle. At the beginning of the blossom period the lupines contain 1.1 per cent and at the end of this period 0.8 per cent of digestible albumen and 5.9 to 7.1 per cent, respectively, starch value.

The wood chickling vetch (Lathyrus sylvester) makes good crops in poor soil and at high altitudes, may be cut twice and makes a hay similar to that of alfalfa in nutritive value. The seeds of all species of Lathyrus, 
however, contain an active poison and should therefore be completely removed, with the pods, before feeding. The wood chickling vetch should be cut before or during early blossom time.

Spurry (Spergula arvensis, Fig. 31) produces a feed for milk cows and sheep in wide use. Its nutritive value corresponds approximately to that of the meadow grasses (1.0 per cent digestibe albumen and 9.6 per cent starch value). It is a notable fact that this forage has little tendency to cause bloat.

Buckwheat (Polygonum fagopyrum, Fig. 32) has a nutritive value similar to that of meadow grass (1.1 per cent digestible albumen, 8.1 per cent starch value). Its agricultural value lies in the fact that, like

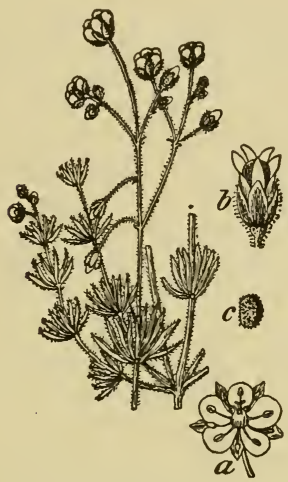

Fig. 31. Spurry (Spergula ar'ensis).

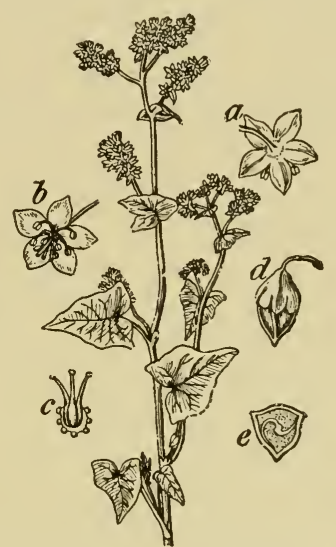

Fig. 32. Buckwheat (Polygonum fagopyrum).

the lupine, it thrives on sandy soil on which clover will not do well. If fed out of doors to white sheep, or to sheep with white markings, to swine of the same description, to white mice or to guinea-pigs, during bright or sunshiny weather, it causes fagopyrism or so-called buckwheat disease. Horses and cattle are more rarely affected. The disease is characterized by a dermatitis, especially in the region of the head, face, eyelids and ears (so-called head erysipelas). This may be accompanied by an affection of the brain (inflammation in sheep) with symptoms of fright, restlessness, raving, stupor and staggering, occasionally accelerated respiration, weak heart action, icterus (hematogenic icterus) and hematuria. If the animals are kept in the stable, or on pasture during cloudy weather, or if of a black color or darkened by adhering dirt, or artificially colored dark, the disease will, as a rule, not develop. Breitenreiter reports exceptional cases. Affected animals recover if they are protected from bright light (e. g., by stabling). 
Contrary to the negative results obtained by Bichelmaier and Hilz, the seed hulls of buckwheat contain a fluorescent body (fluorophyll-Koefeld) extractable with alcohol, ether and chloroform, which causes affections of the gastrointestinal mucosa, swelling of the liver and kidneys and necrobiotic changes in the leucocytes. In white colored animals it causes affections of the skin in the areas exposed to the light.

To prevent fagopyrism white sheep and swine should be permitted on buckwheat pasture on cloudy days only and fed in the stable on bright, sunny days, and furthermore, not exposed to bright sunshine for a week after cessation of buckwheat feeding. Affected animals should be put under shelter at once, or kept in shady places. The harmful action of buckwheat may be held in check to some extent by simuitaneous seeding with millet, white mustard (Sinapis alba) or summer rape, and feeding the mixture.

Mustard is frequently fed alone, to milk cows, and is said to exert a favorable influence on milk secretion. It may also be fed to young cattle and to sheep. This forage must be fed between the time of beginning bloom and the formation of the seed pods, not later, on account of the accumulation of oil of mustard in the seeds. Mustard is usually harmless before bloom. It has frequently been asserted that feeding in later stages causes serious intestinal inflammations, but this seems improbable.

Winter rape (Brassica napus) and common turnips (Brassico rapa) afford large crops in the fall of the year or in favorable spring weather. As a soiling crop they should be cut not later than the first appearance of bloom and fed with chaffed straw, thus serving as a transition feed for soiling. Rape fields are also used as pasture for sheep, after the main crop has been removed. The finer breeds of wool sheep should receive dry forage in addition. Green rape has a favorable influence on the secretion of milk, but the quantity fed shoult be kept within reason. Excessive rations may cause diarrhea, even gastroenteritis, nephritis and death. To what extent influences foreign to the rape itself are concerned in producing the unfavorable effects following the feeding of this plant in large quantities is as yet an open question. Among the agencies suspected are Polydesmus exitiosus, Peronospora parasitica (rape mold). white blister rust (Cystopus candidus), sclerotioides disease of rape (Peziza schlerotioides), caterpillars and butterflies, etc. Young animals in particular frequently experience ill effects from feeding on rape. The injurious effects of rape may be avoided to some extent or entirely prevented by simultaneously sowing of rye, vetches, Italian rye grass, etc., with the rape.

According to Craig, green rape is well adapted for fattening swine. In the United States rape pasture is preferred to red clover for swine.

Beet leaves also constitute a good soiling crop, especially for cattle and swine (mangel and sugar beet). In this connection should be mentioned the leaves of cabbage and of the carrot, of kohlrabi (turnip cabbage) and of late fall turnips. The leaves of beets and turnips are rather 
watery but contain large amounts of vegetable acid salts, especially those of oxalic acid, and comparatively little crude fiber. The oxalic acid content may amount to 3.5 per cent of the entire dry matter. Only half of this is in the form of oxalate of lime. The nitrogen present is, to a considerable extent, in the form of amid compounds and nitrate of potash. On account of this rich content of oxalic acid and saltpeter, together with the bacteria-infected soil particles that are always present on beet and turnip leaves, this kind of forage, if fed in quantity, often causes affections of the kidneys and of the heart (oxalic acid and saltpeter poisoning). The soft and at times fluid character of the intestinal discharges of cattle resulting from these feeds interferes seriously with the production of sanitary milk. To prevent the laxative action of these feeds and the toxic effects of the oxalic acid, prepared chalk (about 3 ounces to $200 \mathrm{lbs}$. of leaves) may be added before feeding. A better practice, however, is to observe moderation in feeding beet leaves and to supplement them with roughage. Cattle receive $40 \mathrm{lbs}$. of beet leaves per day, or $100 \mathrm{lbs}$., if the tops of the root are included (per 1,000 lbs. live weight).

Beet leaves do not constitute a complete ration and should not be fed exclusively under any circumstances. Since they are available in large quantities during beet harvest, it is usually necessary, in order to save them, to ensilage or dry them. Although ensilaging causes the loss of a considerable portion of the water-soluble oxalic acid, it is still necessary to observe the precautions prescribed for feeding the fresh leaves. According to Hussmann, cows take up to 9 lbs. of the dried leaves per 1,000 lbs. weight, per day, and do well. They are suitable substitutes for second crop or aftermath grasses and for clover hay. The quality of the milk in cows does not suffer.

Chicory leaves. In the sugar beet regions of Germany chicory (Cichorium intybus) is extensively cultivated as a substitute for coffee, and the tops of the plants are used as cattle feed. In England this plant is cultivated to furnish pasturage for sheep and in France it is cultivated as a regular forage plant. Two to three cuttings may be made and one acre will yield from 8 to 12 tons of green feed. In general, animals eat the leaves of this plant greedily, digest it well and thrive upon it. Slightly wilted fall cuttings average 54 per cent dry matter, 9 per cent crude protein, 2.3 per cent crude fat, 25 per cent nitrogen-free extract, 8 per cent crude fiber and 9.5 per cent mineral matter. Oppermann reports cases of poisoning from chicory leaves. The symptoms were inflammation of the mouth, suppressed appetite, rumination and gastrointestinal peristalsis, swaying walk. Treatment with veratrin or veratrum album $(2 \mathrm{r} / 2 \mathrm{gr}$.) brought about recovery.

Since it is well known that chicory is subject to attack from rust fungi (Puccinia compositarum), Peronospora gangliformis, Peziza sclerotioides, etc., and since the plant itself is known to be a palatable and agreeable feeding stuff, the suspicion arises that the intoxications observed by 
Oppermann were due to parastic infection or contamination of the chicory rather than to the plant itself.

According to Schulz, continued use of chicory "coffee" causes hemorrhoids and varicose veins as a result of loss of tonus of the blood vessels.

To avoid poisoning it is suggested that changes in feed be made gradually and that not more than $60 \mathrm{lbs}$. of chicory be given per 1,000 lbs. live weight.

In recent years comfrey (Symphytum asperrimum and several other species, $S$. officinale, etc.) have been cultivated as soiling crops, especially for swine. These are oriental herbs, some of them naturalized in the Middle States. They are very succulent, contain little crude fiber, are rich in protein, and are usually greedily eaten by swine, although cattle care less for them on account of their rough hairy character. The crude protein content is 9.5 per cent, starch value 37.5 per cent. Comfrey is also used as feed for horses, goats, rabbits, geese and ducks. The plant grows well under a variety of indifferent conditions, is not easily exterminated and yields well.

Green potato tops, as a rule, are used as forage only in times of famine. Their use as forage is not wholly unattended with danger, especially when fed in the early stages of growth or when set with fruit. Violent cases of poisoning and even fatalities have occurred among cattle and swine under these conditions (solanin poisoning). The symptoms, in cattle, are colic, tympanitis, diarrhea, cessation of milk secretion, convulsions, throbbing heart action, paralysis, and cutaneous affections such as eczema of the limbs, udder, scrotom, perineum (Johne, Moebius, Roemer, Michaelis); in pigs, vomiting, tympanitis, convulsions and paralysis. Drying seems to reduce the toxicity of potato tops, but their palatability also suffers. The best way to utilize this material is to subject it to fermentation as in the preparation of "brown hay" (p. 23), Klappmeyers method of haymaking and ensilaging. Mixed with chaffed hay or straw, it is well liked by cattle and consumed without detriment. Fed in conjunction with ensilaged beet leaves, it has the advantage of neutralizing the laxative effects of the latter. Recently it has been recommended to chaff the potato tops, adding 4 ounces of common salt to $100 \mathrm{lbs}$. of the chaff, and steaming. The water is drained off before feeding. Thus prepared it is wholesome and satisfying and cows like it. Formerly the susceptibility of potato tops to attack by disease (Phytophthora and Polydesmus) made their use as forage objectionable, but this is of comparatively little moment today when disease-resisting varieties of potatoes may be had. The tops of late potatoes (which are more productive and therefore more and more extensively cultivated in preference to the earlier varieties) remain green until the tubers are ready for harvest. The tuber and forage crops may therefore be harvested simultaneously, which is to the advantage of the former.

Thistles.-Various species of thistle, especially the common thistle (Cirsium arvense, s. Cnicus arvense-Canada thistle, cursed thistle, (the common thistle of Europe) are frequently used as accessory feed for horses, swine and ruminants. They are usually chaffed before feeding.

Prickly dyer's broom (Ulex Europaus) is used in some sections as a winter soiling crop. On account of its prickly nature, it is chaffed before feeding and then crushed in a potato or grain crushing machine, or in a machine especially constructed for the purpose. Since the seeds of dyer's broom are reputed to be poisonous, it should be fed before the seed stage.

Fungi (mushrooms, etc.) - Nontoxic fungi not in demand for human food are excellent feed for swine. In nutrient value they are superior to potatoes. They may also be fed to poultry, rabbits and fishes. All edible fungi do not, however, agree with animals. According to Morel, Armillaria mellea (edible) is toxic for 
animals. Since fungi spoil easily, care should be exercised to avoid feeding decomposed material.

When fed to swine, cattle or poultry, fungi should be chopped up, cooked and mixed with bran. They may also be dried, crushed, and fed mixed with crushed potatoes.

In some sections of Germany the flocks of sheep are driven to the pine forests every fall and "masted" on the fungi which grow there in abundance. No cases of poisoning have ever been reported as resulting from this practice.

According to Dittrich, the potato puffball (Scleroderma vulgare) is a good feed for cattle and swine, and the false truffle for goats. The "fly toadstool" (Agaricus muscarius), reputed as poisonous, is said to be greedily eaten by sheep, without harmful results. The term "cow toadstool," common in Germany, is said to be derived from the general inclination of cattle to feed upon several different species of these fungi. Dittrich recommends Paxillus, Lactaria (milk fungi), Russula, Clitocybe (funnel fungi), the medium-sized species of Tricholoma (excepting the nauseous smelling $T$. sulfureum), the large scaly Lepiota, all of the species of Boletus except those suitable for human consumption (yellow boletus or B. edulis) or those that may be too tough or woody (Polyporus-the corky, shell-like outgrowths on trees and decaying logs), the Clavaria, puffballs, spiny fungus, etc. Toadstool fungi are also suitable food for fishes. Even the toxic species, according to Knauthe, may be fed to them without danger.

Certain fungi that are toxic for man may, according to Dittrich, be fed to advantage to animals, e.g., the reddish brown milk toadstool (Lactarius rufus), L. torminosus, Russula emetica, and even the devil toadstool (Bolerus satanas), Hypholoma fasciculare alone of this group, on account of its bitter taste, is not a suitable animal feeding stuff.

\section{Roughage}

The term "roughage" includes hay, straw and chaff".

\section{Hay}

Hay consists of grasses or Leguminosæ, cut and dried in the young, succulent stage, before or during bloom. After blossom these plants rapidly become woody, less digestible and less nutritious. It is therefore important to observe the proper time for harvesting. "Overripe" hay is of inferior value. In regard to hay making see pages 19 and 23.

Compared with green feed (soiling), hay has less nutrient value (owing to increased effort necessary in mastication and digestion) and exercises a less favorable dietetic action, even though, for herbivora, in itself, it is easily digestible, wholesome and stimulating to the digestive processes. It is, in fact, an indispensable part of the ration for herbivora when the latter receive slops, pulps and root crops. According to the variety of plant converted into hay, we distinguish, grass hay, clover hay, leguminous hay, leaf hay, twig hay, etc.

\section{a. Meadow Hay and Aftermath Hay}

As a rule meadow hay and aftermath hay are regarded as equal in value. The second-crop hay (aftermath) is somewhat richer in albumen

IIn America, according to Henry and Morrison, the term also includes corn fodder and silage. Low grade milling by-products, such as oat hulls, ground corn cobs and peanut hulls, are also roughages, rather than concentrates, for they are largely fiber and furnish little nutfiment. Roots are watery and bulky and contain relatively little nutriment per pound, yet based on the composition of the dry substance they are more like concentrates than rough. ages, as they are low in fiber. They are really watery or diluted concentrates, though for convenience they are included under fresh green roughages in appendix Table I., Henry and Morrison, Feeds and Feeding, 16 th ed., 1916, p. 10. 
and fat than the first-crop or regular hay. But since harvest conditions (weather) are frequently less favorable for second-crop hay, it is not unusual that the difference in quality is reversed in this respect. Secondcrop hay may be recognized by the usual absence of flowering parts and the presence of late flowering herbs (Geranium, Sanfuisorba, Euphrasia. Brunella, Heracleum, Colchicum, etc., and in the United States, Ambrosia (rag weed), Alopecurus and corresponding weeds and grasses.

The value of meadow hay and second-crop hay depends upon their botanical composition. The more delicate and tender or the less woody the sweet grasses are, the greater their value for hay. On the other hand, the presence of any of the many species of sour grasses or of Molinia corulea (Europe), a sweet or true grass with properties of the sedges and rushes, or an admixture of scouring rushes or horsetails is objectionable. The sour grasses, provided they have not grown on soil of a saline character (seacoast) when fed to sheep in quantity (admixed with hay) are said to produce anemia. In cattle they are reputed to have an unfavorable effect on the digestive functions, the general condition, and milk secretion.

According to the presence or absence of the sour grasses in meadow hay we distinguish (a) sweet and (b) sour meadow hay.

The chemical composition of the different varieties of hay as far as the important nutrients are concerned varies between a 2.5 and 6.5 per cent digestible albumen content, and a starch value of 19.0 to 40.5 per cent.

An ordinary chemical analysis, as a rule, throws little light upon the real value of any particular kind of hay. Thus A. Mayer found that good meadow hay (Poa pratensis, June grass) contained 6.5 per cent digestible albumen, while the common sedge (Carex vulgaris) contained 12.2 per cent. Their actual nutritive value is just the reverse of what this analysis would indicate. Low-grade hay is generally poor in mineral matter and rich in crude fiber, good hay rich in mineral matter. Alpine hay usually has a high fat content (2.1 per cent).

In judging hay it is not sufficient to confine the examination to a handful removed from a bale. Many samples should be taken and a number of bales opened and spread out to view. Adulterated hay may often be recognized by the different colored contents of a bale, or by the presence of plants of different origin, e. g., good meadow hay mixed with sour grasses or mosses, etc.

The value of hay depends upon its botanical composition. An abundance of Leguminosæ in a mixed hay and the absence of sour grasses and related plants is an indication of good quality and high value. A botanical analysis, which may be limited to the identification of the four groups-sweet grasses, Leguminosæ, sour grasses and foreign matterprovides a better basis for the judging of quality and value than a chemical determination of the nutrients. Packed dried leaves should be placed in warm water and allowed to soften. They may then be spread out and examined and their identity determined. 
Following the botanical examination the physical characteristics should be noted. Wittmack has suggested the following outline for the determination of the value of hay according to the point system:

If the hay contains-

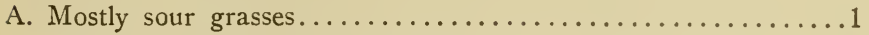

Moderate amount of sour grasses...................

Sweet grasses only or nearly so.................. $2-10$

B. Sweet grasses present, mostly of the third rank (cf. p. 41) ....1-5

Much grass of the second rank.......................

Almost all grasses of the first rank.................. 11-20

C. Clovers or other good herbs:

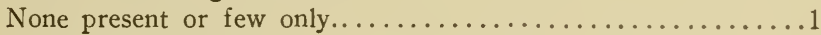

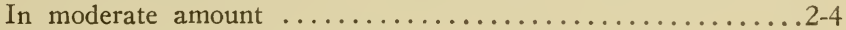

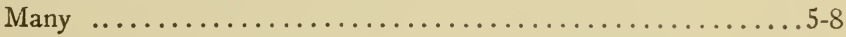

D. Many woody stemmed or more or less injurious plants (rushes,

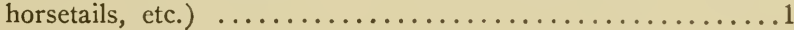

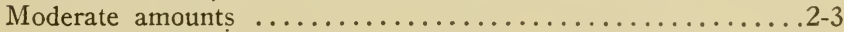

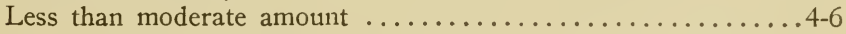

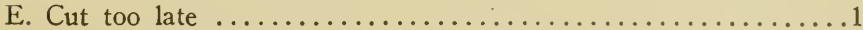

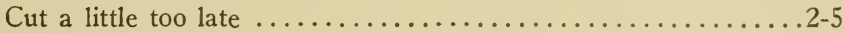

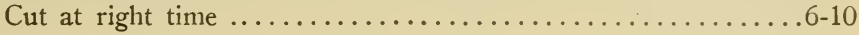

F. Poorly harvested or stored, dusty, etc. ...............

Affected by exposure to rain, dusty or musty........... 2-5

Properly harvested and of good odor................. 6 -10

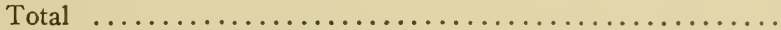

A total of 1 to 30 points indicates hay of the third class.

A total of 31 to 50 points indicates hay of the second class.

A total of 51 or more points indicates hay of the first class.

Classes 1 and 2 are considered fit for storage, class 3 only in case nothing better can be obtained, and provided that it is free from injurious properties or admixtures.

Under $\mathrm{F}$ the color of the hay should receive first consideration. Fresh, properly harvested hay has a greenish color, the shade of green depending upon the character of the soil, dark green indicating rich soil as the origin. Alpine hay has a lighter color than that grown in valleys or river bottoms. Exposure to rain while curing produces a pale or yellowish color. Old hay is pale grayish green.

Properly harvested and carefully stored hay has a pleasant odor resembling that of tea. A pronounced fragrance of coumarin (a substance of vanilla-like odor) is due to the presence of spring grass ( $A n$ thoxanthum odoratum), melilot, white clover and simipar plants. Objectional odors are sometimes masked by the intentional admixture of strong-smelling herbs. The degree of moisture should also be noted, and tested by manipulation.

Hay originating on artificially irrigated meadows is usually of medium 
quality and conspicuously pale or light colored. It is composed mainly of Lolium perenne, often Phlem pratense and Dactylis glomerata and little or no clover. It is said to be inferior in nutritious elements, to affect the secretion of milk unfavorably, to cause diarrhea in lambs and scorbutus in sheep (Koenig). There is no doubt, at least, that hay from irrigated meadows lacks the aroma and palatability that characterizes meadow hay. According to Friedlaender, the proteins of the irrigatedmeadow hay and the nitrogen-free extract of the ordinary meadow hay are more easily digested than respective nutrients of the other hay. As a rule irrigated-meadow hay is deficient in mineral matter, especially the bone-forming salts. On the other hand there is no question that the amount and proportion of these constituents may be materially influenced by fertility conditions and by regulation of the irrigation water supply. In general it would be advisable to supplement rations consisting largely of hay from irrigated meadows, with liberal allowances of salt as a substitute for the absent aroma and as a stimulant for the appetite and digestion. When there is a deficiency of lime salt, daily doses of prepared chalk not exceeding three ounces may be given.

Light colored meadow hay consists chiefly of long-stemmed grasses of rank growth rich in crude fiber. Aromatic herbs are usually absent in this kind of hay. As a result such hay is less palatable and not so well liked by animals. It is usually hay of medium grade.

So-called Mielitz hay, well liked in Berlin for feeding horses, consists principally of Glyceria aquatica (European species) and Phalaris arundacee (Canary grass-common in Europe as well as in the Middle States). The latter species is much inferior to the former. It is a coarse feed, yellowish in color and strawlike, but when properly harvested makes a good hay of medium grade.

So-called Alpine hay (grown in the mountainous sections of Germany) is a hay of high quality, short and fine stemmed, leafy, and mixed with aromatic herbs. Starch value, 38.5 per cent, digestible protein 6.4 per cent,

Salt-marsh hay is brownish in color and very palatable on account of its high salt content. It is classed as a good grade of hay and may be recognized by the species of which it is composed, Juncus botnicus, Triglochin maritimum, Scirpus maritimus, Plantago maritima ${ }^{8}$, etc. Starch value is about 30 per cent, digestible protein about 3 per cent. Such salt-marsh hay as blue joint (Calamagrostis canadensis), cut before maturity equals timothy in value'.

A thorough examination sometimes requires the use of the microscope in addition to inspection with the mere naked eye. The procedure consists in sprinkling a little of the hay on a sheet of paper. The fine, broken material thus obtained is then inspected for the presence of seeds.

American species.

9Henry and Morrison, Feeds and Feeding, 16th edition, 1916. 
This will give valuable information as to the time of cutting. A quantity of the "dust" is placed in a watch glass, moistened with water and a few drops of caustic potash solution and examined under a coverglass with both a low and a high power lens. Among the foreign matter present there may be hay mites (Acarus fœnarius), parasitic fungi, molds, dust, mud and slime. Of the parastic fungi there should be mentioned ergot (blackish hornlike structures 1 to $2 \mathrm{~cm}$. long), smut (blackish, sootlike powder), rust (rust-colored or black dustlike heaps or stripes on the leaves or culms), false mildew (whitish to gray-violet, effaceable moldy layers, usually on the under side of the leaves), true mildew (grayish white coating with black puncta), Epichlö̈ (brownish felt surrounding the culms of grasses), leafspot disease (yellow, reddish, brownish spots on leaves, sometimes in the form of zones, yellowish or whitish in the middle from drying, often with very minute black points), etc. Special note should be made of the presence of the hairs of processionary caterpillars of the oak (Cnethocampa processionea), and those of the pine (C. pinivora), the hawthorne spinner (Porthesia chrysorrhoca), etc., which have frequently been known to cause severe inflammation of the mouth of horses, swelling of the head and urticariform eruptions.

Hygienic requirements for good meadow hay are that it consist chiefly of sweet grasses or herbs cut before bloom, that it contain few if any grasses or herbs that are unpalatable, noxious, or of low nutritive valuc, that it be properly harvested, have a fresh or bright color, pleasant aroma, and contain no admixtures of dusty, earthy, slimy or fungus particles.

Fresh hay with high content of aromatic herbs (coumarin and $A n$ thoxanthum odoratum, etc.), is frequently so intensely aromatic that even horses (especially in close stables) are affected thereby. A sudden change from old to fresh hay has frequently caused febrile gastrointestinal catarrhs, colic, icterus, depression, dullness and even coma, diaphoresis, etc. The causes of these disturbances have not yet been entirely explained. Greedy feeding, imperfect mastication and consquent imperfect insalivation, followed by disturbed digestion, increased bacterial activity, the formation of toxins and irritating products are no doubt in part responsible. Possibly the morbid processes that are active in these conditions could be looked upon as a form of hay fever. Formerly they were looked upon as the result of coumarin poisoning, a view that has been refuted by Froehner. New hay is still relatively rich in water. When stored it sweats and becomes heated, that is, the water in the cells of the heavier parts of the plants passes out by diffusion, and as a result bacterial activity is increased and excessive heat is produced. The water gradually evaporates and bacterial activity ceases. This entire process takes place to completion in the course of 4 to 8 weeks.

If hay has been stored too green or too wet (rain and dew), it may become heated to such a degree that spontaneous combustion occurs. This applies especially to second-crop hay, less to straw, bran, malt, saw- 
dust, etc. Bacterial fermentation may cause a temperature of from $140^{\circ}$ to $158^{\circ} \mathrm{F}$., and this, followed by purely chemical processes of oxydation, may be increased to $266^{\circ} \mathrm{F}$. and more. The latter temperatures causes charring and, attended with sufficient oxygen supply, actual ignition. (According to Henry and Morrison, clover hay, according to actual tests, will ignite at $302^{\circ}$ to $392^{\circ}$ F.-Translator.) Poorly harvested hay may be prevented from overheating by the application of common salt. (Henry and Morrision recommend compacting and covering with other material when hay heats to a dangerously high point and the taking of every other possible precaution to cut out the air-Translator.) After the sweating process is completed the injurious after-effects mentioned above rarely appear. If conditions exist that make it necessary to feed fresh hay, the change should be made gradually (mixing old with the new hay), or, if this is not possible, the new hay should be chaffed with straw and fed sparingly.

As hay becomes older, it increases in dryness, becomes brittle, is easily broken into fine particles and is apt to become dusty. The more delicate and valuable parts are lost. The fresh color disappears, palatability is reduced, the pleasant aroma lost, it becomes less digestible and as a result of loss of proteids is less nourishing. After being stored for one or two years hay loses its stimulating dietetic action, and owing to its "dustiness" may produce catarrh of the respiratory tract. In short, its quality suffers and its value as a feed diminishes.

Uses of the different varieties of hay. The finer qualities of hay are usually preferred for feeding sheep and young stock, the coarser varieties for cattle and the medium sorts for horses. Swine, as a rule, are not fed any hay. They will take it only when chaffed, or steamed, or, better, cooked. They do not utilize it profitably.

Hay alone may serve as a maintenance ration for herbivora, but it is not a suitable producing ration for either horses or cattle. It is absolutely necessary, however, as part of a proper ration for horses and cattle. Daily rations for horses should include 4 to 12 pounds of hay, the larger rations for heavy and slow work, the smaller for work of the opposite character. Cattle, especially milk cows, should receive, if at all practicable, 5 pounds of hay per 1,000 pounds live weight. Compared with straw and other substitutes it is much richer in lime and other salts. Many cows are fed smaller rations of hay, but this is poor economy.

Sweet silage. The starch value of this feed is between 12 and 14 per cent. Digestibility is high, digestive effort comparatively low. Cattle usually like sweet silage or soon become accustomed to it. It is also a wholesome feed for pregnant animals. Sweet silage may be gradually substituted for the hay ration. Fifteen pounds of sweet silage may be substituted for one-third of the hay ration, 22 pounds for half, and 40 to 45 pounds for the entire hay ration. Four to five pounds of sweet silage correspond in value to 2 pounds of hay. The change from hay to sweet silage should be made gradually. For practical purposes 60 pounds of sweet silage and 12 pounds of hay should he fed per 1.000 pounds live weight and a milk yield of $2 \frac{r}{2}$ gallons (10 liters). (In regard to the 
effect of sweet silage on the milk secretion see p. 26). Horses also like sweet silage and digest it well. Rations may consist of 16 pounds sweet silage and 6 pounds of hay with 2 pounds of oats mixed with chaff (cut straw) per day for a work horse. Sweet silage for swine and poultry should be made from young, tender growth, rich in clover. It is to be fed chaffed, sprinkled with water and mixed with beets or cooked potatoes.

Sour silage. (For preparation and characteristics see p. 27.) The digestible protein and starch value of sour ensilage made of grass equal 0.9 and 8.0, potato tops 0.3 and 8.0 , beet leaves 0.7 and 8 , sugar beet leaves and tops 0.2 and 9.5 per cent respectively. Cattle like sour silage, and if the change from dry feed is made gradually they do well on it. Dry feed must be given as supplementary roughage. When first given the silage is very laxative. Horses and sheep are also said to like it. Daily rations for cattle may be as high as 30 to 40 pounds. Milk cows should receive this feed after being milked and not during milking time. Yearlings receive 20 to 40 pounds per 1,000 pounds live weight; fattening steers 30 to 40 pounds at first, later 20 to 36 pounds. As a rule silage is not fed to horses, but where digestion is impaired or inactive it acts as a mild laxative ( 5 to 8 pounds per day). Sheep take 2 to 4 pounds per day.

\section{b. Clover Hay, Lupine Hay, etc.}

To prevent loss of nutrients, palatability and tenderness, clover should be cut before blossom. Only in case of white, crimson and hybrid clover, serradella and esparcet, would it be profitable to cut a little later.

The nutritive value of clover hay is somewhat higher than that of meadow hay. The digestible protein content and starch value range between 4 to 7 and 18.5 to 35.5 per cent respectively. From a hygienic standpoint clover hay, as an exclusive feed, is not desirable. Too large rations are also to be avoided, especially for horses, because digestive derangements, subacute cerebritis and founder may result. Sheep also have become affected with subacute cerebritis after feeding liberally on clover hay that was harvested during wet weather (Oppermann). Vetch hay, which is reputed to be a good vermifuge for ascarids, and to be apt to cause constipation, is most dangerous in this respect. Red, crimson and hybrid clover belong to the same class, while serradella and spurge, even when fed in large quantities, are said to be free from this objectionable feature. These forages are all excellent part rations for milk cows, as in fact for all cattle and for horses, in amounts equal to one-eighth of the hay ration. Colts should not have clover hay during the first year but should be given good meadow hay.

Special care must be observed in feeding lupine hay. Lupines, as already mentioned, are rich in protein and thrive on poor, sandy soils, but sometimes they contain large quantities of a poisonous principle, lupinotoxin (icterogen or lupine alkaloids-lupanin, lupinin, lupinidinspartein, oxylupanin), which may, even when present in small quantities, 
cause violent poisoning, lupinosis, in sheep and horses.

The yellow varieties are more apt to be dangerous than the blue or the white. According to American authors the seeds contain the largest amount of the poison, then the hulls and the leaves in the order named.

The poisonous principle is insoluble in alcohol, ether and fatty oils, slightly soluble in water, and soluble in alkaline fluids and glycerin (Liebscher). The conditions favorable to its development or formation have not been determined. Exposing to a dry temperature of $212^{\circ} \mathrm{F}$. for three hours only partially destroys it.

Heating for several hours in steam, under pressure of one atmosphere, reduces its virulence.

The symptoms of lupinosis are loss of appetite, fever, cerebral symptoms (sheep -Oppermann), dullness, excitement, turning movements, pressing the head against a wall and rubbing, abdominal pains, constipation or evacuation of soft, offensive feces, the latter often bloody, occasionally hematuria and almost invariably icterus. Death may ensue in the course of 3 to 4 days, or the disease may become chronic. If recovery occurs the convalescing period is usually a long one. Postmortem examination of acute cases reveals generalized icterus; numerous small hemorrhages are common (digestive tract, peritoneum, pericardium, etc.); acute yellow atrophy of the liver, etc. Treatment requires, above all, withdrawal of the suspected feed. Oil, but not salines, should be administered to rid the bowels of the ingested lupines. Otherwise the treatment should be symptomatic.

Lupines are by no means always toxic, and since their culture is of great economic importance in certain sections (excellent feed for sheep, especially individuals weakened or emaciated as a result of lungworms and flukes, or anemic from other causes), preventive measures consisting of the simple rejection of the lupine as a forage can not be accepted as practical. A simple precautionary measure would consist of the experimental feeding of a limited number of animals before the general use of a particular lot or crop of forage. Feeding of the hulls gives most reliable results. If the experiment indicates the presence of toxins, the latter must be removed or destroyed. Mere ensilaging or making brown hay out of them is not sufficient for this purpose. The most frequently used successful method is to leach the forage by exposing it to the action of rain. It is put in small cocks and left in the field until well into the winter. This, of course, entails great loss in valuable nutrients.

According to Soltfien, the fresh lupine hay is treated with three times its weight of water and 10 pounds per hundredweight of officinal aqua ammonia. After three days the ammoniated water is drained off and the mass is leached from 7 to 10 days longer in ordinary water. This method also is not unattended with considerable loss of nutrients. About onefourth of the dry matter, principally nitrogen-free extract and salts, is lost.

Julius Kuehn recommends that lupines be steamed for three hours under a pressure of three atmospheres (about 45 pounds to the square inch). This has the advantage of not being attended with loss of nutrients. It is, of course, practicable only where steam pressure is available.

Potato tops are best utilized by drying or ensilaging. Dried potato tops have almost the same value as meadow hay. They should not be fed when affected with fungus diseases or when partly rotted.

Leaf or twig hay.-Leaf hay may be made from the foliage of almost all trees and shrubs, but in particular that of the poplar, ash, willow, asp, sallow willow 
(Salix caprea), elderberry, buckeye, mountain ash, alder, maple, more rarely that of the mulberry, hazelnut, grape, birch, beech, black alder (Rhamnus frangula) and elm. The foliage of poplars, willows and maples is the best. Young birch leaves irritate the urinary tract. The leaves of the beech, oak, alder and hazel nut contain much tannic acid and cause constipation if consumed in quantity. The foliage of laburnum, wild cherry, black alder, yew, oleander, savin and boxwood is poisonous. The bark of the common locust (Robinia pseudo-acacia) is toxic, but not the stripped leaves. Leaf hay should be made in the months of July or August. When dried in the sun it loses its aroma and palatability. It should therefore be dried in the shade with the aid of the wind or air currents and protected as much as possible from rains. Small quantities exert a favorable dietetic affect. Leaf hay must always be fed as a part ration and never without other forage.

If harvested in a fresh condition, in July or August, leaf hay is easily digested and of high value. Eighty pounds of leaf hay are equal in value to 100 pounds of medium grade meadow hay, and is therefore superior in value. Its nutrient value is greatest in May, then gradually diminishes, and in November it has lost at least two-thirds of its original nutrients. It is of particular value for goats, as well as for sheep, less so for cattle or horses. It is used for the latter in times of famine or at other times as a dietetic feed in chronic diarrhea (foliage and finely chopped bark of willows).

Troig hay is also a substitute feed in times of famine or scarcity. The twigs of poplars, linden, maple, less frequently those of the beech, are used for this purpose. They are first crushed, then chaffed and ensilaged (p. 29) and fed to cattle. The digestibility of the organic matter amounts to about 15 per cent. The nutritive value corresponds to that of the straw of the cereals. Twig hay is dried in moderately shady places and preserved tied up into bundles, exposed to the air. The trimmings of grape vines are also used for food and have a value corresponding to that of twig hay.

Sawdust, wood shavings and ground peat are equally inferior in digestibility and are used only in times of scarcity or famine, as filling mass. Wood shavings are said to produce enteritis and colic, but the experience of the late war has shown that apprehension in this respect was exaggerated. By steaming under the action of acids and alkali solutions, wood products may be "converted" in the same manner as straw (p. 31) and in this manner be made more digestible.

Reeds should be cut in the early stages of growth, before the blossom spike makes its appearance. As a substitute for hay they are usually fed green or dried, but chaffed. If harvested in the fall or winter they are much less nutritious but may still be of some value.

The reindeer lichen (Cladonia silvatica) and Iceland moss (Cetraria islandica) are useful substitute materials. Reindeer moss forms dense, light grayish green masses on dry forest and heath soil. Iceland moss is brown or greenish brown on one surface and greenish white or light brown on the other, naked, fringed at the border and rimose at the base. After being gathered it is washed and dried. Mixed with 1 per cent salt solution or molasses, animals usually eat it readily. Its actual feeding value is low.

Ferns (Asplenium, spleenwort), not the poisonous rock brake (Pteridium aquilinum) are used in the dried state, in times of scarcity, as feed for horses and cattle. The roots are fed to swine.

Heather (Calluna vulgaris and Erica tetralis, European species related to the American blueberry, huckleberry, cranberry and others, some of which are said to be poisonous) is used as roughage and in the form of heather meal. The feeding value of the roughage corresponds approximately to that of straw. That of the meal is about midway between that of medium and low-grade meadow hay. Heather is most advantageously harvested in May to June. The more woody parts should be removed.

\section{Straw}

Straw is the product of grasses (grains) and Leguminosæ that have been cut after maturing of the fruit or seed.

Grain straw is one of the poorest in protein and richest in crude fiber of feeding stuffs. The straw of the Leguminosæ, however, is much 
richer in protein, lime and phosphoric acid and may equal good meadow hay, or even clover hay, in this respect. The digestible protein content and starch value of winter cereal straw is 0.4 to 0.5 and 10 to 11 per cent respectively. That of summer cereal straw is 3 to 4 and 12 to 19 per cent, respectively.

The digestibility of the protein and nitrogen-free extract is greater in the leguminous straw (which is relatively low in fiber content), while the digestibility of the fiber is greater in cereal straw. Ruminants utilize the nutrients in straw better than do horses. Cereal straw is not suitable as a complete ration or feed even for animals at rest, but may constitute a part of the ration of horses at rest, for a certain period of time, and even for colts during the second and third years of age. In an emergency, straw may, if well admixed with clover, or not completely deprived of the grain, be used as a maintenance feed for ruminants, but otherwise it should constitute only a part of the roughage ration. Sometimes straw which is intended for litter is first offered to sheep, which pick out the more desirable and nutritious admixtures. These latter may be regarded as hardly second to good meadow hay.

As compared with all other feeding stuffs, straw is characterized by its bulky nature. It is important as a supplementary feed, because it provides the necessary mass required to fill the voluminous digestive canal of herbivorà. Mixed with watery feeding stuffs (slops and beets) it supplies the necessary dry matter, and owing to its rich fiber content and, in case of cereal straw, silicic acid content, acts as a mechanical stimulant to digestive activity. It enforces thorough mastication and ensalivation (chaffed, with grain for horses) and stimulates rumination in cattle and sheep. It also contributes a great deal to the wholesomeness of fermented feeding stuffs (silage) and of clover. This action is ascribed to its favorable effects upon the digestive organs.

Summer straw is less woody (fibrous) than winter straw and consequently more digestible. Straw admixed with different kinds of weeds (except perhaps ragweed-Ambrosia artemisiæfolia) has a considerably higher nutrient value, since most mixtures of weeds approach mediumgrade meadow hay in this respect. When admixed with a good growth of clover it is still more valuable-up to 2.4 per cent digestible protein and 24 per cent starch value.

Of the cereal straws, those of oats and barley are the most valuable. The former contains a large amount of a bitter principle which gives palatability and promotes digestion. It is especially good for horses and sheep. Cattle eat it well, but for these the straw of barley is to be preferred on account of its supposed stimulating effect upon milk secretion. It possesses the peculiar characteristic, however, of attracting or absorbing moisture to such a degree that it is apt to spoil. Milk cows, however, should not be given too much of either oat or barley straw, because both are said to be liable to give a bitter taste to the milk.

Wheat straw, like oat and barley straw, is a common feed for cattle 
but less valuable than either of the others.

Rye straw is harder than any of the others. It is usually avoided for cattle except as litter, but is frequently made a part of rations for horses, chaffed and mixed with grain.

Millet straw, which approaches oat and barley straw in softness of texture and nutrient value, is fed mainly to dairy cattle.

Long storage reduces the value of straw. Its bright color and pleasant aroma disappear; it becomes brittle and dusty, and frequently suffers from the ravages of mice. If improperly stored, exposed to moisture, it becomes moldy and decays.

In the inspection of straw for quality, the interior of bales should receive special attention. It should be free from mold or musty smell, not affected with smut or rust, and should not contain an abnormal quantity of thistles or rushes nor show the effects of the ravages of mice.

A decree of the Royal Prussian War Department issued November 10.1911, with reference to the use of straw for military horses, prescribes the following. Straw used must be rye straw, straight flail-threshed, loose machine threshed or baled long straw. The heads must practically all be at the same end of the bale or sheaf. Sheafs or bales must not contain chaff or broken masses of straw. Good wheat or oat straw is permissible only when rye straw can not be procured.

Hand-threshed flail or straight straw is hard and rigid and contains practically no broken culms.

Machine-threshed smooth straw is softer, contains fewer "blades," and may have a slight machine-oil odor.

Baled long straw is pliable and soft, according to the degree of pressure exerted on the bales. The more or less indigestible sorts of straw may be "converted," that is, the incrustating substances which prevent easy digestion may be dissolved and in this manner the digestibility and nutrient value, increased (cf. p. 30).

Method of feeding. For horses straw should be fed dry, rarely as long straw from racks, and then only when it constitutes a part of the main ration and is substituted for hay (draft horses). As a rule it is chaffed and fed with equal parts of grain. Chaffed hay should be cut in lengths of about four-fifths of an inch. If cut shorter, especially when moistened, it is not thoroughly masticated nor ensalivated and may cause serious and even fatal so-called straw colic (impaction of the ileum or colon). The amount of chaff to be given as a ration must be adjusted like the hay ration, according to the work of the animal. Heavy work horses receive more than light coach or driving horses. Race horses should have no chaffed straw at all.

Cattle may be given straw either as roughage, whole or chaffed in lengths of at least $3 \mathrm{~cm}$. (11/5 inch) mixed with beets, grain concentrates, etc., often with the addition of water, or scalded.

These mixtures are sometimes kept for 24 to 36 hours and permitted to undergo slight fermentation at $104^{\circ} \mathrm{F}$. This increases palatability and digestibility, but the stimulating effect of the raw material (peristaltic motion) is considerably diminished. Heavy rations of straw are not 
advisable for animals in advanced pregnacy. The well-filled paunch, when animals lie on the right side, exercises too much pressure on the uterus and its contents.

For sheep, straw is fed whole, or chaffed in lengths of 1.5 to $2 \mathrm{~cm}$. ( $3 / 5$ to $4 / 5$ inch).

The straw of Leguminosæ frequently causes constipation and indigestion, which is ascribed to the presence of parasitic fungi (plant diseases) and is possibly also due to greedy feeding on this coarse material, and resulting indigestion. These ill effects are most frequently observed following ingestion of vetch, pea and bean straw. Vetch straw in particular is apt to cause constipation in horses and should therefore be fed in moderation and with great care.

Legume straw is mostly used as sheep and cattle feed. Horses do not like it so well.

The straw of Camelina sativa (false flax) buckwheat, rape and turnips resemble legume straw in external characteristics and summer cereal straw in nutrient value. It is used and fed like legume straw. Buckwheat straw is liable to cause the same diseases or disturbances as the green plant (p. 53) or as buckwheat hay (Breitenreiter). Rape straw is liable to cause constipation and flatulent colic in horses.

\section{Chaff and Hulls}

Chaff and hulls are the waste or by-products of the threshing of grains and leguminous plants. They consist mainly of the glumes of the grasses, the awns and the hulls, as well as stems and leaf parts.

Chaff and hulls are considered useful feeding stuffs, except in the case of barley. The long awns of the latter are frequent causes of injuries to the tongue, gums and pharynx. Barley chaff should therefore be discarded altogether as a feeding stuff. The frequent occurrence of the ray fungus (Actinomyces) on the awns of barley make the latter doubly undesirable and dangerous. Since this fungus occurs also on the awns of other species of grain, waste, chaff should not be fed to animals in localities where the disease occurs epizootically, unless first subjected to steaming or scalding. This precaution should also be observed when smut or other fungus infection exists, because many of these organisms are discharged with the feces without losing their germinating power and are thus transferred to the fields with the manure and constitute new sources of infection.

The seed hulls are more readily eaten by animals, and since they often contain considerable admixtures of seeds, they are more nutritious and more easily digested than straw. They are good for swine, which utilize them better than chaff.

Of the various forms of chaff that of oats and barley is the richest in nutrients. Wheat chaff comes next in this respect. The woody and silicious rice glumes (chaff) and those of millet are of the poorest qual- 
ity. They have no value as feeding stuffs but are too frequently found as adulterants in prepared commercial "meals."

The hulls of Leguminosæ are rich in protein and are in every respect equal to good meadow hay in feed value. On the other hand the hulls of buckwheat, mustard, flax, false flax and rape (!) are very inferior and might be compared with winter cereal straw in feeding value. The digestible protein content of chaff varies between 0.5 per cent in barley and 1.4 per cent in oats, while the starch value varies between 22 per cent in rye and 28 per cent in oats. The digestible protein and starch values of the hulls are 3.5 and 20 per cent respectively.

The various kinds of chaff are fed principally to cattle and swine, much more rarely to horses as a substitute for "chaffed straw." The dust particles should first be removed by screening. Chaff should be wet and scalded before feeding to horses, steamed or fermented for cattle and swine (cf. p. 29). The hulls of lupines, beans, rape, and turnips are usually fed to sheep in the dry state.

Pea hulls have a high dietetic value for swine suffering from chronic constipation ( $I / 2$ to 1 pound daily). Buckwheat hulls when properly prepared are also valuable for swine, but are said to be liable to cause constipation in horses, which is true also of spelt chaff.

Great care should be taken in the feeding of any kind of chaff. This feeding stuff is frequently contaminated with parasitic fungi, the seeds of weeds (frequently of a poisonous nature, as cockle seed), etc. As a rule chaff should be used as a supplementary feed only.

\section{Tubers and Root Crops}

Tubers and root crops include potatoes, artichokes, turnips and beets, carrots, etc. All root crops are rich in water and carbohydrates, poor in protein, and poor in lime and crude fiber. Phosphates are present in moderate amount. The digestible protein content is about 0.2 per cent, and the starch value of the potato, according to water content, 13 to 20 per cent; mangel-wurzel, 5 to 7.5 per cent: sugar beet and artichoke, 15.5 per cent; carrots, 8.7 per cent. They are important, easily digestible feeding stuffs for cattle and swine, but, on account of their deficient protein content, not adapted for complete rations. When fed to ruminants the addition of dry roughage is absolutely necessary.

\section{Potatoes}

Solanum tuberosum is the original source of the many varicties. Fig. 33 represents a cross section through a potato tuber. The carbohydrates are present in the potato principally in the form of starch. The more nitrogenous, glassy, soapy varieties of potatoes are preferred as stock feed, while the mealy sorts which are more starchy are preferred for table use, for starch manufacture and for the manufacture of alcohol.

Advantages and disadvantages of potato fecding. Fed in moderation, raw potatoes stimulate digestion and have a laxative effect, hence their 
use in chronic constipation and in conjunction with less digestible and constipating feeds. Fed to excess, they are apt to cause colic, diarrhea and even gastroenteritis. The cause of the latter is not clearly understood but is supposedly an acrid substance, acrin. In the course of time animals may be accustomed to consume comparatively large quantities, but in some cases this is done at the expense of digestive power. In cattle excessive feeding on potatoes may lead to eczema of the hind quarters (slop eczema) and inflammation of the prepuce in males (also in sheep), and horses become subject to collar and saddle boils, eczemas and colic. Prolonged feeding of potatoes is especially contra-indicated for sheep, in which anemic and hydremic conditions may develop.

Immature and sprouted potatoes, even when cooked, have a toxic effect. The poisonous action is ascribed to the glycosid solanin and the less toxic solanidin which is derived from it The solanin content of potatoes grown in moist sandy soil is 0.011 per cent; dry sandy soil,

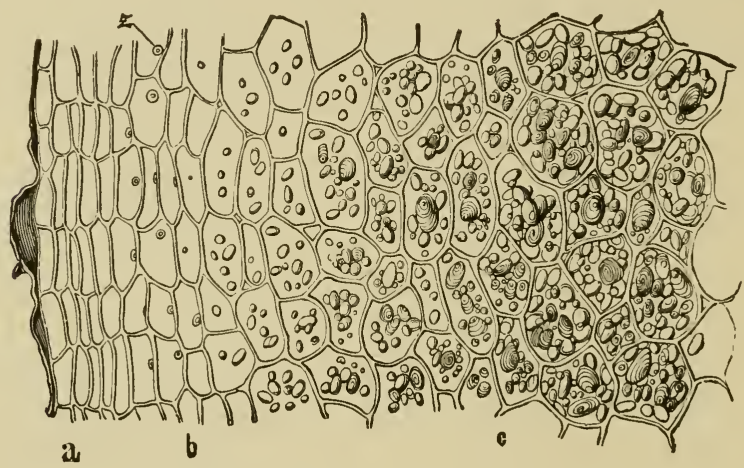

Jig. 33. Section of Potato Tuber. $a$, Epidermis cells; $c$, starch filled cells.

0.013 per cent; soil rich in humus, 0.0076 per cent; moist soil rich in humus, 0.0045 per cent; while potato sprouts contain 0.476 per cent. When it is considered that cattle frequently consume 50 pounds of potatoes or more per day, and swine 20 pounds, it is obvious that they may ingest with this material 8 and 3 grams, respectively, of solanin, a quantity of poison that may well produce the poisonings referred to. Horses are less resistant to the effects of this poison than swine.

The symptoms following the ingestion of sprouted potatoes, or of solanin poisoning, are extreme muscular weakness and even complete paralysis, conatose conditions, inflammation of the brain (sheep) and even death (from exhautsion of respiratory muscles). When fed exclusively, or with insufficient other feed, potatoes and potato peelings, which are poor in lime salts, cause halisteresis ossium (softening, etc., of the bones) in cattle, goats and swine. Cows fed excessively on potatoes produce milk and cream that are hard to churn. The butter is salvy (Henry and Morrison). 
To avoid the disadvantages enumerated, potatoes should be fed in moderate quantities, and only sound potatoes with the sprouts, if present, removed. Sufficient quantities of roughage and concentrates (oil cake and crushed barley) should be fed with them. When fed in large quantity, animals do better if the potatoes are washed, reduced to coarsely cut pieces and cooked, steamed, or leached with water for 12 to 24 hours. The water should be drained off before feeding. The transition to full potato rations for horses should be made gradually-in the course of two weeks. The addition of linseed meal during the change is advisable. It is important that the potatoes be fed in a freshly prepared state and that scrupulous cleanliness be observed.

The use of potatoes. It is generally conceded that potatoes are poor feed for horses. While they provide a certain amount of bulk or volume, they lack strength-giving and endurance-giving qualities. The animals take on fat, but the tissues and muscles become soft. On account of their lack of lime salts potatoes are also unsuitable for young colts. However, during the second and third years, and for horses at comparative rest they may be fed with the mere addition of chaffed straw and hay. Work horses may receive one-quarter to one-third of the grain ration in the form of potatoes, to the amount of 10 pounds. Before feeding, the potatoes should be thoroughly cleaned, cut into pieces, leached in water for 24 hours, or, better, steamed (discard water) then crushed and mixed with salt and equal parts of chaffed straw and some crushed oats. In addition, liberal amounts of good hay should be given. The steamed potatoes should be fed within twenty-four hours after steaming. The mangers should be kept clean and free from leavings.

Recently Paechter and Voeltz have expressed themselves very enthusiastically in favor of steamed potatoes for horses. The practice of feeding potatoes is of very great economic importance in good potato years. Paechter recommends substituting potatoes for the entire oat ration, giving in addition to the potatoes only hay and chaffed straw. Efficiency is said to be kept up to the standard and the number of cases of colic reduced. According to Voeltz, 10 pounds of raw and 25 pounds of steamed potatoes may be given for 1,000 pounds live weight. In the spring of the year when the potatoes begin to sprout and to decay they must be sorted and fed only after being steamed. Leguminous seeds or legume hay should not be fed with liberal rations of potatoes. The same should be said in regard to feedingstuffs rich in sugar (sugar beets, feed sugar, stock beets).

Ruminants may be given large rations of potatoes to advantage. Mature cattle and sheep may receive one-half of the entire nutrient ration in the form of potatoes, but young growing animals should not receive more than one-third. For milk cows daily rations should not exceed 30 pounds, fattening cattle 50 pounds, wethers and suckling ewes 2 to 3 pounds, fattening sheep 5 pounds per head. For ruminants as well as for other animals an abundance of concentrates and roughage 
should be supplied with the potatoes. When fed in small quantities to ruminants, potatoes may be given raw, crushed and mixed with one-sixth of their weight of chaff. If large quantities are fed it is better to steam or ferment them before feeding. Cleanliness is indispensable.

Potatoes are a very important feeding stuff for pigs. They will fatten pigs rapidly and economically. According to very carefully conducted experiments by Lehmann in Goettingen and Voeltz in Berlin, the gross proceeds from $100 \mathrm{~kg}$. of potatoes ${ }^{10}$ fed to fattening swine was 6 to 7.35 marks ( 100 pounds of potatoes and $\$ 0.75$ to $\$ 0.92$, respectively. These figures are based on prewar conditions.). Varieties rich in protein may even be fed exclusively and produce gains. It is better, however, to supplement potato rations with feeding stuffs rich in proteinmilk for little pigs, and later on bran, then cracked grain, oil cake, fish meal with thresher chaff, etc. Little pigs receive 1 pound as daily rations, fattening hogs 12 to 20 pounds. Larger rations impart an insipid taste and a soft, smeary consistency to the meat and bacon. They also affect the firmness of the bones (halisteresis). For all swine the potatoes should be cooked or steamed.

Long-continued storage results in no inconsiderable loss of nutrient substances. In order to increase their keeping qualities and protect them from loss during transportation, the practice of drying has been resorted to for a number of years. This has become of importance for the commercial as well as for the home-used product.

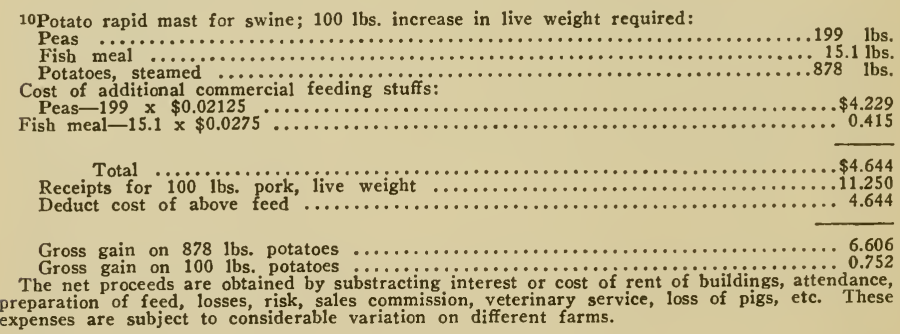

Keeping pigs in the open:

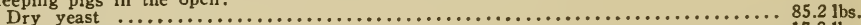

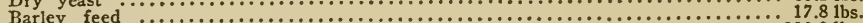

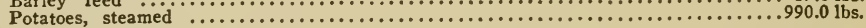

Extra expenses:

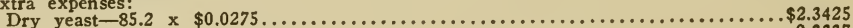

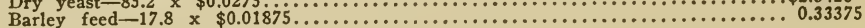

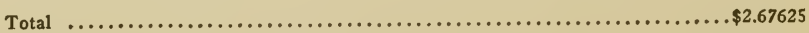

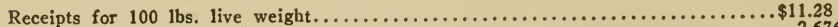

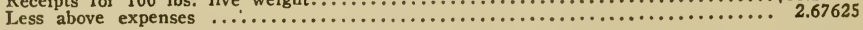

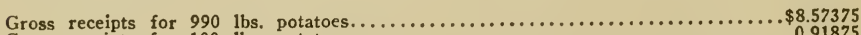

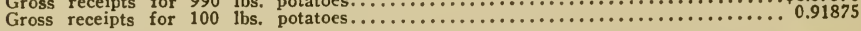

Note: The original figures were given in Marks and Kilograms, which accounts for the extended fractions. - Translator. 
Dried potatoes are prepared as follows:

1. By drying raw sliced potatoes.

2. By drying steamed potatoes in drums (flakes).

3. By expressing the water and subsequent drying (pressed potatoes).

There is no difference in the palatability of flaked or sliced potatoes for ruminants or horses. Both forms are readily eaten when slightly moistened and mixed with chaffed straw. On the other hand, swine do not like sliced potatoes dried by means of furnace gasses as well as they like other preparations. It seems that the pressed potatoes are somewhat more palatable than either of the other forms.

Dried potatoes contain about 12 per cent of water, 7.4 per cent crude protein, of which 2.4 per cent is digestible ; 70 per cent digestible nitrogenfree extract, 2.3 per cent crude fiber and 3.9 per cent ash. Digestible albumen 1.6 per cent, starch value 71.5 per cent.

Dried potatoes agree excellently with all species of animals and are easily digested. For horses 33 to 40 per cent of the oat ration may be replaced with dried potatoes (with the addition of 4 ounces of peanut meal). According to Voeltz, the entire oat ration may be replaced with 30 pounds of dried potatoes per 1,000 pounds live weight. Dried potatoes have a favorable effect upon the "condition" and upon the hair when shedding. One hundred pounds of dried potatoes correspond to about 350 or 400 pounds of raw or cooked potatoes. Large rations of potatoes should be accompanied with daily portions of prepared chalk, potassium phosphate and common salt, of each 50 grams, or a little less than 2 ounces, per horse.

Cattle will take comparatively larger rations of dried potatoes than of steamed potatoes, and with equally good results.

Pigs fatten well on dried potato rations and the meat product is satisfactory. Provided sufficient proteids are furnished in other form, such as milk, fish meal and tankage, the balance of the ration may consist entirely of potatoes. Rations per 1,000 pounds live weight may be composed of 25 to 30 pounds of potato flakes or pressed potatoes (or 16 to 20 pounds of dried sliced potatoes) mixed with water, skim milk or whey, well stirred and fed immediately to avoid fermentation. The flakes are sometimes fed in the dry state.

\section{Artichokes}

The tubers of Helianthus tuberosus (artichoke) cultivated in southern Germany and many sections of the United States, contain more water than the potato, but they are also richer in protein and more wholesome. They are given to horses in the raw state, cut or crushed, while swine do better on them when cooked. In other respects they are fed just as potatoes, but it seems that animals must become accustomed to 
the taste before they relish them. Large rations should be avoided for dairy cattle because they tend to produce watery milk and scouring. A few cases of poisoning are on record.

\section{Beets and Roots}

The most important root crops are: Beta vulgaris and its many varieties (field beet, mangel wurzel, sugar beet, common garden beet, etc.), Brassica napus (kohlrabi, rutabaga, etc.), B. rapa (common white turnip) (the two latter species are really cabbages), and Daucus carota (the carrot, one of the Umbelliferæ). As shown by the chemical analyses in the appendix, they all contain a large amount of water, carbohydrates (especially sugar) and nonalbuminous nitrogen compounds (nitrates and amid compounds), which compose one-third of the entire proteids.

Animals are fond of these root crops, which have a laxative effect and are valuable in chronic constipation. Carrots are reputedly good vermifuges (ascarids) and have a favorable effect in catarrhal conditions of the upper air passages, dissolving the mucous secretions and allaying local irritation. They are sometimes given to colts as a digestive tonic. When fed to excess they are apt to cause scouring and, in horses, paraplegia (carotism) and, reputedly, abortion. Excessive rations of turnips are said to cause inflammation of the brain in sheep (Oppermann). According to experiments conducted by Albrecht, carrots in otherwise good condition may be stored for a long time without acquiring injurious properties. Whether soil conditions or long periods of storage have unfavorable effects remains to be demonstrated. Excessive feeding of carrots to sheep has been supposed to cause anemia and dropsical conditions. In cattle and swine, when fed with insufficient roughage they have been suspected of causing brittleness and softening of the bones. In cattle fed almost exclusively on root crops serious oxalic acid and saltpeter poisoning with hematuria have been observed. When fed in large chunks these roots may cause choking and the attendant complications. When spoiled or decomposed they may cause serious and even fatal poisoning. It is said that exposure of slightly spoiled roots to the air for several days will sometimes lessen their injurious effects.

Method of feeding.-In general, roots are not suitable feed for horses, although carrots are frequently used in a dietetic way. The daily ration may be 10 or 20 pounds. On the other hand, roots are excellent cow feed, especially for milk cows. In moderate amounts (20 pounds) they are a good milk feed and agree well with pregnant animals. When fed to excess they exert an unfavorable influence upon the quantity and quility (bitter taste) of the milk. This objection may be overcome in case of rutabagas and kohlrabi by steaming, but not in case of turnips and the true beets. The water used for steaming or scalding must of course be discarded. All of these roots, but especially carrots, are good for sheep ( 2 to 4 pounds). They have poor fattening qualities 
and consequently are less suitable for swine. In this respect potatoes are far superior. Swine may receive 2 to 4 pounds of roots per day to advantage. In times of potato scarcity the root rations may be increased to 24 pournds. The result in fat production is fairly satisfactory. If roots are fed in large quantity they should be cut or crushed and cooked or steamed before feeding. The water is retained and the mass mixed with the supplementary ration. The latter may consist of onethird concentrates rich in protein (fish-meal, tankage or dry yeast) and two-thirds in the form of cracked grain and bran. For horses and cattle root crops must be liberally supplemented with concentrates and roughage. Horses and cattle take them raw, cut into small pieces and mixed with chaffed straw or chaffed hay. For swine they may be given raw or steamed.

Squash and pumpkins are fed to sheep and milk cows raw and chopped, and cooked for mast for cattle and swine. They are not suitable for horses on account of large water content, but when given in large quantity have been observed to cause poisoning with symptoms of alternating depression and excitability, stertorous breathing, mydriasis, fever, reddening of the mucous membranes, muscular trembling and suppressed peristalsis.

Apples and pears are very wholesome for animals, provided they are not excessively decayed. Plums in moderate amounts are also health promoting. Ingestion of excessive amounts by pigs have caused prussic acid poisoning with excessive vomiting. As is well known, the pits of plums contain no inconsiderable amount of prussic acid.

The roots of Triticum repens (couch grass, quick grass) might also be mentioned in this connection. Their feeding value corresponds to that of the best clover hay. In harvesting especial care should be observed in removing all particles of earth or sand. This is accomplished by harvesting in dry weather and subsequent screening or running through a thresher, or through manipulation with a pitchfork.

They are fed fresh to swine and cattle, mixed with straw and hay for the latter.

They are a valuable winter feed when dried. Special machinery exists for the separation of the tufted plants. After being thus reduced in size the material is dried out of doors or in special drying apparatus. As a dry winter feed they are chaffed and used for horses and cattle.

Couch grass is a vile weed in fields and gardens and its extermination is best accomplished by pasturing with sheep.

Translator's addition: The chufa (Cyperus esculentus) should also be mentioned here. The chufa sedge, frequently a weed on southern farms, produces numerous small chaffy edible tubers. They are relished by pigs, which are usually turned in to harvest the crop. As chufas are low in digestible crude protein, feeds rich in protein should be added to balance the ration. They grow hest on light sandy soils, viclding from 100 to 150 bushels of 44 pounds each per acrc. Like artichokes, the tubers remain in the ground uninjured through the winter. Good crops of chnfas 
have produced 307 to 592 pounds of pork per acre, after making allowance for the other feed consumed by the pigs. (Henry and Morrison, Feeds and Feeding, 16th edition, 1916.)

\section{Cereal Grains and Legume Seeds}

The feeding stuffs known collectively as grains are characterized by their high content of digestible nutrients and for this reason are referred to as concentrates. Their chemical composition is subject to variation according to the stage of development, as is the case with all vegetable feeding stuffs. As is well known, the organic substances contained in the grains are not carried into them with the plant juices in the same form in which they appear later. This explains why unripe grains, or grains interrupted in the process of maturing by breaking of the stems of the plants (lodging) or injured by insects, or prematurely ripe from effects of dry weather, show a variation in their chemical composition. The protein bodies circulate in the plant tissues in the form of amid compounds and are converted into albumen or other proteids at the points or in the cells where they finally lodge. The carbohydrates circulate as water-soluble substances (grape, cane, sugar, inosite, etc.) and as such are carried into the seeds and fruits, where they are gradually changed into insoluble substances (starch, galactan, mannan, etc.). Soil, conditions of fertility, plant variety, climate, weather during growth or harvest, etc., all influence the chemical composition and nutrient content of the seeds and grains. Elevated and dry soil tends to produce grain rich in proteids and well supplied with glumes or chaff. Drouth tends to reduce the relative amount of nutrients in grain, and excessively wet weather produces grain of a soft and loose texture. Summer grains are usually richer in protein and contain less starch than winter grains. Wet weather may cause grains to sprout in the field before harvested, which entails a serious loss in protein and starch value (20 to 25 per cent).

The different varieties of grain are highly digestible. (See chart in appendix.) Their nutrient efficiency may be increased by removal of the more or less indigestible chaff (glumes) and hulls.

In order to utilize to good advantage, the nutrients that are present, grains fed to cattle and swine are frequently cracked, crushed, ground, soaked or scalded, more rarely cooked or steamed with other feedingstuffs. Mere soaking is not sufficient to insure complete digestion.

Barley, Indian corn, rye and buckwheat, intended for horses, are also frequently crushed or previously soaked and mixed with chaffed straw. Oats mixed with chaff, for horses, are usually fed dry and whole, unless defective teeth make crushing necessary. But even horses with good teeth utilize the nutrients in oats to better advantage if the oats are crushed before feeding.

\section{The Cereal Grains}

The grains contain on an average of from 8 to 14 per cent of crude protein, which consists mainly of albumen; a moderate amount of fat, 
1.5 to 6 per cent; large amounts of starch, 45 to 65 per cent; and comparatively little mineral matter, 2 per cent in decorticated grains and 4 per cent in whole grains with the glumes. Potash and phosphoric acid predominate among the salts, while lime is present in very small amount, 0.05 per cent.

In the structure of the grain (see Fig. 34) we distinguish:

1. The seed coat, composed of an inner and an out layer. The nutritive value and digestibility of the seed coat correspond approximately to those of the glumes or chaff.

2. The body of the grain, or endosperm. The endosperm consists of an outer layer of cells rich in albumen, the aleurone layer, which incloses the endosperm proper (composed of starch-filled cells).

3. The embryo, which is located at the base of the grain in a depression in the endosperm and consists of cotyledon, stem and radicle.

Samples for the examination or inspection of the quality of grain should be taken from different depths and regions of the bin or sack and thoroughly mixed. In Germany farmers may send such samples to the agricultural experiment stations or to the hygienic institutes of the veterinary colleges for grading. Each sample should consist of at least two pounds of grain, carefully packed and sealed. In the grading of grains and in the determination of their value the following points are considered: $:^{10}$

1. Requirements for soundness.-The grain must be properly matured (shriveling indicates immaturity), have a natural gloss and a sufficient degree of dryness, must not have a musty, moldy or other foreign odor, must not show signs of germination, moldiness, nor be spotty; not contaminated with injurious fungi (rust, ergot or smut); contain no injurious insects, and no grains marked by weevils. Germinated grains (Fig. 35) may be recognized by the three curly threadlike rootlets at the base and, on section, the presence of a cavity which contained the embryo. This cavity varies in size with the length of time that the germinating process was active. Awns should not be mistaken for, or confused with, the rootlets referred to (Fig. 36). This possibility is greatest in awned oats. Most varieties of oats are unawned, but the awned varieties have a slightly bent, bristly process about 1.5 to $2 \mathrm{~cm}$. ( $3 / 5$ to $4 / 5$ in.) long, extending from the back of the outer glume-the awn.

2. Weight.-The weight of grain is determined either by weighing a standard measured amount or by weighing a standard number of grains, usually 100. Uniform size of the grain is a positive advantage in weight. A liter of oats will weight 400 to 520 grams, medium grade 440 to 462 grams. For storage or elevator purposes the minimum weight

\footnotetext{
10For ufficial grain standards of the United States for wheat, corn and oats, see Service and Regulatory Announcements, Bureau of Markets, U. S. Dept. of Agriculture, No. 33 . There are no United States Standards for rye.-Translator.
} 


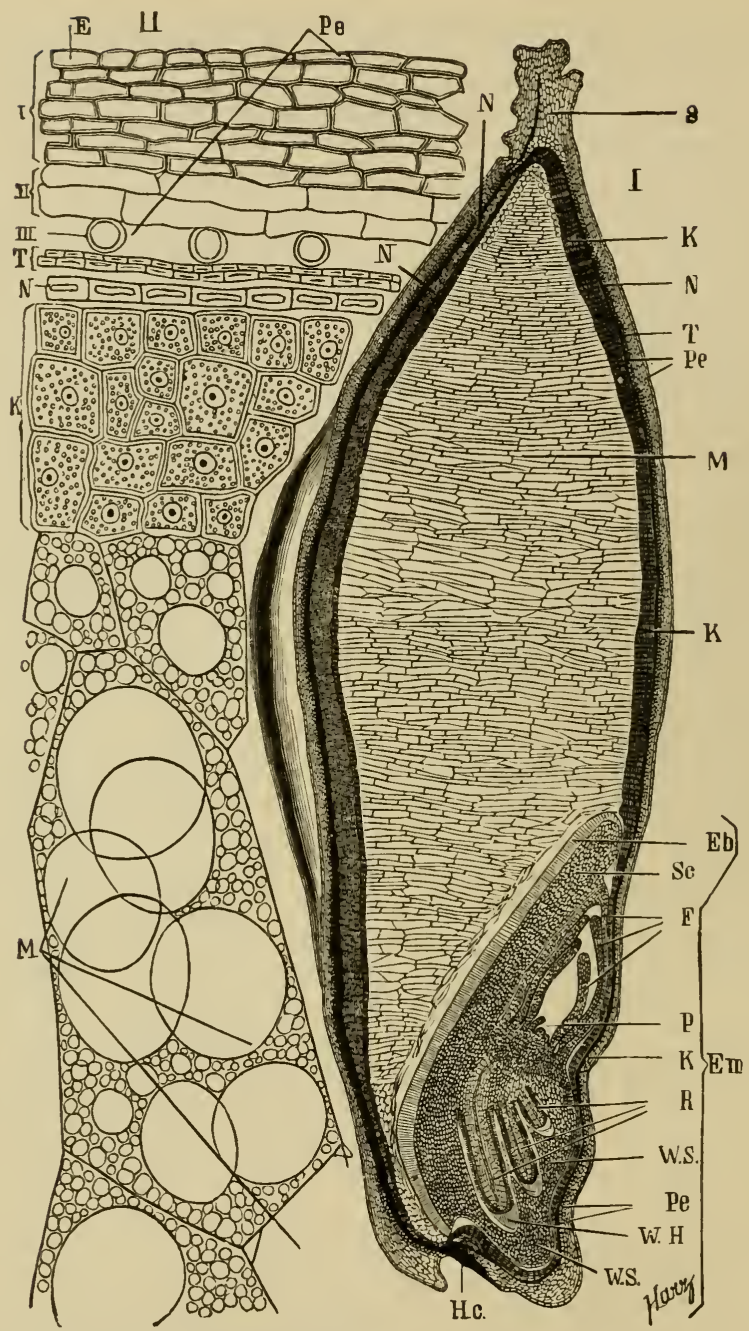

Fig. 34. Barley grain (according to Harz).

I . Entire fruit, long section, without glumes. $E m$, germ; $R$, rudimentary root; $W . H$., root cap; $F$, rudimentary leaf; $W s$, root envelope; $K$, aleurone layer; $M$, starchy body; $N$ and $T$, seed coat; $S$, vestige of style.

II. Cross section, $P e$, seed coat; $E$, outer layer.

11. Cross section, $P$, styled cont; E, out rin layer.

II. Transverse cells. III. Tubular cells. Other marks same as under I. 
should as a rule not fall below 462 grams ( $46.2 \mathrm{~kg}$. per hectoliter or $35.67+$ pounds per Winchester bushel). ${ }^{11}$ The weight of rye should not be less than 716 grams per liter or 55.28 pounds per bushel. ${ }^{11}$ In general, the individual grain weight, or weight of a standard number of grains, constitutes a better basis for the grading of grain as to quality. The larger grains are heavier and relatively richer in nutrients than the smaller ones which contain more crude fiber. One hundred grains of rye of the best grade will weight 2.70 , medium grade 2.20 to 2.70 , low grade 2.00 grams. One hundred grains of oats weigh $3.30,2.85$ to 3.20 , and 2.50 to 2.70 grams, respectively, for high, medium and low grades.

Moisture causes grains to swell, and increase in individual or grain weight. The weight of a standard measure of grain does not, however,

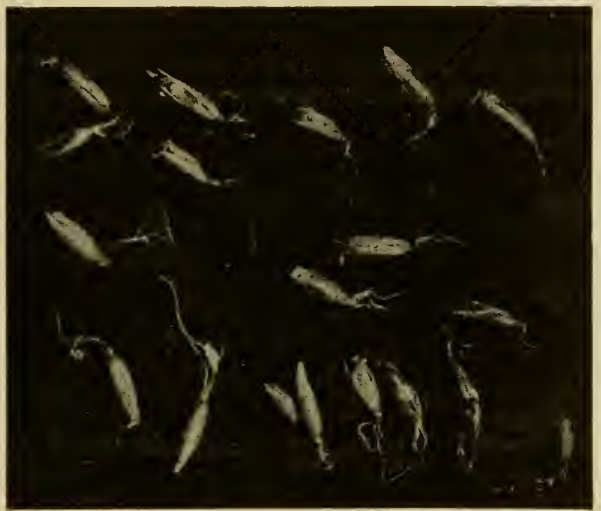

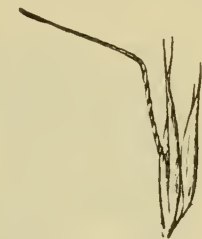

Fig. 36. Awned oats (rough oats).

Fig. 35. Germinated grains.

increase in the same proportion from absorbed moisture, because the additional moisture increases the size of the grains and reduces their number per standard unit of measure.

3. Purity. - The best grades of grain must be absolutely clean and pure. Good medium grades must not contain more than 1 per cent foreign matter, including chaff and dust. The degree of impurity is determined by separation of the foreign matter and subsequent weighing.

Of the foreign matter occurring in grains we distinguish:

a. Harmless material like sand, dust, pebbles, earth, pieces of wood, manure, or feces of rodents and insects; chaff; broken, undeveloped, sterile, and germinated grains; parts of weeds like calyxes, capsules, hulls, seeds, etc.; vetch seed, peas, rape seed, plantain, etc.

b. Harmful or noxious substances like ergot, rust and smut fungi, molds, cockle seed (black or brown, roundish or reniform, 2.5 to $3 \mathrm{~mm}$.

11United States Standard, determined by State law. 
in diameter with verrucose surface and white interior), Lolium temulentum (grass fruit 5 to $8 \mathrm{~mm}$. long, short oval form, yellowish gray or greenish gray awn 10 to $12 \mathrm{~mm}$. long, broad at base, rough and sharply pointed), or buttercup seed, knotweed seed, mustard, etc. Various devices are in use for cleaning grain (Figs. 37 and 38).

4. Moisture content.-Air-dried grain contains from 12 to 15 per cent of water. (See page 3 for methods for determination of exact water content.) The mere handling of the grain will give an approximate idea of the water content. Properly dried oat grains have hard, sharp points and produce a clear "ringing" sound when rubbed between the hands. Damp oats are "tough" and do not have sharp points, are soft or doughy between the teeth, while the dry grains snap or crack. Oats that have been wet down to increase their weight have a rough surface after drying out.

5. Size and Form.-As a rule the larger, fuller, more rounded or plump and the more even or uniform the comparative size of the grain,

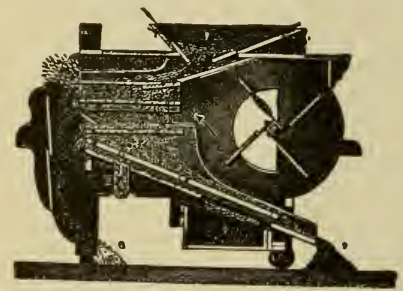

Fig. 37. Grain-cleaning machine-Fanning

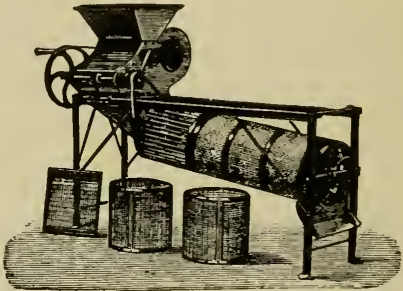

Fig. 38. Rotary screening and cleaning machine.-Trieur.

the better its quality and the greater its value. Normally developed grains are referred to as "medium; when extra large and well rounded out in form, "plump"; when not fully developed, "lean"; and when stunted in growth or shrunken, as "screening." (Fig. 39.) The latter are generally rich in crude fiber and deficient in starch, etc. In regard to size, oats are an exception in this respect. Small-grained varieties of oats are generally richer in protein and therefore more highly valued.

6. Color.-A fresh, bright color indicates sound and fully matured grain. Grains of a dull, pale appearance, especially when spotted and with dark ends or tips, indicate exposure to moisture, poor storage, and mouldiness. In order to improve the appearance of poor quality grain it is sometimes treated with oil. This fraudulent practice may be detected by compressing the suspected grain between tissue or blotting paper, which absorbs the oil and reveals its presence. Mixing and agitating suspected oiled grain with powdered bronze causes the latter to adhere to the oiled surfaces. Powdered metallic copper dusted on the surface of water contained in a thoroughly clean glass vessel (tumbler) 
takes on a lively motion. The addition of oiled grains checks this motion, while the addition of unoiled grain has no effect.

7. Odor.-The normal odor or smell of grain diminishes in intensity with age. Unpleasant, close, damp, moldy or musty odors indicate various forms of decomposition. These odors are intensified by heating or warming the grain by holding in the hand, breathing upon it, etc. Such grain also has a bitter, rancid taste. Fraudulent attempts are sometimes made to destroy or disguise these odors by treating with powdered aromatic herbs (marjoram) and mixing with fresh and more aromatic grain (oats).

Among the true grains we have oats, barley, wheat, corn, spelt, rice and millet. Buckwheat resembles the grains in chemical composition.

\section{a. Oats}

Oats are extensively cultivated in Germany, Russia, Sweden, Austria, Hungary, Rumania and North America. In addition to the common panicled oats, Avena sativa, a number of varieties of an oriental species, $A$. orientalis, are cultivated in Southern Europe and experimentally in the United States (white and black Tartarian oats, Hungarian oats, etc.). The panicle in this oriental species is developed unilaterally, not symmetrically as in the common oat, whence the German name, "flag oats," from its fancied resemblance, when in bloom, to a flag. Naked oats, A. nuda, are of no economic importance in Germany. A. strigosa, sand or purr oats (Fig. 36), which grow wild on poor, sandy soils in northern Germany, and $A$. fatua, wind or wild oats, with small, slim, yellowish gray grains, are of no great value as feeding material.

A. fatua resembles the common oat, occurs in Wisconsin and Minnesota and is a naturalized European species. These wild species of oats are sometimes mixed with the cultivated species. They have coarse hulls and a large twisted and bent awn 2 inches long. The large, dark glumes have green tips and yellowish red or brownish hairs. The hilum or scar, where the seed was attached to the stem, is dark colored, elevated, and resembles a horse's hoof in form, whence the name, horsefoot oats. Avena brevis is another common wild species of Europe with seeds still smaller than those just mentioned and equally indifferent in value. There are early and late varieties of Avena sativa with many subvarieties of each. In Germany these various varieties are usually known by the name of the region or country where they originated as American, Canadian, Pomeranian, Silesian, Scotch Longfellow, etc. (A similar custom of naming prevails in the United States.-Translator.)

The individual oat grain has a flat ventral and an arched dorsal surface. It is inclosed by an outer, hard, strawlike glume and an inner covering of finer texture, also a glume. The latter is attached at its base to the lower border of the fruit or grain. Each spikelet in the oat panicle usually contains two grains, the lower main grain, which is the larger and more valuable (size 12 to 20 by 2.5 to $3.5 \mathrm{~mm}$.), and recognized by the short, stubby stem to which the upper or secondary grain 
was attached (size 8 to 13 by 2 to $3 \mathrm{~mm}$.). These two grains are inclosed in common by two large glumes which usually remain attached to the straw when threshed. In the awned varieties of oats the lower main grain only is supplied with an awn. The main grains are frequently separated from the threshed product by special machines and used for seed.

According to the degree of development of the oat grains they are classified as plump, medium, lean, and screenings, or first, second, third and fourth grade. In plump grain (first grade, Figs. 39 and 40) the inner glume bulges or is convex. In medium or second grade grain this glume is flat. In lean or third grade grain it is hardly visible, and in screenings or fourth grade grain the borders of even the outer glume are curled inward. A cross section, at the largest diameter, of plump grain is oval in form, and dorsal and ventral surfaces convex to an almost equal

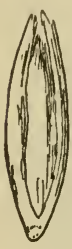

a

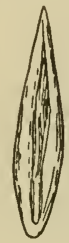

b

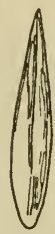

$c$

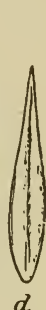

$d$

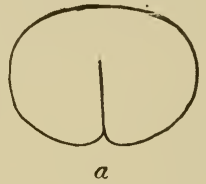

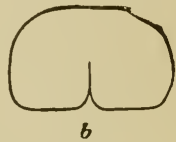

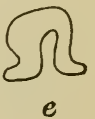

e

Fig. 39. Ventral surface of different oat grains. $a$, plump or full grain; $b$, normal or medium grain; $c$, lean grain; $d$, screening grain.

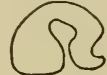

d

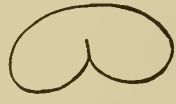

$c$

Fig. 40. Cross sections of different oat grains. $a$, Plump or full grain; $b$, normal or medium grain $c$, lean grain; $d$ and $e$, screening grain.

degree. Medium grade grain thus sectioned shows a flattened ventral surface, lean grain a kidney shaped outline, and screenings or fourth grade grain shows an irregular figure which consists chiefly of glumes (sterile grain). In medium grade or normal grain the glumes should exceed the grain by not more than one-quarter of its length. In poor grades of oats the glumes are considerably longer.

The weight of the glumes or hulls of oats vary between 21 and 49 per cent. In fine hulled varieties it is usually under 26 per cent and in coarse hulled varieties it is usually over 29 per cent. Long glumes and sterile grains tend to increase the percentage weight of the hulls. The German army regulations require that oats may contain a maximum of 30 per cent glumes or hulls.

The following table gives the chemical constituents of the more valuable grain proper and of the less valuable hulls, of the oat.

\begin{tabular}{|c|c|c|c|c|c|}
\hline $\begin{array}{l}\text { Grain } \\
\text { Hulls }\end{array}$ & \begin{tabular}{l}
\multicolumn{2}{c}{ Crude protein } \\
$\ldots \ldots \quad 14.1$ \\
$\ldots \ldots \quad 4.6$
\end{tabular} & $\begin{array}{l}\text { Crude fat } \\
7.55 \\
1.7\end{array}$ & $\begin{array}{c}\text { Nitrogen-free } \\
\text { extract } \\
74.1 \\
58.6\end{array}$ & $\begin{array}{c}\text { Crude fiber } \\
2.2 \\
27.5\end{array}$ & $\begin{array}{c}\text { Mineral } \\
2.77 \\
7.65\end{array}$ \\
\hline
\end{tabular}


On account of this marked difference in chemical composition the proportion of hull to pure grain in oats is an important consideration in the determination of its value. The fineness of the hull therefore plays an important rôle in the judging of quality.

Among the fine-hulled varieties of oats may be mentioned Oderbruch, Rhenish, Kamchatka, so-called American potato oats and the black varieties of oats. Varieties with hulls of medium weight are Warthebruch, Propsteier, Ruegen, Silesian and most of the awnless varieties of golden oats, Swedish oats and Danube oats. So-called barley oats, Scotch Longfellow, Podolian, white Canadian and many Russian and American varieties belong to the coarse-hulled class.

The amount of crude protein in oats varies between 6 and 17 per cent, (average 10 per cent); crude fat 5 per cent ( 3 to 7 per cent), about three times as much as that of rye, wheat or barley; nitrogen-free extract 58 per cent, Crude fiber 11 per cent, mineral matter 3.3 per cent, water 12 per cent, digestible protein 5.6 to 9 per cent and a starch value of 55 to 63 per cent.

The digestive coefficient of oats is high. Oats are more rapidly digested than the other species or grains, and the protein and fat in particular have higher digestive coefficients, except the fat in Indian corn (dent) wnich has a higher digestive coefficient than the fat in oats. The digestive coefficient of the carbohydrates of oats is lower on account of the large percentage of hulls. The easy digestibility of oats is due in part to the presence of large amounts of starch-dissolving and albumendissolving ferments, but above all to the fact that the presence of the hulls prevents the formation of a doughy mass in the stomach but aids in keeping the contents loose and spongy and permits the free circulation or admixture of the digestive fluids.

Of all the species of grains oats are the most wholesome and palatable. They are taken with relish by swine as well as by all herbivora. Digestive disorders such as follow the feeding of other grains do not occur after the careful feeding of oats. These agreeable properties of oats were formerly ascribed (Sanson) to the presence of an alkaloid, avenin, in the glumes or hulls. More recent investigations, however, have demonstrated that avenin does not occur in oats. Traces of cholin and trigonellin occur.

Freshly harvested and not thoroughly dry oats are considered less digestible and less nutritious than the thoroughly dried grain. They are said to produce sweating and weakness and sometimes gastrointestinal catarrahs, colics and hemaglobinuria. Immature, damp or mouldy oats of recent harvesting are especially dangerous. The cause of this may be looked for chiefly in the presence of the fresh mold. Well-bred horses are more sensitive to the effects of such feed than the coarser types, It is best to store oats for about three months after harvest and let the sweating process run its course completely before beginning to feed. The change from old to new oats should even in this case be made 
gradually. In recent years, however, the supposed danger of feeding fresh oats is more and more disregarded and it is generally assumed that fresh sound oats, properly harvested, may be fed without danger, provided the change to the new feed is made carefully and gradually.

Long storage impairs the value of oats, causes loss of nutrients ${ }^{12}$ and makes them less digestible. As a rule oats should not be kept in storage longer than one year.

Judging.-Good oats should be mature, well filled, dry, thin hulled, not too small, uniform in size and have a good odor. There should be no admixture of foreign matter and no odor suggesting kiln drying. Good oats should be free from ergot, rust and smut fungi, seeds of corn cockle and poisonous darnel (Lolium temulentum), as free as possible from undeveloped grains, and the seeds of vetches, charlock, brome and other weeds, and free from sand, earth and other dirt. German military regulations provide for the rejection of oats containing injurious insects or traces of the same, worm webs, etc. The standard weight per liter should not, if possible, be below 462 grams (462 to 500 grams). In judging or grading oats the proportionate amounts of plump, normal, lean and screening grains should be noted. Uniform normal grains are superior and preferable to a mixture of plump and screening grades. The color should be yellowish white, pale yellow or grayish white, rarely black and shiny. Of the yellow varieties the golden yellow is preferable. Exposure to rain after cutting causes loss of bright color and the appearance of spots. The lighter colored varieties take on a shade of gray, or even an ash gray; the golden yellow varieties become reddish to grayish yellow. To improve the color oats are sometimes bleached with sulphur, recognizable by the presence of an odor of sulphur fumes. (Smith estimates that in six months beginning October 1, 1908, nearly $19,000,000$ bushels of oats and barley were bleached at 13 grain centers in three North Central States of the United States.-Translator.) Green tips on the glumes or hulls, shrinking or shriveling and light weight indicate immaturity. The protein content of oats of this character is usually unchanged, but the starch value is much reduced. In the black varieties of oats the entire grain should be of coffee brown or black color. If the tips only are black this indicates a spoiled condition. Spoiled oats have frequently been the cause of serious poisoning. Inspections should always be made in daylight, with blue background (blue paper) to aid in recognizing the various shades of colors.

The odor should be characteristically aromatic. Foreign, unpleasant, close, musty, moldy, or kiln-dry odors should be absent. The latter is due to the kiln-drying of oats harvested in unfavorable weather. Such

\footnotetext{
12Losses caused by storage of grains depend upon the oxygen supply and moisture content of the grain. In hermetically closed containers (silos) oats lose 1 per cent of their total carbon in one year. In vessels or containers through which a constant stream of air is slowly forced the loss amounts to 6.5 per cent. The oxidizing processes which go on in the oat grain are favored by high water content and high temperature. They affect chiefly the starch content, to a less degree the fat, and to a slight degree only the crude protein and sugar. In flour or cracked grain the losses are greater than in whole grain.
} 
oats may also be recognized by the darker color. Foreign odors may be intensified, to aid detection, by warming a sample of the grain in the hand, or by breathing upon it.

The taste should be sweetish. Grain with a musty, bitter, rancid or moldy taste should be rejected.

The stage of maturity should also be considered. The grains should be well matured.

With reference to the stage of maturity we have-

a. Milk-ripe or green-matured grains, distinguished by their green color and milk-like contents. Water content 50 per cent or more. Will not keep.

b. Yellow or waxy stage. May be easily crushed with the finger nail. This is the proper stage for cutting.

c. Fully matured grains, can not be bent but break when pressed upon with the finger nail. Have a riper color. When cut in this stage the grain easily shatters. This latter is still more pronounced in dead ripe grains.

d. Dead ripe grains are hard and brittle. When threshed they are usually mixed with many broken grains.

$e$. Prematurely ripe grains, resulting from drying up of milk-ripe grains as a result of drouth or excessive heat or too early harvesting. Such grains are slender, undeveloped, stunted, shriveled and of light color. They are of inferior value, mold easily and are not fit for storage.

Among the foreign admixtures of oats should be mentioned parasitic fungi, weed seeds and animal parasites, larvæ of the oat fly, etc., all injurious to the health of animals. Of the parasitic fungi of oats there are Ustilago (smut), Puccinia (rust), Erysiphe (mildew), rarely Secale cornutum (ergot). Among the important weed seeds we have corn cockle, poisonous darnel, wild mustard, vetches and chick pea (Lathyrus sativus), charlock, corn, crowfoot, wild morning glory, knotgrass, thistle, corn flower, larkspur, dog fennel, wild oats (Avena fatua), sorrel (Rumex), brome grass, spurry, etc. After storage, oats may be further contaminated by molds and bacteria, weevils, larvæ of the grain moth, meal mite, etc. In regard to injurious effects following the feeding of spoiled or contaminated oats, see Klimmer, Hygiene, special chapters on molds, fungi, poisons, etc. Brief reference should be made at this place, however, to musty oats.

Musty oats may produce digestive disorders accompanied by symptoms of loss or appetite, constipation, colic and diarrhea, polyuria, dizziness, difficult deglutition, swaying of the hind parts, and even paralysis. These symptoms usually disappear with a change of feed. The exact nature of the toxic substance in musty oats is not known. Musty oats may be recognized by their color and usually also by their odor. The odor may be removed by thorough aerating (frequently turning) but the toxic properties remain. The addition of a little common salt increases the palatability of musty oats and tends to diminish their toxic effect. 
Uses of oats. Oats are the most valuable and wholesome feed for horses of all classes and ages. They are usually fed whole, but it is better to crush or roll them and mix them with equal parts of chaffed straw. Young horses and old ones with defective teeth should have their oats crushed (not cut or rough ground). The same applies to greedy feeders and to animals in run-down condition. These oat and chaff mixtures should, in general, be fed in the dry state, especially to driving and coach horses. In these cases it is often well to reduce the chaff and hay rations. Heavy work horses, on the other hand, may have more chaff and hay and have the chaff and grain well moistened with water. Moistening the feed with water, however, affects ensalivation unfavorably, and since this affects the digestive processes, it is usually better to feed dry. When oats are the only concentrate in the ration, the daily amount should be adjusted according to age, character of work and size, 10 to 18 pounds for work horses, 3 to 6 pounds for colts during the first year, 10 pounds for light working horses.

Since oats are relatively high priced, various substitutes have been recommended. Indian corn is perhaps the most suitable of these. It is said that corn affects the mettle of horses and has a tendency to make them sweat. Lavalard and Muentz, however, as well as others, have shown that neither efficiency nor temperament are affected unfavorably. According to Hannsson, when Indian corn is used as half of the concentrate ration it exceeds oats 20 per cent in value. If barley is substituted for half of the concentrate ration, its fluctuating chemical composition must be taken into consideration and only full-grained material used. According to Hannsson, 1 pound of barley corresponds to 1.12 pounds of oats. Daily rations of concentrates for work horses, consisting of 8 pounds of barley and 10 pounds of oats, have shown no unfavorable effects due to the barley, nor was efficiency sacrificed. When rye is used as a substitute for a part of the ration, it should be cooked or steamed to avoid the effects of subsequent swelling. It should be fed in the proportion of one part to two or three parts of oats. Wheat, like buckwheat, is apt to cause cutaneous pruritus in horses and be very annoying. It is often fed to stallions. Hannsson had good results with wheat bran. Legumes (field peas) may be fed in amounts of from two to four pounds to horses doing heavy work. Oil cake (linseed palm seed, cocoanut, sesame and corn oil cake) are not much used for this purpose, but may be given in quantities of 2 to 4 pounds per day. Mixtures of dried brewers' grains, palm-seed cake, ground straw, etc., with molasses, 6 pounds daily, have proved highly satisfactory. These rations not only keep animals efficient but they have a favorable dietetic effect.

Very recently Rosenberg reported good results from the substitution of meal flat cakes for oats. One variety of these cakes consisted of 10 parts linseed meal and 30 parts oatmeal, dextrinated peameal and rye flour. Another variety consisted of 40 parts of oat and peameal 
and 20 parts of flaxseed, while a third kind was made up of oat, pea and wheat flour or meal and 10 parts of flaxseed. In addition all of these contained 1 per cent of common salt and 7 per cent of water. In size they were 4 by 4 inches, and about $3 / 5$ inch in thickness. They are thoroughly baked, brittle and of a pleasant bread odor. Daily ration for a horse, 5 pounds, broken, without further preparation; 10 pounds of hay and water as usual. The efficiency of the horses was not reduced. Experiments were conducted on 124 military horses in Russia. These cakes require only one-fourth of the storage space required for a corresponding amount of grain, an important item from a military point of view. On the other hand, Lebedew obtained unfavorable results with cakes made of rye, barley and peas. Digestive disorders and exhaustion were frequently observed. None of the many other feed cakes prepared and offered as substitutes for oats for horses have come up to expectations (pea cakes, Thorley food, Huch blood-feed, Achenbach concentrate, compressed oats, etc.). Attention should be directed, however, to what has already been said in regard to dried potatoes (sliced, flaked and pressed, p. 73) which have proved very valuable. They are in proportion of 77 pounds of dried potatoes and 13 pounds of dry yeast to 100 pounds of oats. Further reference to substitutes for oats as rations for horses will be made in succeeding pages.

On account of the relatively high price of oats this excellent feed is not extensively used for other domestic animals. Occasionally it is used as a concentrate in rations for calves, as much as $11 / 2$ pounds per day, or 2 pounds for bull calves. It is also fed to young animals of all species, bulls, less frequently to milk cows, lambs ( $1 / 4$ pounds), rams, ewes (up to 1 pound per day), little pigs and to convalescents. All of these animals digest the ration more thoroughly if the oats are given in the crushed form, except milk cows, fattening cattle and swine, which do as well on the coarsely ground grain. Sheep and calves only may receive the grain whole for best results. When fed dry to sheep the oats may be mixed with twice the volume of chaffed straw, and this is occasionally practiced with cattle also. For milk cows, coarsely ground oats may be mixed with bran, meal, oil cake, etc., and fed alone or mixed with crushed root crops (intensive feeding). The method of feeding crushed oats to cattle in most common use in Germany is to mix with hot slops or scalding water and adding cooked potatoes or beets to make a mash. Swine usually receive coarsely ground oats scalded with hot water and mixed with cooked potatoes.

\section{b. Barley}

Botanical.-Origin: Hordeum vulgare, $H$. distichum and $H$. hexastichum. These species are characterized by the fact that there are three spikelets at each joint of the rachis, while in wheat and rye there is only one. The fruit of most species of barley is intimately inclosed by the glumes (Figs. 41 to 43 and 46 ). The grains of rye are naked 
and fall out when threshed. Wheat grains are only partially inclosed by the glumes and are otherwise naked, as in rye. The rachis of the glumed varieties of wheat is brittle at maturity and is easily broken up into its segments, one for each spikelet. The rachis of a head of barley is tough and does not break.

Chemical.-The glumed varieties of barley are the only ones of economic importance in feeding animals. The glumes constitute from 12 to 16 per cent, average 14 per cent, of the weight of the threshed grain. The crude fiber content is therefore lower, and the digestibility of the total organic matter is higher than that of oats. Starchy, protein-poor and thin hulled varieties of barley are preferred. The crude protein contents amount to 12 per cent, digestible protein 8.8 per cent, crude

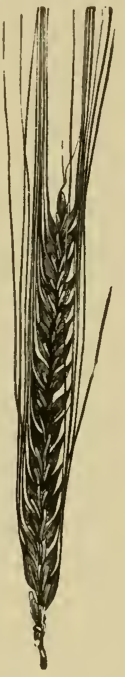

Fig. 41. Two-rowed barley.

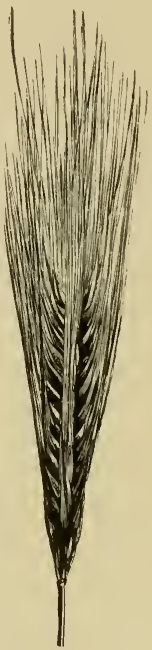

Fig. 42. Four-rowed barley

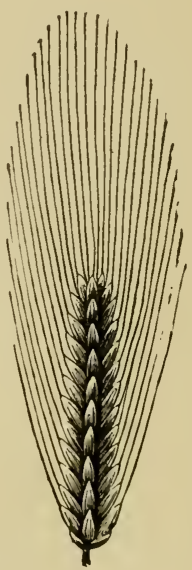

Fig. 43. Six-rowed barley.

fat 2.4 per cent, nitrogen-free extract 64 per cent, water 14 per cent and mineral matter 2.5 per cent, the latter containing 0.775 per cent phosphoric acid and 0.012 (winter barley) to 0.059 per cent lime; starch value, 68 per cent. Numerous feeding experiments have shown that eosin, used in denaturizing feed barley, is generally harmless. It has also been demonstrated that eosin under these conditions exercises no unfavorable effect upon the character of the meat products, fat, etc. Cases are recorded, however, which show that serious illness and even fatal results may follow the ingestion of eosin barley and that the quality of the meat products may suffer. 
Eosin itself, in quantities present in the material under consideration, is not poisonous, but may become so when combined with the effects of intense light. Eosin belongs to a group of photo-dynamic substances which influence the effects of light on albuminous bodies (light sensitization). In light sensitization very small amounts of sensitizing agents are required to bring about catastrophic effects, especially when the light irritation has reached a certain intensity. Under stabling conditions eosin is harmless, but it has produced serious results in animals kept out of doors in the bright sun (inflammation and necrosis of the skin, sunstroke, heatstroke, etc.). The author himself is of the opinion that the objections raised against eosin-treated barley are not founded upon strong evidence.

Judging or grading. The grain weight of the large, two-rowed varieties of barley is, on the average, 4.4 grams per 100 grains, and 2.4 to 5.6 (average 3.8) grams for the small, four and six rowed varieties. One liter of barley weighs 500 to 700 (average 600) grams.

Barley that has been rejected by distilleries is about the only kind that is ever used for feeding animals in Germany, and this has frequently been damaged by rain. Such grain can be recognized by its dull and uneven color and the brown and blackish tips of the glumes. Musty odor and bitter taste are indications of a spoiled condition.

Among the common contaminations may be mentioned wind oats, rye, wheat, oats, earth, parts of straw, seeds of weeds (vetches, brome, dodder [Cuscuta], corn cockle, spurge, morning glory), sand, mouse excrement, bracts and scales of Compositæ, parasitic fungi (Fusarium heterosporium, Ustilago, Puccinia, Erysiphe), etc.

Uses. While barley constitutes the chief concentrate feed for horses in southern Europe and the Orient, it is used only to a limited extent in Germany. While it gives the animals a fine external appearance (full form and smooth hair coat), it does not furnish the energy and endurance furnished by oats and is said to be more apt to cause colic and diarrhea. If used at all in Germany, where it is usually cheaper than oats, it is as a substitute for one-third to one-half of the oat ration. According to Hendricks, this is a profitable substitute, and while animals maintain their efficiency on such rations they also improve in general appearance. It is fed crushed or soaked in water and mixed with chaffed straw or hay. Crushed and scalded, or made into a slop, it is an excellent feed for run-down horses.

Barley is better adapted as a feed for fattening cattle and milk cows, crushed, dry or scalded. Its most extensive use is in the feeding of swine. Barley is the best growing feed for swine over three months of age. For younger pigs oats are preferable. It is an excellent feed for fattening swine. For best results it should be rough ground and scalded. As barley is a high-priced feed, potatoes are substituted for it wherever practicable. 


\section{c. Rye and Wheat}

Botanical and chemical. The cultivated species of rye and wheat are derived from Secalc cercale (rye) and the various species of Triticum (wheat). The wheat plant has been under cultivation much longer than rye. The latter is cultivated chiefly in the colder central districts of Europe. It is extensively imported into Germany from Rumania, Russia and America. Rye, which is always a naked seed, and wheat, which is usually so, are free from strawlike hulls and as a result are poor in crude fiber (1.8 per cent) but correspondingly richer in digestible organic matter: Crude protein 11 per cent, crude fat 1.8 per cent, nitrogen-free extract 70 per cent, mineral matter 2.1 per cent, digestible albumen 7 to 11 per cent in full grains and flat grains respectively, starch value 65 to 72 per cent in flat grains and full grains respectively. As a rule the flat, stunted, shriveled or poor grades only are used as feeding stuffs, the better grades being used for human food.

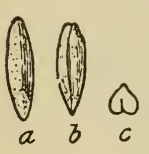

Fig. 44. Grain of rye.

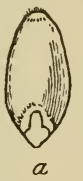

( $\mathrm{X}$ 1.3.)
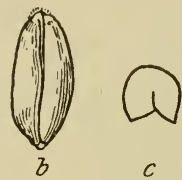

C

Fig. 45. Grain of wheat. (X

2.) $a$, Dorsal; $b$, ventral side; $c$, cross section.
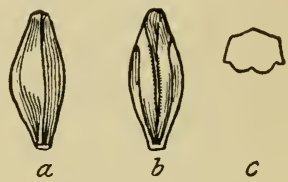

Fig. 46. Grain of barley. (X 2.)

Rye, like oats, is an energy or force producing food rather than a fattening food. When fed to horses, especially fresh in the sheaf, it is apt to cause digestive disturbances, in rare cases cerebral affections and founder (laminitis). Cracked rye and rye flour are also more apt to cause digestive troubles than the same products made from wheat. Rye possesses the property of swelling enormously when moistened ( $2 \mathrm{r} / 2$ times its normal volume).

For horses not more than half the oat ration should be replaced with rye. The rye should always be fed whole, boiled $1 \mathrm{r} / 2$ hours, and mixed with chaffed feed. The change must be made gradually. Draft oxen may receive from 4 to 6 pounds and fattening sheep not more than 1 pound of rye, prepared as for horses. Boiled rye is sometimes given as a special diet to cattle run down in condition from the effects of disease. Swine may be given 2 pounds of rye daily (for fattening), but always cracked and scalded or steamed and mixed with other feed, such as potatoes.

Whot has been cultivated from the earliest historic times. In China it was cultivated three thousand years before the birth of Christ. It was formerly much used as a horse feed. It is richer in nitrogen than any other grain (12.6 per cent protein). Many varieties are known and cultivated-winter, summer, awned, awnless, etc., and these are 
again divided into numerous subvarieties. In addition to the numerous varieties of Triticum vulgare or common wheat which are cultivated in the best localities in Germany (the common English or rough wheat and Polish, hard or flint wheat), a number of species of glumed wheat are cultivated, namely, $T$. spelta or German wheat or spelt, $T$. monococcum or one-grained wheat (Ein-korn or one corn) and T. dicoccum or twograined wheat or emmer. Wheat, like barley, is chiefly a fattening feed, and less adapted for energy production. Like rye, especially in a fresh state, in the sheaf, for example, it is apt to cause digestive troubles. Laminitis has been observed following the feeding of wheat, rye and barley. Wheat, in Germany, is used mainly as a feed for fattening cattle and swine, more rarely as a feed for horses (stallions), cracked or cooked for the latter.

\section{d. Indian Corn}

Botanical. Indian corn, maize, Zea mays, is cultivated in Germany principally as a soiling crop. In southern Wuertemberg and Baden it is

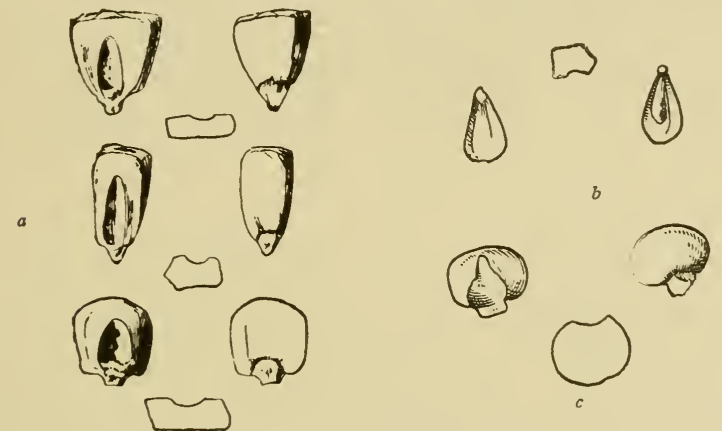

Fig. 47. Grains of Indian corn. a, Horse-tooth maize-Dent corn. $b$, Common maize or corn. $c$, Cinquantino.

sometimes raised for the grain. It is largely imported to Germany from the United States (horse-tooth maize), Hungary and Rumania (Danube maize) and Argentina (La Plata maize).

Chemical. Indian corn is characterized by its high content of crude fat ( 5 to 6 per cent). Its digestible albumen varies between 6.5 and 8 per cent, its starch value 81.5 to 83 per cent, nitrogen-free extract 70 per cent, crude fiber 1.7 per cent, and ash or mineral matter 1.4 per cent.

Judging and grading. The weight of Indian corn by measure, for the large and medium grain varieties, is 700 to 780 grams per liter, and 740 to 870 grams per liter for the small-grained varieties. One hundred grains of a good medium grade of American mixed dent corn will weigh 31.4 grams, white dent corn 37.7 grams, Rumanian dent corn 19.12 grams, yellow corn from the Grand Duchy of Baden 21.13 grams, Turk- 
ish maize 26.8 grams, yellow La Plata maize 25.0 grams and Cinquantino 12.5 grams.

The most important parasitic fungus affecting Indian corn is Ustilago maidis (corn smut). The minute spores of $U$. maidis are hardly recognizable by the naked eye but may be detected by the black color which they impart to the hands when affected shelled corn is handled, or by the black scum that forms on the surface of water which has been poured into a vessel full of infected grain.

The digestibility of Indian corn is high, and it agrees well with all animals, provided strict cleanliness is observed to prevent fermentation or spoiling of leavings in the feeding troughs or mangers. Corn spoils or becomes moldy very readily in the presence of moisture.

Uses. Indian corn is not as pronounced an energy-producing food as oats, but, like barley, has good fattening qualities. For this reason it is not suited to replace entirely the more expensive oats as a horse feed. The softer and more starchy varieties are not suited to replace oats to a greater extent than one-fourth or one-half of the grain or oat ration, and only then when the comparative prices of corn and oats warrant the subsituation. Furthermore, it is adapted only for slow working animals that are able to masticate the grain well and that are not overfatigued. The softer and more starchy varieties may be fed whole. The harder varieties should be crushed and mixed with oats and chaffed feed. The crushing should be sufficient merely to crack the shell, not to reduce the grain to fine particles.

Indian corn is an excellent feed for fattening cattle, sheep and swine. While the effect of the oil in the grain when fed in large quantities improves the meat product of cattle and sheep by lowering the melting point of the tallow, its effect on the quality of the meat products of swine is the opposite. It has a tendency to make the bacon oily and the meat soft. These objections may be overcome by limiting the corn grain ration to one-half. Corn is a less desirable feed for milk cows on account of its softening effect upon the butter.

The methods of preparing corn for the feeding of cattle, sheep and swine are the same as those recommended for the other grains. Sometimes it is fed whole to horses and sheep after having been soaked in salt water for 24 to 48 hours.

In regions where Indian corn is extensively cultivated it is sometimes ground with the cob to induce more thorough mastication. In countries where the imported product is used the expense of transportation would exclude this method of feeding.

\section{e. Millet and Rice}

Millet (Panicum miliaceum) and rice (Oryza sativa) are used as animal feeding stuffs in a limited way only. Rice is used chiefly when it is low in price or when unfit for human consumption on account of a slightly spoiled condition. 
Millet is ground or cracked, rice is hulled, and either are fed raw or cooked, mixed with chaffed feed. Both are used mainly as horse feed as substitutes for part of the oat ration. Cooked rice is also widely used as a feed for dogs and is highly prized for this.

\section{f. Buckwheat}

Buckwheat, although, strictly speaking, not a grain, but a member of the sorrel-wort family (Polygonaceæ), to which belong the various kinds of dock, knotgrass, water peppers, smartweed and garden rhubarb or pie plant, is very similar to the grains, and especially to wheat, in its nutritive value. It contains 7.5 per cent digestible albumen, 53 per cent starch value, 2 per cent crude fat, 62 per cent nitrogen-free extract, 10 per cent crude fiber, 2 per cent mineral matter and 14 per cent of water. When cracked or coarsely ground it is occasionally used as a substitute for part of the grain ration of heavy work horses, but also for working oxen, fattening cattle and swine. It is cooked for the latter, and is used to replace one-half of the grain rations of these classes of animals. The feeding of buckwheat is only rarely followed by the toxic effects mentioned in detail on page 51. The toxic substance is present in the hull. The danger of possible poisoning may easily be avoided by removing the hulls by screening.

\section{The Legumes}

The legumes are characterized by their high content of albumen or protein, which varies between 14 and 30 per cent. Of all natural feeding stuffs (those not altered by commercial processes) the legumes are the richest in protein. The soy bean, serradella (Ornithopus sativus) and the lupines have a high fat content in addition (17, 8 and 4 to 7 per cent respectively). The remaining legumes which concern us as feeding material have a fat content equal to that of most of the grains, 1.5 to 2 per cent. The mineral content (salts of lime and phosphoric acid) is also high ( 3 to 4 per cent) compared with the grains. But the amount of nitrogen-free extract is considerably lower. The starch value varies between 50 and 83 per cent. The following are most important for feeding purposes: Peas, beans, vetches, serradella, soy beans and lupines.

\section{a. Field Beans, Peas, Vetches and Serradella}

Botanical.-Progenitors: Field beans (Vicia faba), pea (Pisum arvense), vetch (Vicia sativa), serradella (Ornithopus sativus).

While Pisum sativum (sugar pea, dwarf and climbing pea) are cultivated in our gardens as a vegetable, $P$. arvense (field pea) is cultivated exclusively as a forage plant.

Chemical.-Beans, peas, vetches and serradella have about the same chemical composition and digestive coefficient. They are therefore used as feed in the same way. They contain on an average 14 per cent of 
water, 17 per cent of digestible albumen (serradella 14 per cent), 67 to 70 per cent starch value (serradella 49 per cent), 1.6 per cent crude fat (serradella 7.5 per cent), 50 per cent nitrogen-free extract (serradella 33 per cent), 6 per cent crude fiber (serradella 20.5 per cent) and 3 per cent mineral matter.

Digestibility and wholesomeness.-They are digested and assimilated rather slowly but very completely. On account of their high content of digestible albumen, they are specially adapted to correct protein deficiency. Their use, however, must be attended with care, since they are apt to produce digestive disturbances. This peculiarity is due to their slow digestibility, their constipating effects (tannic acid), their pronounced property of swelling with the absorption of water and their tympanitic action. These objectionable qualities are most pronounced when the seeds of the plants mentioned are immature, insufficiently reduced in size (too coarsely ground) or otherwise improperly prepared. Vetches are most to be feared in this respect, then peas. Beans are much less dangerous. Large rations are said to cause cerebral affections in horses, lumbar affections, roaring and laminitis and to aggravate existing blind staggers in horses as well as to cause stiffness in lambs and pigs (according to Oppermann also in sheep). The causes have not been definitely determined. Some authors ascribe these troubles to an accidental admixture of Lathyrus satious (chickling vetch). All of the objections enumerated are at least partly compensated for by the fact that these fruits are very nourishing, lasting in their effects, strength-giving, and produce firm flesh and fat (swine). In addition, lukewarm soups made from coarsely ground roasted seeds have a good effect in chronic diarrheas.

In judging or estimating the quality of leguminous seeds much weight should be placed upon proper color. A reddish tinge in the yellow varieties of peas is said to indicate freshness and good quality. Immature yellow peas have a uniform color and are spotted with greenish areas. Long storage produces a pale color; yellow peas become gray, and green peas become yellowish green. Immature green peas are grayish green while properly matured green varieties are pale bluish green. Peas frozen or frosted in the field have a blistered skin and glassy seed lobes or cotyledons.

Broken or otherwise injured peas easily become the prey of mites and molds. This is common in peas that have been attacked by borers and weevils. Moisture favors the development of molds. Low-grade commercial peas frequently contain vetches and field beans, which however, does not impair their feeding value. Charlock (poisonous) is a frequent admixture. Ground peas are frequently adulterated with pea-hull bran, which has less than one-half or one-third the value of the pure meal. Indian peas (mother peas) are sometimes admixed with the seeds of Cicer arietinum (chick-pea) and Cajanus indicus, which are reputed to be poisonous for horses, causing paralytic symptoms. The chick-pea has 
a warty, shrivelled appearance, is somewhat cone-shaped and varies in color. It is cultivated in southern Europe, north Africa and India in place of the common pea. Similar properties are possessed by Lathyrus sativus, the chickling pea, which is cultivated in southern Europe.

Vetches are frequently admixed with broken seeds of the various grains and the seeds of weeds. Since vetches mature very unevenly, it is common to find spoiled seeds. The latter probably are the cause of many of the bad results obtained in feeding them. Cooking or steaming overcomes many of the possible dangerous consequences. Vetches have a bitter taste and for this reason are not eaten readily by horses.

The numerous varieties of field beans may be divided into two groups, the small horse bean or field bean (Vicia faba minor), with oval, angular, blue, brown or greenish yellow seed and long, smooth, thick pods, and the large broad bean or horse bean (Vicia faba major) with flat, kidney shaped, grayish yellow, green or violet to black seeds and slightly bent or curved pods. Beans harvested in a damp condition or stored in a damp place easily become moldy. Spoiled beans lose their luster and show traces of moldiness either on the outside or only on the inside of the pods. Occasionally beetles (Bruchus granarius and B. rufimanus) attack the seeds. The various species of Phaseolus, cultivated as vegetables, are rarely used as feed for animals.

The poisonous Rangoon bean or moon bean of the Dutch East Indies bears a resemblance to Phascolus multiflorus (scarlet pole bean) and is occasionally found as an adulterant of feeding stuffs. It contains a glucosid, phaseolunatin, from which large quantities of prussic acid are evolved ( 0.115 per cent) which determines their toxicity. It is differentiated from the field bean (Vicia faba) by its spotted, marbled hull. Dammann and Behrens report mass poisonings among horses, cattle and swine with Java beans containing prussic acid. According to these authors the poisonings referred to were caused in part by Phaseolus lunatus, $P$. vulgaris, Cajanus indicus and a species of Dolichos. But not all species of Dolichos are toxic. D. lubia, for example, is cultivated as a forage plant in Italy, D. uniflorus and $D$. biflorus in East India and D. sinensis in South America.

Uses. Peas, beans and white vetches are used as feed for the coarser breeds of work horses, as substitutes for one-fifth to one-half of the grain ration, according to the coarseness of the breed and character of the work. Colts of these breeds are also fed from 2 to 4 pounds of peas or beans per day, as substitutes for part of the grain ration. Stallions receive similar amounts during the breeding season to stimulate sexual desire.

The softer forms of leguminous seeds may be fed to horses without special preparation, with oats and chaffed feed. The harder varieties should be cracked or soaked in water about four hours- 6 pounds of peas or beans for 5 quarts of water. They may also be boiled in soft water, or in hard water with 1 gram (15 grains) of soda added for each 2 pounds of beans or peas. Beans or peas will not get soft when boiled 
in hard water. During harvest time beans and peas are sometimes fed in the straw, without being threshed. To prevent constipation or undue accumulation of intestinal contents bran may be fed with legume rations. This is highly reconmended and in case of constipation absolutely necessary.

For ruminants the legumes are a good fattening feed as well as a good energy-producing feed. Working oxen may have several pounds per day during the working season. With careful feeding they are also good for young growing animals and for milk cows, but should be avoided for pregnant animals. The unfavorable action upon the milk secretion which has been ascribed to legumes does not seem to exist in fact.

For sheep legumes should be soaked in water twenty-four hours before feeding; for cattle, either coarsely ground, crushed or soaked.

For swine the Leguminosæ are a good fattening feed, producing a firm flesh and a fat that melts at a higher temperature than ordinary lard. At the finishing stage, however, large quantities of legumes should be avoided, especially beans, and barley substituted. It is generally supposed that they produce a bitter taste when fed at that stage, but this is contrary to reports of Kuehn. Legumes should be cooked and crushed before feeding to swine. This is especially necessary in the case of beans with leathery skins.

\section{b. Lupines}

The lupines are cultivated species of Lupinus luteus, L. albus and angustifolius (blue lupine).

The yellow flowered lupine produces the richest seeds. They contain 38 per cent of crude protein, 4.5 per cent of crude fat, 25.4 per cent of nitrogen-free extract and 14 per cent of crude fiber. Unfortunately all lupines have a bitter taste, which is imparted to the milk, and this fact materially affects their feeding value. This bitter principle may, however, be removed by steaming or cooking and subsequent leaching. Some varieties of lupines also contain a toxin, (mentioned on page 63), which has been the cause of fatalities in horses and sheep (Schulz).

Lupines not treated for the removal of the bitter principle must be fed with the precautions mentioned on page 64 (experimental feeding). Sheep become accustomed to them more readily than other animals, horses not so readily, and cattle and swine sometimes refuse altogether to eat them. One-half pound per day, coarsely ground and mixed with chaffed feed, is excellent for sheep. Sheep in a run-down condition soon recover flesh on this ration. Larger rations are apt to be followed by digestive disturbances, cerebral disorders, irritation of the urinary organs and, especially in horses, constipation, colic and laminitis.

When lupines are intended to be fed in large quantities they should first be leached to remove the bitter principle, which also removes the toxins that may be present. The process consists in steaming under pressure or cooking for from 15 minutes to one or two hours and then 
leaching for 8 to 10 hours. The leaching is best accomplished in wire baskets set in running water (p. 30). It is impossible to avoid considerable losses of nutrients in this operation. As long as they are still wet or damp, the leached lupines spoil rapidly. To avoid spoiling they should be fed at once or dried artificially. Horses may receive 10 pounds of leached lupines per day, milk cows 7 pounds, fattening cattle as high as 17 pounds, ewes with lambs $1 / 2$ pound, fattening sheep and rams 1 pound. For cattle and swine the leached lupines must, in addition, be crushed. Horses and sheep take them whole with chaffed feed. The transition to lupine feeding must be made gradually. The leaching process must be conducted with care and the product tested by "taste." Horses usually object more or less to leached lupines and swine may refuse them obstinately.

\section{c. Soy-Beans}

The soy-bean, or soja bean (Soja hispida, Fig. 48) is cultivated chiefly in eastern Asia (China, Japan, Java) and in recent times in central and

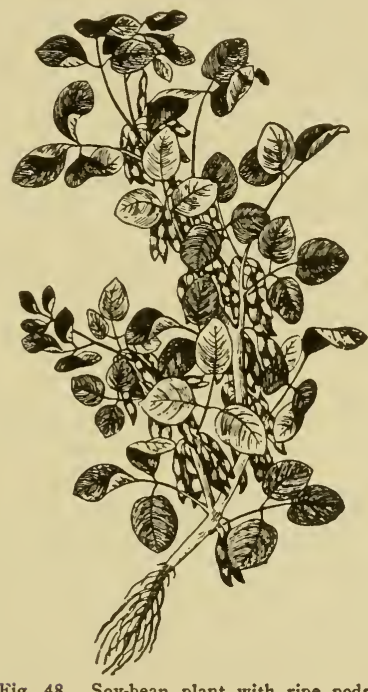

Fig. 48. Soy-bean plant with ripe pods.

southern Europe and the Western States of North America. In Germany their cultivation has as yet not proved very profitable. The climate is too cold. It is possible that soil inoculation with specific nitrifying bacteria may aid in the production of increased yields.*

Their seeds are characterized by a high fat and protein content, 18

* See Bulletins Agr. Exp. Sta. of Kansas.-Translator. 
and 35 per cent respectively. As a fattening and energy-producing feed soy beans are most successfully fed in a coarsely ground state.

\section{d. Miscellaneous Seeds}

Flaxseed, derived from cultivated flax (Linum usitatissimum) is highly nutritious and of great dietetic value. Its high market value prevents its more extended use as a feeding stuff.

Flaxseed contains 18 per cent digestible albumen, 11.9 per cent starch value, 36.5 per cent crude fat and 23 per cent nitrogen-free extract.

The nutrients contained in flaxseed are in a high degree digestible. They contain a lare quantity of substances that dissolve into a slimy mass in water and have a very favorable effect upon the digestive organs. Flaxseed is principally used in special diets for catarrhal conditions of the digestive organs, in conjunction with irritating feeding stuffs (raw potatoes) and in the nourishment of weakly animals. It is also used for recently weaned calves and to replace the fat in skim milk. For the latter purpose about $11 / 2$ ounces of ground linseed (linseed meal) should be added to 1 quart of boiled milk while still warm. Linseed is also fed to mares with suckling colts and to milk cows, at the rate of 1 pound per 1,000 pounds weight, in the form of meal, dry or as a broth.

The seed of field spurry (not adapted to the hot summers of the United States) is fed to horses in a crushed state, and to cattle crushed and scalded. It is well liked by these animals. The seed, like the plant itself, is said to have a favorable effect upon the secretion of milk.

Turnip seed and rapeseed (Brassica rapa and B. napa) are sometimes used to increase the fat content of rations, principally for fattening cattle, in quantities up to 3 pounds per day. They should be fed ground. Their dietetic effect is about the same as that of oil cake prepared from the same material.

Hempseed (Cannabis satiza) is used like rape and in addition is a common feed for run-down horses. It is also fed to breeding males to stimulate sexual desire.

Beechnuts (Fagus sylvatica), which contain 10 per cent digestive albumen and 86 per cent starch value, are occasionally fed to swine and fattening cattle, crushed or cooked, in moderate amounts. They should not be fed to horses because they contain a base resembling trimethylamin (fagin) which is apt to cause violent poisoning in these animals (colic, cerebrospinal irritation, cardiac paralysis). Fed to excess they produce soft bacon in swine and soft butter when fed to cattle.

Acorns (Quercus rubor) and horse-chestnuts (Esculus hippocastanum [E. glabra, Ohio buckeye]) contain, when fresh, 1.5 per cent digestible albumen, 34 per cent starch value and 50 per cent water. On account of their high water content they are subject to moldiness. This may be overcome by storing in thin layers, frequent turning, artificial drying or reduction to flakes and subsequent drying. 
Dried horse-chestnuts are easily hulled. When used fresh, horsechestnuts are crushed, otherwise ground, and improved by cooking or steaming and mixing with other feed. Fattening pigs receive upwards of a pound per head per day. Swine thus fed produce a "kernelly," firm bacon. Milk cows are fed 5 to 10 pounds per head per day, sheep up to 2 pounds per day. Animals must be gradually accustomed to the bitter taste. The bitter taste may be removed by leaching, usually after subjecting the horse-chestnuts to cooking or steaming. Feeding in large quantities should be avoided on account of their constipating effects. They are often fed in small quantities for their stimulating effect on the appetite and their binding effect when the latter for any reason is desired. They are said to cause tannic acid poisoning in poultry. When fed before they are fully matured they are apt to cause serious digestive disorders in horses, cattle, goats and sheep.

Acorns are rich in a bitter principle known as quercit and in tannic acid. They agree well with swine (4 pounds of fresh or 2 pounds of dried acorns per 100 pounds live weight), but in cattle they are apt to cause gastroenteritis and obstinate constipation. They are used mainly as a feed for fattening swine in rations of 2 pounds per day. When properly supplemented with other concentrates (rye meal) they produce a high grade of bacon. Occasionally they are fed to sheep that run on heaths ( 1 pound) and to fattening cattle ( 4 to 6 pounds). Large quantities fed at a time are not wholesome, especially for pregnant sows. For pen-fed swine it is best to cook them. The water in which they were cooked should be discarded. The milk from acorn-fed cows and sows does not agree well with the young.

\section{Milling By-Products}

The chicf by-products of the milling industry that are used as feeding stuffs are bran and middlings. They occur in the processes of hulling, grinding and clipping.

Chemical.-The brans contain chiefly the outer, hard, fiber-rich tissues of the grain, the protein-rich and fatty germ, the albuminous aleurone layer (Figs. 34 and 39), and frequently the glumes and husks (oats, rice, barley). They are therefore richer in fiber than the whole grains. Brans made from pure grain, like wheat and rye, or hulled oats and barley, however, are richer in both protein and fat than the whole grain. They always contain less starch or carbohydrates.

Middlings are made from the wastes that occur in the various milling processes and which contain starchy matter and gluten, etc. Compared with the whole grains, they are rich in digestible carbohydrates.

13Translator's note: The term "Futtermehl" (feed meal) in the original German work is here translated "middlings," to which it corresponds. It shou'd be noted, however, that this term, as used in the United States, is more or less general in meaning and does not indicate a product of constant composition. 
Digestibility and wholesomeness.-Bran and middlings are easily digested and are usually well assimilated. They might be regarded as roughages rather than concentrates.

Given in small quantities, bran, especially wheat bran, has a good dietetic effect, exerting laxative and soothing influences on the intestinal mucous membranes. It is therefore a desirable supplement to the less digestible and constipating leguminous seeds and exerts a favorable influence on catarrhal conditions of the digestive as well as the respiratory organs (distemper).

Disadvantages.-Continued and excessive feeding of bran and especially of middlings has a laxative effect on the digestive organs. Bran, when fed in quantities of 12 to 20 pounds per day (e.g., millers' horses) is liable to produce intestinal concretions (triple phosphate), or urinary calculi and sediments in sheep, due to its rich phosphoric acid content (Klimmer) ${ }^{14}$. Bran is rich in phosphoric acid but poor in lime salt, and when fed in conjunction with other substances that are deficient in lime,

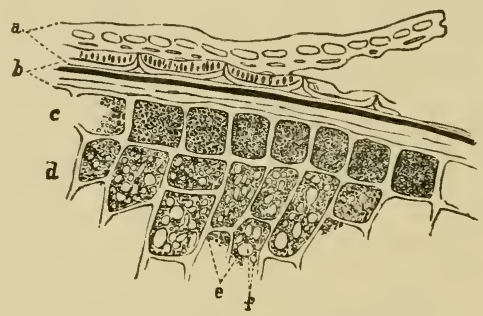

Fig. 49. $a, b$, The three outer coats or skins of the wheat grain; $c$, aleurone layer; $d$, starch cells; $e$, starch grains; $f$, fat globules.

like hay, it leads to lime starvation (osteomalacia of lower jaws, bones of the legs and joints, poor teeth, faulty mastication, chronic gastrointestinal catarrh).

Middlings are heavy and pasty in character, are liable to get "lumpy" in the stomach and ferment, and induce catarrh, tympanitis and colic, unless thoroughly mixed with plenty of chaffed feed or water. Damp flour or refuse particles of dough from bakeries or the kitchen are liable to undergo fermentation and, when fed to animals, may produce serious indigestion.

\footnotetext{
14The various forms of bran are very rich in phosphoric acid compounds and contain, in addition, considerable quantities of magnesia. The ammonia, which is formed by the various decomposition processes that take place in the alimentary canal, precipitates the phosphate of magnesia in the form of triple phosphate (phosphate of ammonia and magnesia). The latter not infrequently accumulates to form stones and concretions in the intestines of the horse. On the other hand, the salts of phosphoric acid and magnesia may be absorbed to a considerable extent and excreted by the kidneys. In the course of catarrhal affections of the bladder, ammoniacal fermentations may be set up and convert urea into ammonium carbonate. The ammonia, as in case of intestinal fermentation, precipitates the phosphate of magnesia as triple phosphate, and cystic stones and concretions are the result (sheep).
} 
Determination of quality.-Pure bran contains only such by-products as are formed in the process of grinding pure, clean grain (Society of German Agricultural Experiment Stations).

Brans and middlings are, to an excessive degree, liable to be adulterated, usually with other brans and middlings of inferior quality, screenings, mill sweepings, ground husks and chaff, castor-oil beans, sawdust, fruit pits, olive seeds, sand, infusorial earth, clay, lime, barite, gypsum, chalk, etc. Screenings contain, on the one hand, defective, undersized, undeveloped and broken grains and harmless weed seeds, many of them nutritious, others of no value whatever. On the other hand there are frequently present poisonous seeds of great variety, poisonous darnel, cow wheat, yellow rattle, corn cockle and charlock. There may also be parasitic fungi, ergot and smut, mouse excrement, etc; in fact, contaminations of almost any kind or variety, the feeding of which would be a serious matter. While feeding experiments have not shown that all of these contaminations are injurious to health, it is best to regard all of them with suspicion. As with other poisons, the susceptibility of animals varies greatly with reference to the contaminations above mentioned.

In considering the possible harm that can be done by these foreign admixtures or adulterations it is not sufficient to rely upon the results of a few individual experiments, but it is well to be governed by the results of general experience. Reports of mass poisonings of cattle and especially of swine that have been fed on adulterated bran, middlings and other concentrates are frequent enough. Wheat bran imported from Russia into Germany was found to be contaminated with anthrax spores. In regard to poisoning with corn cockle, see chapter on poisonous plants. With reference to the detection of adulterants, see special chapter.

Since it is frequently no easy matter to detect or recognize the exact character of adulterants, it would be wise not to purchase bran, middlings or waste products of the vegetable oil industries without a guaranty of their purity, absence of screenings, freedom from spoiled admixtures, etc. The purity of these products should further be controlled by the enforcement of suitable state or national laws.

Uses.-Fattening cattle may be given from 4 to 6 pounds, especially of rye bran; fattening swine 1 to 1.5 pounds of middlings with rye bran, buckwheat bran, pea bran, or, more rarely, wheat bran in addition. Milk cows may have 4 to 6 pounds of wheat bran or barley bran, horses up to 4 pounds of wheat bran, calves and fattening sheep 1 to $11 / 2$ pounds of bran and middlings. For horses bran is best in the form of a mash or slop; for cattle it should be mixed with other feed and moistened, or fed dry by itself; for pigs, scalded or cooked, in the form of slop. Middlings give best results when well mixerl with warm water, in the form of slop. With reference to feeding milk cows with milling by-products it should be borne in mind that the feeding of large quantities of wheat bran, rice feed meal and millet polish have a tendency to make soft butter, while the by-products of the leguminous seeds have the opposite effect. Rye 
bran is more of a fattening than a milk-producing feed and makes a coarse grade of butter.

Wheat bran.-Wheat bran varies in composition according to that portion of the grain which predominates. Bran made from the tips of the grain is rich in crude fiber, 27 per cent, but valuable at that. After the tips have been removed, the grains are freed from their skins or seed coats and thus the coarse forms of bran are produced. The kernels are then crushed and ground into fine flour. The siftings of the latter constitute the fine bran. A good grade of bran contains the skins of the grain, the aleurone layer and parts of the starchy matter. Chemically it is composed of water 13 per cent, digestible albumen 9 per cent for fine bran and 11 per cent for coarse bran, starch value 42.5 to 48 per cent, fat 4.5 per cent, nitrogen-free extract 53 per cent, crude fiber 9 per cent, and mineral matter 5 per cent, containing 2.5 per cent phosphoric acid. Wheat bran is used chiefly as concentrate feed for milk cows, calves and horses. For the latter it is also used for dietetic purposes in conjunction with legumes and potatoes, or for catarrhal conditions, in amounts varying between 3 and 4 pounds.

Wheat middlings contain water to the extent of 12.5 per cent, digestible albumen 11 per cent, starch value 73 per cent, fat 3.3 per cent, nitrogen-free extract 63 per cent, fiber 4 per cent, mineral matter 2.5 per cent. Middlings are used chiefly in milk substitutes for calves, one-fifth to onehalf pound; pigs, one-tenth pound. It is administered in the form of warm broths with bran, flaxseed, etc.

Rye bran is usually not differentiated into coarse and fine grades. The starch value is 47 per cent, digestible albumen 11 per cent. Rye bran, as already stated, is fed principally to fattening cattle and swine.

The milling by-products of barley and of oats vary considerably in composition according to the methods employed in clipping, hulling, etc. Barley bran and feed meal (the latter sometimes improperly called grits) are the by-products of the clipping, hulling and cleaning processes employed in the manufacture of so-called French or table barley. Barley flour is the by-product of the rolling and screening processes to which the cleaned grain is afterwards subjected. The value of these waste or byproducts depends upon the proportionate amounts of flour and hulls present (microscopical examination).

Oats in the course of their manufacture into oatmeal are first hulled. The hulls are sometimes ground and sold as oat bran, but this is hardly worth more than oat straw. In the process of hulling, cleaning, grinding and polishing the oat kernel there are produced first, the husks or hulls; second, oatmeal dust, consisting of the hairs at the tip of the kernel and of which there is a great volume; and lastly, oatmeal proper. The value of the by-products of oatmeal manufacture is subject to considerable variation, depending entirely upon their composition.

The by-products of millet meal consist of the almost indigestible and worthless hulls, rich in silicic acid, and the fine meal produced in polish- 
ing the hulled seeds. These two by-products when ground together constitute millet bran.

Buckwheat bran is a by-product of the manufacture of buckwheat flour and buckwheat meal. It is liable, under certain conditions, to cause buckwheat disease, fagopyrism (see p. 53).

Rice feed-meal is produced as a by-product when rice grains are polished. This should contain no hulls, but frequently these are added and ground into a mixed meal. The rice hulls, or glumes, are fery silicious and consequently hard to digest. Even when quite fresh, rice feed-meal contains free fatty acids and consequently has a sour smell and an acid reaction. When fed to cows the butter is soft in character. Swine fattened on this meal produce soft meat and bacon. This effect can be counteracted by simultaneous feeding of pea or barley meal:

So-called rice bran is composed chiefly of hulls and broken kernels.

Corn bran and corn feed-meal are characterized by their high fat content.

In the factory manipulations of the seeds of legumes the outer leathery skins (almost wholly indigestible) and the seed germs with some of the starchy matter, etc., constitute the by-products.

These substances are frequently ground up together and put on the market as corn bran. Compared with rye or wheat bran, this material is of very inferior value.

\section{Brewery and Distillery By-Products, Etc.}

This group includes the by-products of (1) breweries (brewers' grains, malt sprouts, hops and yeast), (2) distilleries (distillery slop), (3) wineries (skins or husks of pressed grapes), (4) cider presses (pomace of apples and similar fruit).

\section{Brewery By-Products}

The principal steps in beer brewing are: Soaking the barley in water, followed by spreading it out in a layer and the sprouting of the grain, and the formation of a ferment which converts starch into sugar (so-called diastase and peptone). When the sprouted germ has attained one or two times the length of the grain the germinating process is artificially interrupted by drying $\left(55^{\circ}\right.$ to $100^{\circ} \mathrm{C}$.). This is followed by partial caramelization and the formation of aromatic substances.

The sprouts (malt sprouts) are then removed from the grain, which is known in this stage as malt. Malt has the external appearance of barley but possesses a pronounced sweet taste.

The malt is then digested in water at a temperature of $60^{\circ} \mathrm{C}$. (malted) until the starch has been converted into malt sugar and dextrin and the latter have become dissolved. The fluid, mash, is then separated from the grain (brewers' grains) and boiled with hops, thus made into wort, filtered, cooled in special apparatus, and then fermented in special vats with the aid of yeast. After fermentation is completed and the fluid has cleared by settling, the beer is ripe.

Malt sprouts contain 12 per cent of water, 11.4 per cent digestible protein and 39 per cent starch value. The lighter in color that malt sprouts are, the more easily they are digested. In a general way they are a valuable concentrate feeding stuff for horses (up to 6 pounds), for fattening cattle and milk cows ( 2 to 4 pounds), for swine ( 1 to 2 pounds), for sheep ( $1 / 2$ to 1 pound). They should be soaked or scalded 
for cattle and swine and usually fed dry to horses. Large quantities are said to cause diarrhea, paresis of the paunch, and abortion in pregnant animals.

Malt sprouts attract and absorb moisture readily and are consequently subject to moldiness. Moldy malt sprouts have an injurious effect, cause yellow atrophy of the liver and even death. In the inspection of malt sprouts for quality, stress should be laid on the specific malty odor. The sprouts should be dry, light yellow, not dusty nor infected with fungi (moldy). Adulteration with sand and other mineral matter is easily detected by floating the material in water.

Brewers' grains contain the glumes, fruits and seed husks, most of the protein and fat and all the starch of the malt (barley grains) that has not been converted into sugar.

Wet brewers' grains contain on an average about 77 per cent of water, 3.5 per cent digestible protein, and have a starch value of 13 per cent. They spoil very easily (become sour, moldy, or decompose) which seriously affects their wholesomeness and their palatability. To preserve them they are frequently dried or ensilaged (pickled). Dry brewers' grains should have a light gray color and an aromatic odor. Dark color indicates overheating, which impairs digestibility, or it may be due to spoiled material. When stirred up with warm water they should have neither a sour nor a moldy odor. Dry brewers' grains contain 14 per cent digestible protein and have a starch value of 50 per cent.

The German and Dutch dried brewers' grains are made from pure barley malt. Brewers' grains imported from America usually contain, in addition, corn and rice refuse, while the Swedish product contains a considerable quantity of hulls. They are therefore more strawlike in nature.

Unspoiled, wet or dry brewers' grains are a palatable and wholesome feeding stuff. Wet brewers' grains are fed principally to milk cows and fattening cattle (20 to 40 pounds) and to swine (25 pounds per 1,000 pounds live weight). They are not suitable for sheep nor for horses doing heavy work. Horses do well on dry brewers' grains, however, 5 pounds of grains being given with 4 or 5 pounds of oats instead of a full ration of 10 pounds of oats. The dry grains are also good for milk cows and fattening cattle ( 6 pounds) and for fattening sheep (up to 1 pound). They are given dry or slightly moistened, mixed with chaffed feed or root crops. They are not so profitable for swine because the latter do not digest them as completely. The feeding of spoiled grains (moldy, sour, rancid) to horses has frequently been observed to result in serious poisoning, gastric catarrh, nephritis and cystitis. When rich in alcohol they may produce alcohol poisoning.

Spent hops are also occasionally used as a feeding stuff. When fresh they contain 25 per cent of dry matter. Their digestibility, however, is low on account of the tannic acid that is present. Their nutritive value corresponds to that of grain straw. Hops are wholesome and stimulate 
the digestive functions and the appetite. They are fed to milk cows and to fattening cattle. For horses they are mixed with molasses.

Beer yeast (Saccharomyces cerevisia) contains-

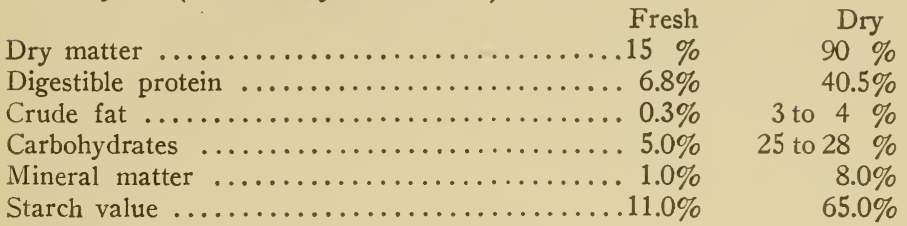

Yeast is one of the most protein-rich vegetable feeding stuffs available. Brewers' yeast has a bitter taste on account of the presence of hop resins. This bitterness is absent in "mineral yeast," which is cultivated in solutions of sulphate of ammonia and other salts and sugar. Cooking or steaming will remove this taste and at the same time kill the yeast fungus and destroy its enzymotic action (alcoholic fermentation and $\mathrm{CO}_{2}$ formation). Otherwise when fed in conjunction with sugar or other rich carbonaceous feeds the carbonic acid formation may be so active that fatal tympanitis results.

The thick gruel-like mass obtained by cooking yeast may be fed to horses, milk cows and fattening cattle, mixed with chaffed feed at the rate of 10 pounds per 1,000 pounds live weight. It should be first mixed with coarse-ground grain, bran or steamed potatoes. It must be fed strictly fresh because it spoils readily and may then cause dangerous poisoning.

In order to preserve yeast for any time the fresh material can be sterilized with steam, dried, and then fed in its pure state, in the form of meal slops or mixed with other feeding stuffs. Yeast is also put on the market in the form of yeast "zwieback," or beer yeastcake.

Dried "mineral yeast," on account of its rich protein content, is also adapted for young, pregnant and weak or "run-down" animals. The daily ration for calves and colts during the first year may be as high as 300 grams (three-fifths of a pound), for horses and cattle 1 pound, for pigs at 5 weeks of age $11 / 2$ ounces with weekly increases of about onethird of an ounce until the total amounts to 300 grams or three-fifths of a pound. Sheep may have two-fifths of a pound and laying hens 25 grams (five-sixths of an ounce).

\section{Distillery Waste or By-Products}

The by-products of distilleries consist of so-called distillery slop. The starchy raw material used in this industry (potatoes, corn, rice, etc.) are treated with malt (diastase) which converts the starch into sugar. The sugar is then fermented with yeast to produce alcohol and $\mathrm{CO}_{2}$. The final step consists of the separation of the alcohol by distillation. The residue is the so-called distillery slop or wash.

Potato "slop" contains 0.5 per cent of digestible protein, 2.5 per cent starch value, 0.6 per cent crude fiber, 0.7 per cent mineral matter, 0.1 
per cent free acetic acid and about an equal amount of lactic acid. These slops are very watery ( 96 per cent water) and are therefore very subject to decomposition.

Uses.-Distillery slops are fed to fattening cattle in quantities up to 15 gallons per day, milk cows and working oxen $7 \frac{1}{2}$ to $12 \frac{1}{2}$ gallons, fattening swine and sheep about 2 to 3 quarts. These slops are rarely fed to horses, except possibly to working horses at rest, 10 to 15 quarts per day. It is best not to feed these slops at all to young stock or to pregnant animals. When fed at all it is best to have them perfectly fresh and if possible still warm. Slops that have become cold should be reheated before feeding. Feeding troughs must be kept scrupulously clean, because any material that may be left decomposes rapidly and may then become injurious to health. On account of the acidity of slops and their deficiency in lime salts, from 1 to 2 ounces of prepared chalk should be added to the daily ration. In addition to this, care should be observed that sufficient roughage (10 to 12 pounds per day) is given, to counteract the debilitating effects of the slops on the digestive organs and to supply the proper amount of volume in dry matter.

Disadvantages.-Excessive quantities of slops, 25 to 35 gallons per day, have an unfavorable effect upon the milk secretion as well as on the quality of the meat and fat. In cattle they are frequent causes of indigestion, diarrhea, "slop cough" and eczema. In horses they cause colic, in pregnant animals abortion, and in sheep malignant jaundice.

"Slop eczema" is observed following liberal feeding of potato slop, raw potatoes, potato tops and waste products of starch factories. It is a moist form of eczema attacking chiefly the hind feet and legs below the hock (Johne). These objectionable features of slop feeding may easily be avoided by the conscientious observation of strict cleanliness and moderation in feeding. Serious disease has been observed to follow the feeding of slops that were made from spoiled, rotten, or badly sprouted potatoes. Slops rich in alcohol may cause serious and even fatal alcoholic poisoning.

Rye and corn slops are richer in organic matter (protein, fat and nitrogen-free extract) and contain less mineral matter than the foregoing. It is not advisable to feed more than $71 / 2$ to $121 / 2$ quarts of corn slop per day to milk cows, because larger quantities produce soft butter. The seeds of corn cockle, already referred to in the previous pages, are a frequent contamination of rye, and, when present, will exert their poisonous effects in the slops made from this grain.

Sugar Refinery slops have a bitter, acid taste and are not relished by animals. On account of their high salt content they are liable to cause diarrhea. These objections may be partly overcome, however, by digesting these slops with twice their volume of potatoes, the addition of prepared chalk and liberal quantities of roughage, hay or straw. Fattening cattle are really the only class of animals that should have this material.

To give them keeping qualities these various slops are sometimes 
dried ("dry slops"). According to the raw material and their method of preparation, the final products vary considerably. The amount of digestible protein varies between 13 and 15 per cent, starch value ranges betwen 54 and 61 per cent in corn slop. Their digestibility also varies greatly. Thus the digestive coefficient of the crude protein, as determined on sheep, ranges between 49 and 80 per cent, that of the nitrogen-free extract between 54 and 85 per cent, and of the crude fat between 92 and 94 per cent. The commercial dried slops are mainly those made from the grains. Dried rye slop is said to contain about 8 per cent of digestible protein and 41 per cent starch value, while potato slop (dried) contains about 9 per cent digestible protein and has a starch value of 31 per cent.

Quality.-Good dry slops, like dry brewers' grains, should be free from carbonized matter, have a fresh, aromatic odor like that of freshly baked bread, and when scalded with hot water should have neither a sour nor a moldy smell.

Adulterations of dry slops consist of rice hulls, peanut hulls, grain chaff, corn screenings, ground cornstalks, mineral matter like lime, etc.

The feeding of dry slops is conducted under the same rules and precautions as that of dry brewers' grains.

\section{By-Products of Wineries and Cider Presses}

The lees (husks or skins, etc.) of wineries, in wine countries, are fed to cattle ( 5 pounds), sheep and goats ( 1 pound) and swine ( $1 \mathrm{r} / 2$ pounds), raw, cooked or pickled (ensilaged). When fed in excessive quantities or with insufficient dry feed they may cause diarrheas and eczemas similar to those caused by distillery slops.

The grape seeds, when thoroughly dried, are a good feed for pigeons and when ground may also be used as feed for swine.

Apple and other fruit pomace is sometimes fed to swine, sheep, fattening cattle and working oxen, more rarely to young stock, but never to milk cows the milk of which is intended for the manufacture or Emmental cheese. According to Stutzer this material is hard to digest.

\section{Sugar Refinery By-Products}

The by-products of beet-sugar manufacture consist of (1) beet pulp and (2) molasses.

The chief phases of sugar manufacture are as follows:

The beets are thoroughly cleaned by washing and scrubbing with machinery, and reduced to pulp. The sugar is then removed from the latter by a process of leaching, pressing or centrifuging. The waste from these operations consists of the so-called beet pulp. The fluid product which contains the sugar in solution is then clarified by boiling and precipitation of the albuminous matter and treated with lime to precipitate organic substances (organic acids), filtered, and the excess lime removed with carbonic acid gas, then again filtered through animal (bone) charcoal, which also has a bleaching effect on the solution. The juice thus purified is evaporated in a vacuum until the proper consistency is attained, then run into crystallizing vats. The filtrate is still further evaporated and set aside to complete 
crystallization. The final filtrate is a noncrystallizable brown mass, syrup or molasses. This is subjected to the strontium process and the last traces of crystallizable sugar are extracted. This "molasses" is then either utilized as a feeding stuff or incinerated and worked for potash and calcium chlorid.

Beet pulp in its fresh state, after having been pressed to remove some of the water, is still a very watery material ( 85 to 90 per cent. It contains 0.6 per cent digestible protein, a starch value of 10.5 per cent, crude fiber 3 per cent and mineral matter 0.7 per cent. Beet pulp prepared according to Steffen is much richer in dry matter (30 per cent). It is the result or product of a special process of sugar manufacture in which only the "purer" portions of the beet juice are extracted.

Beet pulp ferments or decomposes very easily, and to overcome this disadvantage it may be ensilaged or dried.

Fresh or ensilaged beet pulp is fed chiefly to cattle. Milk cows receive 40 pounds per 1,000 pounds live weight, fattening cattle 60 to 80 pounds, fattening sheep and swine 60 pounds. Horses at rest, or under light work, may receive 20 to 40 pounds per head per day, but this is not a common practice. Beet pulp is not suitable for hardworking horses nor for young stock or pregnant animals. It must be fed with the greatest care, and it is usually best not to feed it at all to such animals. Milk cows should not receive larger quantities than indicated, especially not when the balance of the ration is deficient in protein and fat. Excessive quantities of beet pulp give rise to hard, white butter of inferior or bad taste, and the milk, if feed to young animals, often causes diarrhea. IVhen feeding wet beet pulp to ruminants care should be observed that a sufficient amount of dry matter (roughage) is provided.

Dry beet pulp, if fresh and properly stored, contains 10 to 11 per cent of water, 3.6 per cent digestible protein, and has a starch value of 52 per cent. It absorbs moisture readily and swells considerably in water. It should have a pleasant odor, be free from foreign admixtures and moldiness and have a grayish-brown color. Horses may have 4 to 5 pounds, milk cows 6 to 9 pounds, fattening cattle 10 to 15 pounds, working oxen 8 to 12 pounds, calves 1 to 4 pounds, per day and per head, administered with warm slops, diluted molasses or warm water. Swine may have $11 / 2$ to 3 pounds with skim milk, whey or diluted molasses, and sheep 3 to 4 pounds, dry. In addition lime and prosphates should be given. Injurious effects are not as liable to follow the feeding of dry beet pulp as when fresh or ensilaged pulp is fed. Dried beet pulp is sometimes made into bricks, to facilitate handling and improve keeping qualities. These should be thoroughly broken up before feeding and soaked for from 4 to 6 hours, otherwise they may lead to obstinate cases of choking.

Molasses is a viscous, dark brown mass with a characteristic odor and usually an alkaline reaction. If improperly made or preserved it readily sours. It contains a varying amount of water, on the average 22 per cent, and not over 32 per cent if unadulterated; 60 per cent nitrogen-free 
extract (sugar) and 7 per cent mineral matter. The crude protein, which is present to the extent of about 1.0 per cent, consists almost entirely of nitrogenous substances of a nonalbuminous nature (betain, glutamic acid, aspartic acid, leucin, ammonia, etc.). Thus molasses is poorer in albumen or digestible protein than any other feedingstuff. The mineral matter consists of potash 78 per cent, sodium 13 per cent, lime 0.3 per cent, magnesia 0.4 per cent, iron and phosphoric acid 0.7 per cent, sulphuric acid 1.6 per cent and chlorin 7.5 per cent. Its starch value is 48 per cent.

For feeding purposes molasses is diluted with sufficient warm water to make it readily miscible with other feedingstuffs, like chaffed feed, dry pulp, bran, etc. To avoid diarrhea the feeding of molasses should begin with minimum quantities, which may be gradually increased. An abundance of dry feed should always be given with it. Moderate quantities of molasses are very wholesome for horses; they reduce the number of cases of colic and moderate the course of the disease should it appear. It is therefore regarded as a good dietetic feed, but does not seem suitable to substitute for any large portion of the oat ration, especially for horses doing hard or fast work. Large rations of molasses should not be given in any case; they are liable to produce diarrhea and to overtax the kidneys. Excessive rations of molasses may also produce cutaneous exanthemas (grease), general weakness, paralytic symptoms and toxic laminitis. Proper quantities for horses are about 3 pounds per day, milk cows $2 \frac{1}{2}$ pounds, working oxen 3 to 4 pounds, fattening cattle and sheep 4 pounds, swine 5 pounds, per 1,000 pounds live weight. Molasses should be avoided for animals in advanced pregnancy on account of its reputed tendency to cause abortion. But the latter is probably the case only when the material is spoiled. It is not a regular occurrence at any rate (Albrecht). In stable-fed animals that suffer from the effects of alkaline earth deficiency, especially the salts of potassium, molasses has proved to be an actual curative agent.

To facilitate the handling of the product, dry molasses mixtures have been prepared. These consist of various kinds of pulps containing from 30 to 40 per cent of molasses, chaffed straw and 40 per cent of molasses, wheat bran and dried distillery slop with 50 per cent of molasses, corn germ meal and coconut cake with 60 per cent of molasses, brewers' grains with 50 to 60 per cent of molasses, palm seed cake with 60 to 70 per cent of molasses, etc. Voigt recommends palm-seed and cocoanut molasses feed as a substitute for oats and corn. This is cheaper than corn and only half the price of oats. Good results were obtained in feeding this mixture to omnibus horses. These molasses pulps are especially adapted for milk cows (soaked in three or four times their volume of water for 12 hours), as well as for horses. Swine do not like them so well. Peat has been used as an absorbent for molasses, but the former is entirely indigestible. It has also been used to prevent the intestinal absorption of the potash salts which are very abundant in 
molasses, but in this respect peat has no advantage over easily procurable digestible absorbents. Peat has a tendency to increase the keeping qualities of molasses, but oil cake, malt sprouts, brewers' grains, etc., have the same advantages. Ground straw and molasses (in the proportion of 1 to 3 ) also has good keeping qualities. Peat-meal molasses contains 80 per cent of molasses and has proved suitable or wholesome for horses, cattle, swine and calves.

The objection to peat-molasses which have just been enumerated apply also to the commercial "Klimaxmelasse," which is a compound of horsechestnut meal, twig meal and molasses. So-called pepton feed, which contains no peptone, is not much better. It consists of molasses, blood and the stomach contents of slaughtered animals. So-called milk-molasses contains about 50 per cent of molasses and the curd of skim milk, peanut shells, oat hulls, potato pulp and sometimes a little inferior bran. Blood-molasses consists of molasses, small amounts of dried blood, and peanut shells, millet-seed hulls, rice and oat hulls, which latter are all more or less indigestible.

So-called Hansa-blood-molasses contains, according to Zellner, 18 per cent protein and fat and 20 per cent sugar. "Cibus" is the trade name of a mixture of molasses and converted cellulose. "Tumelin" is a mixture of beet-sugar molasses and cornstalks with an addition of linseed meal and phosphate of lime. "Tutolin" contains cornstalks, salt, phosphate of lime and, for the greater part, molasses. Molasses cakes consist of potato pulp, rye bran and molasses.

Valuation.-In feeding molasses mixtures the molasses content and the character and wholesomeness of the absorbents must be taken into consideration. Compounds of which the absorbents are unknown should be avoided. Their cost is frequently out of all proportion to their real value. Very frequently good money is expended for peanut and millet hulls, potato peelings, rice chaff, ground fruit pits, sawdust, etc.; in a word, refuse, that no one with good sense would pick up from the street to use as feed for his cattle (Kellner). Not only entirely worthless but very frequently spoiled and injurious substances are mixed with molasses and sold to the unsuspecting consumer. It is necessary that every purchase of mixtures of this character be examined as to the nature of its contents and that a guaranty of the composition, protein, fat, sugar and water accompany the same. The water content is of importance because upon it depend the keeping qualities of the mixture. In peatmolasses the water content should not exceed 25 per cent and in other molasses mixtures 20 per cent. The objectionable features of these mixtures may be overcome by purchasing the pure molasses and making home mixtures, or by various club arrangements. A saving of actual money is also accomplished by such procedure.

"Roborin concentrate feed" is another molasses mixture that should be mentioned here. It contains, besides 9 per cent of sugar, a limeblood-albumen preparation ( 47 per cent albumen, 12 per cent mineral 
matter, including phosphate of lime) as principle constituent. It is generally considered wholesome and nutritious for horses and milk cows. Unfortunately it is relatively high priced.

Disadvantages.- Sickness has often been observed following the feeding of molasses and beet pulp, especially in oxen and horses. This has sometimes been referred to as beet-pulp disease. The symptoms manifest themselves as indigestion, lumbar weakness, cerebral disturbances, edema of the lower portions of the limbs, hemaglobinuria, intestinal paralysis, colic, skin eruptions, laminitis, etc. Postmortem examination reveals dropsical conditions and erosions and ulcers of the abomasum (?). These affections are particularly to be feared when slops and insufficient dry roughage are fed with excessive rations of molasses. To what extent the high potash content of molasses may be responsible for these conditions is yet to be determined. At any rate, these objections may easily be avoided by care in mixing and adjusting the rations.

$\mathrm{H}$. and C. Stolzenberg succeeded in obtaining alcoholic extracts of substances with a nauseous taste which, injected into guinea-pigs, produced weakness, dullness and loss of hair.

"Feed sugar," that is, sugar contaminated with molasses, has been found to serve as a good feed for horses, 5 pounds for 800 pounds live weight. The transition to this character of feed should be gradual. Increased consumption of water is not to be feared. This material is also a good feed for swine, less so for fattening cattle and sheep, but, according to Malpeaux, excellent for the latter. Its frequently reported injurious effects are not based upon fact.

According to Kellner it would seem to be of advantage to displace the manufacture of sugar feed with the manufacture of beet pulp according to the Steffen process.

\section{Starch Factory By-Products}

Starch factory by-products, important as feeding stuffs, are the following: (1) Of potatoes, potato pulp or fiber; (2) of wheat, spent grains, slop or wash and gluten; (3) of rice, rice slop or wash and gluten; (4) of corn, corn germ, corn oil and corn glucose cake.

Potato pulp is the residue that remains after the starch has been removed (washed) from the crushed potatoes. It contains the peel or skin, fiber and part of the starch, and constitutes a very insiped and watery feeding stuff. When fresh it contains from 3 to 10 per cent of dry matter, which percentage is increased to 25 or 30 after the "surplus" water has been expressed, and to 86 per cent when subsequently dried. Of the dry matter about 50 to 60 per cent represents starch, 3 to 5 per cent crude protein, ( 0 per cent digestible albumen), 0.1 per cent crude fat and from 10 to 12 per cent fiber.

Fresh potato pulp, which is very watery, is subject to rapid decomposition. It must therefore be fed as fresh as possible, or dried or ensilaged. 
Fattening cattle receive up to 60 pounds of fresh potato pulp, milk cows 40 to 50 pounds, swine up to 20 pounds, per head per day. Scalding, cooking or steaming, especially for swine, is advisable. Large rations are liable to produce gastro intestinal catarrhs, diarrheas, and milk of poor quality.

The feeding of spoiled potato pulp has been known to produce serious disease. Dried and ground potato pulp may be fed to horses and fattening cattle in quantities of from 5 to 7 pounds per head per day, milk cows 4 pounds.

In the manufacture of wheat starch, the broken grains are subjected to a process of fermentation, the starch and small grain particles are removed by a process of washing, and the so-called spent grains remain as refuse. The latter contains the hulls or skins, germs and gluten. The residue from the washing of the crude starch consists of slop or wash that is very rich in gluten and starch. In the more modern processes of starch manufacture wheat flour, instead of the whole grain, is used. The flour is washed and "worked" through screens. The residue is a pure, sweet gluten.

All of these by-products are rich in water and spoil readily. They are characterized by their high protein and fat content and, unless spoiled, constitute a good feedingstuff for fattening cattle, milk cows and swine. To preserve the gluten it is dried. This very expensive gluten, extracted from wheat flour, and corn and rice gluten, are the feeding stuffs richest in protein at our disposal (76 per cent protein).

Rice wash and rice gluten (the latter is also dried) correspond in a general way to the by-products of the manufacture of wheat starch of the same name.

Corn germ cake and corn oil cake contain the germs, skins, gluten and starch waste. Corn glucose cake or "Maizena" contains the skins and more or less gluten. Gluten meal consists chiefly of gluten and a few skins. Corn germ cakes contain 14 per cent of digestible albumen, a starch value of 72 per cent, fat 7 to 11 per cent. Maizene contains 21 per cent of digestible albumen and 3 per cent of fat. Corn gluten meal contains 32 per cent digestible albumen and 2 per cent of fat. The nutrients are easily digestible, but more suitable for the production of fat than of energy, and when fed in large quantities produce soft butter and soft bacon. They are well suited for fattening cattle and are used to some extent for feeding milk cows and young stock.

\section{By-Products of Oil Production}

Vegetable oils and fats are obtained from the seeds of plants rich in these substances. They are extracted by subjection to repeated hydraulic pressure, the seeds being placed in specially constructed fabric bags, or the fats and oils dissolved Irom the previously cleaned, hulled and broken seeds (sometimes at high temperatures, $90^{\circ}$ to $100^{\circ}$ C.). Sometimes the material is subjected to both processes. The extract solvents used are carbon disulphid, petroleum ether, benzine, carbon tetrachlorid, and other volatile solvents of oils and fats. The oil-containing seeds are thus deprived of their oily and fatty parts only, the other nutrients being retained, practically unchanged and easily digestible. 
The refuse of these processes consists of oil cake or cake meal and extract meal.

Digestibility and wholesomeness.-Vegetable oil by-products are rich in fat and protein and highly digestible ( 80 to 90 per cent). The digestibility of the nitrogen-free extract and crude fiber varies considerably according to the amount of hulls and skins present. Since these byproducts have a weakening effect upon the digestive organs and not infrequently cause diarrhea, they should be supplemented with salt or with feedingstuffs containing this mineral.

Disadvantages.-When improperly stored, the by-products in question, especially when they contain approximately 20 per cent of water (normal 10 to 12 per cent), are liable to become rancid or moldy or to decompose through the activity of bacteria. Thus fed, they are liable to disturb the health, to a slight or to a very serious extent, or even to cause fatal disease.

Valuation.-Oil cakes are considerably richer in fats than the meals obtained from extract processes. The latter are often put on the market under the misleading name of oil-cake meal. The guaranties on these products are often given in general or common terms for the protein and fat, which is intended to give the impression that the material in question is a press product, not an extract product, and consequently rich in oil.

In addition to fraudulent practices of the character just enumerated, the by-products of vegetable oil manufacture are frequently adulterated with the seeds of worthless weeds, hulls, shells, peelings, and with other low-grade oil cakes and oil meals, or even mineral matters. The greatest care should therefore be observed in the purchase of these materials and a guaranty of the exact content of protein and fat required, as well as a guaranty of purity and soundness. In addition, the guaranty should be controlled by a state institution that makes it its business to verify the same, upon request. (In reference to detection of adulterations, see special chapter.)

Uses.-Oil factory by-products are used chiefly as fattening feeds (meat and fat production) and for milk cows. In order, however, not to sacrifice quality for quantity, in the resulting products, moderation in feeding these materials must be observed. The maximum daily rations for milk cows should not exceed 3 pounds, fattening cattle 6 pounds, fattening sheep $11 / 2$ pounds, fattening swine 2 pounds. Working oxen may have as much as 4 pounds, and calves 3 months of age, up to 1 pound. At the finishing stages these amounts must be reduced. As a source of energy for working animals these feeding stuffs are less suitable. They should be fed only sparingly to horses. They should be fed in the form of crushed cakes or ground meal to horses, sheep and cattle. It is best to feed the crushed cakes dry, with other feeds. When given in the meal form they are usually moistened with a little water immediately before feeding. It is frequently pointed out, however, that 
these meals are digested better if fed in the dry state. For pigs these materials are usually scalded or boiled before feeding.

The most important by-products of oil manufacture are the following:

Linseed by-products.-From the seeds of common flax, Limum usitatissium. This has the advantage over other oil by-products in that it swells in water and forms a larger amount of gelatinous material which is so important from a dietetic point of view. If the seeds have been steamed this property is destroyed.

Linseed cake, which is put on the market in the form of round slabs, has a dirty greenish brown color and a characteristic linseed odor. It contains from 30 to 33 per cent of crude protein, of which 27 per cent is digestible albumen; 8 per cent fat, and a starch value of 72 per cent. The linseed meals which have a more dark-green color contain 35 per cent crude protein, of which 31 per cent is digestible albumen; 3 to 4 per cent of fat, and a starch value of 65 per cent. Both forms are nearly free from starch. If the iodin test produces a pronounced reaction it points to adulteration with starchy matter (weed seeds, etc.).

Linseed by-products are frequently contaminated with all kinds of seeds and earth particles, and owing to their high price, are frequently adulterated with screenings, charlock, dodder, hempseed or with other oil cake of inferior value or quality, like rape, poppy, castor bean, mustard, etc., or hulls of peanuts; cottonseed, cocoanut shells, spoiled feed meals made from the grains, mineral matter, etc. These adulterations of course affect their chemical composition, their dietetic value and even their wholesomeness. In a case reported by Dahl linseed cake contained 2 per cent of carbonate of lead and caused the death or required the slaughter of 10 cows and a calf. Mere ocular inspection is not sufficient to detect these adulterants. For particulars see the chapter on the detection of adulterants.

The linseed by-products are fed chiefly as dietetic substances to animals that are in a weak or run-down condition and to young stock during the weaning period. They are usually too expensive to be used as a regular part of the rations for milk-producing, fattening or working animals. If given in small amounts, 1 pound per day, they constitute an excellent feed for milk cows. Quantities in excess of 2 to 4 pounds daily for milk or fattening cattle should, however, be avoided, on account of the unfavorable effect of large rations on the quality of the milk and meat products. Linseed by-products are usually fed ground and wet or made into gruels or broths.

Rapeseed and turnip-secd cake.-The seeds of Brassica napus and B. rapa. Rape seeds have a dark brown color, turnip seeds a brown color and not as smooth a surface as the former. Rape cake has a strong, onionlike, pleasant odor, and a greenish yellow color which becomes more grayish yellow with age. That which has been subjected to the action 
of higher temperatures has a darker background from which the brownish black broken seed coats stand out in relief.

Chemically, rape cake consists of crude protein 28 to 34 per cent, of which 23 per cent is digestible albumen; from 8 to 10 per cent crude fat, 7.2 per cent mineral matter, and 11.5 per cent water. The starch value is 61 per cent. This by-product contains also two glucosids, sinigrin and sinalbin. These substances, under the influence of moisture and the action of a ferment, myrosin, produce the volatile allyl mustard oil. Heating to $100^{\circ} \mathrm{C}$., as well as the conditions existing in the paunch of ruminants, destroys the power of myrosin to split glucosids. To prevent the formation of oil of mustard, these by-products should be fed in the dry state. The amount of oil of mustard and other volatile oils and injurious substances formed depends on climatic conditions under which growth took place, methods of extracting the oil, duration of storage, and the action of fungi and bacteria. A number of phenomena in this connection require further investigation for their explanation. The native German rape and turnip seeds, fed in moderate amounts, have no toxic effect. Unfavorable effects are observed chiefly from the feeding of Indian rape and mustard seed, rich in mustard oil, (0.56 per cent). When fed in amounts not exceeding 3 pounds they have produced gastro-enteritis, nephritis, abortion, cerebritis (sheep), milk of bad odor, serious effects on calves, and death.

Rape and turnip seed cake is frequently contaminated (or adulterated) with weed seeds, charlock, field mustard, corn cockle, knotgrass, notch weed (Atriplex), etc., other oil cake of inferior grade (mustard seed cake, recognized by the strong mustard odor), plant refuse, sand and earth, etc., etc.

Milk cows should receive not over 2 pounds per day, to prevent bitterness and softness of the butter. Fattening cattle and working oxen take 4 pounds, sheep one-third of a pound and swine not more than one-half of a pound. Larger quantities produce greasy bacon and soft meat. It should not be fed to young stock because it is liable to cause diarrhea. Rape and turnip seed by-products have a bitter taste and are not liked well by animals, which must be accustomed to them gradually.

Palmseed cake.-From the oil palm, Elaeis guineensis. 'The ground color of these by-products is whitish gray, with the dark broken seed coats showing in relief. Their taste is indifferent and their odor resembles that of tub butter. The meal is not readily miscible with water. Under the influence of moisture or after long storage they are apt to become rancid. The various commercial grades are designated according to the countries where they originate. Adulteration of the cakes seems to be relatively rare. The meals are of course more subject to adulteration.

Palm-oil cake is usually sold under a guaranty of its contents or composition-16 to 18 per cent crude protein and 6 to 8 per cent of fat. The crude fiber, which is present to the extent of from 25 to 35 per 
cent, is highly digestible. The digestible albumen content is 13 per cent, starch value of the cake 70 per cent, and of the extract by-product 66 per cent. These by-products are wholesome, but animals must become accustomed to them before eating them readily. They are fed chiefly to milk cows, 4 pounds daily per head. They increase the fat content of milk and give a firm consistency, a pleasing yellowish-white color and an agreeable taste to the butter. On account of their high price they are usually not fed to fattening cattle.

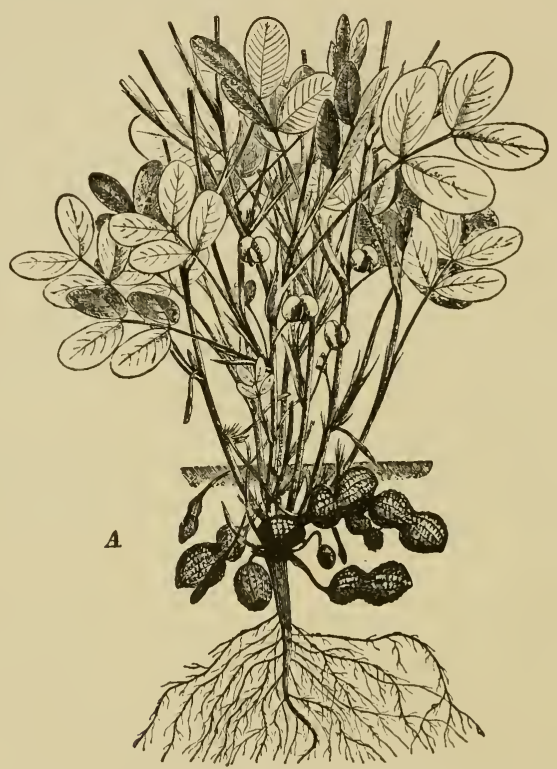

Fig. 50. Peanut. $A$, fruit, developed under ground. (Taubert.)

Peanut by-products.-Origin: Peanut, Arachis hypogea, an annual, tropical, herbaceous Papilionaceæ. Peanuts ( 1.5 to 3.5 by 1 to $1.5 \mathrm{~cm}$.) have a brownish white coriaceous, veined, almost indigestible, hull and two seed kernels about the size of a hazlenut and inclosed in a brownish red, brittle seed coat. The latter is frequently removed and ground and in this form is known in commerce as bran. It contains over 40 per cent of crude fiber and is therefore a feeding stuff of very doubtful value.

Shelled peanuts spoil readily, especially during ocean transportation. The peanut by-products made in Europe are therefore more valuable than those that have been transported over long sea routes and have become rancid or moldy en route. 
High-grade by-products should have a light whitish-gray ground color sprinkled with the reddish particles of broken seed coats. Spoiled material has a yellowish or brownish color and a sharp, moldy, rancid taste and smell, while the odor of the fresh material resembles that of beans.

The better grades of peanut by-products ${ }^{15}$ contain 48 per cent of crude protein (of which 39 to 45 per cent is digestible albumen), 8 per cent crude fat, 5 per cent crude fiber and 1 per cent sand in the so-called German product, while the Marseilles peanut cake and meal usually contain from 2 to 3 per cent of sand. The starch value varies between 76 and 77.5 per cent.

High-grade peanut cake is wholesome and has a high digestive coefficient. Decomposed or rancid material, however, has frequently been observed to have caused violent poisoning with symptoms of digestive disorders and paralysis. In the case of peanut by-products, special stress should be put on the importance of fresh, uncontaminated material.

Adulterations usually consist of peanut hulls and seed coats (socalled peanut hull meal, a greenish powder, hardly of equal value to straw), poppy seeds, niger seeds, castor beans, mustard, rapeseed byproducts, rice hulls, various kinds of seed skins, grain screenings, etc.

Peanut meal or cake is fed in daily quantities not exceeding 4 pounds to milk cows and fattening cattle, 3 pounds for horses (as substitute for 6 to 8 pounds of oats), and not to exceed 1 to 1.5 pounds for sheep and fattening swine. Smaller quantities may be fed as supplementary feeds to young stock.

Cotton seed by-products.-Origin: Several species of cotton, belonging to the Malvaceæ, Gossypium arboreum, G. barbadense, G. herbaceum, G. hirsutum, G. peruvianum, G. religiosum. (Fig. 51.)

Cottonseed is surrounded by a feltwork of cotton fiber which is intimately united with the seed coat. After removal of the cotton, which consists of filaments varying in length from 1 to $4 \mathrm{~cm}$. and shorter ones varying in length from 0.5 to $3 \mathrm{~cm}$., there remains the naked oval seed, about the size of a pea, consisting of a brittle, blackish brown seed coat and a loosely inclosed oily seed kernel. The nutritive value of cottonseed hulls is about the same as that of wheat chaff. American cottonseed meal containing the hulls is usually coarse in character and unevenly mixed with cotton fiber. In Germany these fibers are removed and the meal is reground and put on the market as "German doublescreened and defibrinated meal."

Cottonseed oil is derived from the whole or the decorticated cotton seeds, either by means of hydraulic pressure or extracting (dissolving) fluids. The cake from the whole seeds has a greenish yellow ground

\footnotetext{
15But little peanut meal is sold in the United States and that which is sold is chiefly from unhulled nuts, containing about 28 per cent crude protein and 23 per cent fiber. (Henry and Morrison, Feeds and Feeding-1916.)-Translator.
} 
color, in which the broken seed coats are visible. The cake made from decorticated seed has a uniform light yellow color, nut-like taste and agreeable odor. A darker shade of color frequently indicates old, overheated or poorly stored material.

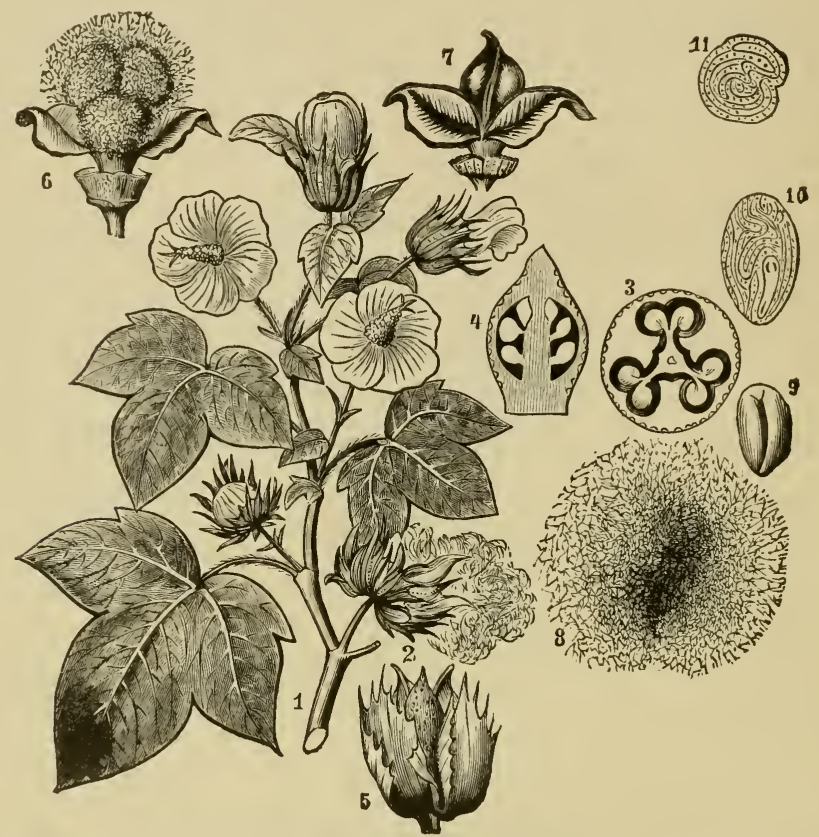

Fig, 51. Cotton plant. 1, Branch with flowers and ripe fruit (2); 3, cross section of fruit pod or boll; 4 , longitudinal section of same; 5 , boll with calyx; 6 , open ripe fruit pod, with three woolly seeds; 7 , empty capsule; 8 , seed surrounded with cotton fibers; 9 , seed with cotton fibers removed; 10 , longitudinal section of seed; 11 , cross section of seed.

Whole cottonseed meal (American) contains 25 per cent crude protein, of which 17 per cent consists of digestible albumen; 6 to 8 per cent fat (no starch-important in detecting adulterations), a starch value of 39 per cent, and 7 per cent of mineral matter. The by-products of decorticated seed are usually accompanied by a guaranty of 46 per cent of crude protein and 10 per cent of fat. The latter is characterized by its high digestive coefficient (98 per cent) and gives excellent results when fed to fattening animals and milk cows. The digestible albumen content is 39 per cent and the starch value 73 per cent.

The feeding of cottonseed by-products has frequently been followed by serious poisoning in calves, young stock, and also in mature animals, 
with symptoms of diarrhea, bloody urine, gastroenteric catarrh, often of a hemorrhagic nature, nephritis, abortion, etc. Postmortem examinations usually reveal hemorrhages in the mesentery, intestines and kidneys, ascites, cloudy swelling of the heart, liver and kidneys and cardiac paralysis.

The harmful principle in cottonseed has not been definitely determined

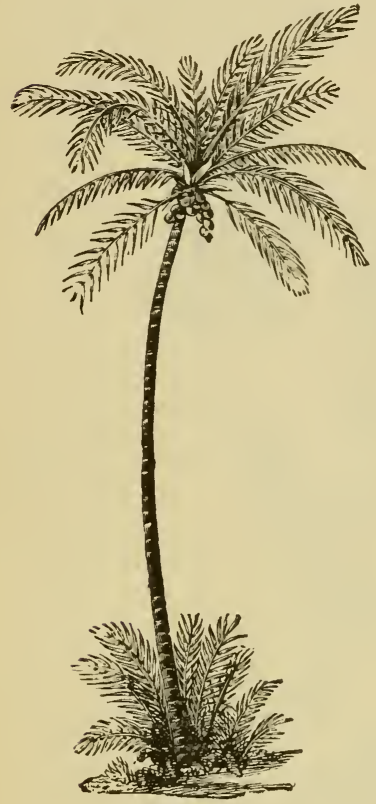

Fig. 52. Cocoanut palm.

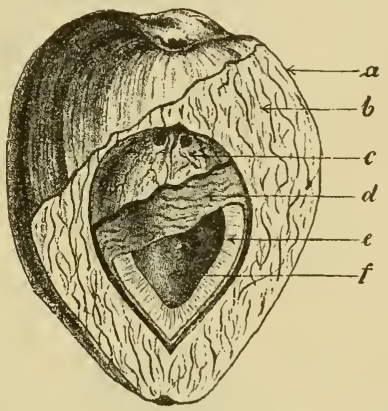

Fig. 53. Cocoa nut. $a$, Outer fruit covering; $b$, fibrous cnvelope; $c$, inner fruit shell; $d$, seed shell; $e$, endosperm of the seed proper; $f$, cavity, filled with "milk" when fresh.

but in all probability this is of the nature of bacterial products (p. 147). Prolonged heating destroys the toxic substance.

Cornevin succeeded in extracting the toxic principle with water and killing dogs with subcutaneous injections. Symptoms, diarrhea and loss of consciousness. Withers and Carruth extracted gossypol with ether after the seeds had been decorticated and the fat removed with gasoline. Gossypol killed guinea-pigs when injected intraperitoneally. Since young stock and pigs are more sensitive to the effects of the toxic principle in cottonseed, the latter is usually withheld from them. Furthermore, these products are unsuited for pregnant animals and those that are suckling their young. 
Formerly, aspiration of the too abundantly present fibers caused disease of the lungs and bronchi, and pieces of wire from the cotton gins have caused internal injuries. To avoid accidents of this nature, cottonseed by-products, unless they are dependable wares, should be carefully screened and, if necessary, moistened before feeding.

The daily ration of cottonseed by-products for milk cows and horses should not exceed 2 pounds, for working oxen, .4 pounds, fattening cattle up to 5 pounds, and sheep two-thirds of a pounds. If fed in the

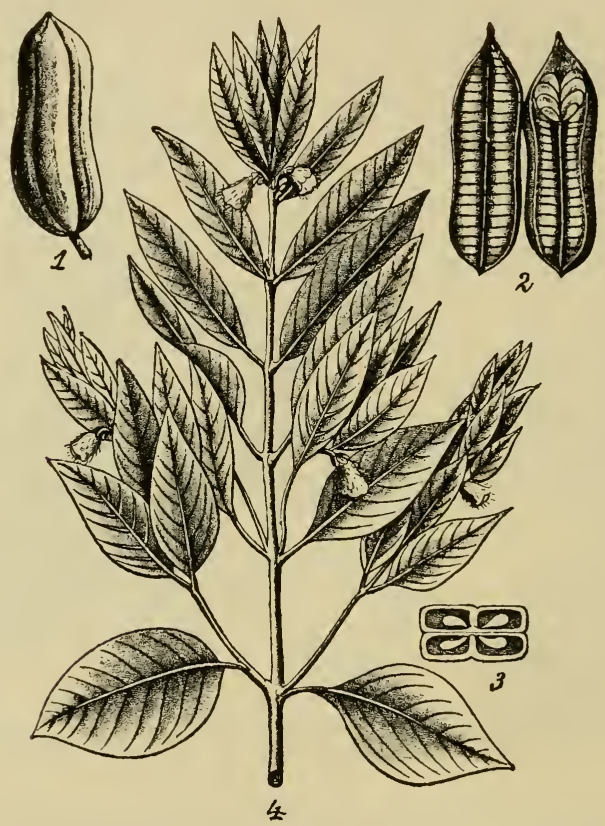

Fig. 54. Sesame. 1, Closed fruit capsule; 2, open fruit capsule; 3, cross section of fruit capsule.

quantities indicated they do not affect the milk or butter unfavorably. Larger quantities, however, produce a dry, hard and colorless butter.

Cocoanut by-products.-Origin: Cocoanut palm, Cocos nucifera, Fig. 52. The cocoanut is enclosed by an outer fruit covering (Fig. 53,a), within which are the fibrous envelope, $b$, which is used as material for making mats, the inner fruit shell, $c$, from which are manufactured buttons, trinkets, etc. and the seed (copra, $e$ ), which furnishes the cocoanut oil. The by-products serve as feeding stuffs. 
The interior of the seed, when fresh, is filled with "milk," which is used as an article of diet for human beings.

Cocoanut by-products have a light brown to reddish color and a taste and odor resembling those of the hazlenut. After prolonged storage they easily become rancid and brittle or crumbly and then have a scratchy unpleasant taste.

They contain about 18 to 24 per cent of crude protein. The cake contains 16.3 per cent of digestible albumen and 10 to 12 per cent of fat with a high melting point. The starch value of the cake is 76.5 per cent.

They are used in the same manner as the palmseed by-products already discussed. Spoiled cocoanut cake, like all decomposed oil byproducts, will cause poisoning. Cocoanut by-products are used mainly as feed for milk cows, about 4 pounds per head per day.

Sesame by-products.-Origin: Sesamum indicum, resembling fox glove in appearance (Fig. 54).

Fresh cakes have a light yellowish or light green color and pleasant taste and are odorless. They become rancid and moldy very easily and should therefore be stored with great care. They are characterized by their high content of phosphoric acid. The cake is usually guaranteed to contain 42 per cent of crude protein and 8 per cent of fat. The digestible albumen content is about 35.5 per cent and the starch value 79 per cent.

Animals like the cakes, and as a rule they are wholesome and agree well with them. Fed in large quantity they impart a soft character to the butter. Daily rations are the same as those given for peanut byproducts. According to Hansson and others, they increase the quantity of the milk yielded but reduce the percentage of fat.

Poisoning has also been repeatedly observed following feeding on sesame cake. Thus, Deyerling reported an instance in which 111 head of cattle showed symptoms of poisoning fifteen minutes after feeding on sesame cake. The symptoms were cough, depression, trembling, salivation, tympanitis and fever. Recovery set in one and a half hours later.

Sunflower seed cake.-Origin: Sunflower, Helianthus annuus. This usually contains a large percentage of seed hulls (10 to 15 per cent) and foreign admixtures, weed seeds, earth particles, etc. It is usually guaranteed to contain 38 per cent of crude protein and 12 per cent of fat with a rather low melting point. The digestibility of this material is about the same as that of other oil seed by-products made from the whole seed. Sunflower seed cake is characterized by its good keeping qualities.

Poppy seed by-products.-Origin: Poppy, Papaver somniferum. This product is whitish gray, yellowish red, dark brown, dark blue or black in color and has poor keeping qualities. It contains 35 per cent of crude protein, of which 26.5 per cent is digestible albumen, and 12 per cent crude fat. The starch value is 66 per cent. Narcotic principles occur 
in ripe seed to the extent of mere traces at the most, but are present in much larger quantities in unripe milky seed and seed capsules and may gain entrance into the by-products through the medium of these. For these reasons the feeding of poppy seed by-products is usually avoided in the case of horses, young stock, pregnant cows or cows suckling their young, and confined to fattening cattle, sheep and swine. Milk cows take 2 pounds, but only under the condition that the milk product is not sold as food for children or infants. The use of poppy seed by-products is frequently condemned for its effects on the milk (fat, taste, color, etc.).

Hempseed cake.-Origin: By-product of the seed of hemp, Cannabis sativa. It contains on the average 30 per cent of crude protein, of which 22.5 per cent is digestible albumen, and 10 per cent of fat. Its starch value is 45 per cent. It is frequently contaminated with stems, leaves and particles of earth. Feeding this material has been followed by narcotic effects, congestion of the brain, diarrhea and abortion. The feeding of very moldy cake has been known to cause derangements of the central nervous system (difficulties of mastication and deglutition, paralysis of the tongue, paraplegia and even death). Postmortem findings, negative. Hemp cake is much used in the eastern provinces of Prussia as horse and cattle feed, especially for adult male animals. Work horses receive up to 3 pounds, fattening cattle 3 to 5 pounds, fattening sheep 1 pound, milk cows 1 pound. When it is fed in large quantities the quality of the butter suffers.

Soy-bean cake. Origin: Soy-bean, Soja hispida. It is characterized by its exceptionally rich portein content ( 45 per cent crude protein, of which 38 per cent is digestible albumen) and high digestive coefficient. Milk cows may be given 3 pounds, fattening cattle and working oxen 4 pounds, horses 3 pounds, fattening sheep and stock hogs 1 pound, and smaller quantities for young stock.

Beechnut cake.-Origin: Beech, Fagus sylvatica. Like beechnuts, this product is very liable to cause poisoning in horses (see page 97). For this reason it is avoided as a feed for horses.

Madia cake.-Origin: Madia sativa, an American Compositæ. It is liable to contain narcotic substances and is therefore used only as feed for fattening cattle, in moderation.

Camelina cake.-Origin: Camelina sativa, false flax, a member of the Cruciferæ. This product is frequently contaminated with rape and mustard seed. It is not very palatable and has an onion-like or mustardlike odor, which affects the taste of the milk and meat of animals feeding upon it. Camelina cake is also reputed to cause abortion.

Candle-nut cake.-Origin: Aleurites triloba, a euphorbiaceous shrub, native of some of the Pacific Islands. The oil has many uses. It is said also to have a laxative action.

Castor oil bean cake.-Origin: Ricinus communis, castor oil bean plant, Euphorbiaceæ. The toxic principle in this cake is destroyed by sub- 
jecting the cakes to a high temperature. If this precaution is not taken, serious poisoning results. Symptoms, gastrointestinal inflammation, violent diarrhea, paralysis, swelling and dark red discoloration of the conjunctiva, accelerated and weak pulse, nephritis, cloudy swelling of the liver, due to the toxic principle, ricin. According to Bierbaum, 0.4 grams of castor oil beans, and according to Miessner 0.1 gram of castor oil beans in a single dose, or consecutive daily doses of 0.05 grams per 1 kilogram (2 pounds) live weight, for several days, are fatal to horses. Bierbaum fed 204.5 grams of castor oil beans in the course of 26 days, and 240 grams in the course of 45 days, to horses. In the latter instance there followed considerable loss of weight but no other observable symptoms. Rabbits die after consuming 0.75 to 1.0 gram of castor oil bean seed per kilogram live weight. On the other hand, Miessner found that a single dose of from 30 to 50 grams will kill a horse. Sometimes other oil-cake products are adulterated with castor oil seed cake that has not been deprived of its toxic principle. For the detection of castor oil bean by-products, see page 135 .

Almond-seed cake is a very palatable and wholesome feedingstuff for milk cows.

Mustard seed cake.-Origin: Species of mustard, Sinapis nigra, S. alba and $S$. arvensis. Not suitable as a feedingstuff for domestic animals.

Cocoa oil cakes are used as feed for milk cows and swine, rarely for horses. According to Hansen, they contain $1 \frac{1}{2}$ per cent theobromin. They are readily eaten and digested when given in small amounts. In quantities as high as 2 pounds they may produce poisoning in swine, cattle and poultry. Symptoms, exhaustion, swaying of the hind parts, general spasms, death from cardiac paralysis.

They contain, further, 14 per cent of crude protein, which is entirely indigestible. Cocoa cakes decrease the milk secretion to the extent of 1 quart per day and decrease the percentage of fat $1 / 4$ per cent.

Niger cake.-Origin: Ramtil, Guizotia abyssinica is wholesome, but contains a large per cent of woody cellulose and is therefore less digestible and of less value than other oil cakes. Milk cows and fattening sheep may take 10 pounds per 1,000 pounds live weight.

Pumpkin-seed cake.-Origin: Pumpkin seed, Cucurbita pepo. Made from hulled seeds. Wholesome and nutritious.

Kapok and olive cake.-Their value, etc., has not yet been demonstrated.

The by-products of caraway, fennel, anise and coriander seed, which occur in the distillation of their volatile oils, contain in entirety the original fats and oils and are suitable as feed for fattening cattle and milk cows.

Mahwa nut oil cake.-Origin: Bassia longifolia and B. latifolia, natives of Borneo, India, Senegal, etc. The seeds produce a fixed oil. Ramm and Moeller recommend the "cake" for milk cows. It contains little protein but is rich in fat and carbohydrates. 


\section{Feeding Stuffs of Animal Origin}

The principal feeding stuffs of animal origin are:

1. Milk and the by-products of creameries, butter-making and cheesemaking (skim milk, buttermilk, whey).

2. Preparations from meat, blood, bones, or the entire carcasses of animals.

\section{Milk and Its By-Products}

Milk.-The nutrients in milk (albumen 3.5 per cent, fat 3.5 per cent, sugar 4.5 per cent and salts 0.75 per cent) are almost completely digested by suckling animals. Digestive coefficient, 98 per cent.

Whole milk is used as food for newborn animals or to supplement the milk supply of the mother when necessary. It should be fed at the temperature of the mother's blood. Sour or otherwise spoiled milk usually does not agree with young animals. Older calves, or swine, however, may do well on it.

Hygienic requirements are that the milk originate from healthy animals, be produced under sanitary conditions and properly kept.

Skim milk differs from whole milk chiefly in the practical absence of fat ( 0.1 per cent or more) which reduces its value 50 per cent. The addition of sugar, starch or fat (linseed meal, etc.) or other carbohydrates tends to replace this loss.

Skim milk is used as a food chiefly for young stock after six weeks of age. It should be given as fresh as possible and at a temperature of freshly drawn milk. It is good for fattening calves, lambs and swine. It is rarely used for colts or given to milk cows ( 5 to 8 quarts for the latter). While animals, under certain conditions, thrive upon sour milk, it is not advisable to let milk sour purposely before feeding it, since the process of sour fermentation is attended with breaking down of the sugar and consequent loss of food value.

To prevent transmission of infectious diseases, such as tuberculosis, foot-and-mouth disease, etc., skim milk should be boiled or pasteurized before feeding. The pasteurization of creamery skim milk should be required by law. Skim milk from creameries and skimming stations should always be regarded with suspicion, since it is a fruitful source of alimentary tuberculosis of swine. The enforcement of laws requiring the pasteurization of skim milk before it is offered for sale has resulted in the practical extermination of feeding tuberculosis of swine in Denmark. A similar law is in force throughout Germany. Bang has pronounced the Danish regulation, as the best veterinary sanitary police measure that has been adopted in Denmark in the last ten years. The slimy residue obtained from cream separators frequently contains the germs of disease, tubercle bacilli, and should therefore not be used for feeding but rather destroyed by burning or burial. (This is prescribed by law for German creameries.)

Skim milk as well as whole milk should come from healthy animals, be produced under sanitary conditions, and be properly kept or preserved. 
Buttermilk either has the character of sweet skim milk containing about 0.5 per cent of fat, and in that case may be used for like purposes, or it is more or less sour. When of the latter character it is used, mixed with coarsely ground grain or potatoes, for fattening swine.

It is said that calves and pigs do not thrive on a certain sour buttermilk product which has recently been imported from Holland on a rather large scale as food for infants. It causes diarrhea in calves and pigs and should be boiled before feeding and fed sparingly if at all.

Whey.-There are sweet and sour wheys. The former are obtained by treating sweet milk with rennet to separate the casein, which also includes most of the fat. The latter are obtained from the separation of the casein from sour milk. Whey contains from 4.5 to 7.5 per cent of dry matter, 1 per cent albumen, 0.2 to 1.3 per cent of fat. The sweet wheys contain, in addition, about 4.5 per cent of milk sugar, while the sour wheys contain only a fraction of this amount. Most of the sugar in sour whey has been lost by conversion into lactic acid by bacterial action. Wheys have about one-half the feeding value of skim milk or one-quarter that of whole milk. The starch value of sweet whey is 6.4 per cent, while that of sour whey is only 5 per cent.

Wheys are fed chiefly to swine, boiled and mixed with other feeding material; more rarely to fattening calves or milk cows. Sour wheys have a laxative effect and are used dietetically in constipation, like sour milk and buttermilk.

\section{Preparations from Meat, Blood, Bones, Etc.}

Meat meal or tankage consists practically of leached meat scraps, obtained in the manufacture of meat extracts. After the scraps have been boiled or heated under steam pressure, in water, the latter, with the soluble portions of the meat, is drawn off and manufactured into "extract." The residue is dried and ground into a fine meal (American meat meal or tankage). ${ }^{16}$ Another product marketed under the same name is obtained by subjecting to the same process the cadavers of animals that died from the effects of disease or that were slanghtered for consumption but afterwards condemned for food purposes. This is marketed under the name of "German cadaver meal." 16

American meat meal contains about 10 to 12 per cent of water, 70 to 75 per cent of crude protein (64 per cent digestible albumen), 10 per cent of fat and 3 to 4.5 per cent of mineral matter or ash. The digestive coefficient is about 90 per cent. It is generally very wholesome. It is used as feed for growing pigs during the first few months in amounts of 50 grams ( $12 / 3$ ounces) per head per day. As the pigs get older they may take from $1 / 2$ to 1 pound and even 2 pounds per day per head. Ex-

16 The products referred to as "American meat meal" and "German cadaver meal" are also obtained in the Americsn market, but usually all under the general name of "tankage." Purchasers and feeders should be guided by the guaranteed chemical analysis as well as by the reputation and character (whether meat packer or fertilizer manufacturer) of the firm putting the product on the market.-Translator. 
cessive amounts cause diarrhea in young pigs. It is less frequently used as calf feed $(0.6 \mathrm{~kg} ., 11 / 5 \mathrm{lbs}$.). Cattle may have 2 pounds per day and horses one-half pounds. The latter do not eat it as well as other animals. This dislike may be overcome, however, by beginning with very small quantities and mixing the feed containing it with other substances to mask the taste. Dammann recommends meat meal as a tonic food for anemic sheep. American meat meal is deficient in lime and phosphates. For young animals this deficiency should be corrected by the addition of the missing salts.

Meat meals are also valuable as poultry feed.

German cadaver meal is richer in mineral matter or salts than American meat meal, because it contains the bones and the intestinal contents of the cadavers. It also contains considerable amounts of crude fiber and nitrogen-free extract. According to analyses made by the author, it contains, on the average, from 8 to 13 per cent of water, 50 to 60 per cent of crude protein (20 per cent of this being digestible albumen), 13 to 15 per cent of fat, 0.1 to 0.5 per cent nitrogen-free extract, 1 to 1.5 per cent crude fiber, and 18 to 19 per cent of mineral matter or ash ( 5 to 12 per cent of this is phosphate of lime). The starch value is 70 per cent.

Exposure for several hours to a temperature of $270^{\circ} \mathrm{F}$. will destroy, with certainty, all disease germs in cadavers. Experiments and investigations of Hagemann, Ellenberger and Klimmer, Glage, Haefke, as well as practical experience, have demonstrated that meat meal, even when made from cadavers already in advanced stage of decomposition, agrees with animals. Its practical uses are the same as those of American meat meal, but its digestibility is lower. (The same is true of the corresponding American product.-Translator.)

In addition to these valuable meat meals, other meals, of inferior value, the product of cannery refuse, consisting mainly of tendons, cartilage, fasciæ, rancid fat, etc., are put on the market.

The waste material of glove factories (ground leather) is sometimes found on the market under the misleading name of "meat meal." This contains 18 per cent of indigestible protein, 5 per cent of fat, and 55 per cent of leather-like substances. It contains little digestible matter and is worthless as a feeding stuff.

Tropon wastes, according to Hagemann and Ramm, contain 88.4 per cent of dry matter, consisting of 3.1 per cent ash, 18.3 per cent crude fiber, 3.3 per cent crude protein (3.0 per cent digestible albumen), 8.85 per cent fat and 37.75 per cent nitrogen-free extract. They are valuable as a fattening feed for swine. Their feeding value per 100 pounds, with barley feed meal and bran at $\$ 5.55$ per 100 pounds, is $\$ 11.72$.

Fish meals are either by-products of the fish oil industry or they are made from dead or spoiled fish. They are produced either by steaming or cooking the raw material and subsequent drying in vacuum tanks or by exposure to the air. Sometimes the fats are removed from the dried meal with the aid of benzin or bisulphid of carbon. The best material 
is made from haddock and from herrings (Clupea, etc.). Fish meal made from cod is less valuable, but rich in phosphate of lime. Fish meals contain from 45 to 58 per cent of crude protein ( 40 to 44 per cent digestible albumen) and from 2 to 20 per cent of fat with large amounts (30 per cent) of phosphate of lime which is furnished by the bones. The starch value of these products, when they are low in fat, is about 44 per cent; when rich in fat, about 64 per cent. The digestive coefficient is about 90 per cent. They are used as feeding stuffs in the same manner as the meat meals and feed lime. The more fatty fish meals are liable to impart a fishy taste to the meat and bacon and possibly also to the milk. This is not the case with the meals of low fat content. Anthrax spores and pseudo-anthrax bacilli have repeatedly been found in fish meals as a result of contamination with anthrax cadavers, etc. Fish do not contract anthrax.

Blood meal, obtained by drying and grinding the blood of slaughtered animals, contains about 85 per cent of crude protein ( 72 per cent digestible albumen) and 2.5 per cent of fat. When properly made, especially when not subjected to too high temperature when drying, it is highly digestible (digestive coefficient as high as 90 per cent), agrees well with animals, and is a good dietetic feed in case of anemia. The starch value is about 72 per cent. It is used as a feed for weakly colts, anemic sheep, fattening swine (Zoubek, Zaitscheck, etc.), 1 to 2 pounds per 1,000 pounds live weight. It is also used in the preparation of cakes or biscuits and to supplement molasses feed mixtures (p. 86 and 109).

Paunch mixed feed is made from the dried and aerated paunch contents of slaughtered animals, 40 per cent, molasses 30 per cent, cadaver meal 17 per cent (low-grade tankage), and 13 per cent of potato pulp. It is marketed under the name of Paunch mixed feed. Its composition is, from its nature, variable. Its nutritive value is determined mainly by the tankage, molasses and potato pulp that have been added to it. The feeding value of the paunch contents of slaughtered animals is usually equal to that of straw. Their use is therefore not justified even on an economic basis.

According to Hohncamp, Nolte and Blanck, paunch mixed feed contains :

Crude protein,

Crude fat,

Nitrogen-free extract,

Crude fiber,
$23.0 \%$, of which $14.8 \%$ is digestible.

$2.2 \%$, of which $0.9 \%$ is digestible.

$45.8 \%$, of which $13.9 \%$ is digestible.

$15.0 \%$, of which $5.7 \%$ is digestible.

Cattle seem to like this feed fairly well.

Glue concentrate consists of the subcutaneous connective tissue with the adhering particles of flesh, tendons, etc., that have been scraped from the hides of slaughtered animals, dried and ground. Its composition var. ies. A sample which was supposed to contain some bone meal in addition, analyzed by Hanssen, contained 7.1 per cent of water, 56.1 per cent crude 
protein, 4.0 per cent crude fat and 36.6 per cent mineral matter or ash. It is eaten readily by, and agrees well with, swine and cattle.

Bone feed meal, phosphate of lime feed or precipitated phosphate of lime, is a by-product of the manufacture of glue from bones. The bones are cleaned and ground and the salts are extracted with hydrochloric acid, precipitated with milk of lime and dried. The powder thus obtained is called bone feed meal. It contains about 38 per cent of phosphoric acid, of which 90 per cent is citrate-soluble. It is white or yellowish white in appearance, odorless, and is composed, chemically, of dicalcium and tricalcium phosphate. The dicalcium phosphate is readily soluble in citric acid. It is therefore an index of value, and the amount present should be given in the manufacturer's guaranty. These preparations should be free from toxic substances, especially sodium fluorid, which, in recent years, has occasionally been found present to the extent of from 4 to 5 per cent. It has caused serious poisoning.

Other substances besides those just mentioned are now and then put upon the market. They consist mainly of tricalcium phosphate, are therefore hard to digest and of low value (degummed bone meal, bone ash, ground mineral phosphate, etc.)

The experiments of Koehler throw light upon the digestibility or assimilability of some of these salts. Of dicalcium phosphate 55 per cent, precipitated tricalcium phosphate 37 per cent, degummed bone meal 13 per cent and bone ash 14 per cent are assimilable.

Cock chafers or May bugs (Melolontha vulgaris) in seasons when they are plentiful are used as feed for swine. To prevent invasions with Echynorrhynchus gigas, of which the grub of the May bug is the intermediate host, it is advisable to boil the "bugs" (beetles) before feeding.

\section{Substitute Feeding Stuffs}

Most of the substitute feeding stuffs have already been referred to and discussed in the preceding chapters. A few additional substances of this character are mentioned below.

Sea algae.-Sea wrack or seaweed (Fucus serratus, closely related to the widely prevalent $F$. vesiculosis) and Laminaria flexicaulis (kelp or devil's apron, the fronds of which commonly grow in clusters and are sometimes 30 to 50 feet in length) have been successfully used in feeding experiments* with horses (Sauvageau and Moreau). Many Laminaria are rich in mannite and are used as food by the Chinese and Japanese. Horses do not like them at first but become accustomed to them.

Dog biscuits before the war were made from poor-grade wheat flour, coarse oat and corn meal, beets, slaughterhouse refuse and American tankage, and contained on the average 9.5 to 10.5 per cent of water, 2.5 to 3.9 per cent of salts (phosphoric acid 0.6 to 1.2 per cent), fat 3.3 to 4.1 per cent, crude protein 10.5 to 22.7 per cent and nitrogen-free extract 60.6 to 66 per cent. These analyses have only a relative value, since the crude protein and crude fat content could easily be supplied with low- 
grade material. Necessary requirements for these biscuits are that they serve the purpose of complete rations for dogs and that they be wholesome. Dog biscuits put on the market during and after the war frequently contained substances indigestible for carnivora, such as chaff, hay, seed hulls, leaves, sawdust, bran refuse, excessive amounts of salts in the form of carbonate of lime, ground and cracked bone, etc. Dogs nourished on these products for any length of time inevitably suffer in health (Hanslian).

\section{Calculation of the Money Value of Feeding Stuffs}

In the preface of this work attention was directed to the necessity of utilizing every possible home product for feeding purposes. Whenever possible, low-priced feeding stuffs should be used to replace expensive material. Production expense should be reduced to the minimum. Feeding rations should be accurately adjusted to the requirements of each individual animal. The least deficiency, or the least excess, should alike be regarded as unnecessary waste of material.

The market prices of many feeding stuffs offered to the public are far from being commensurate to their actual value. This is true in both senses of the word. While the content of digestible nutrients was formerly used as the sole basis in calculating the money value of feeding stuffs, Kellner has demonstrated the error of this method. A more accurate method consists in using the starch value of a given feed, with due consideration of the digestible albumen content, as a basis for calculation. In addition, the following points should be considered, viz.: agreeableness, keeping quality, value of the resulting manure, and the expense of transportation, storage and preparation.

According to estimates made on the basis of average prices for 1907 and 1908, the value of $1 \mathrm{~kg}$. of digestible albumen is 26 pfennigs, and of $1 \mathrm{~kg}$. starch value nearly 20 pfennigs ( $31 / 4$ and $2 \frac{1}{2}$ cents per pound, respectively). To estimate the actual value of a feeding stuff according to these values, multiply the starch value of 100 pound's of the feeding stuff in question by $2 \mathrm{r} / 2$ cents, and add to this the product obtained from the figure indicating the digestible albumen content in $100 \mathrm{~kg}$. or 100 pounds respectively. Thus, $31 / 4$ minus $21 / 2$ equals $3 / 4$ cent; or, to reduce to decimals, 3.25 minus 2.50 equals 0.75 .

For example: Oats contain 7.2 per cent digestible albumen and a starch value of 59.7 per cent The value of 100 pounds is estimated as follows:

$$
\begin{aligned}
& 59.7 \text { times } 2.5 \text { cents equals } \$ 1.4925 \\
& 7.2 \text { times } 0.75 \text { cents equals } 0.54 \\
& \text { Total .................\$2.0325 }
\end{aligned}
$$

According to the rules adopted by the Association of German Experiment Stations, the money value of feeding stuffs may be estimated by multiplying the proteinand fat contents by 2 , the nitrogen-free extract content by 1 , adding the three products thus obtained and dividing the price of the feeding stuff by the sum. The quotient will be the price unit of the feeding stuff in question.

Example for estimating the price unit of peanut cake containing 45.5 per cent protein, 7.5 per cent fat and 25.6 per cent nitrogen-free extract, the market price being $\$ 1.88$ per 100 pounds:

$$
\begin{aligned}
& \text { Protein .................... } 45.5 \text { by } 2=91.0
\end{aligned}
$$

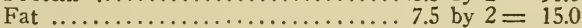

$$
\begin{aligned}
& \text { Nitrogen-free extract ..........25.6 by } 1=25.6 \\
& \text { Total } \ldots \ldots \ldots \ldots \ldots \ldots \ldots \ldots \ldots \ldots, \overline{131.6} \\
& \text { Dividing the price } \$ 1.88 \text { by } 131.6=\frac{1.88}{131.6} \$ 0.144+=\text { Price unit. }
\end{aligned}
$$

With the price unit in our possession, the trade allowance or rebate due from the merchant is easily calculated according to the instructions given on page 130 . 
A few years ago Neubauer prepared a graphic table showing at a glance the actual money value of a list of feeding stuffs. The feeding stuff number and the albumen or digestible protein number constituted the basis of the calculations.

The feeding stuff number or index of a feeding stuff represents the amount of feeding stuff required to furnish a starch value of 100 per cent. Peanut cake, for example, with a starch value of 77.5 per cent, contains, in addition, 45.2 per cent of digestible protein or albumen. Accordingly its feeding stuff index would be $100 \times 100$

\section{5}

$$
\text { Coarse wheat bran with a starch value of } 42.6=\frac{100 \times 100}{42.6}=234.7
$$

The albumen index indicates the amount of digestible albumen contained in 100 starch values of a given feeding stuff. Peanut cake, for example, contains, in addition to a starch value of 77.5 per cent, digestible albumen to the extent of 45.2 per cent. Its albumen index, therefore, is $45.2 \times 100$

$$
\frac{77.5}{2}=58.3
$$

The albumen index of wheat bran with a starch value of 42.6 per cent and 9.8 per cent albumen content is $9.8 \times 100$

$$
\frac{1.8 \times 100}{42.6}=23 \text {. }
$$$$
\text { And so on for other feeding stuffs. }
$$

As will be explained more in detail in the chapter on feed standardization, feeding rations on farms are usually compounded, or should be, as far as possible or practicable, with products of the farm itself. The starch value and the albumen content is ascertained and then an estimate is made of what is lacking to make the ration complete. The deficiency is then corrected by the addition of purchased ingredients.

To illustrate:

Swine, during the first fattening period, require, per 1,000 pounds live weight, daily -3 pounds digestible albumen and 27.5 pounds starch value.

Farm-grown products will supply-2.5 pounds digestible albumen, and 25.0 pounds starch value.

There remains to be supplied by purchase -0.5 pounds digestible albumen and 2.5 pounds starch value.

The albumen index of the supplementary feed is $\frac{0.5 \times 100}{2.5}=20$.

The nutrients which are lacking are rarely supplied by a single feeding stuff, but usually by two or three. If two are decided upon we select one with a lower, another with a higher albumen index than the correction requires.

To illustrate: If we have the choice of

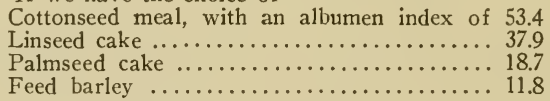

we select the two feeding stuffs best suited for the purpose. The combination sought is one with an albumen index of 20 and must therefore be a mixture of two of the available feeding stuffs with a starch value of 100 and an albumen index of 20.17

Neubauer's "feeding-stuff price chart" is a convenient graphic guide for the selection of the most economical "pair" of feeding stuffs necessary to balance a deficient farm-grown ration. It consists of a single sheet, ruled in millimeter spaces. The verticle base line (ordinate) contains the albumen indices of the various feeding stuffs, expressed in millimeter spaces and extended in parallels to the horizontal base line (abscissa). The feeding stuff index of the feeding stuff in question is noted

\footnotetext{
17Since the feeding value of the digestible albumen is included in the starch value, and since one pound of digestible albumen is equal in feeding value to about one (exactly 0.94) pound of starch value, in estimating the value of a feeding stuff or ration we add, for each pound of digestible albumen, not its cost price, but the difference between its cost price and the cost price of one pound of starch value, viz., not 3.25 cents, but the difference between 3.25 cents and 2.50 cents, or 0.75 cent, to the cost of each pound of digestible albumen.
} 
on these horizontal lines. Supposing it is desired to substitute two other feeding stuffs (a pair) like dry yeast and dricd potatoes for a single feeding stuff like, for example, oats. All that is necessary to determine the amounts of each is to locate the points of intersection of the coordinates (the ordinate and the abscissa) of the feeding stuff index of one of the feeding stuffs of the combination sought and the albumen index of the other of the feeding stuffs of the proposed combination. The points of intersection of these two lines with the line indicating the feeding stuff to be replaced indicate the amounts of the two substitutes which, together, have the same starch value and the same content of digestible albumen as the feeding stuff (oats) to be replaced.

\section{Examination or Inspection of Feeding Stuffs \\ Meal, Grits and Cake}

The value of a feeding stuff is determined by its purity, soundness and nutrient content. The purity and soundness of soiling crops, roughage, root crops or of whole grains are usually easily ascertained. The suggestions made along these lines in the chapters on feeding stuffs and contaminations and admixtures will suffice for this purpose. The nutrient content of these feeding stuffs may also be approximately estimated when the conditions of growth and manner of harvesting are known. On the other hand, the estimation of the value, etc., of meal, grits, cake, etc., may meet with greater difficulties. Our ordinary senses, sight, smell, taste and feeling, are not sufficient for this purpose. It is rather necessary to resort to chemical analysis and microscopical examination. In general, it would be a safe practice not to purchase feeding stuffs that are sold under indefinite names, like Victoria feed, blood concentrate, oatworth, calf meal, groats, or other meaningless terms. As a rule the cost of these substances bears no definite relation to their actual value. They frequently contain indigestible, spoiled, or low-grade material or even injurious waste products. Even guaranties of protein and fat content do not protect against fraud. Sometimes these products are almost entirely indigestible and consequently worthless. Mahwa or bassia meal, for instance, which stock does not even like, contains 27 per cent of crude protein and therefore appears rich in albumen and valuable, but of the 27 per cent of crude protein present, less than 1 per cent consists of digestible albumen. Cocoa shells, with 14 per cent of crude protein, contain no digestible albumen whatever. Peanut hulls, millet shells, rice chaff, etc., all belong to a class of feeding stuffs generally used but are, in reality, worthless filler.

The nutrient contents are determined according to the methods given on page 3 and the following pages. As a rule, these determinations are made to the best advantage by the agricultural experiment stations.

\section{General Rules for the Purchase of Commercial Feeding Stuffs}

The Feeding Stuff Section of the German Agricultural Society and the Association of Agricultural Experiment Stations of the German Empire have established the following rules for the trade in feeding stuffs:

1. Every sale shall be accompanied by a guaranty- $(a)$ Of the exact nature of the feeding stuff, its soundness and purity (freedom from foreign substances, inferior material, indifferent or injurious admixtures not necessarily a part of the character of feed indicated by the name).

(b) Minimum content of the nutrients which determine its value.

2. The guaranty shall be on paper, either in the form of a signed quotation, bill . of sale or invoice. Retail sales, under 200 pounds, shall be guaranteed by a specia] written statement to the purchaser. The guaranty shall contain the name and character of the feeding stuff, guaranteed composition, origin (when this is an indication of definite quality), and furthermore, whether, and to what extent, reimbursement will be made for deficiencies.

Retail packages shall be marked on the container with a printed copy of the guaranty or by means of a glued label or a metal or paper tag attached to a certain designated portion of the package.

The labels or printed matter on the containers shall contain the name of the dealer and his trade mark, weight of the package, name of the feeding stuff, guaranteed chemical composition in unequivocal terms (fat, protein, etc.), the time or date up to which adjustments will be made, the name of the experiment station 
which controls or checks the products of the firm in question, and the terms and conditions under which the experiment station in question will verify the statements contained in the guaranty.

3. The guaranty of the nutrients which determine the value of the feeding stuff shall have reference in all cases to the protein and fat, but for the carbohydrates only when the latter are expressly included in the statement. The guaranty for fat and protein shall be stated in separate terms for each ingredient. The guaranteed contents shall refer to the minimum content of each nutrient. The indication of a variable minimum, like 18 to 20 per cent, shall not be permitted.

The seller shall be responsible to the purchaser for all deficiencies below the guaranteed contents. Adjustments shall be made either (1) according to the principle of compensating ingredients or (2) according to the principle of chemical latitude.

a. Compensating ingredients.-By this is understood the substitution, according to actual money value, of one ingredient that may be present in excess, for another that may be below the guaranteed percentage.

The limits for fat within which this method of adjustment is permissible are 1 per cent in feeding stuffs of 10 per cent or less fat guaranty, or 2 per cent in feeding stuffs of higher guaranteed fat content.

The limits for protein are 3 per cent but not exceeding 10 per cent of the guaranteed protein content.

The limits for this method of adjustment in the case of deficiency of guaranteed carbohydrates or nitrogen-free extract are 5 per cent.

In the case of certain specified feeding stuffs, special written agreements between buyer and seller constitute the basis of adjustments.

$b$. Chemical latitude.-Chemical latitude shall be permitted only upon special agreement between buyer and seller. The words "within chemical latitude" inserted in the guaranty shall suffice for this purpose. This means that deficiencies up to $11 / 2$ per cent of crude protein or $1 / 2$ per cent of fat shall be disregarded unless the deficiency exceeds either of these respective figures, in which case full compensation or adjustment shall be made to the buyer.

In the calculation of compensation for deficiency in nutrient contents one part of crude protein is estimated at the same money value as one part of fat.

The value of one part of carbohydrates (or nitrogen-free extract) is based on methods of calculation determined by the Association of Agricultural Experiment Stations (see p. 131).

The calculation of compensation or damages for deficiency of nutrient contents shall be based entirely upon nutrients specifically guaranteed.

4. When feeding stuffs are sold on the basis of actual percentage of nutrients present, there can be no basis on which compensation may be demanded.

5. Feeding stuffs containing spoiled, unsound or inferior ingredients not designated in the name or on the label, upon presentation of proof to this effect, may be returned and shall be accepted by the seller, and the latter shall, in addition, be liable for all expenses incurred in the transaction.

6 . The determination of the contents of feeding stuffs shall be made by agricultural experiment stations mutually agreed upon by buyer and seller. Samples of feeding stuffs for chemical analysis shall be taken as follows:

7. The sample shall be taken by the consignee or his agent at the receiving station of the railroad, or within three days after delivery at final destination on the farm, etc., in the presence of an agent of the seller or of a disinterested person who has previously been instructed as to these conditions, and in the manner following:

a. In the case of oil cake, at least 20 whole cakes shall be taken from as many different portions of the shipment. The cakes shall then be broken into pieces of about the size of a walnut, either by passing through a thoroughly cleaned oil-cake crusher or by other suitable means. The crushed mass shall then be thoroughly mixed and a four-pound sample removed. The particles composing the sample shall not be further reduced in size.

$b$. In the case of grains, meals, brans, etc., a suitably constructed sampler shall be inserted horizontically into the sacks while the latter are lying on the floor, or. in case a sampler is not available, a spoon or scoop may be used. The sample should not be taken with the hands. Fifteen per cent or more of the sacks must be sampled. and at least five sacks. If there are less than five sacks in the shipment all of them must be sampled. The samples should be taken from different portions of the sacks, not all from the middle or center. 
If the total sample material greatly exceeds four pounds in weight, it should be spread out on a large, clean sheet of paper and carefully and thoroughly mixed. The mass should then be spread out into a layer about one inch thick and four pounds of the same removed for a sample. The entire thickness of the layer should be used in making the sample. This is necessary in order to include the finer particles, like sand, etc., which are apt to be found in the lower portions of the layer or next to the paper. Lumpy portions appearing in the samples should not be crushed.

Wet or spoiled sacks should not be included in the general sample, but should be sampled separately. It is also permissible to take the required number of sacks, empty them on a clean floor and mix the entire mass thoroughly, level off in a layer about one foot in thickness and then by means of a scoop, as described above, take a mixed sample from at least twenty different places, but not from the edges of the mass. When the suspected error is of especial importance this method is preferable to the one first described.

If the material is delivered in bulk, on a pile, the latter should be reduced to a level mass, about one foot thick, and samples taken in the same manner.

$c$. The samples thus procured should be divided into three sub-samples of at least one-half pound each. The latter are then placed into dry nonporous containers, preferably of tin or glass, hermetically closed, sealed and marked with the character of the contents. One sample is sent to the experiment station, the second is kept by the consignee, in a dry place, for possible future use, and the third sample is held at the disposal of the seller or shipper.

d. A copy of the foregoing instructions for taking the sample shall be furnished by the seller to accompany the shipment of a feeding stuff, in addition to an affidavit by the seller, in which is indicated the brand, sack number, weight and guaranty of contents, as well as car number (or name of ship or boat) and name of shipper. In disputed cases, samples are not recognized as valid without such affidavit.

\section{Agreements As to Classification for Quality or Grade}

1. Qualitative tests of all feeding stuffs shall be required when they contain more than normal percentages of sand or mineral admixtures. When these exceed 1 per cent, quiantitative determinations shall be made by incineration and extracting with hydrochloric acid, and the results reported to the sender of the sample.

2. The Standing Committee on Feeding Stuffs recommends that, in the analysis of all brans, the presence or absence of apparently ininjured weed seeds, be rcported. When these are present, attention should be directed to the fact that they are indications of adulteration with screcnings. The determination of the number of seeds per kilogram and their botanical identification shall be a matter of choice or judgment.

3. If smut spores are present in excessive numbers, attention should be called to this fact.

\section{Hygienic Examinaticn}

In determining the hygienic condition ${ }^{18}$ of feeding stuffs, greatest stress should be placed on purity and soundness. The only occasion offered the veterinarian to express an opinion in regard to the hygienic condition of feeding stuffs is when disease or illness follows its ingestion. In sucli cases the samples examined are chosen as far as possible from those parts of the feed that have caused the injury. In such cases there is no object in taking general samples, or "average" samples. This is a different matter from the sclection of a sample of feeding stuff proposed for purchase. In the latter case an "average" sample would be sought.

For examining concentrates for the purposes here in view we resort to (1) chenical, (2) biological (serological), (3) above all, microscopical methods and (4) animal inoculation.

It would be necessary to go far beyond the scope of this work if we should undertake to treat this subject with any degree of completeness. We shall therefore limit ourselves to the giving of a few hints and refer the reader to the text books or handbooks of Beyhien, Hartwich and Klimmer, Koenig, and Boehmer.

18Examinations or analyses of this character are made by all hygienic institutes of veterinary colleges as well as by the agricultural experiment stations (in Germany). 


\section{CHEMICAL EXAMINATION}

\section{A. Determination of Albumen, Fat, Nitrogen-Free Extract, Crude Fiber,} Mineral Matter or Ash and Water

See page 3 , etc.

B. Determination of Sand, Lime, Infusorial Earth, Barite and Other Minerals Sand, gypsum, barite and other minerals admixed with feeding stuffs may be injurious to the health of animals. The following methods are employed for their detection.

Chloroform test.-Agitate 5 to 10 grams of the feeding stuff with chloroform. The feeding stuff material will float and the sand, etc., sink to the bottom of the flask. Separation and quantitative determination follows.

Carbonic acid test.-The feeding stuff is washed off with water or chloroform, as indicated above, and the residue treated with dilute mineral acid. The presence of lime is indicated by effervescence (carbonic acid gas).

Ash analysis (see p. 4). - The determined ash content is compared with that of the unadulterated feeding stuff. To determine the amount of sand in the ash the latter is treated with dilute hydrochloric acid and the residue boiled in a 5 percent solution of bicarbonate of soda. The residue consists of sand, clay (earth) and a part of the un-dissolved silicic acid present in the glumes or chaff.

The permissible sand content in feeding stuffs is 0.2 to 0.3 percent.

\section{Determination of Corn Cockle, Ergot, etc., in Meals} by Means of Vogl's Reagent.

To 2 grams of meal, placed in a test tube, add 10 c.c. of 70 percent alcohol containing 5 percent of hydrochloric acid; agitate thoroughly, heat slightly and allow to settle.

If the fluid remains colorless-Wheat and rye.

If the fluid becomes yellowish-Rye (sometimes), corn, barley, oats, peas.

If the fluid becomes orange-(Rye, barley, corn), rice, millet, corn, cockle, bearded darnel.

If the fluid becomes red-(Rye, barley, corn, rice, millet) vetches, ergot.

If the fluid becomes bluish green to green-Cow wheat and yellow rattle (Hartmann).

Seed skins (bran) of green rye produce a red color; skins of yellow rye grains, a pale ocher yellow; both together produce an orange color. The seed skins of wheat do not give this reaction; those of barley as a rule also fail to give it. Vogl's reaction is not applicable to rye bran.

Vogl's reaction is therefore ambiguous. It serves mainly as a guide and to assist in finding suspicious material. To complete the latter process the slightly warmed solution or mixture is poured on a piece of blotting paper and the stained particles picked out for microscopic examination.

Ergot stains the solution red. The addition of ether and a few drops of sulphuric acid changes this to violet. If the red color is due to vetches, the addition of the latter reagents produces a greenish yellow precipitate.

The detection of corn cockle with Vogl's reaction is assisted by previous moistening of the meal in question with concentrated hydrochloric acid (intensified reaction). The presence of 0.8 percent of corn cockle meal (with hulls of cockle) may be detected by this method. Microscopical examination gives more definite results (pp. 140-145).

\section{Iodin-Starch Reaction}

Certain by-products of oil production contain mere traces of starch (linseed cake and meal). Cottonseed by-products contain no starch whatever. On the other hand the seeds of weeds that are frequently used to adulterate oil by-products usually contain more or less starch.

The presence of starch is detected as follows: One gram of the suspected meal is boiled in about 10 c.c. of water, allowed to cool, and treated with a few drops of Lugol's solution $(1: 10: 200)$ (iodin, potassium iodid 10, water 200). A resulting blue or blackish blue color indicates the presence of starch (see p. 137).

\section{E. Testing Spoiled Feeding Stuffs}

Spoiled meals have an unpleasant musty or moldy odor. Heating in water or potash solution intensifies the odor. Gawalowsky's test is the most reliable. Mix 1 gram of the suspected meal with 4 to 5 c.c. of potash solution in a wide test tube. 
In the course of ten minutes this mixture is converted into a gluey or pasty mass The mass in the test tube is then heated to a temperature not exceeding $86^{\circ} \mathrm{F}$. and a 50 percent solution of sulphuric acid carefully added. Spoiled meals will give a characteristic, disagreeable odor, while fresh or unspoiled meals will give an odor of paste or one resembling meat broth.

\section{Biological (Serological) Examination}

Biological methods of examination have now attained importance in the detection of sources of adulteration and contamination of feeding stuffs. For the purposes in question, precipitation and complement fixation are the chief biological methods employed. Anaphylaxis has only a very limited application.

The biological methods are specific albumen reactions.

Biological reactions are resorted to, above all, in cases where the adulterants or undesirable admixtures are not sufficiently characteristic morphologically to be definitely recognizable by botanico-microscopical means. Biological reactions have become of considerable importance in the detection of castor oil seeds. While the seed skins are easily recognized by their radial palisade cells (Fig. 84), the botanicomicroscopical determination of the toxic decorticated seeds, which have in late years been used as adulterants of oil cake, is not sufficiently accurate.

Complement fixation with specific serum is a definite means for the detection of the poisonous castor oil beans. This reaction is strictly specific and will reveal the presence of 0.5 percent of castor oil beans in a feeding stuff. The toxic principle of the castor oil bean is destroyed by heating at $212^{\circ} \mathrm{F}$. for five minutes. Seeds thus treated fail to give the complement fixation reaction.

With reference to technic of the complement fixation test, see Klimmer, Handbuch der Nahrungsmitteluntersuchung, Vol. 3. Anti-ricin serum may be obtained from Merck, Darmstadt, or may easily be produced by careful immunization of rabbits. The first dose per $1 \mathrm{~kg}$. live weight consists of $0.001 \mathrm{mg}$. ricin Merck, subcutaneously injected, followed in 8 to 10 days with 3 to 5 or 8 to 10 times the first dose. In regard to testing the serum, see Klimmer's work just referred to.

According to Miessner, as well as according to Pfeiler and Engelhardt, the precipitation test is also of practical value. 5 percent adulterations, sometimes as low as 1 per cent, may be detected with certainty.

Whether the "rapid method" (Thermo-precipitation) recently recommended by Kranich gives sufficiently accurate or reliable results is yet to be demonstrated. The difficulties attending the use of the precipitation test in the detection of the source of vegetable albumens lie in the fact that plant extracts (bean meal, rice, barley, field beans, soy beans, Stramonium, castor oil beans, etc.) frequently produce precipitates with normal sera.

Agglutinins (conglutinins) for red corpuscles which are present in some plants are of value only under certain specific conditions and when used with the greatest care, for the differentiation of vegetable substances. They are not adapted for general use because they occur in a great variety of toxic (Ricinus, Croton, Datura) as well as harmless (beans, peas, lentils, vetches) plants.

The hemolysins are more promising in this respect. They possess the property of dissolving washed red blood corpuscles in isotonic sodium chlorid solution $(0.85$ to 1 percent) (see Klimmer, loc. cit., p. 136). They occur, it seems, in only a very few species of plants. The best known vegetable hemolysin is saponin which, as is well known, is the toxic principle of corn cockle (Agrostemma githago). Saponin occurs also in Saponaria officinalis (soapwort) and in Delphinium (larkspur), both poisonous. The fact that it also occurs in the seeds of Atriplex (notchweed) and Sorghum saccharatum is of little importance, since it is present in traces only. Hemolysins have also been found in the seeds of the sand vetch or winter vetch and in the common vetch (Vicia villosa and $V$. sativa).

Hemolysins may be used for the detection of corn cockle seed in meal, flour, bran, bread, etc. This is of special importance when the characteristic perisperm of the corn cockle seed has been removed. Rusconi's method consists in the preparation of a doughy mass from 5 grams of the meal or bran in question and 4 grams of a 2 percent solution of neutral sodium citrate. This dough is then worked through a fine-meshed linen cloth with the gradual addition of 16 c.c. of the same citrate solution. The liquid thus obtained is filtered, and 3 c.c. of the clear filtrate is treated with 1 c.c. of a suspension of red blood corpuscles (1 to 100), incubated for 
2 to 3 hours, and then kept in a refrigerator for several hours. If hemolysis takes place, recognizable by clarification and red coloration of the fluid, saponin is present.

For the examination of bread, take 10 grams of finely grated and subsequently sifted bread crumbs, put in an Erlenmeyer flask with 5 c.c. of 90 percent alcohol and 5 c.c. chloroform. Bring to boiling point; filter at once through dry filter. The residue is treated in the same manner with alcohol and chloroform for a second and $a$ third time. The three filtrates are mixed and evaporated on a water bath. The residue is dissolved in 5 c.c. of physiological salt solution, filtered and, if necessary, neutralized. Take 2 or 3 c.c. of the clear filtrate and add a few drops of a suspension of red blood corpuscles and proceed as above.

\section{Microscopic Examination}

For microscopic examination 30 to 50 grams of a good average sample of feeding stuff are necessary.

Preparation of the Feeding Stuff for Microscopical Examination

Preliminary tests are made with the naked eye. The material, if light colored,

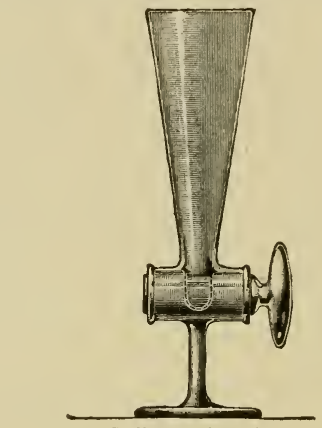

Fig. 55. Sedimentation glass.

is spread out on a smooth sheet of black paper; if dark colored, on a smooth sheet of white paper. It is then searched for clumps or particles of unusual size or appearance that would indicate spoiled or impure material. These are preserved for the time being for later examination for the presence of mites, mold fungi, etc.

Oil cake should be ground into a fine meal.

Meals and brans are separated into four grades by means of Nobbe's compound sieve, which consists of three different sieves with $11 / 2,1$ and $1 / 2 \mathrm{~mm}$. meshes.

The upper sieve retains the coarse admixtures, pieces of the rachis of the heads of grains, skins and glumes (chaff), pieces of straw, large seeds of weeds, vetches, corn cockle, dodder seed and ergot.

The second sieve retains the smaller sized weed seeds, Atriplex (notchweed), Capsella (shepherd's purse), Chenopodium (goosefoot), Euphorbia (spurge), Lepidium (cress), Papaver (poppy), Urticaria (nettle), Galium (cleavers), Viola (violets) and broken seeds, millet, rice and pea hulls, ground or broken pits of stone fruits, oat hulls, pieces of caterpillars, moths, mouse excrement, etc., as the case may be. (Test with magnifying glass.)

In the third sieve the shells or skins of weed seeds and mites are commonly found. Contents of this sieve should be examined with aid of a magnifying glass.

The contents of the fourth compartment are used for microscopical examination of the character of the starch grains, the presence of microorganisms (smut and mold fungi) and, aided with iodin solution, the presence of mineral matter (sand, chalk, gypsum, kaolin). The presence of mineral substances is frequently suggested by the dust which they make. They are not stained, either blue or brown, by iodin. 
Sometimes Schaffnit's method is used to separate the various ingredients of meals and brans. Schaffnit's agitator funnel (Fig. 56) is used by filling to at least half capacity with chloroform and about 20 grams of meal or substance to be examined. The funnel is then closed as shown in Fig. 56-A, thoroughly shaken, and set away to allow contents to separate and settle. Sand, mineral matter and aleurone cells sink to the bottom, and are separated from the other parts as illustrated in Fig. 56-B. They are released by removal of the lower stopper and subjected to exami-

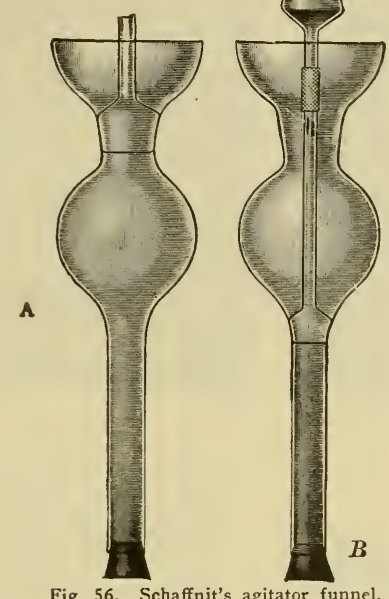

Fig. 56. Schaffnit's agitator funnel.

nation. The lighter particles (skins, hulls, plant tissue, hairs, mites, etc.,) float on the surface. They are removed with the chloroform and examined.

\section{Examination for Starch Grains}

For the examination of the starch grains the contents of the lowest compartment, which contains the finest meal, are used. Meals rich in fat must first have the latter removed by treating with ether, or alcohol and ether, to dissolve and remove the fat. After removal of the fat the sample is mixed with water or diluted glycerin to form a thin milky or turbid fluid. This material is used for the preparation of microscopic slides to be examined with. and without the addition of a dilute iodinpotassium-iodid solution. If the meals are of a cereal nature, examine for hairs, note their length and compare thickness of walls with lumen.

The starch grains and cells of the various species of grains and leguminous seeds frequently have characteristic forms which alone may indicate their nature or origin.

The diameter of the starch grains of the most important species of grains are given below.

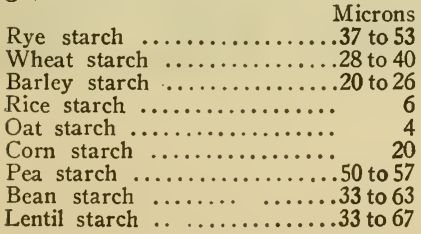

Microns

Potato starch ............60 to 185

Peanut starch ................ 4 to 25

Acorn starch ................. 10 to 30

Horse-chestnut starch ....... 5 to 26

Millet starch ............ 5 to 15

Buckwheat starch ......... 5 to 20

Poisonous darnel ............ 2 to 6

Corn cockle .............. 1 


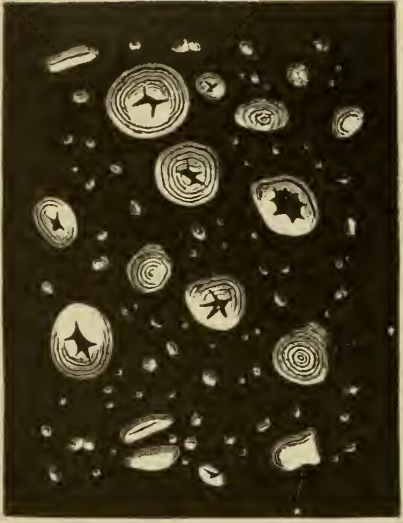

Fig. 57. Rye starch. (X 300.)

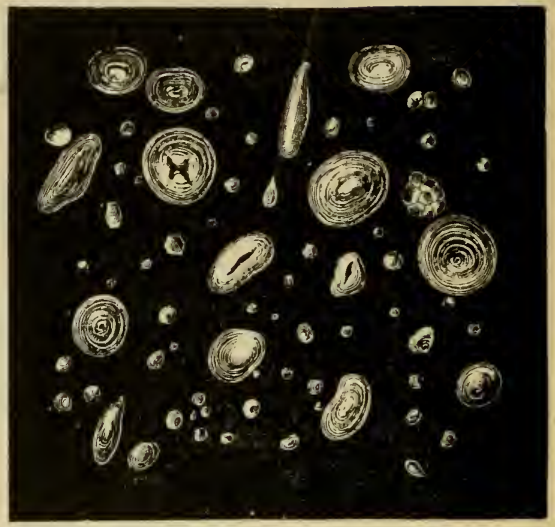

Fig. 58. Wheat starch. (After Moeller.) (X 300.)

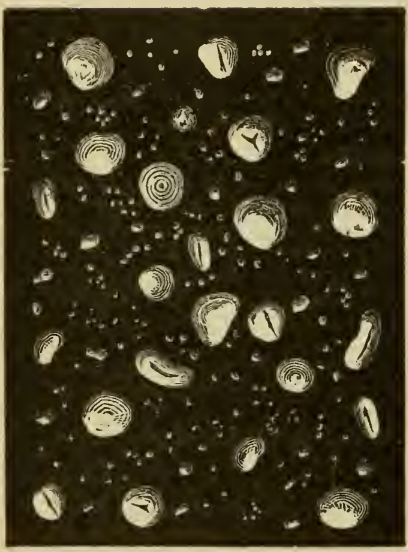

Fig. 59. Barley Starch. (After Moel. ler.) (X 300.)

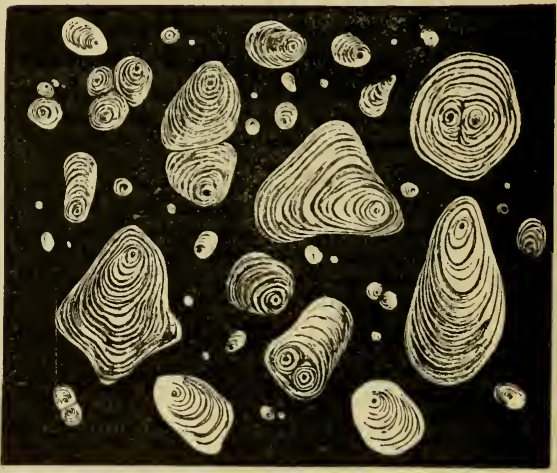

Fig. 60. Potato starch. 


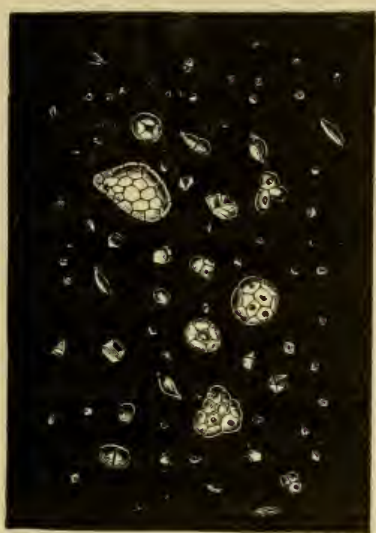

Fig. 61. Oat starch. (After Moeller.) (X 300.)

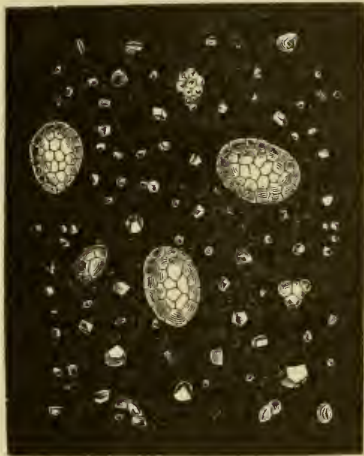
Fig. 62. Rice Starch. (After Moeller.) (X 300.)

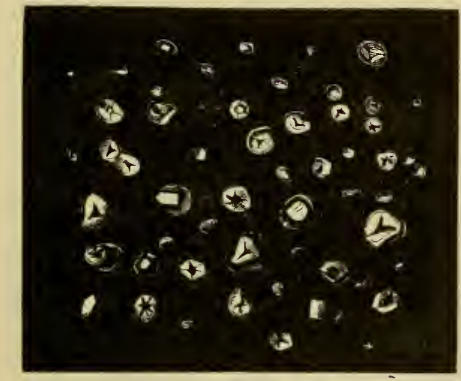

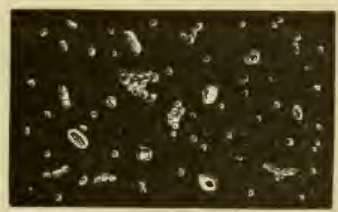

Fig. 64. Buckwheat Starch.

Fig. 63. Corn Starch. (After Moeller.)
X 300.)

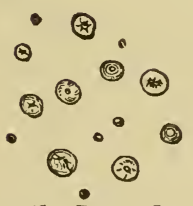

Fig. 65. Peanut Starch.

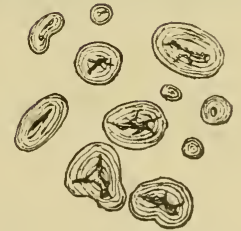

Fig. 66. Bean Starch. 


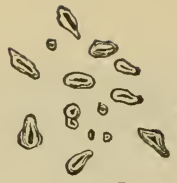

Fig. 67. Acorn Starch.

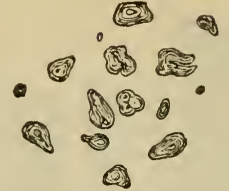

Fig. 68. Horse-Chestnut

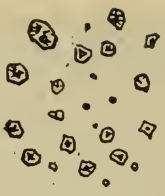

Fig. 69. Millet Starch (Poi sonous darnel and Polygonum, or knotgrass).

The following key will assist in the determination of the origin of starch grains. Since some of the characteristics are common to several varieties, a sharp distinction is not always possible.

1. Starch grains simple, bounded by curved surfaces.

A. Disk-shaped or globular, without distinct lamination.

a. Grains mostly lens-shaped, large and many small sizes; few transition forms: Wheat, rye, barley starch.

$b$. Grains globular with nuclear vacuole: Peanut starch.

B. Oval and elongated, usually with nuclear vacuole and laminated.

1. Concentric nuclear fissure and lamination.

a. Grains bean or kidney shaped, nuclear vacuole fissured: pea, bean, vetch starch.

b. Grains irregularly sinuate, flask-shaped, with long, concentric nuclear fissure and indistinct lamination: Acorn starch.

2. Eccentric nuclear vacuole and lamination.

a. Grains large, conchiform, lamination very distinct, eccentric: Potato starch.

b. Grains irregularly sinuate, lamination and nuclear vacuole eccentric: Horse-chestnut starch.

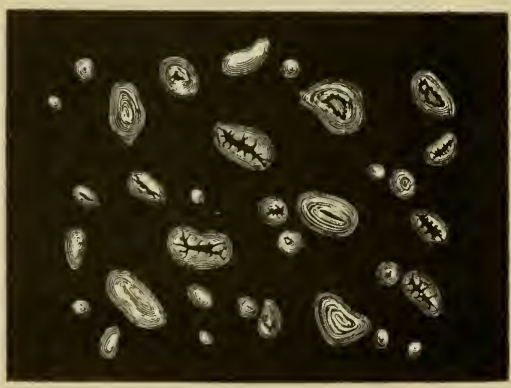

Fig. 70. Disk-shaped starch.

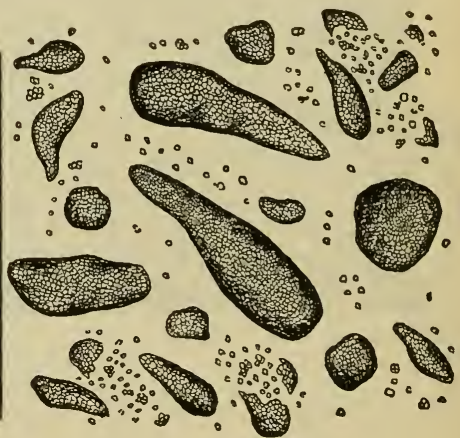

Fig. 71. Corn cockle starch.

II. Grains simple or compound. Individual grains (broken) polyhedral, entirely or partly bounded by plane surfaces.

1. Composed of simple small grains and of compound large spheroidal grains and parts of grains:

a. Regular and with sharp edges, often with nuclear vacuole, polyhedral: Rice starch.

b. Edges rounded, no nuclear vacuole, many shapes: Oat starch.

2. Composed of simple and of large irregular compound grains:

a. Sharply defined borders, rounded or polyhedral, nuclear vacuole fissured: Corn starch. 
b. Grains small with sharp edges, nucleus large: Millet starch.

c. Grains rounded, polyhedral, occasionally gnarled, in columnar bundles, nucleus large: Buckwheat starch.

III. Grains very small, punctiform in appearance under 200 diameters magnification: Lolium temulentum, corn cockle, chenopodium, notchweed and several other weed starch grains.

The starch grains of rye, wheat and barley are lenticular in form, sometimes concentrically laminated, with central nucleus or nuclear fissure. The results obtained from microscopical examination are not infallible. However, meal gruel (1 to 50 ) well stirred and carefully heated to $62.5^{\circ} \mathrm{C}$. $\left(144.5^{\circ} \mathrm{F}\right.$.), then rapidly cooled and subjected to examination will show the wheat starch almost wholly intact (Fig. 73 ), while rye starch grains will be swollen and mostly ruptured (Fig. 72). Barley starch exhibits a greater variety of form and more irregularity.

The starch grains of corn cockle (Fig. 71) are flask or spindle shaped. Upon the exertion of pressure they break up into innumerable polyhedral granules with rounded edges and 1 micron diameter.

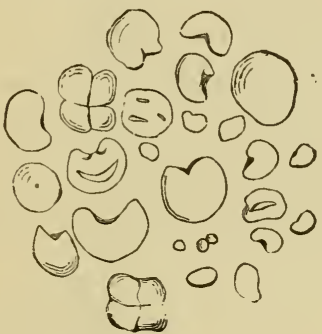

Fig. 72. Rye flour heated at $62.5^{\circ} \mathrm{C}$. $\left(144.5^{\circ} \mathrm{F}\right.$.)

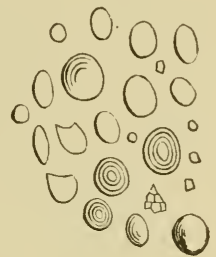

Fig. 73. Wheat flour heated at $62.5^{\circ} \mathrm{C} .\left(144.5^{\circ} \mathrm{F}\right.$.

\section{Examination of By-Products Containing Shells, Hulls, Skins, etc.}

The contents of the various screens are spread out upon a sheet of white or black paper. Particles of similar appearance are picked out with the aid of fine forceps and laid aside for identification. Those that can not be identified with the naked eye or with the aid of a magnifying glass are cleared by boiling for a moment in a 1 to 2 percent solution of potash, strained through fine gauze, washed, then similarly boiled in equal parts of glycerin and acetic acid, filtered and washed. The residue is examined, with the aid of a teasing needle, under the microscope, using 150 to 300 magnifying power. The material may also be successfully cleared by light boiling for 30 minutes in 1.25 percent sulphuric acid in a flask with return condenser. The product is washed, filtered, and the residue boiled for 30 minutes in 1.25 percent potash solution in a similarly equipped flask, then filtered, washed and subjected to examination. Various species of weed seeds are easily recognized by the dark color of their skins or membranes.

In the following paragraphs a few of the most important feeding stuffs and their most common and dangerous adulterations are briefly mentioned and illustrated. For further and more detailed information and instruction the reader is referred to the works already quoted under 1,2 and 3 . When doubts arise as to the exact nature of certain substances, they may be compared with corresponding material of known origin.

In determining the character of these foreign substances due consideration must be given to the question of whether they are naturally or accidentally present (e. g., moderate amounts of weed seeds) or whether they were added with the intention to defraud, or adulterate. In the former instance, when these substances are present in limited amounts, and not of a toxic nature, no special objection can be made. Poisonous substances or intentional adulterations are another matter. 


\section{Meals and Brans of Rye, Wheat, Barley, Corn and Oats}

According to their origin these show-

1. The more or less characteristic starch grains.

2. Characteristics brought out by Vogl's reagent (not applicable to rye).

3. When sifted through Nobbe's sieves, bran particles, etc., should not appear in any considerable amount.

In the case of brans which may contain a few traces of the glumes (chaff) of the species of grain in question (Figs. 74 and 75 ), those of other varieties, or darkcolored, woody particles, should not be present.

4. Schaffnit's method (p. 137) should not reveal the presence of sand, mineral matter, hairs, etc.

5. Shells, hulls, and other woody parts should not be present. For the detection of these substances the contents of the coarser sieves or, better, the whole meal, should be used. The examination is conducted according to instructions given under "Examination of By-products Containing Shells, Hulls, Skins, etc."

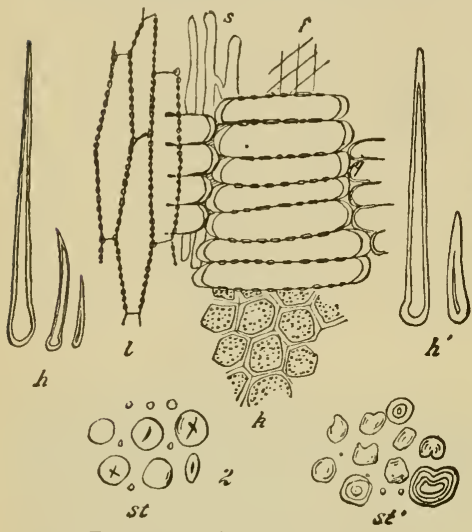

Fig. 74. Rye. (After Wittmack.)

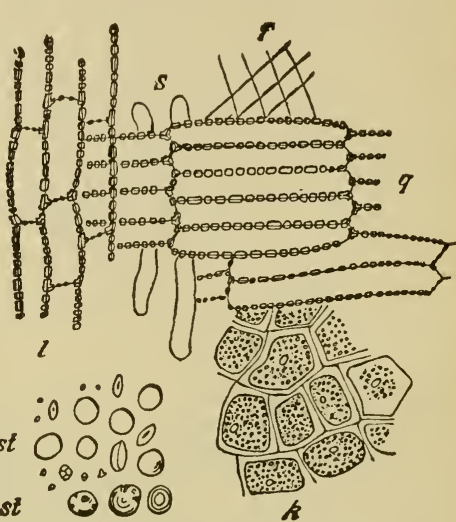

Fig. 75. Wheat. (After Wittmack.)

Explanation: $h$ and $h^{\prime}$, Hairs; 1 , longitudinal, $q$, transverse cells; $s$, tubular cells of the seed coats; $f$, pigment layer of the seed coat; $k$, aleurone layer; st, starch grains; st $t^{\prime}$, the same converted into paste at $62.5^{\circ} \mathrm{C}$. (144.5 $5^{\circ} \mathrm{F}$.).

The glumes (chaff) of the cereals are either bright or dull in appearance, smooth or carinated, and consist chiefly of long bast fibers and woody or silicified, closely packed cells (Fig. 76).

6. Test for ergot. Vogl's method does not suffice for this. For the chemical determination of ergot, make an emulsion of a small quantity of the suspected feeding stuff with a 60 percent solution of chloral hydrate, allow to settle for a few minutes and filter. The filtrate, if ergot is present, has a bright cherry red color. A drop allowed to dry on filter paper leaves a reddish spot which, when treated with alcohol-ammonia, becomes a dirty violet. The balance of the solution is agitated with ether. After settling, the supernatant ether has a pink color while the sediment is colorless. Microscopic examination is unreliable unless characteristic pieces of ergot are accidentally met with. In a shake mixture the ergot and bran particles float on the surface after the mixture has been allowed to stand a while. Centrifuging has the same effect. The floating particles are cleared by boiling in 1 to 2 percent hydrochloric acid solution and then treated with chloral hydrate, or the particles, thus treated with hydrochloric acid, are stained with dimenthylamidoazobenzol, thionin and safranin. The ergot tissues stain yellow, other tissues blue, violet or variegated, and may thus readily be recognized under low magnifying power. 
As to the microscopic characteristics of ergot, see Klimmer, Hygiene. It is easily distinguished from the grain seed coats, etc., even when unstained.

In addition to the microscopical examination, spectroscopic examination should be resorted to if necessary.

Macerate 10 grams of meal for 5 to 6 hours in sulphuric acid-alcohol (10 drops of a 20 percent solution of sulphuric acid in 20 grams of 95 percent alcohol) and filter. Alkalize the filtrate with ammonia, filter and examine with spectroscope. Ergot shows two absorption bands in the green (90 to 99 and 112 to 122) and a blue band (145, when the sodium D-line is at 70 and the Potash $a$ on 26 and potash $b$ on 219 ).

7. Very frequently the spores of smut, especially Tilletia caries, occur in wheat and mixed brans, rarely in others. To examine, sift the bran or meal with a $1 / 4 \mathrm{~mm}$. (not more than $1 / 2 \mathrm{~mm}$.) mesh.

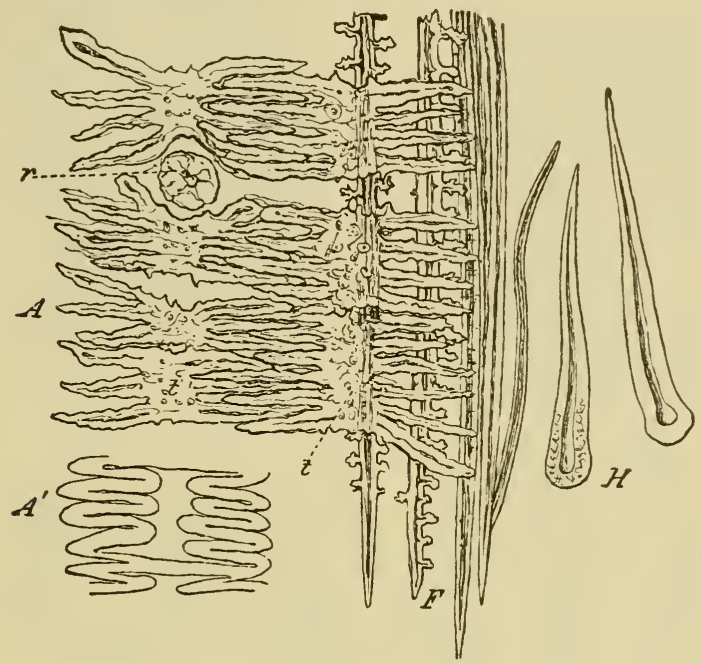

Fig. 76. Rice. Cells of the external covering of the glumes.

4 , Outer seed coat cells treated with caustic potash; $A^{\prime}$, the same treated with water; $t$, protuberances on same; $r$, round cell, with hair, $h ; F$, cells of the subjacent fibrous tissue. (After Boehmer.)

A portion of the sifted material is removed with the tip of a knife blade, moistened with water and examined under a magnifying power of 50 diameters with open diaphragm. If the material is previously boiled in dilute caustic soda solution, the smut spores become more distinctly visible. If a slide, made from the sifted material mixed with water, but otherwise untreated, and the material spread just sufficiently thin to permit examination, shows 20 smut spores in a microscopic field, the material is considered of inferior grade (see illustration in Klimmer, Hygiene).

8. Testing for evidence of spoiling.

In the examination of vegetable oil by-products, use is made of the iodin-starch reaction (p. 134). After proper preparation of the material, search is made for seed shells, hulls, etc. The fruit hulls and seed coats of oil seeds frequently contain thick-walled bast and stone cells, deposits of tannic acid and characteristic pigments. If ricin poisoning is suspected, search is made for traces of castor oil beans (p. 147). 
Further hints for the examination of oil cakes and oil meals have already been given in this chapter and with the description of the feeding stuffs under consideration. For more minute details reference should be made to special literature on the subject, especially Koenig. 19

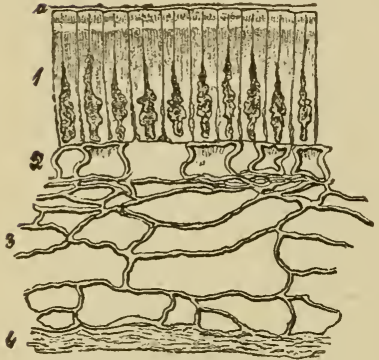

Fig. 77. Green pea. 1, Palisade cells; 2, columnar cells; 3 and 4 , parenchyma.

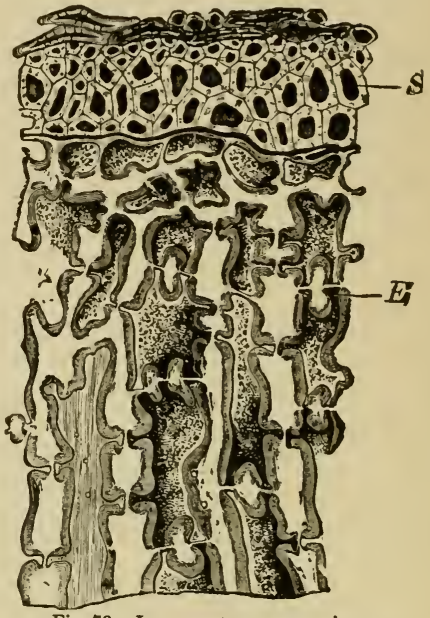

Fig. 78. Ivory nut, cross section.

$S$, Seed coat; $E$, endosperm. (After Moeller.)
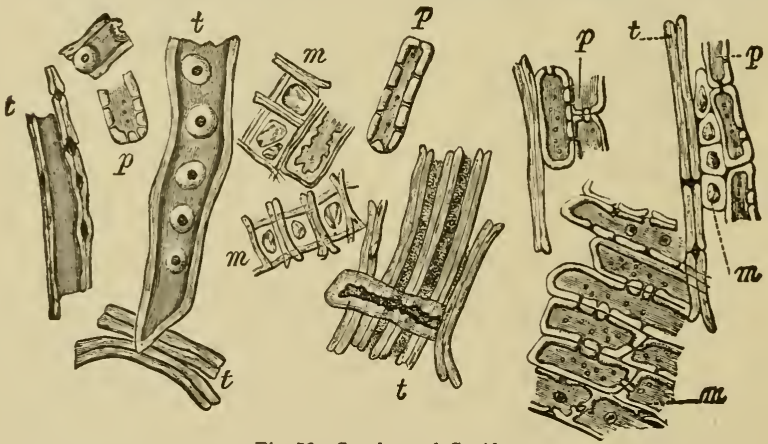

Fig. 79. Sawdust of Conifer.

$t$, Tracheid; $p$, wood parenchyma; $m$, (above), medullary rays of the fir; $m$, (below), medullary rays of the pine. (X 160.) (After Moeller.)

The tough seed coats of the Leguminosæ are composed of very long and to some extent thick-walled palisade cells containing tannin and covered on the outside with a layer of cuticle (Fig. 77). The chief adulterants of meals, brans, oil cakes, etc., consist of rice chaff, fruit-stone refuse, sawdust, weed seeds, screenings and castor oil beans.

19Koenig, Untersuchung landwirtschaftlicher und gewerblich wichtiger Stoffe. P. Parey, Berlin, 1911. 
The highly silicified glumes of the chaff of rice have no feed value whatever but rather interfere with the digestibility of other feeding material. Rice glumes may be recognized by the cells of their cuticle, with their long, firmly interlocking, jagged projections (Fig. 76). Between the latter cells are found simple round cells which come to view after treatment with caustic solutions (p. 141).

The refuse of button manufacture from the ivory nut, Phytelephas macrocarpa, has no feeding value. The comparatively thin seed coat consists of sclerenchymatous cells, prominent among which are the outer spindle-shaped cells. Beneath the seed coat lies the well-developed endosperm $(E)$. It consists of cells with exceptionally thick walls with peculiar buttonlike pores at the base.
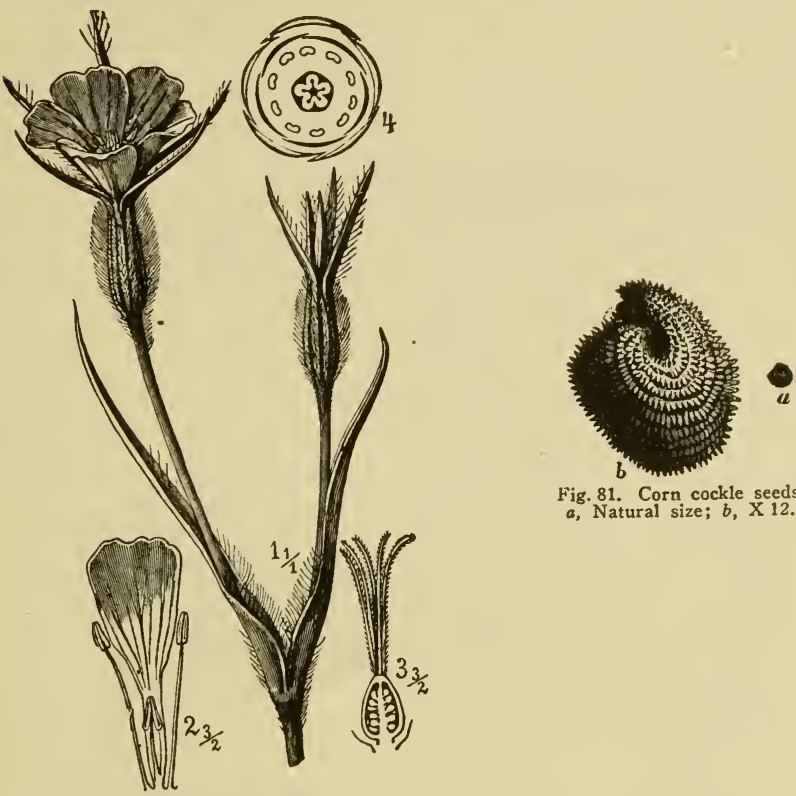

Fig. 81. Corn cockle seeds. a, Natural size; $b, \mathrm{X} 12$.

Fig. 80. Corn cockle.

1, Flower stem; 2 , longitudinal section of flower 3 , longitudinal section of ovary with stigma; 4 , cross section of flower.

Sawdust stains yellow upon addition of caustic potash solution and is easily recognized with the unaided eye or by means of low magnifying power. In sawdust from Coniferæ the microscope reveals chiefly the characteristic tracheids and medullary ray cells. Parenchymous cells, except in the fir (Abies, Fig. 79) are less frequently met with. In sawdust from deciduous trees libriform tissues predominate.

Feed meals and brans are frequently adulterated with screenings. The latter consist of all kinds of weed seeds, broken grains of the cereals, ergot, spores of fungi, chaff, maggots, beetles, mouse excrement, particles of earth, sweepings, etc.

Weed seeds are usually easily recognized by their brown, blackish and often rough seed coats. They occur in the screenings and are often ground up and mixed with meals but chiefly with bran. 
According to resolutions of the Association of German Agricultural Experiment Stations, bran, and above all, meal or flour, must be the product of previously thoroughly cleaned grain. The term "bran" can not properly be applied to ground hulls, pods, chaffs, etc., like ground peanut shells, millet hulls, rice chaff, oat hulls, etc. The terms grout or groats (German Schrot) are applied to coarsely ground whole grain with no parts thereof removed nor any foreign material added.

Of the numerous weed seeds mention is here made merely of the poisonous corn cockle, vetches, the various species of Polygonum or knotgrass, cow wheat, Atriplex or notchweed, corn crowfoot (Ranunculus arvensis), poisonous darnel and other grass seeds, field mustard, charlock, corn flower, etc.

The seeds of corn cockle when viewed with the unaided eye appear as roundish, reniform, blackish structures about $2 \mathrm{~mm}$. in diameter (Fig. 81, a). Under low

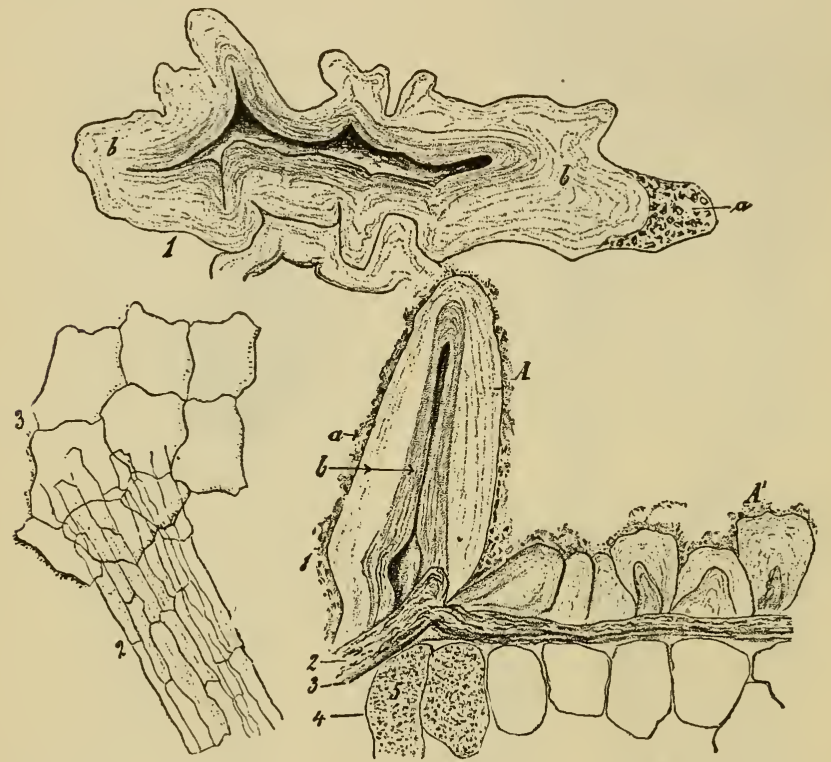

Fig. 82. Corn cockle. 1, Outer seed coat; A and $\mathrm{A}^{\prime}$, protuberances; $a$, warty excrescence on the same; $b, 2$, and 3 , strata of parenchyma; 4 , starch cells; 5 , starch grains in cross section; $B$, tangential section, figures as preceding. (X 200.) (After Boehmer.)

magnifying power the spirally arranged protuberances can be recognized. When cleared material (p. 143) is viewed under the microscope the characteristic cells of the seed coat can be recognized (Fig. 82). The starch grains have the characteristics mentioned on page 141. In searching for the latter the meal, bran, etc., under examination should be moistened with water only, and not brought in contact with or boiled in acids or caustic solutions.

In regard to Vogl's reaction see page 133; hemolysis, page 135 . The saponin reaction is also sometimes used to detect the presence of corn cockle seed. Extract one part of meal with two parts of 85 per cent hot alcohol, filter while still hot, and when cool treat with absolute alcohol. Saponin precipitates when cold. It may be purified by redissolving in alcohol and precipitating in absolute alcohol. Identification: Effervescence in water and reddish violet color when treated with concentrated sulphuric acid. 
Castor beans are not infrequently used as adulterants of oil meals, peanut meal, etc., especially those of South Russian origin. The presence of ricin (a toxin) gives them their poisonous character (gastrocnteritis, nephritis, agalactia, fainting, spasms, death).

Microscopically their thick, slivery, sharp-edged and longitudinally marbled skins are characteristic. Macerated material shows the radially arranged palisade cells (Fig. 82) and the parenchyma with its varied spiral tubes (Fig. 83).

The decorticated seeds have little that is characteristic to distinguish them microscopically. Their presence is determined by the complement fixation test (p. 134).

\section{Bacteriological Examination}

The spoiling or decomposition of air-dry feeding stuffs (meals, brans, oil cakes, etc.) is caused chiefly by molds.

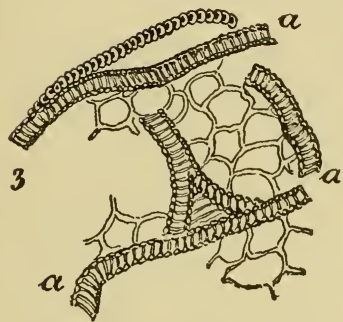

Fig. 83. Castor bean seed.

Parenchyma of the seed after treatment with ether and alcohol.

$a$, Spiral tube of the seed coat.

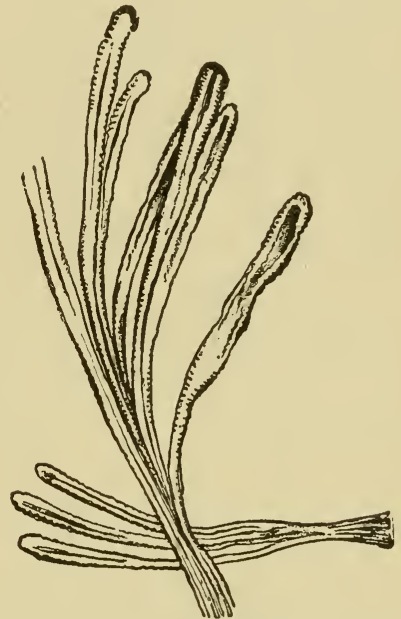

Fig. 84. Castor bean seed. Elongated cells of the seed coat after treatment with ether and caustic potash. (X 300.) (After Koenig.)

For the detection of their presence we resort to-

1. Odor. Musty, moldy, sour or rancid odors indicate the presence of mold fungi.

2. Cultural methods. For this purpose use covered Petri dishes containing a layer of sterilized sand 2 to $5 \mathrm{~mm}$. in thickness. Two grams of the feeding stuff to be examined are spread over the sand with the aid of a sterilized brush and moistened with water which has been slightly acidulated with lactic acid. Some of these dishes are kept at a temperature of $37^{\circ} \mathrm{C}$. $\left(98.6^{\circ} \mathrm{F}\right.$.), and others at ordinary room temperature. Good feeding stuffs will show at most an insignificant moldiness after 24 hours and do not smell putrid, musty nor rancid.

For the detection of mites see Klimmer, Hygiene. 


\section{Section II}

\section{Principles of Nutrition and Feeding}

\section{A. General Matter}

The character of feeding influences the development, serviceableness and resisting power of the animal body. Insufficient nutriment prevents the proper development of the organs of the body. Muscles and glands (udder) lose functioning power and the body as a whole becomes stunted. A poorly nourished body is more susceptible to disease, suffers more from the effects of fevers and requires a longer time to recuperate. During starvation the body is nourished by its own tissues, particularly the fat ( 95 per cent may be consumed). Muscles and glands are also drawn upon (40 to 50 per cent); the bones suffer less ( 12 per cent), and the nervous system least ( 2 to 3 per cent). Reduction to one-half of the body-weight of an animal in good condition results in death. Overfeeding should also be avoided. Excessive amounts of feed cannot be digested; they decompose, ferment, and may give rise to disturbance of appetite, gastrointestinal catarrh, overloading, constipation, colic, etc.

Feed (nutriment) is composed of the various feeding stuffs, and the latter, on their part, are composed of nutrients.

The various nutrients, with the exception of water and common salt, are practically never ingested separately, that is, as such, but in combination with other nutrients and indigestible matter, which latter serves chiefly to give volume or bulk. Nearly all feeding stuffs consist of mixtures of this kind. Only a few feeding stuffs, however, contain the nutrient elements required for the proper nourishment of the animal body, in mixtures of proper proportion (so-called complete feeding stuffs, like milk for sucklings and grass for herbivora). As a rule, a mixture of several feeding stuffs is required, so that an excess of a certain nutrient in one will balance a deficiency in the other, and vice versa. Feeding stuffs which, though not necessarily constituting complete rations in themselves, constitute the greater part of the ration, are referred to as basal feeding stuffs, like hay for herbivora and potatoes for swine. Feeding stuffs which, owing to their chemical composition or other characteristics, are fed in smaller quantities, like potatoes for horses, chaff and pods for swine, are referred to as supplemental feeding stuffs. Basal and suplemental feeding stuffs should not be confused with correctives or by-feeds, which are characterized by their unbalanced composition and are therefore used for correcting deficiencies of certain nutrients. Correctives frequently have dietetic and stimulating effects on digestion (young thistles in the spring of the year for horses) or specific action on 
the secretory function of the milk glands (cottonseed meal for cows), etc.

The term concentrates is applied to feeding stuffs rich in easily digestible nutrients and containing comparatively little indigestible material or water, like the grains, oil cake, malt sprouts, dried brewers' grains, bran, feed meals, etc. Feeding stuffs comparatively poor in nutrients but containing large quantities of indigestible matter like crude fiber are referred to as roughages, like straw chaff, hulls, low-grade hay, etc. Succulent and fluid feeding stuffs include green feed (soiling), silage, root crops and tubers, distillery slops, milk and creamery by-products.

The animal body requires water, salts, a part of the albumen and of the fat (or of the carbohydrates) for tissue building and for tissue repair. These substances are therefore referred to as organic substances. The substances which, in the course of metabolism, constitute sources of heat and energy, are called combustibles. The chief and most important of these are the carbohydrates, most of the assimilated fat and no inconsiderable portion of the albumen. The physiological action of nutrients is in proportion to the amount of heat produced in the process of their combustion, 1 minus the heat units that are lost in the undigested or unassimilated products of excretion (feces and urine). The action of the organic nutrients may therefore be looked upon as a calorimetric effect. Numerous determinations have demonstrated that 1 gram of albumen develops 4.1 calories in combustion, 1 gram of fat 9.3 calories, and 1 gram of carbohydrates 4.1 calories. The different combustibles may replace one another, or be substituted for one another in proportion to the amount of heat they produce in combustion. They are isodynamic in the same proportion (Rubner). One part of fat corresponds to 2.27 parts of carbohydrates or albumen. These values, expressed in terms of calories are referred to as fuel value or energy value. This unit of measurement may also be used to express the requirements of animals for available energy. For example, an ox weighing 1,200 pounds requires for its maintenance a daily supply of 12,800 calories.

If an animal is supplied with just sufficient nutrient elements in its feed so that it will neither gain nor lose weight, the ration is referred to as a maintenance ration. On the other hand, if in addition to this an excess of nutrients is supplied which goes to form muscle, fat, milk, wool, or useful work, the entire amount of feed supplied is referred to as a productive ration.

In feeding for production we might compare an animal with an engine or a machine which converts coarse feed products of low value (grass, hay, beets, etc.) into refined food products of high value (meat, fat, milk, etc.), or into work, or valuable raw material (wool, leather, horn, etc.) Successful feeding operations must therefore be governed and guided by the principle of producing the greatest possible results with the least possible expense.

In order to determine with scientific exactness the amount and chemical composition of feed required for an animal under different conditions it is necessary to determine what part of the nutrient elements are converted into tissue and energy. This is computed on the basis of the amount and character of the feed consumed and of the products of excretion found in the feces and urine or thrown off by the lungs and the skin. As a rule these calculations are based on the amount of nitrogen

1The fuel value of a given feed is determined by burning a weighed amount of the same in a bomb-like apparatus (calorimeter) filled with condensed oxygen. 'Ihe calorimeter is submersed in a measured quantity of water and the gain in temperature of the latter, measured with a thermometer, gives the result in terms of calories. For more detailed information see Berthelot, Praktische Anleitung zur Ausfuehrung thermochemischer Messungen, 1893; O. Kellner, Landw, Versuchsstationen 1896 , vol. 217, p. 293 , etc. 
and carbon consumed, although sometimes they are based on the amount of energy conversion. For technical details the reader is referred to Kellner, Die Ernaehrung der Landwirtschaftlichen Nutztiere (The Nutrition of Domestic Animals).

The energy contained in the nutrients which animals consume is used up in part by the work connected with the process of digestion (mastication, mechanical and secretory functions of the digestive organs, etc.), by processes of decomposition of various kinds, mechanical work connected with absorption, circulation and assimilation, and finally converted into heat. The experiments of Rubner have shown to what extent the various nutrients are able to provide this energy. $\mathrm{He}$ found, for instance, that a dog, in order to maintain its energy equilibrium, with the surrounding air at a temperature at $33^{\circ}$ C. $\left(91.4^{\circ}\right.$ F.), must consume 140.2 calories in the form of pure meat, or 114.5 calories in the form of fat, or 106.4 calories in the form of cane sugar, for each 100 calories of heat given off. Thus the net energy value of meat is only 71.3 per cent of its total energy value, that of fat 87.3 per cent and that of cane sugar 94 per cent. The difference is converted into heat and might be looked upon as loss.

The act of feeding in itself is thus always attended with heat production. The latter process is always materially influenced by the physical character and the chemical composition of the feed. For example, roughage like straw requires more mechanical work in its mastication and its conveyance along the course of the alimentary tract than gruel. According to Zuntz and Hagemann, the mechanical work required by the horse to masticate $1 \mathrm{~kg}$. of meadow hay amounts to 167.4 calories, $1 \mathrm{~kg}$. of a mixture of oats and chaffed straw $(1: 6)$ requires 64.2 calories, $1 \mathrm{~kg}$. of a mixture of corn and chaffed straw $(1: 6) 35.7$ calories, and $1 \mathrm{~kg}$. green alfalfa 30.4 calories. The work required to digest feeding stuffs free or nearly free from crude fiber, like meat, rice and bread, is about 9 per cent of their total energy value. The total energy value of $1 \mathrm{~kg}$. of oats is 2,622 calories, but the available useful or net energy, which remains after deducting the above mentioned losses which occur in the process of digestion, is only 2,121 calories. That of $1 \mathrm{~kg}$. of meadow hay (total 1,580 ) is only 699 ; that of $1 \mathrm{~kg}$. of wheat straw (total 705 calories) requires 1,165 calories for the work of digestion, etc., or 460 calories more than it actually contains. The amount of heat produced in the digestion of a liberal "production" ration (for fat or milk production) may be so great that the conversion of the available calories into tissue or energy becomes independent of the surrounding temperature (as in ruminants, for example). On the other hand, the amount of heat produced in this manner in swine, which subsist on milk, tubers, root crops and grain, etc., is much less, owing to the nature of the feed consumed. In swine the surrounding temperature exercises a comparatively great influence on the conversion of the food elements into tissue and energy. The effect of the temperature of the surrounding atmosphere is also less in herbivora kept on maintenance rations consisting of roughage like hay and straw that require a great amount of mechanical work in their digestion; in other words, feeds that furnish a large amount of thermal energy. But even under such conditions low external temperatures always call for an increased food supply.

\section{Nutrient Requirements}

\section{Assimilation and Utilization}

Digestion and assimilation (or metabolism) of feed are influenced by species, breed, individuality, exercise, etc.

Feeding stuffs rich in crude fiber are digested and utilized by cattle to better advantage than by any other farm animals. Sheep come next in this respect, followed by horses and swine in the order named.

In regard to the utilization of crude protein there is no difference between cattle and sheep and only a slight one in favor of the horse. The same is true of the nitrogen-free extract, but there is a more marked difference in the ability of the different species of farm animals to digest and utilize the crude fat. Roughage like wheat chaff or brewers' grains and distillery slops are utilized much less perfectly by swine than by 
herbivora. There is more uniformity in this respect with regard to oil cake and the grains. But the digested portions in this instance produce a greater gain in swine than in ruminants. The difference, according to Fingerling, amounts to 30 per cent if the nutrients are administered in easily digestible form.

According to Kellner, and contrary to general belief, age and breed do not influence digestibility. Individual animals, however, may show a difference of 3 or 4 per cent in this respect.

The influence of exercise has at various times been the subject of study and investigation. The results have shown that moderate exercise does not affect digestion unfavorably (this does not take into detailed consideration the effect of exercise upon the digestive processes in the different portions of the digestive tract). Grandeau and Leclerc found, however, that active work, in a walk or trot, has an unfavorable influence upon protein digestion.

Excessive additions of carbohydrates to the ration may, under certain conditions, retard digestion. The same is true of the fats when administered in bulk but not when given in a finely divided state. Increase of the proteids favors digestion. The relative proportions of the nutrients to insure digestion of all feeding stuffs, should not exceed 1 to 10 per cattle, nor 1 to 12 for swine. Cattle powders, milk powders, fattening powders, appetizer powders, etc., have no favorable effect upon digestion in otherwise healthy animals.

\section{Organic Nutrients}

The nutrient requirements vary according to species, breed, variety, age, purpose, etc. The live weight of the animal should constitute the basis of feed standardization and should be determined by frequently repeated weighings before feeding and always at the same hour of the day.

In the first place all animals require a certain amount of digestible albumen or protein. While albumen or protein may be substituted to a certain extent for the fat and carbohydrates of a ration, it can not be replaced by the latter. The comparatively high price of protein is at the bottom of the custom usually followed in preparing rations with the minimum protein content. And yet agricultural interests in particular have frequently pointed out that it is better to feed an excess of protein than an excess of carbohydrates, on the economic ground that it results in a richer manure!

After completed development of all the organs, the requirements for proteids, in addition to the minimum for the support of life, are only what is required for the complete digestion of the food. Muscular energy and fat can be produced, or furnished, as a rule by the carbohydrates and the fat. Accordingly the requirements for protein are not high. In general, the need of mature animals is supplied by 1 pound of digestible protein for every 8 or 10 pounds of digestible nitrogen-free extract (carbohydrates plus fat $\times 2.2$ ). 
With reference to the digestibility and utilization of the nitrogenous compounds which are not albumens, see page 8 and following pages. With reference to vitamins see page 7 .

The fats and the carbohydrates may replace each other. One part of digestible fat corresponds to about 2.2 parts of digestible carbohydrates. For practical reasons it is not advisable to feed mature herbivora daily more than 1 pound of fat per 1,000 pounds live weight. Larger quantities are liable to cause digestive disturbances or to impair the appetite. On the other hand, young growing animals can digest, and actually require, considerably more fat. In general, fat is easily digested. Fats of low melting point (rape, linseed and poppy seed oil) are more easily digested than fats with a high melting point.

In regard to digestibility of crude fiber and nitrogen-free extract see page 11 and following pages.

The proteids, carbohydrates and fats may all form fat tissue. The question of fat formation from the proteids has long been a subject of dispute but it is now considered possible. This is a matter of little economic importance, however, (cf. p. 150 and reference above).

According to investigations of Kellner, nitrogenous substances not of an albuminous nature (like asparagin in particular) take no part in fat formation in the animal body.

The formation of fat in the animal body from nutrient fat of either vegetable or animal origin has been definitely demonstrated by numerous experiments. Even such fats as do not normally occur in certain species of animals, like rape oil, sheep tallow (in dogs) and iodin fat, are deposited in the animal tissues without material chemical changes and provided they consist of palmatin, stearin and olein, they are also excreted with the milk. These facts are of practical importance because they enable us to influence or control in one way or another the character (melting point, etc.) of the body fat as well as the fat secreted with the milk, by feeding liberal quantities of nutrient fat (oil cake, corn, rice feed meal, etc.). However, the nutrient fat is secreted in the milk, or with the milk, to a limited extent only, as will be explained more in detail in the chapter on feeding dairy animals. Sunflower seed cake, corn germs and tankage fed to sheep produce a soft, fatty tallow. Rapeseed cake with bran produce tallow of medium consistency, while peanut cake with coarsely ground barley, palmseed cake, as well as cottonseed meal, produce a hard, dry crumbly tallow. The following feeds for swine produce bacon of quality indicated ( 1 and 2 indicate good quality, 3 somewhat soft consistency, 4 to 5 poor quality): Grain, 1.5 ; barley, 1.4; corn, 2.7 ; feed beets, 1.7 ; carrots, 1.5 ; turnips, 1.6 ; wheat bran, 2.8 ; sunflower seed cake, 3.4 ; two-thirds grain plus one-third palmseed cake, 1.0. Notwithstanding that under ordinary conditions the body fat of each species of animal still possesses its peculiar characteristic, this is due to the fact that ordinarily there is always a deficiency of fat nutri- 
ents and the body fat is produced chiefly through cell activity from carbohydrates and proteids.

According to Rubner, 87 per cent of the digested fat in carnivora is deposited in the tissues. In herbivora, in which more extensive bacterial changes occur in the digestive tract, the amount is less (Kellner). For oil emulsions it is 64.4 per cent, for the fats contained in roughages 47.4 per cent, for the fats in the grains and the seeds of the legumes and their by-products 52.6 per cent. Kellner is of the opinion that the last percentage would be applicable to the total fat content of the usual feed mixtures.

Under ordinary conditions the main source of the body fat in our farm animals is to be found in the carbohydrates. Fat formation from the carbohydrates is not affected by the nutrient ratio, even within wide limits $(1: 2.4$ to $1: 14)$. According to Kellner, $1 \mathrm{~kg}$. of digested starch can form $248 \mathrm{gm}$. (56.4 per cent of its total calories), crude fiber 253 gm. ( 57.0 per cent), cane sugar 188 gm. (46.2 per cent), body fat in the mature ox. The rest is used up in the work of assimilation and in the fermentation and decomposition processes of the stomach and intestine. In this respect swine utilize the digestible carbohydrates, fats and albuminous substances to the extent of 20 to 25 per cent more than ruminants (no decomposition in the fore stomachs).

The pentosans are hardly inferior to the carbohydrates as fat producers. On the other hand, the organic acids take no part in fat formation. With reference to conditions obtaining in the secretion of milk, see chapter on feeding dairy animals.

While all three of the principal nutrients are concerned in the formation of fat, flesh is formed by the protcids exclusively.

A material increase of body protein (excepting nitrogenous products in the form of milk, wool and fetal structures) does not take place in mature animals. But such an increase is very great in suckling calves. According to Soxhlet, the latter utilize on an average 72 per cent of the digestible proteins in milk in the building of fleshy tissue. As age advances this percentage gradually decreases until it practically reaches the zero mark in mature animals. In the latter the muscle fibers no longer increase in number, and an increase in their size is possible in a limited way only. Accordingly, this question does not concern us in the fattening of mature animals in an average condition of flesh. In such animals the chief end sought is fat production.

Above everything else, the carbohydrates of the feed and the glycogen stored up in the body tissues are the chief sources of muscular energy. Proteins or albumen are required merely to the extent that they are necessary for repairing the wasted muscle substance, which is the same at rest as it is during or after exercise. The body fat is not utilized in the production of muscular energy until the supply of carbohydrates becomes insuffcient. The organized proteids are drawn upon only in case both carbohydrates and fat fail to supply the demand. In 
the feeding of work animals, therefore, the main problem is to furnish a sufficient supply of nitrogen-free nutrients, while high protein content is of minor importance.

Zuntz and his co-workers have studied the problem of the consumption of nutrients in different kinds of work and demonstrated that the dog employed in draft work on a level course utilizes 29 per cent of the entire energy expended, in useful performance, and 30.7 per cent in steep up-grade work. Man utilizes 33 per cent, herbivora in horizontal motion 35 per cent and in horizontal draft 31.3 per cent.

Zuntz, Lehmann and Hagemann determined the following valuations for the horse:

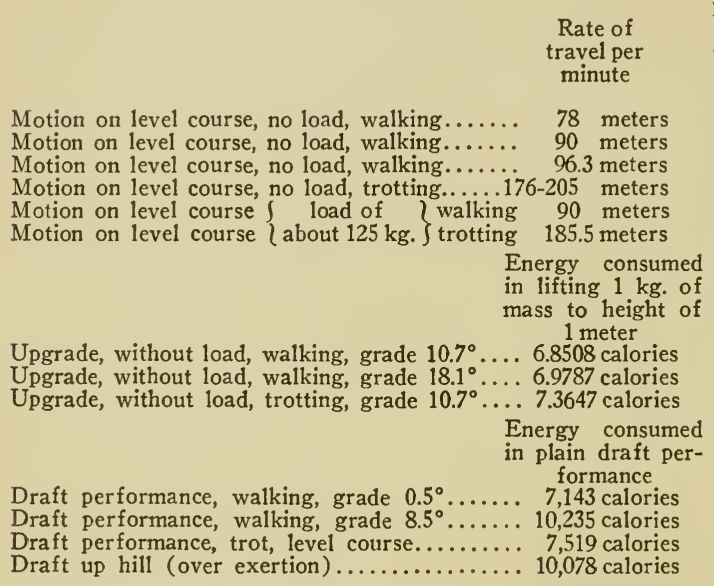

Energy consumed per $1 \mathrm{~kg}$. of mass (animal + harness + load, if any) for distance of one meter 0.3256 calories 0.3530 calories 0.4346 calories 0.5478 calories 0.3914 calories 0.6007 calories

Efficiency

$34.3 \%$

$33.7 \%$

$32.0 \%$

Efficiency

$31.3 \%$

$22.7 \%$

$31.3 \%$

$23.0 \%$

Energy consumption and effciency are to no inconsiderable degree affected by individuality, practice and fatigue. On the other hand, the amount of energy consumed is not affected by the character of the nutrients. Digested albumen, fat and digested carbohydrates may, after deduction of the work or energy required for mastication and digestion, replace one another according to isodynamic values.

\section{Inorganic Nutrients}

In addition to the organic nutrients, animals require a sufficient supply of inorganic substances. These are absolutely necessary for the support of life and the maintenance of health. Withdrawal of these substances from the food causes disease and death. For instance, pigeons when deprived of the mineral matter in the food, but receiving an abundance of albumen, fat and carbohydrates, will die in from 13 to 29 days (they 
will live 12 days when all food is withheld), and dogs will die in from 26 to 36 days.

Under natural conditions animals usually receive sufficient mineral matter ${ }^{2}$ in their food. When kept in captivity or under domestication, especially when fed under the stable conditions, with factory by-products and receiving straw instead of hay, they are liable to suffer from lack of these important elements and become diseased (halisteresis). Proper attention should therefore be given to the inorganic constituents of the animal's feed.

The mineral matter occurs in feeding stuffs in part as inorganic salts, in part as organic compounds. The latter, though occurring in very small quantities are, on account of the facility with which they are absorbed, of great importance. Among the mineral substances which are necessary for the support of life we have potash, sodium, calcium, magnesium, iron, phosphorus and chlorin. They are therefore referred to as biogenic elements. In addition they have certain special functions to perform in the economy of the animal organism, as, for instance, the function of phosphate and carbonate of lime in building and maintaining the structure of the bones. If lime is absent the bones become soft and brittle. Deficiency in the supply of iron is apt to produce anemia, while deficiency in potash causes licking disease, etc.

The salts of phosphorus are necessary, above all, for the growth and maintenance of the bony structures of the body. Of course these salts have additional functions in the vital processes of the body. The life of every cell is dependent, among other things, on the presence of the nutrient salts.

The content of lime and phosphoric acid salts is dependent in the first place on the kind of feeding stuff, and the latter, on the other hand, on soil conditions and the moisture content of the soil. In times of drouth there is lack of water as a solvent for the salts; under such conditions plants can take up only a limited quantity of these substances and as a consequence animals are supplied with a deficiency. It is a common observation that softening and brittleness of the bones assumes an enzootic character in dry seasons. Again in dry seasons (times of stress) feeding stuffs rich in lime, like hay, are frequently displaced by those of an opposite character, like straw, which are deficient in lime. The unfavorable effects are further emphasized by increased consumption of the salts in question by the animal organism. This is particularly true with respect to the salts of lime and phosphorus in the latter stages of pregnancy when the bony structures of the fetus draw heavily upon

2Excess quantities of mineral matter taken up with the food and not used for tissue building are excreted in the feces and urine. When the total ash or mineral matter in the food gives an acid reaction, the phosphoric acid, lime and magnesia are for the greater part excreted with the urine, while under opposite conditions they are excreted with the feces. The ash content of meat milk, many grains and varieties of oil cake has an acid reaction. while that of green feed and roughage, roots and tubers is alkaline. Since the latter constitute the main nutriment of herbivora, the urine of these animals is alkaline in reaction and consequently poor in phosphoric acid, lime and magnesia; on the other hand, the opposite conditions prevail with sucklings and carnivora. 
the reserve supplies, and during heavy milk secretion or rapid growth. The amount of phosphate of lime excreted with the milk is quite marked. A cow giving 12 liters of milk per day excretes $84 \mathrm{gm}$. of salts which consist of lime 22.6 per cent and phosphoric acid 27.7 per cent. Thus the daily loss of these bone salts amounts to about $37 \mathrm{gm}$. Since the proportion of salts in milk may be regarded as constant (except in the colostrum), the loss of phosphate of lime is in proportion to the milk yeld. The heavy drain upon the bone-forming salts during pregnancy and increased milk secretion is a general explanation of the relative frequency of fragility or brittleness of bones in cows. The requirement for bone salts is influenced by the size and rate of growth of an animal.

The following table gives the lime and phosphorus requirements of the different species of animals according to sex and age. It should be noted also that animals (except sucklings) can utilize only one-half to one-third of these salts contained in the various feeding stuffs, and that the feed supplied should therefore contain twice or three times the actual requirement of these salts.

\section{Lime and Phosphoric Acid Requirements of Animals}

$$
\text { Kind of Animal }
$$

Wt. in lbs.

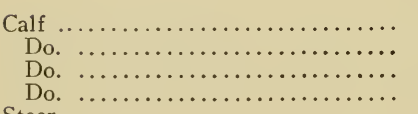

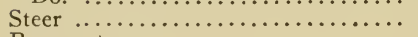

Pregnant cow
Milking cow 10 liters per 1,000 ibs. wt.

100

300

per 1,000

per 1,000

per 1,000

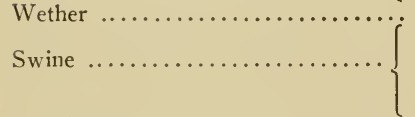

Dog $\{$ small breed.............. $\{$ large breed .....................
100 lbs.

100 lbs.

100 lbs.

100 lbs.

80 lbs.

100 lbs.

100 lbs.

$100 \mathrm{lbs}$.

$100 \mathrm{lbs}$.

$110 \mathrm{lbs}$.

Horse
3-6

6-9

1,000
Age

2 to 3 weeks 5 months

5 to 6 months $14-1$

1 year

mature

mature

1 month

$51 / 2$ months

7 months

$8 \mathrm{~T} / 2$ months

10 months

$111 / 2$ months

13 months

$14 \mathrm{r} / 2$ months

16 months

2 yrs., mature

$1-240$ days

8-11 months

1 year

mature
Lime re- Phosphorquirement ic acid reperday quirement per day $15 \mathrm{gm} . \quad 14 \mathrm{gm}$. 16

21

50

50

100

3.2

3.8

2.7

3.2

2.5

2.7

50.0
18

$18.5-22$

19

25

25

70

2.3

2.5

2.0

3.3

4.0

3.1

4.1

3.9

0.04

0.05

25

According to investigations of Soxhlet, the proportions of the daily amounts consumed and the amounts utilized by a suckling calf of 100 pounds live weight are as follows:

Consumed

Utilized

Lime …... $14.75 \mathrm{gm} \ldots \ldots \ldots \ldots \ldots .14 .31 \mathrm{gm}=97.0 \%$ of amount consumed. Phosphoric acid $18.90 \mathrm{gm} . \ldots \ldots \ldots \ldots \ldots \ldots \ldots \ldots \ldots \ldots+13.70 \mathrm{gm} .=72.5 \%$ of amount consumed. 
The percentage of other mineral matter utilized (except oxid of iron, which is 38 per cent) is less than 38 per cent of the amount consumed. According to the results above tabulated, the lime consumed has been so completely utilized that only 3 per cent of the amount consumed was excreted. Since a small portion of every mineral substance that plays a rôle in metabolism is excreted, even when entirely wanting in the feed consumed, the small amount of lime $(0.44 \mathrm{gm}$.) excreted can not be regarded as an excess in the feed supplied. On the contrary, the eagerness with which suckling calves consume lime-containing substances like mortar, lime and chalk is an indication that they do not receive an adequate supply in the milk and that the milk of our highly developed breeds of cattle is deficient in this bone-forming mineral and that an additional supply of lime in the form of precipitated chalk ( $15 \mathrm{gm}$. or $1 / 2 \mathrm{oz}$. daily) is advisable. Such daily doses of lime would have the additional advantage of assisting or furthering the utilization of the phosphoric acid in the building up of the bones.

Phosphoric acid and lime can usually be obtained on the market in the form of calcium phosphate, under such names as phosphated feed lime, bone feed meal, or precipitated calcium phosphate. Since lime and phosphoric acid precipitate each other in the digestive tract when the contents are alkaline in reaction and thus prevent absorption of either, or at least hinder the process, it is best to administer them separately and at different times. For example, the lime preparation (calcium chlorid $1 / 2 \mathrm{oz}$.) (or prepared chalk up to from 3 to 6 ounces per day for cattle) may be given daily for three successive days followed by some readily absorbable phosphate (sodium phosphate, tablespoonful three times a day for cattle) for three days. then lime salts again for three days, and so on, provided, of course, that the feed used is deficient in both of these elements. If both are deficient, both must be provided in this artificial manner. Since the proportion of lime to phosphoric acid in the bones is a rather constant one (52-40), an excess of either will not be used in the formation of bone tissue. As a matter of fact, an excess of phosphoric acid has a distinct tendency to make the deficiency in lime more pronounced than ever. In the feeding of large amounts of concentrates like the grains and oil cakes, with slops, beets, potatoes and straw, there is a deficiency of lime salts. This deficiency can usually be corrected and ordinarily it suffices merely to add the latter to the ration, but it is best to do this on the three-day interval plan. Where liberal fertilizing with phosphates is practiced for crops, addition of these salts to the feed can usually be dispensed with.

Lime in the form of prepared chalk is recommended with the feeding of sweet pressed feed and with sour silage. The lime precipitates or neutralizes the free acids and forms readily soluble compounds (lactate 
and acetate of lime). ${ }^{3}$ In other respects calcium chlorid is preferable, though it possesses the unpleasant or inconvenient property of being very hygroscopic. For this reason it is not used in the form of the pure salt but in solution. Calcium chlorid is purchasable in tins (calcium chlorid 70 per cent, water of crystallization 30 per cent), and this may be used in making a 1 per cent solution. Cattle, sheep and horses may receive one-half liter ( 1 quart) daily per 1,000 pounds live weight (about five-sixteenths of an ounce of calcium chlorid). Swine may have 3 pints of the solution per 1,000 pounds live weight, mixed with the feed. For sheep and horses it is best to administer it with the drinking water. The virtues of calcium chlorid solution have been widely arvertised and actively exploited in recent years. It is noted here, however, that this salt, or its solution, has no specific action on the function of milk secretion. The same effects may be had with any feed that is rich in lime salt, or with other soluble salts of lime.

Common salt.-Depriving an animal of this single mineral alone will result in death. It is an indispensable nutrient and serves among other purposes as the basis of hydrochloric acid formation in the stomach. The formation of hydrochloric acid is influenced by the relative proportions of the potash salts to those of sodium and hydrochloric acid, to the extent that the potash compounds displace the sodium in its combinations with chlorin and the resulting potassium chlorid (on account of the greater affinity of potash for chlorin) can no longer serve as the basis of hydrochloric acid production in the stomach. ${ }^{4}$ Since feeding stuffs (especially beets and molasses) contain a greater or less abundance of potash compounds, but are relatively deficient in sodium chlorid (as shown in the table in the appendix), the addition of common salt to rations is indicated to promote secretion of gastric juice and digestion. The craving of the organism for common salt when animals subsist on feeding stuffs rich in potash is due, in part, to the fact that the presence of the latter salt results in a certain loss of common salt. As already suggested, the potassium combines with the chlorin of common salt to form potassium chlorid, and the sodium which is liberated combines with the acid radicle of the potash. In this respect carbon dioxid is of chief importance. The result is that the organism (the blood) contains an excess of potassium chlorid and sodium carbonate. The kidneys. whose function it is to regulate the composition of the blood, excrete the excess (in this case potassium chlorid and sodium salts) and thus the sodium and chlorin content of the blood is lowered.

It is a common practice to give animals regular rations of salt. It is probably in rare cases only that there is an urgent necessity for this practice (different forms of licking disease). According to investigations of

\footnotetext{
3The anorehension that administration of carhonate of lime with its neutralizing effect upon the mastric inice would affect the full or normal utilization of nutrient flements has bern removed bv the results of exucrimente of Volhard. Vollhard found that the utilization of fond elements wase not affected even when tlre ammunt of lime consumed was sn ercat that 42 grams was daily excreted with the feces. thus excluding the possihility of acid reaction at any timc.

$42 \mathrm{NaCl}+\mathrm{K}_{2} \mathrm{CO}_{3}=2 \mathrm{KCl}+\mathrm{Na}_{2} \mathrm{CO}_{3}$.
} 
Weiske and Wolff, and contrary to popular opinion, common salt in no way materially affects digestion or utilization of nutrient elements favorably, providing that the animals in question receive normal and sound feed (meadow hay for sheep, meadow hay, oats and wheat straw for horses). However, additions of common salt to the ration are of decided value in stimulating appetite, favoring the production of hydrochloric acid in the stomach, and thus aiding gastric digestion, and diminishing the injurious effects of less suitable feeding stuffs, and further, increasing the deposit of proteins and inhibiting their breaking down. Stimulation of appetite is indicated in the feeding of large quantities of relaxing feeding stuffs (boiled potatoes, beet pulp, beets, meals, bran and oil-cake slops, potato fiber and other insipid material) to fattening animals and milk cows. But here too the requirements vary according to locality; in sea coast regions or other places where plants contain an abundance of common salt in their composition, additional doses of salt are hardly required. Animals may be provided with this nutrient mineral in the form of stock salt or rock salt.

Stock salt (German product) is common salt denaturized by the admixture of $1 / 4$ to $1 / 2$ per cent oxid of iron, $1 / 2$ per cent wormwood, and a small amount of red clay and powdered gentian root. Rock salt (German lick stone) corresponds more or less in its composition to stock salt, or it contains variable amounts (10 to 14 per cent) of gypsum, magnesium and sodium sulphate. These German "lick stones" are by-products of salt production from saline spring water, consisting of the residue or waste remaining in the evaporating pans.

(In the United States "stock salt" is merely coarse or impure table salt, more or less pure, and rock salt is the natural product of salt mines. -Translator.)

Daily doses for horses are $1 / 2$ to 1 ounce, milk cows $1 / 2$ to nearly 2 ounces, fattening cattle 3 to 5 ounces, sheep $1 / 8$ to $1 / 4$ ounce, and swine $1 / 6$ to $1 / 2$ ounce. It is not expedient to exceed these quantities. If common salt is given in excessively large doses, as, for instance, in the form of brine, it exerts an action similar to that of other neutral salts, namely, laxative, retards digestion and prevents full utilization of the nutrients and may even cause disease.

In exceptionally rare cases there may be a deficiency of potash salts (in addition to deficiency of sodium salts) in the feed. This actually occurs in some regions of the Erz mountains (between Saxony and Bohemia) and gives rise to diseases known among the populace as stable ill (Stall Mangel, licking disease). Animals refuse their feed (hay, drink and concentrates) and show a greedy desire for earth, manure, rotten straw, wood, etc., emaciate, become constipated and die from starvation. Postmortem examination usually reveals nothing striking except emaciation and anemia. The basis of the trouble is an alkali deficiency (especially salts of potash) and is technically known as halisteresis simplex, to distinguish it from deficiency of the bone-forming 
minerals (halisteresis ossium), which manifests itself in brittleness of the bones (osteomalacia) and in softness of the bones (rachitis). That the trouble is die to improper feed and not to other local conditions is demonstrated by the fact or observation that animals in other regions, when fed on hay from localities where the disease prevails, become affected in the same manner. On the other hand, hay from regions habitually free from the trouble will cure affected animals in the afflicted localities. Hay from these aftlicted regions is referred to as "sour hay." Such hay, however, is not "sour" because, as was formerly assumed, it contained unusual acids (humic acid), but because it is deficient in bases (potash) and will not serve to neutralize the excessive amounts of acid which are formed in the body when large quantities of hay are fed. The acids of the body eliminate the small supply of potash and rob it of this vitally important salt.

While the excess alkali in good hay represents about 30 units (nilligram equivalent for 100 grams of dry matter), hay which causes licking disease contains only from 5 to 10 units. Sometimes there is more chlorin present than can be taken up by the alkalies. The trouble can easily be avoided, however, by an abundant supply of feed that is rich in the missing alkalies (potash and sodium), $e . g$., molasses, 6 to 10 pounds for working oxen and fattening cattle, 3 to 4 pounds for milk cows, beginning with small quantities and gradually increasing.

Similar conditions prevailing in moorland or marsh pasture regions, may, in the opinion of the author, be remedied in the same way.

Lack of iron or its salts in feeding stuffs is probably only an exceptional occurrence, since the natural feeding stuffs usually contain an excess of this element. Lack of iron in the organism (anemia) is probably much more frequently due to other basic causes. This common ailment of sheep is attempted to be overcome by the administration of various iron preparations (sulphate of iron, daily 0.5 to $1.0 \mathrm{gm}$. for sheep, 3.0 to 5.0 gm. for cattle; blood meal, etc.).

In the feeding of animals the requirement of salt or mineral matter should be kept in mind in the selection of suitable feeding stuffs, rational fertilization, and, where necessary, in the correction of deficiencies by the addition of the salts found wanting. Care should be observed that the various mineral constituents are present in the proper proportions. The composition of milk may be used as a basis in this respect, because, with milk as a food, animals not only thrive best but the excretion of mineral matter is at a minimum. The mineral matter in cow's milk, figured on the basis of one liter consists of potash $1.7 \mathrm{gm}$., sodium 0.4 , lime 1.7, magnesia 0.2 , phosphoric acid 2.0, sulphuric acid 0.1 and chlorin $1.0 \mathrm{gm}$. These figures are, of course, more directly applicable to the requirements of the growing animal. The mature animal requiring considerably less potash and phosphoric acid, the proportion of these elements should be adjusted according to the character of work (muscular work, milk production, breeding, etc.) performed. 
The salts of iron have not as yet been discussed. The newborn animal possesses a greater supply of these than mature animals and can draw upon this excess for some time. Milk, compared with other feeding stuffs, is decidedly poor in iron.

The proportion in which $\mathrm{C}_{\mathrm{a}} \mathrm{O}, \mathrm{M}_{\mathrm{g}} \mathrm{O}, \mathrm{K}_{2} \mathrm{O}$ and $\mathrm{Na}_{2} \mathrm{O}$ occur is an important matter, as well as the proportion of the total chemical bases to the mineral acids. There should be an excess of the bases. An excess of acids would neutralize the bases of the skeleton and tend to dissolve the latter, that is, produce halisteresis and rachitis. With respect to acid excess, it should be noted that in the process of albumen combustion the oxidation of the sulphur produces sulphuric acid. In herbivora the presence of hippuric acid causes a further loss of the alkalies or bases. Since crude fiber constitutes the raw material from which hippuric acid is produced, grasses rich in this material (grasses of poor quality) have a tendency to deplete the supply of lime in the body. A marked excess of one salt as compared with the others required may disturb metabolism and under certain circumstances produce an actual deficiency of such other salts, even when the latter are taken up in normally required amounts. The magnesia content should not exceed that of lime in the ration, but should rather be in the proportion of 1 to 1.7 as compared with lime (the proportion in which these two salts occur in the blood).

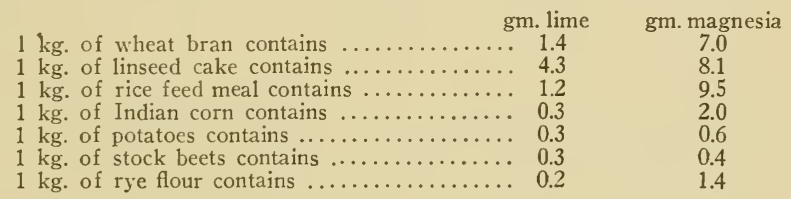

In contrast to the above,

$1 \mathrm{~kg}$. of meadow hay contains ........... 9.5

$1 \mathrm{~kg}$. of red clover hay contains ............ 20.1

$1 \mathrm{~kg}$. of oat straw contains ............. 3.8

$1 \mathrm{~kg}$. of cow's milk contains ............ 1.7

$1 \mathrm{~kg}$. of meat contains .................. 0.3

\section{Testing Feed Utilization and Assimilation}

In all feeding thorough digestion and complete utilization should be the objects constantly kept in mind, so that the end attained will justify the outlay. Examination of the feces will inform us in regard to the degree of digestion and absorption. The degree of utilization of the nutrients would be determined in an exact manner by chemical analysis. Here inspection of the feces would give some information along this line, though by no means always entirely satisfactory even for practical purposes. The presence of undigested grains should be noted (pressure exerted upon such grains forces out the soft interior, distinguishing them from empty skins or hulls!). Undigested particles of potatoes or other food fragments are significant. The microscope will be an aid in recog- 
nizing unaltered plant tissues, while the iodin test is specific for starch granules (blue color).

Morever, feed utilization may be controlled by noting the "condition" of an animal, its live weight, and the character of its "performance." Feeding should be adjusted to "performance." A common error consists in short rationing an animal (especially milk cows) during the cold winter months. In such cases an animal may receive a sufficient, or nearly sufficient, maintenance ration, but have nothing left for "production." We do not get the full advantage of the animal's producing power. This raises the cost of production as illustrated by the following statement, in which the price of milk is figured at 18 pfennigs per kilogram (about 4.5 cents per quart) and the starch value, including the albumen, is estimated at the same figure ( $18 \mathrm{pf}$. per $\mathrm{kg}$. or 4.5 cents). ${ }^{5}$

$\begin{array}{cc}\begin{array}{c}\text { Amount of feed received } \\ \text { Starch value } \\ \text { Kilogram }\end{array} & \begin{array}{c}\text { Albumen } \\ \text { Kilogram }\end{array} \\ 3.0 & 0.30 \\ 3.2 & 0.36 \\ 3.4 & 0.42 \\ 3.6 & 0.48 \\ 3.8 & 0.54 \\ 4.0 & 0.60 \\ 5.0 & 0.90 \\ 6.0 & 1.20 \\ 7.0 & 1.50\end{array}$

Cost of feed
in pfennigs
(1/4 cent)
54.0
57.6
61.2
64.8
68.4
72.0
90.9
108.0
126.0

Milk yiclded
Kilogram
(about 1 qt.)
1
2
3
4
5
10
5
20

$1 \mathrm{~kg}$. milk (1 qt.) Cost of feed in pfennigs $(1 / 4$ cent $)$

57.6
30.6
21.6
17.1
14.4
9.1
7.2
6.3

Furthermore, in the feeding of milk cows special attention should be given to the proper proportioning of proteids in the feed. Since large amounts of protein are excreted with the milk, the feed should be relatively rich in this nutrient. It follows, therefore, that in recent times highly nitrogenous oil-cake is preferred to rape and palm-cake, crushed grain, molasses, bran, etc. If the principle of feeding according to product yielded were strictly carried out the ration of each individual animal should be accurately weighed and the amount fed adjusted in proportion to the live weight of the animal and its actual yield of milk. But serious objections, or difficulties of an economic character, may be raised against this practice. These individual weighings require much extra labor, and special feeding arrangements are necessary to insure that each animal receives the ration intended for it, and no more (see article on mangers and feeding racks in the author's work on hygiene).

Where individual feeding is impracticable, so-called group feeding may be resorted to. This consists of dividing the herd into a number of groups the individuals of which have similar requirements. The number of groups formed would vary with the size of the herd and with the help available. Ordinarily from three to eight such groups answer

\footnotetext{
5Translator's Note: Since the idea intended to be conveyed is just as vividly illustrated with metric weights and German money denominations, the translator transcribed the original copy without any changes.
} 
the purpose very well. The three-group arrangement would provide, for example, for cows yielding from 1 to 3 liters of milk, 3 to 10 liters, and over 10 liters daily, respectively.

Below is given an illustration of a five-group arrangement:

Group I Group II Group III Group IV Group V

Feeds 15-20 Liters 10-15 Liters 5-10 Liters 1-5 Liters Dry Cows

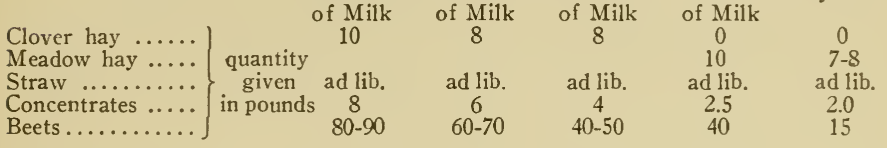

The concentrates consist of 3 parts wheat bran, 4 parts cottonseed meal or cake, 4 parts sunflower meal or cake and 4 parts peanut meal or cake.

When group feeding is not practicable in every detail, the same basal feed may be given to all animals (hay, straw, chaff, beets), and the concentrates may be adjusted to the requirements of the individual, without disturbing the arrangement of the cattle. According to Geissler, one may, for instance, give one measure of feed to all cows yielding 5 liters (or quarts) of milk, 2 measures to those yielding from 6 to 8 liters (or quarts), etc. A name plate should be provided for each cow, giving the usual information with regard to age, breeding date, etc., and temporary chalk marks may indicate the number of measures full of concentrates for each animal.

The cost of the feed should of course bear a certain relation to the animal product, in order to insure the expected pecuniary advantage. The fact that one animal may be a more economical or profitable feeder, produce more milk, meat or muscular energy from a given amount of feed than another, has long been common knowledge. For decades this fact has been regarded with indifference. Even today we have as yet no proper conception of the extent to which feed utilization (especially in dairy cattle) can be increased or the degree to which productive power may be developed.

In experiments with feed utilization, especially as conducted on dairy cattle, it has frequently been shown that the expense of feeding not infrequently even exceeds the returns. The Danish control or testing associations, first organized about twenty years ago, deserve much credit for drawing general attention to these conditions. Cow-testing associations, organized on the Danish plan, and which have as one of their objects the identification of every "passive" animal in the district, have now been established in nearly all civilized countries. (In the United States since 1905.-Tranlator.)

The following illustration shows to what remarkable extent the "cost of production" may vary:

The Danish Control Association Alling showed (1896) that among 54 cows the best two, A and B, produced 5,268 and 7.862 pounds of milk and 234.4 and 309.95 pounds of butter, respectively, at a cost of 62.6 and 58 öre (öre $=a$ little less 
than $1 / 3$ cent) per pound of butter. On the other hand, the poorest two cows, C and $\mathrm{D}$, produced 5,861 and 3,111 pounds of milk and 205.3 and 139.91 pounds of butter, respectively. The cost of the feed for these cows per pound of butter produced was 115.6 and 112 öre. The market price was the same in both instances, 92 öre per pound.

This illustration shows clearly that production power considered by itself is no safe basis of valuation for a cow, but that the cost must also be considered. Compare cow A with cow C:

The number or percentage of passive cows (for which the feed cost is higher than the product value) is subject to considerable variation in different dairies. On an average the number of passive cows in dairies in general ranges from 35 to 60 per cent. By systematic culling of the cows recognized as unproductive, and breeding up from the productive animals, these associations have succeeded in increasing the milk and butter production and in lowering the feed requirements and production cost. The following averages based on figures from 250 cows in the Testing Association of Faarup will illustrate:

$\begin{array}{ccccc}\text { Year } & \begin{array}{c}\text { Pounds of } \\ \text { milk }\end{array} & \begin{array}{c}\text { Per cent } \\ \text { of fat }\end{array} & \begin{array}{c}\text { Feed units } \\ \text { consumed }\end{array} & \begin{array}{c}\text { Pounds of butter } \\ \text { produced by } 100 \\ \text { feed units }\end{array} \\ 1899-1900 & 5162 & 3.34 & 3921 & 4.87 \\ 1900-1901 & 5284 & 3.44 & 3919 & 5.10 \\ 1901-1902 & 6104 & 3.50 & 4144 & 5.74\end{array}$

The improvements thus brought about in the course of a few decades are simply marvelous and are in accord with observations made in other countries, as for instance the Control Association Gramm in Schleswig-Holstein, 1899 to 1902 (also cow-testing associations and registers of merit or advanced registers in the United States.-Translator).

In 1902 the net profit per cow in 20 dairies ranged between 13.59 and 147.37 marks $(\$ 3.39$ and $\$ 36.84)$. The differences are still more marked when the annual yields of the best and poorest cows of the same dairy are compared with a statement of production expenses. Even in small dairies with from 5 to 11 cows the annual difference between extremes amounts to from 79 to 244 marks ( $\$ 20$ to $\$ 61$ ).

\begin{tabular}{|c|c|c|c|c|c|c|c|c|c|}
\hline \multirow{4}{*}{$\begin{array}{l}\text { Year } \\
1899\end{array}$} & \multirow[b]{2}{*}{$\begin{array}{l}\text { Pounds } \\
\text { of milk }\end{array}$} & \multirow[b]{2}{*}{ Fat } & \multirow[b]{2}{*}{ Pounds } & \multicolumn{3}{|c|}{ Feeding units consumed } & \multicolumn{3}{|c|}{100 feeding units Net } \\
\hline & & & & $\begin{array}{l}\text { Concen- } \\
\text { trates }\end{array}$ & $\begin{array}{l}\text { Other } \\
\text { feed }\end{array}$ & Total & $\begin{array}{l}\text { Pounds } \\
\text { of milk }\end{array}$ & $\begin{array}{l}\text { Pounds } \\
\text { of butter }\end{array}$ & $\begin{array}{l}\text { less cost } \\
\text { of feed }\end{array}$ \\
\hline & & & 191.77 & 1,074 & 3,600 & 4,6 & 114 & 4.10 & 8.96 \\
\hline & & & 19 & 1,0 & & 4,6 & 12 & 4.23 & 25.00 \\
\hline & 5,7 & 3.25 & 201 & 1,0 & 3,4 & 4,6 & 127 & 4.45 & \\
\hline & 6,580 & 3.2 & 233.73 & 1,053 & 3,647 & 4,700 & 140 & 4.95 & 71 \\
\hline
\end{tabular}

The net profit from the best and the poorest cow under equal conditions of feed supply and keeping expense has been observed and determined in four experiment stations of the United States, as follows:

Annual Net Profit from-

\begin{tabular}{|c|c|c|c|}
\hline Experiment Station & The best cow & The poorest cow & Difference \\
\hline ....... & . $\$ 121.21$ & $\$ 43.71$ & $\$ 77.50$ \\
\hline Michigan & 76.25 & 6.38 & 69.87 \\
\hline New Jersey ............ & 52.21 & 0.14 & 52.07 \\
\hline Connecticut & 45.21 & -4.29 & 49.50 \\
\hline
\end{tabular}

The fact that a cow of good capacity will give almost double the product yielded by a cow of poor qualities, under the same conditions of feed and keep, of the same breed and the same herd, the same live weight and period of lactation, should certainly emphasize the practicability and the economy of breeding and feeding with a definite purpose in view.

\section{Calculation of Feeding Rations and Feeding}

Aside from maintaining health, the aim of rational feeding is to produce maximum returns from a minimum outlay. Feeding rations are 
calculated on the basis of live weight of the animal, taking into consideration age, size, sex (males in general require more nutrients than females, and the latter more than castrated animals), breed, individuality, the end sought and the capacity of the animal. The following condensed feeding standards from Kellner will afford an idea in this respect. (More exact details may be obtained from Klimmer-Johne, Hygiene of Domestic Animals, 2nd Ed., p. 148, etc.)

Digestible Nutrients

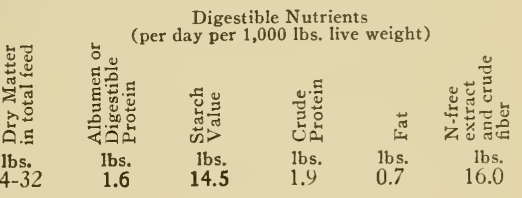

1. Mature fattening sheep....24-32

2. Lambs

(a) Wool breeds

5- 6 months, 56 pounds.... 27

6- 8 months, 66 pounds.... 25

8-11 months, 76 pounds.... 23

11-15 months, 82 pounds.... 22

15-20 months, 90 pounds.... 20

(b) Mutton breeds

5- 6 months, 60 pounds.... 28

6- 8 months, 76 pounds.... 27

8-11 months, 92 pounds.... 26

11-15 months, 108 pounds.... 25

$15-20$ months, 140 pounds.... 24

(c) Fattening lambs

6- 7 months, 60 pounds.... 31

7- 9 months, 80 pounds.... 30

9-11 months, 100 pounds.... 28

3. Growing pigs (fattening pigs)

2- 3 months, 40 pounds.... 44

3- 5 months, 100 pounds.... 36

5- 6 months, 130 pounds.... 32

6- 9 months, 180 pounds.... 28

9-12 months, 260 pounds.... 25

4. Growing cattle

(a) Milk cows and working oxen

2- 3 months, 140 pounds.... 23

3- 6 months, 280 pounds.... 24

6-12 months, 480 pounds.... 26

12-18 months, 640 pounds.... 26

$18-24$ months, 800 pounds.... 26

(b) Future fattening animals

2- 3 months, 150 pounds.... 23

3- 6 months, 300 pounds.... 24

6-12 months, 500 pounds.... 26

12-18 months, 700 pounds.... 26

$18-24$ months, 860 pounds.... 26

\begin{tabular}{|c|c|c|c|c|}
\hline 3.0 & 16.4 & 3.3 & 0.8 & 15.6 \\
\hline 2.5 & 13.0 & 2.8 & 0.6 & 13.5 \\
\hline 1.8 & 10.7 & 2.1 & 0.5 & 11. \\
\hline 1.5 & 10.2 & 1.8 & 0.4 & 11. \\
\hline 1.2 & 9.7 & 1.5 & 0.4 & 11.0 \\
\hline 4.5 & 17.2 & 5.0 & 1.0 & \\
\hline 3.5 & 15.4 & 4.0 & 0.7 & 1 \\
\hline 2.5 & 13.8 & 3.0 & 0.5 & 14 \\
\hline 2.0 & 11.4 & 2.4 & 0.4 & \\
\hline 1.5 & 10.2 & 1.8 & 0.4 & 12. \\
\hline 3.5 & 17.0 & 4.0 & 0.8 & 10. \\
\hline 3.0 & 16.0 & 3.5 & 0.7 & \\
\hline 2.5 & 15.0 & 3.0 & 0.7 & 14 \\
\hline 6.2 & 33.8 & 6.6 & 1.0 & \\
\hline 4.5 & 32.0 & 5.6 & 0.9 & 25 \\
\hline 3.5 & 26.5 & 4.4 & 0.7 & 22 \\
\hline 3.0 & 24.5 & 3.9 & 0.5 & 20 \\
\hline 2.4 & 19.8 & 3.2 & 0.3 & 18 \\
\hline 3.4 & 18.5 & 3.7 & 2.0 & \\
\hline 2.8 & 15.2 & 3.1 & 1.0 & 13 \\
\hline 2.3 & 11.5 & 2.6 & 0.6 & 12 \\
\hline 1.8 & 9.0 & 2.2 & 0.4 & \\
\hline 1.3 & 8.0 & 1.6 & 0.3 & 11 \\
\hline 4.5 & 19.5 & 5.0 & 2.3 & 1 \\
\hline 3 & 16.5 & 4.0 & 2.0 & \\
\hline & 13.5 & 3.2 & 1.0 & \\
\hline & 10.0 & 2.6 & 0.5 & \\
\hline 1.5 & 9.0 & 1.8 & 0.4 & \\
\hline
\end{tabular}

In calculating feeding rations the volume and water content should be considered. These should be adjusted to the capacity of the digestive canal, its physiological peculiarities and the kind of work expected of the animal.

On account of the relatively small capacity of the stomach, horses should have concentrated feeding stuffs with little tendency to swell in 
water, mixed with chaffed feed in such a manner as to insure thorough mastication and ensalivation. Bulky feeds, like straw, those of low nutrient content or watery in character, like roots, tubers, slops, pulps, etc., are not suitable for horses in large quantities, especially when speed is expected. On the other hand, a certain amount of bulky feed, judiciously administered, is frequently economical for work horses.

Cattle, like other ruminants, are able to utilize very voluminous feeding stuffs rich in crude fiber. Cattle differ from sheep, however, in that the latter require dry roughage of fine texture while the former consume very watery material, like slops, pulps and beets, to advantage. Work cattle, however, demand more concentrated and less watery rations. Concentrated rations for cattle economize by lessening the work of carrying about unnecessary bulk. In all cases, however, for hygienic reasons as well as on economic grounds, sufficient dry matter should be administered in connection with concentrates and bulky watery feeds.

Swine do not masticate their feed thoroughly; their digestive tract is comparatively short, and the food mass passes through in a comparatively short time. They should, therefore, receive easily digestible rations with no undue amount of crude fiber. Cooking, steaming and grinding assist in making nutrients more soluble and expose them more directly to the action of the digestive juices. Swine, therefore, should receive easily digestible, watery, but otherwise concentrated rations.

The volume or bulkiness of the ration should always be adjusted, within certain limits, to the species of animal and the purpose in view. Excesses one way or another may produce undesirable effects. Too much volume tends to distend the stomach, overburden the abdomen, cause curvature of the spinal column (swaying back and "pot belly"). exert pressure upon the womb and fetus in pregnant animals, and interfere with normal respiration by displacing the thoracic organs. On the other hand, nutriment that is excessively concentrated fails to fill properly the digestive canal, fails to stimulate properly the digestive organs, and produces a sensation of hunger which in turn tempts animals to bite and chew on the feeding mangers and walls.

It is of great importance also, for the attainment of our object in feeding, that too much feed should not be given at one time and that no additional nutriment be offered until the last feed has been thoroughly cleaned up.

Agreeability and palatability should be given due attention, especially when the end in view calls for the consumption of large masses of feed. This is attained by special preparation, variety and system in administration. The less attractive feeding stuffs shoult be given first, or mixed with those that are more relished. In horse and cattle feeding it is customary to give the roughage first and follow with the concentrates, either alone or mixed with chaffed feed or root crops. Following the latter a little more hay or straw may be added. Changes in the order of administering the different constitutents of a ration are not infrequently made 
and the practice is not objectionable as long as the object sought is attained, viz., complete consumption without undue excitement or disturbance of the animal.

With the great variety of feeding stuffs at our disposal it is an easy matter (as a rule) to correct deficiencies or to produce desired dietetic effects. Thus young succulent grasses and aromatic (yarrow or milfoil, caraway, wild thyme, common or wild marjoram and mint) or bitter herbs (common tansy, mugworth and wormwood, chicory, germander or heart clover, elecampane) and the common thistle are regarded as excellent appetizers and digestive tonics. Young thistles fed to horses produce a smooth and glossy hair coat and promote shedding. Bran, linseed meal and hempseed meal are credited with similar virtues. The latter also soothe irritated mucous membranes of the digestive tract and assist the movement of constipating feeding stuffs (legumes) through the alimentary canal.

Condimental feeds should also be mentioned at this place. These include common salt and such feeding stuffs as contain ethereal oils, bitter principles, salts, certain vegetable acids, and limited amounts of alkaloids. Their importance in nutrition does not depend upon their actual nutrient value, but is ascribed to their stimulating effect upon digestion and metabolism. Results of experiments on animals, under normal conditions, do not, however, bear out this view. Feed utilization is unaffected, but these substances no doubt play an important role by making possible the consumption of large quantities of feeding stuffs not relished under ordinary conditions. The importance of condimental feeding stuffs consists chiefly in the fact that when occasionally added to the ration they stimulate the appetite and the secretion of the digesive fluids and possibly influences the intestinal flora and thus indirectly serve to control fermentative processes and decomposition.

Every change of feed should be made gradually. Disregard of this rule may lead to digestive disturbances (diarrhea, constipation), permanent aversion to the new feeding stuff, loss of appetite, etc. Changes of feed are most frequent at the time of year when green fodder displaces dry fodder, and vice versa, or when root crops, silage, new hay and oats or molasses are first available. Other occasions are when concentrates are changed at weaning time or when the usual methods of preparation are modified. The time required for making changes depends upon the extent and character of the change. As a rule a period of ten days should be covered. While sound and hygienically unobjectionable feeding stuffs demand care in this respect, still greater caution should be observed with feeding stuffs possessing undesirable peculiarities. While sudden changes to such feeding stuffs may result in actual and dangerous disease, gradual transition may be accomplished without the least harm.

The temperature at which feed is administered is of importance. The maximum temperature for young animals is $104^{\circ} \mathrm{F}$; more mature ani- 
mals tolerate $113^{\circ} \mathrm{F}$. Feed that is too hot may under circumstances cause fatal disease. The minimum temperature is more difficult to determine, but ranges in the neighborhood of $44^{\circ}$ or $45^{\circ} \mathrm{F}$. Stabled animals should not receive water that is too cold. Aside from the danger of digestive disturbances (diarrhea and colic) and possible abortion in pregnant animals, feed at too low temperature abstracts considerable heat from the body, which must be replaced at the expense of so much nutriment.

Mangers, feeding racks and boxes as well as all vessels and implements used in connection with feeding should be kept clean and all traces of leavings, especially of wet or steamed feeding stuffs should be removed. The latter have a tendency to decompose rapidly, and the consequences of this we should seek to avoid. Cleanliness is indispensable in successful feeding. Neglect in this respect is the explanation of many cases of poor appetite or of the supposed presence of undesirable feed admixtures. One should not be deceived with the idea that the leavings of one feed will be consumed with the next ration. This is particularly applicable to the horse. Sensitive animals will submit to a certain degree of starvation before they will eat leavings with an unpleasant or sour smell. The preparation of the feed (cooking, steaming, scalding) should immediately precede feeding. The practice of letting feeding stuffs of this character stand around for days before using is, on account of their great tendency to ferment and spoil, condemnable to say the least.

The time or times for feeding must be chosen to suit the age as well as the use of the animal. While a single feed per day suffices for dogs, cattle should be fed three times (rarely twice or in case of bulky feed, four times), sheep four times, swine three or four times, horses three times, and young stock four to six times. Toward the end of the fattening period, when the appetite has become less keen, it pays to feed oftener, in smaller quantities, but the periods should be distributed as equally as possible throughout the day. Regularity of feeding should be strictly observed. If the periods between meals are unusualiy prolonged the feed is taken up with too much greed, mastication is neglected, ensalivation suffers, and overeating may occur, causing disturbances of digestion and nutrition. If the feeding intervals are too short the appetite fails and the rations are not fully consumed; the beslavered feed that remains produces aversion and is wasted, and nutrition suffers.

Milk cows should be fed after milking. The common practice of feeding before milking reduces the milk yield, and in case of dry feeding (hay) pollutes the air and, in turn, infects the milk with bacteria.

Work animals should have sufficient intervals of rest. Horses should rest two hours, work oxen three. Oxen require more time to ruminate.

The percentage of dry matter in the ration serves as a basis for the volume administered. The daily requirement of dry matter for young, suckling animals is between one-fiftieth and one-sixtieth of the live weight. As the animal develops this should be increased. At the age of 
one year it should be one-fortieth for ruminants, while more mature, producting herbivora may have as high as one-thirty-third of their live weight. Mature horses, work oxen and boars require one-fortieth, and growing pigs, after weaning, and fattening swine demand one-thirtythird of their live weight in the form of dry matter. While the values given should be rather closely followed for the digestible nutrients, a variation in the total dry matter, amounting to 10 per cent, is of less consequence, provided always that any change from the accustomed volume is made gradually. A considerable proportion of the dry matter for herbivora is furnished in the form of hay, horses requiring about (5) 8-10 (20) pounds, cattle (6) 12 (28), sheep (1) 2 (4-5) pounds per day per head, or, figured on the basis of live weight, horses one onehundredeth, cattle one-eightieth, and sheep one-fiftieth per total live weight.

In the past, feeding rations were based on the chemical composition of the feeding stuffs, under the impression that a correct relative proportion of the nutrient elements was all that was required. But Kellner has pointed out the fallacy of this assumption. "Should we persist in this assumption and ascribe equal values to the various nutrients, irrespective of their source, whether contained in straw or in the grains, we should blunder most seriously. Nor should the crude fiber of the various feeding stuffs be looked upon as useless and our attention confined to the other ingredients as formerly. This would be a serious mistake."

The value of crude fiber is subject to variation. The crude fiber contained in certain feeding stuffs requires more energy for its digestion than it furnishes the organism. In other feeding stuffs a certain amount of the digested crude fiber is equal in value to that of starch. The fact that the energy value of a feeding stuff does not correspond directly to its chemical composition is due to its variable physical character (its requirement for mastication and overburden of the digestive tract), to its characteristic chemical "structure," its possible content of valuable nonnutrients (enzymes and stimulants) as well as to its mere bulk or volume, its behavior toward fermentative processes, etc.

Kellner has determined the energy value of the most important feeding stuffs and introduced it in the calculation of rations. The energy value of a feeding stuff includes the total productive action of all of the digestible organic substances, hence all of the albumen or protein, fat and carbohydrates combined. The energy value of starch is used as a basis. In the calculation of feeding rations, according to Kellner's method, it is necessary to consider only the starch value and the digestible proteids. This not only simplifies calculations but, since the peculiarities of the different feeding stuffs are also taken into consideration, the results are considerably more accurate.

The starch value of feeding stuffs the nutrients of which are 100 percent available can be readily calculated. According to Kellner, thus:

1 part of digestible protein $=0.94$ parts of starch value.

1 part of digestible fat, in roughages, chaff, root crops and their by-products $=$ 1.91 parts of starch value.

1 part of digestible fat in grains and their by-products not belonging to the oilproducing seeds $=2.12$ parts of the starch value.

1 part of fat in oil cake or meal $=2.41$ parts of starch value.

1 part of digestible nitrogen-free extract and crude fiber (combined) $=1.0$ parts of starch value.

Since the digestible nutrients of only a few feeding stuffs (potatoes, corn, hulled rice, some feed meals, oil seeds and oil cake, gluten, and feeding stuffs of animal 
origin, like tankage, etc.) are completely metabolized, i.e., are 100 percent available, this fact should be taken into consideration in calculating the starch value and the difference should be adjusted. The available energy or "value" of the various classes of feeding stuffs as well as that of the individual feeding stuffs is subject to considerable variation. This is due to differences in digestibility, the amount of work required in the act of digestion, losses from fermentative processes in the digestive canal, etc. Thus, in potatoes 100 percent of the digestible nutrients are available and metabolizable; in small field beets only 72 percent; poor meadow hay 49 percent, and good meadow hay 78 percent. The nutrients in the seeds of the grain-bearing grasses (cereals), Leguminosæ and oil-producing plants are 90 to 100 percent metabolizable. Most of the by-products of the sugar, starch and distilling industries are somewhat less metabolizable (about 80 to 90 percent). Milling by-products show a very considerable variation in this respect (70 to 100 percent), and the various chaffs, shells, hulls, etc., are still lower in "value." In general all varieties of straw are inferior in this respect ( 30 to 50 percent), and the same may be said of poor grades of hay and green forage in the woody stage, while young succulent grasses approach the grains in the facility or completeness with which their digestible nutrients are metabolized.

Kellner standardized the energy values of the various feeding stuffs. The objection might be raised that this is impossible in view of the variety of purposes aimed at, breed, age, manner of preparation, mixture of feeding stuffs, their content in mineral matter, stimulating substances, etc. It is known from practical experience that these factors influence results. Though these weak points are admitted, they are of secondary importance when the positive value of Kellner's method is considered in connection with the former custom of basing feeding rations almost wholly upon the chemical composition of the ingredients. Furthermore, the diffculties met with in Kellner's method may be expected to be gradually overcome as our experimental knowledge is increased.

Instead of the formerly used "nutritive ratio," which indicated the relative amount of digestible nitrogen-free nutrients and digestible ${ }^{6}$ crude protein, Kellner expresses the proportion of digestible pure albumen (albumen ratio) to that of the digestible nitrogen-free extract.

In order to reduce the ratio to terms of two figures and thus simplify calculations, the fat. is multiplied by 2.5 (old method) or by 2.2 (Kellner's method) and added to the carbohydrates.

The nutritive ratio of meadow hay which contains 5.4 percent digestible crude protein (of which 3.8 percent is digestible albumen), 1.0 percent digestible fat and 25.7 percent nitrogen-free extract is determined thus:

$$
\begin{aligned}
& 5.4: 1 \times 2.5+25.7 \\
= & 5.4: 28.2 \\
= & 1: 5.2
\end{aligned}
$$

The albumen ratio of the same feeding stuff is determined as follows:

3.8: $1 \times 2.2+25.7$

$=3.8: 27.9$

$=1: 7.3$

The nutritive ratio is referred to as "medium" when the proportion of crude protein to nitrogen-free extract is expressed by $1: 5$ to 6 , narrow when expressed by $1: 2$ to 4 , and wide when expressed by $1: 8$ to 12 .

Those nutrients which are taken up in excess of the requirements of the body for maintenance and which are digested and absorbed are deposited in the body either as fat (or albumen, muscle) or they are used up in the production of muscular energy, milk, wool, etc.

The standardization of feed, or the calculation of a ration, for the

"The word "total" and not the word "digestible" was probably intended to be used here by the author.-Translator. 
horse is a very simple matter. Each animal receives a certain amount of hay and oats mixed with chaffed straw, as explained on pages 61,66 and 85 . If it is desired to substitute some other feeding stuff for the oats, proceed according to outlines on page 83 .

The standardization of rations for cattle, which receive their feed in courses, so to speak, and for swine, usually meets with more difficulties. The difficulties arise in providing the various nutrients in sufficient quantity and proper proportion and at the same time avoiding all waste. The following procedure is suggested:

In the first place the products of the farm should constitute the basal portion of the ration. These should be distributed in an appropriate manner among all the animals of the farm, taking due consideration of the seasons. The basal feed, if at all possible and practicable. should consist of a not too moderate amount of good hay. Although the nutrients contained in such hay may frequently be obtained at less expense from other sources or in different form, nevertheless a minimum of 5 pounds of hay per 1,000 pounds live weight is desirable from a dietetic point of view. The common present-day practice of furnishing the necessary nutrients chiefly in the form of concentrates and providing the necessary bulk exclusively in the form of straw may under certain conditions have pecuniary advantages, but not infrequently this is at the expense of the health or well-being of the animal. For example, this method of feeding tends to deplete the organism of its lime salts, especially in heavy milkers, unless this mineral is artificially supplied. Too frequently this not done.

The five-pound hay ration referred to. together with the concentrates, root crops and industrial by-products, is not sufficient to furnish the entire necessary bulk of the ration for herbivora. The dry matter in the daily ration should be about 25 pounds per 1,000 pounds live weight. The combination referred to-hay. concentrates, root crops, if available. and the industrial bv-products-contains onlv about 13 pounds of dry matter. so that the difference, about 12 pounds. mav be provided in the form of straw or chaff. While the sunply of the extra 12 pounds of dry matter in the form of straw is entirelv anpropriate for the purpose. an excess over this amount ner 1.000 pounds live weight. in view of the high energy requirement for the digestion of this character of feed, would be quite irrational.

In addition to the hay and straw portion of the ration (or chaff substituted for the straw). cattle should receive feeding stuffs rich in carbohydrates. like beets, potatoes. slops and shredded root crops or pulp. The character and amount of these substances must be gauged according to existing conditions. Milk cows. for example. should have from 20 to 30 pounds of potatoes or 30 to 50 pounds of beets, or corresponding amounts of similar feeding stuff. per 1,000 pounds live weight.

After the character and amount of the roughage is determined, such 
concentrates as are necessary to produce specific effects are added. For example, palmseed cake to improve the fat content of the milk; wheat bran or linseed cake for dietetic considerations. Then consult Table I in the appendix and determine the amount of nutrients in which the ration is deficient, and supply these with an addition of concentrates. To provide variety, to increase palatability and thus stimulate the appetite, the added concentrates should consist of a mixture of two or three different materials. The determination of the digestible albumen and starch value of feeding stuffs, which vary in their composition from the values given, or which have not been incorporated in the tables, is made according to the suggestions given on pages 69 and 70 .

In calculating feeding rations the values of the digestible albumen and the starch value of the first four items (hay, straw, carbonaceous feeding stuffs, and the specific concentrates, are determined and added together. The sum thus obtained is subtracted from the total required per 1,000 pounds live weight per day, as indicated in the tables. The remainder indicates the amount to be added in the form of concentrates. If only one kind of concentrate is to be added it may be selected from Kellner's tables to correspond in albumen and starch value with the material needed. If the deficiency is to be made up by the addition of two different concentrates, the calculation is somewhat more difficult. To make the matter more concise and clear a working example follows.

Supposing it is desired to compound a ration for cows yielding 30 pounds of milk per 1,000 pounds live weight. Such cows would require daily 2.2 to 2.5 pounds of digestible albumen and 11.8 to 13.9 pounds starch value. Local farm conditions permit (let us assume) and require per 1,000 pounds live weight 5 pounds good meadow hay, 12 pounds oat straw, 50 pounds beets (average), to be fed up. In addition to this it is desired to administer 2 pounds of coarse wheat bran and 2 pounds of cottonseed meal (decorticated). In order to determine whether this combination in itself is correct and sufficient the following calculations are necessary:

$1 \mathrm{lb}$. containsDigestible Starch Albumen value

Meadow hay, good quality....0.038

Oat straw .................0.010

Beets, a verage $\ldots \ldots \ldots \ldots \ldots .001$

Wheat bran, coarse ..........0.091

Cottonseed meal, decorticated.0.395
0.310

0.170

0.063

0.426

0.723
The quantity taken

\begin{tabular}{ccc} 
The ration & \multicolumn{2}{c}{$\begin{array}{r}\text { The quantity taken } \\
\text { contains- }\end{array}$} \\
$\begin{array}{c}\text { Selected } \\
\text { Digestible }\end{array}$ & $\begin{array}{c}\text { Starch } \\
\text { consists of- }\end{array}$ \\
albumen & value \\
5 lbs. & 0.190 & 1.550 \\
12 lbs. & 0.120 & 2,040 \\
50 lbs. & 0.050 & 3.150 \\
2 lbs. & 0.182 & 0.852 \\
2 lbs. & 0.790 & 1.446
\end{tabular}

1.332

9.038

11.8 to 13.9

3 to 4.8

The ratio of albumen to starch value is $1: 3.0$ to $1: 4.8$.

Malt sprouts happen to have a similar ratio $1: 34$, Brewers' grains $1: 36$, cocoanut cake $1: 47$.

Supposing that it was desired to make up the deficiency with cocoanut cake only, 
the calculation would be made as follows: 100 pounds of cocoanut cake contain 16.3 pounds of digestible albumen and 76.5 pounds starch value. Thus 1 pound of digestible albumen would be furnished by 100 pounds divided by $16.3=6.14$ pounds of cocoanut cake. Such a large quantity of one ingredient, especially of this character, would not be at all suitable for the purpose. It would be much better to use a mixture of two or three concentrates, selecting some with a lower, others with a higher albumen-starch ratio, so that the ratio of the mixture would be the same or nearly the same as that required.

Supposing that we should select-

Peanut cake with 38.7 percent digestible albumen and 75.7 percent starch value; Rice feed meal with 6.0 percent digestible albumen and 68.4 percent starch value.

To solve this algebraic problem, let $x$ equal the amount of peanut cake and $y$ the amount of rice feed meal which together are necessary to furnish the deficient 1 pound of digestible albumen and 3.5 pounds of starch value; then-

$$
\begin{gathered}
1 \text { (the desired albumen })=\frac{38.7}{100} x+\frac{6}{100} y \\
3.5 \text { (the desired starch value) }=\frac{75.7}{100} x+\frac{68.4}{100} y
\end{gathered}
$$

To eliminate the fractions, mutliply the equations by 100 , thus:

$$
\begin{aligned}
& 100=38.7 x+6 y \\
& 350=75.7 x+68.4 y
\end{aligned}
$$

By multiplying the upper equation by 68.4 and the lower equation by 6 and subtracting one from the other for the elimination of $y$, thus:

$$
\begin{aligned}
6,840 & =2,647.08 x+6 \times 68.4 y \\
2,100 & =454.2 x+6 \times 68.4 y \\
\hline 4,740 & =2,192.88 x \\
x & =\frac{4,740}{2,192.88}=2.162 \text { (pounds of peanut cake). }
\end{aligned}
$$

Having found the value of $x$, that of $y$ is easily determined by a new equation with $x$ expressed in known terms, thus:

$$
\begin{aligned}
& 100=38.7 x+6 y \\
& 100=83.6+6 y \\
& 6 y=100-83.6=16.4 \\
& y=16.4 \div 6=2.7 \text { (pounds rice feed meal). }
\end{aligned}
$$

The required amounts of digestible abumen ( 1 pound) and starch value ( 3.5 pounds) will be contained in 2.16 pounds of peanut cake and 2.7 pounds of rice feed meal. These amounts should be added to the ration under consideration.

\section{B. Special Feeding}

\section{Maintenance Feed}

1. Maintenance rations for oxen at rest in the stable, per 1,000 pounds live weight per day, with temperature at 53.6 to $61.25^{\circ} \mathrm{F}$. (according to Kellner) should contain on an average 15 to 21 pounds of dry matter, 
0.6 to 0.8 pounds digestible albumen and 6.0 pounds of starch value (albumen ratio $1: 12-14)$. Small animals expose a relatively larger surface to radiation and consequently require more heat. The starch value just given applies to animals of about 1,200 pounds live weight. Larger animals (1,400 to 1,600 pounds) require slightly less (11.60 and 11.10 respectively), and lighter weights $(600,800,1,000$ pounds) require more (15.2, 14.0 and 13.0 pounds) starch value. The albumen ration remains the same.

The feeding stuffs should consist mainly of roughages; deficiency in albumen should be corrected with oil cake, brewers' grains, etc.; those of the carbohydrates with roots and tubers and their waste products. This also provides the necessary mineral matter.

According to Kellner the following ration is sufficient:

1. $12.6 \mathrm{lbs}$. oat straw, $25.6 \mathrm{lbs}$. beets, $1.0 \mathrm{lbs}$. rape cake.

2. $14.2 \mathrm{lbs}$. oat straw, $2.6 \mathrm{lbs}$. clover hay, $0.5 \mathrm{lbs}$. rape cake.

3. $13.0 \mathrm{lbs}$. oat straw, $3.7 \mathrm{lbs}$. clover hay, $0.6 \mathrm{lbs}$. rape cake.

4. $13.3 \mathrm{lbs}$. rye straw, $3.8 \mathrm{lbs}$. clover hay, $0.6 \mathrm{lbs}$. rape cake.

2. Rations for wool-producing sheep, where slight increase of weight is desired (not strictly a maintenance ration), for 1,000 pounds live weight, according to Kellner, for the coarser breeds, daily 1 pound digestible albumen and a starch value of 8.3 pounds. For the finer breeds, 1.2 digestible albumen and 9.0 starch value.

Since wool is produced from the albumens, wool-producing sheep should receive a sufficient supply of this nutrient. However, not all forms of albumen can be converted into wool with equal facility. Among other substances, keratin is required in considerable amount in the formation of wool. This occurs very sparingly as a constituent of feeding stuffs. In order to supply the building material for the production of wool in sufficient quantity, Zuntz recommends animal epidermal structures like horns, hoofs, etc., in digestible form. This is of special importance when the albumen requirements are supplied in part in the form of salts of ammonia and urea. Zuntz's preparation is put on the market in the form of cakes under the trade name of Ovagsolan.

The basal feed should consist of hay and varieties of straw. Root crops and tubers should be given as supplemental feeds only, on account of their high water content. Deficiencies in albumen may be corrected with small quantities of oil cake, lupines, dried brewers' grains or similar nitrogenous material. During the recent years of stress in Germany attempts have been made to supply the albumen requirements to the extent of 33 per cent in the form of ammonia preparations. Silage, neutralized with ammonia and commercially prepared urea (which is low in cost) may be used for this purpose. Below are given a few mixtures or rations to serve as illustrations. 
Fine-Wool Sheep

\section{Per 1,000 Pounds Live Weight Per Day}

1.

Legume straw ....10 lbs. Clover hay ...... 5 lbs. Meadow hay II... 5 lbs. Straw (picked over $)^{1} \ldots \ldots .8$ lbs. Lupines ......... $1 \mathrm{lb}$. Cracked corn ....2 2 lbs.

\section{2.}

Pressed potato chips .......4 40 lbs. Meadow hay II... 6 lbs. Legume straw .... 5 lbs. Straw (picked over $)^{7}$........16 lbs. Lupines ......... $1 \mathrm{lb}$. Rice feed meal.... $1 \mathrm{lb}$.
3.

Beets $\ldots \ldots \ldots 20.0$ lbs. Meadow hay II . 10.0 lbs.

Straw (picked over $)^{1}$......12.0 lbs. Rapeseed hulls .. 5.0 lbs. Rye bran ...... 2.5 lbs. Rape cake ..... $0.5 \mathrm{lb}$.

4.

Potatoes ......15.0 lbs. Meadow hay II. 10.0 lbs.

Clover hay ..... 5.0 lbs. Straw (picked over $)^{1}$.......12.0 lbs. Cottonseed cake . $0.5 \mathrm{lb}$.

5.

Turnip cabbage...25 lbs.
Meadow hay .... 5 lbs. Alfalfa hay ..... 5 lbs. Straw (picked over $)^{7}$......... 10 lbs. Rape hulls ..... 4 lbs. Rice feed meal.... $1 \mathrm{lb}$. Beans ......... $1 \mathrm{lb}$.

\section{6.}

Corn silage .....30 lbs. Meadow hay II... 6 lbs.

Bean or peavine hay ........... 6 lbs. Rape hulls ...... 4 lbs. Straw (picked over $)^{1}$....... 8 lbs. Cottonseed meal .. $1 \mathrm{lb}$.

\section{Rations for Work Animals}

Since the nitrogen-free nutrients under ordinary conditions serve as the sources of muscular energy, wide rations will answer the requirements of work animals $(1: 8-10)$. Narrow rations $(1: 7)$ are, however, better for work animals that are not yet fully developed and for those from which more intensive work is required (race horses, carriage horses, etc.). The object in supplying more albumen in these cases is to provide a better blood supply, which in turn acts as the carrier of the necessary oxygen for combustion. The extra supply of albumen is therefor not to any extent concerned in supplying muscular energy.

Work animals can consume relatively large amounts of fat in the form of feeding stuffs rich in this nutrient (1 pound per 1,000 pounds live weight). Loss of appetite which is apt to follow feeding fat in these amounts is not liable to result in work animals. The exercise necessarily associated with work counteracts this tendency. Fat is a very valuable nutrient for work animals on account of its concentrated form and its energy value of more than twice that of the carbohydrates. It has the additional advantage of less bulk than carbohydrates.

Rations for work animals are calculated on the basis of the maintenance ration ( 6 pounds of starch value for oxen and 6.6 pounds for horses per 1,000 pounds live weight) plus the energy required for the work performed. According to Zuntz and his coworkers two-thirds of the energy value of the ration, above that of maintenance requirement can be converted into useful work. The physiological energy value of one gram of 100 per cent available nutrient amounts to 1,598 kilogram meters $^{8}$ for the carbohydrates, $3,642 \mathrm{kgm}$. for the fats and 1.968 for albumen. Thus

\footnotetext{
7Straw designated "picked over" is estimated as used up to the extent of 75 per cent and of the same composition as "very good summer cereal straw."

$8 \mathrm{~A}$ kilogram-meter is the work done in lifting 1 kilo 1 meter against gravity or the amount of energy required to do this work. -J. R. M.
} 
the useful energy per gram of 100 per cent available nutrient, in excess of maintenance requirement, amounts to-

533 kilogram-meters for 100 per cent available carbohydrates,

1,214 kilogram-meters for 100 per cent available fat,

656 kilogram-meters for 100 per cent available albumen.

Feeding stuffs the digestible nutrients of which are not 100 per cent available are estimated on the basis of starch value instead of digestible nutrients.

1. Rations for work oxen, at moderate work, should contain:
Digestible albumen ............... 1.0 to $1.5 \mathrm{lbs}$.
Digestible fat $\ldots \ldots \ldots \ldots \ldots \ldots \ldots \ldots \ldots \ldots \ldots \ldots \ldots \ldots$ to $0.5 \mathrm{lbs}$.
Digestible carbohydrates ............ 10.0 to $12.0 \mathrm{lbs}$.
Dry matter ................... 20.0 to $25.0 \mathrm{lbs}$.
Starch value $\ldots \ldots \ldots \ldots \ldots \ldots \ldots \ldots \ldots \ldots \ldots$ to $9.4 \mathrm{lbs}$.

For oxen employed at average work the albumen is increased to 1.4, the fat to 0.5 , the carbohydrates to 12 , the dry matter to from 25 to 28 pounds, and the starch value to 9.7 pounds. At hard work the digestible albumen should be raised to 1.8 or 2.0 pounds and the starch value to 12.8 pounds. If economy or circumstances make it desirable, the albumen ratio may approach that of 1:5.

The bulk of the feed should not be too watery for work animals, and any tendency in this direction should be corrected by the addition of the necessary dry matter. Furthermore, excessively bulky feed for hardworking animals should be avoided. Roughages alone are not sufficient even for very light work. A suitable feed mixture may be composed of roughage, a moderate amount of chopped potatoes or similar feeding stuffs (beets are less suitable) or dried or ensilaged beet pulp or chips. To balance the ration, oil cake, grain, coarsely ground Leguminosæ, molasses, etc., are added. Ample time should be allowed for the consumption and rumination of the noon meal and for rest ( $2 \frac{1}{2}$ to 3 hours).

\section{A. Rations for Moderate Work, Per 1,000 Pounds Live Weight Per Day.}

1.

Potato wash ...50.0 lbs.

Meadow hay ....7. $7.0 \mathrm{lbs}$.

Summer cereal straw ......6. 6.0 lbs.

Rape Cake .... 3.0 lbs. Dry beet pulp... $4.0 \mathrm{lbs}$.

Rice feed meal.. 2.0 lbs.

\section{2.}

Ensilaged beet pulp .......60.0 lbs.

Meadow hay III. 6.0 lbs.

Summer cereal straw ...... 5.0 lbs.

Winter cereal straw $\quad . \ldots \ldots$. 5.0 lbs.

Cottonseed cake. 2.5 lbs.

Peanut meal .... $1.0 \mathrm{lb}$.

\section{3.}

Dry beet pulp.... 6 lbs.

Clover hay ....... 2 lbs.

Meadow hay III.. 2 lbs.

Summer cereal

straw .......6 6 lbs.

Winter cereal

straw .......6 6 lbs.

Coarse-ground

beans ........2 $2 \mathrm{lbs}$.

Palmseed meal ... $1 \mathrm{lb}$.

Cocoanut cake .... $1 \mathrm{lb}$.

Peanut meal ..... $1 \mathrm{lb}$.

4.

Beets .........40 lbs,

Clover hay ....... 4 lbs.

Meadow hay II... 4 lbs.
Winter cereal straw ....... 12.0 lbs. Malt sprouts ... $2.0 \mathrm{lbs}$. Cottonseed meal (decorticated). $3.5 \mathrm{lbs}$.

5.

Potatoes .....20.0 lbs.

Clover hay .... $5.0 \mathrm{lbs}$.

Meadow hay II. 5.0 lbs.

Winter cereal straw ...... $4.0 \mathrm{lbs}$.

Pea or bean straw ....... $5.01 \mathrm{lbs}$.

Rape cake ...... 3.0 lbs. 


\section{B. Light Work. Per 1,000 Pounds Live Weight Per Day}

1.

Potato wash $\ldots . .50 .0$ lbs. Meadow hay iI.. 4.0 lbs.

Winter cereal straw ...... 8.0 lbs. Summer cereal straw .......10.0 lbs. Sesame cake ... $0.5 \mathrm{lb}$.

2.

Ensilaged beet pulp .......40.0 lbs. Meadow hay ...4 $4.0 \mathrm{lbs}$.

Winter cereal straw ...... $8.0 \mathrm{lbs}$.

Pea or bean straw ....... 8.0 lbs. Cottonseed cake.. 1.5 lbs.

\section{3.}

Meadow hay II.. 5.0 lbs.

Clover hay .... $6.0 \mathrm{lbs}$.

Winter cereal straw ...... 6.0 lbs.

Summer cereal straw ....... $7.0 \mathrm{lbs}$.

Rape cake ..... 2.0 lbs.

\section{4.}

Potatoes ......10.0 1bs.

Clover hay .... $5.01 \mathrm{bs}$.

Winter cereal

straw ....... 10.0 lbs.

Oat straw .... 8.0 lbs.

Peanut cake .... $1.5 \mathrm{lbs}$.
5.

Beets .......25.0 1bs.

Clover hay ....6 6.0 lbs.

Winter cereal straw .......6. $6.0 \mathrm{lbs}$ Oat straw ..... $8.0 \mathrm{lbs}$ Poppy-seed cake. $2.0 \mathrm{lbs}$

\section{6.}

Dry beet pulp... 5.0 lbs. Winter cereal straw ....... 9.0 lbs. Wheat chaff ...6 $6.01 \mathrm{bs}$,

Pea or bean straw ...... $3.0 \mathrm{lbs}$.

Fresh brewers' grains ......6. 6.0 lbs. Low-grade rye .. $2.5 \mathrm{lbs}$.

2. Rations for work horses, like those for work oxen, should be adjusted to the character of the work. Kellner gives the following nutrient values per 1,000 pounds live weight:

Light Work Average Work Hard Work

Digestible albumen ................. $1.0 \mathrm{lb}$.

Digestible fat $\ldots \ldots \ldots \ldots \ldots \ldots \ldots \ldots \ldots \ldots \ldots, 0.4 \mathrm{lb}$.

Digestible carbohydrates ............ $9.8 \mathrm{lbs}$.

Starch value ...................... $9.2 \mathrm{lbs}$

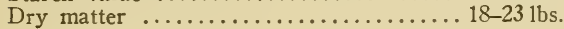

1.4 lbs.

$0.6 \mathrm{lb}$.

$11.3 \mathrm{lbs}$.

$11.6 \mathrm{lbs}$.

21-26 lbs.
$2.0 \mathrm{lbs}$.

$0.81 \mathrm{~b}$.

13.7 lbs.

15.0 lbs.

23-28 lbs.

The greater the efforts required of the animal, the less roughage should be included in the ration. Heavy or fleshy horses should rarely have more than 20 pounds of roughage per 1,000 pounds live weight per day, usually less than 15 pounds and sometimes even less than 10 pounds. The roughage may consist of hay, not too soft in texture, like alfalfa, esparcet and clover, also spring and winter cereal straw, especially those of oats, wheat and barley. Oats take the lead among the concentrates, even though their value is often overestimated and though cheaper concentrates may frequently be substituted to advantage. The average oat ration for an ordinary work horse is about 10 pounds per head per day. The amount, however, should be adjusted according to age, character of work and weight of the animal, between 3 and 18 pounds.

Rations for military horses, according to German commissary regulations in garrisons (small ration), are:

Ration I, 9,200 gm. oats, 7,000 gm. hay, 3,500 gm. straw.

Ration II, $5,500 \mathrm{gm}$. oats,

Ration III, 5,150 gm. oats, $2,500 \mathrm{gm}$. hay, 3,500 gm. straw.

Ration IV, 4,750 gm. oats,

Rations for marches, practice and maneuvers (large ration):

Ration I, 9,200 gm. oats, 7,500 gm. hay, 1,750 gm. straw.

Ration II, $6,000 \mathrm{gm}$. oats, ?

Ration III, 5,650 gm. oats, \} 2,500 gm. hay, 1,750 gm. straw.

Ration IV, 5,250 gm. oats, 
The term "straw" as used above means "rye straw," and the chaffed straw mixed with the oats, which amounts to $1,750 \mathrm{gm}$. in the small rations, is included in the total straw ration. $4,000 \mathrm{gm}$. of wheat or oat straw is regarded as equal to $3,500 \mathrm{gm}$. rye straw.

Ration I is intended for heavy, cold-blooded horses, Ration II for horses of the heavy cavalry and artillery type, and of the machine gun division, Ration III for part of the light cavalry, and Ration IV for all other troop divisions. Increases above these rations are provided for in the regulations.

The following table gives a summary of rations composed of substitutes:

\section{Guide for Feeding Work Horses}

\begin{tabular}{|c|c|c|c|c|c|c|c|c|}
\hline Feedstuff & $\begin{array}{l}\text { Heavy } \\
\text { Grams }\end{array}$ & $\begin{array}{c}\text { Average } \\
\text { Grams }\end{array}$ & $\begin{array}{l}\text { Amoun } \\
\text { Light } \\
\text { Grams }\end{array}$ & $\begin{array}{l}t \text { of ea } \\
\text { Heavy } \\
\text { Liters }\end{array}$ & $\begin{array}{l}\text { ch Feed } \\
\text { Averag } \\
\text { Liters }\end{array}$ & $\begin{array}{l}\text { lstuff } \\
\text { e Light } \\
\text { Liters }\end{array}$ & $\begin{array}{c}\text { Hay } \\
\text { Grams }\end{array}$ & $\begin{array}{l}\text { Straw } \\
\text { Grams }\end{array}$ \\
\hline Barley & 6,500 & 6,000 & 5,500 & $8 \mathrm{I} / 4$ & $71 / 2$ & $63 / 4$ & 2,500 & 1,750 \\
\hline Rye and whea & .. 6,000 & 5,500 & 5,000 & & $71 / 2$ & $7 \mathrm{r} / 4$ & 2,500 & 1,750 \\
\hline Peas ........ & ..... 4,500 & 4,000 & 3,500 & . & $43 / 4$ & $41 / 2$ & 5,000 & 3,500 \\
\hline Beans ....... & ..... 4,500 & 4,000 & 3,500 & $53 / 4$ & $51 / 2$ & $51 / 4$ & 5,000 & 3,500 \\
\hline Vetches ..... & $\ldots \ldots 4,500$ & 4,000 & 3,500 & 5 & $43 / 4$ & $41 / 2$ & 5,000 & 3,500 \\
\hline Corn ... & . 7,000 & 6,500 & 6,000 & $10 \mathrm{r} / 2$ & 10 & $91 / 4$ & 2,500 & 3,500 \\
\hline Buckwheat & ...8 8,500 & 8,000 & 7,000 & 12 & 11 & 10 & & \\
\hline Lupines ..... & ..... 4,500 & 4,000 & 3,500 & $51 / 2$ & 5 & $41 / 2$ & 5,000 & 3,500 \\
\hline $\begin{array}{l}\text { Meadow hay } \\
\text { Red clover } \\
\text { Alfalfa }\end{array}$ & green 40,000 & 35,000 & 30,000 & & & & & \\
\hline $\begin{array}{l}\text { Green oats } \\
\text { Green rye } \\
\text { Green wheat } \\
\text { Green lupines }\end{array}$ & ....35,000 & 32,000 & 30,000 & & & & & \\
\hline
\end{tabular}

The following combinations are in common use for nonmilitary horses:

\section{A. For Horses at Average Work, Per 1,000 Pounds Live Weight, Per Day Per Head}

1.

Oats .......... $6 \mathrm{lbs}$.

Meadow hay II....15 lbs.

Alfalfa hay ...... 6 lbs.

Winter cereal straw $1 \mathrm{lb}$.

2.

Oats .......... 9 lbs.

Meadow hay II.... 6 lbs.

Clover hay ....... $6 \mathrm{lbs}$.

Winter cereal straw $2 \mathrm{lbs}$.

\section{3.}

Oats ...........12 lbs.

Meadow hay II... 8 lbs.

Clover hay ...... $5 \mathrm{lbs}$.

Winter cereal straw 3 lbs.

4.

Oats ........... $5 \mathrm{lbs}$.
Corn ............ 5 lbs. Meadow hay II... 6 lbs. Clover hay ...... 6 lbs. Winter cereal straw 2 lbs. Peanut cake .....0.75 lb.

5.

Oats ........... $7 \mathrm{lbs}$. Corn ............... $3 \mathrm{lbs}$. Meadow hay II... 5 lbs. Spring cereal straw 3 lbs. Winter cer'l straw $1.5 \mathrm{lbs}$. Field beans .....2.0 lbs. Brewers' grains with molasses ... 3 lbs.

6.

Corn ............10 lbs. Meadow hay II.... $6 \mathrm{lbs}$.
Clover hay ...... 6 lbs. Winter cereal straw. 3 lbs. Peanut cake ...... $1 \mathrm{lb}$.

\section{7.}

Potatoes ........18 lbs. Meadow hay II....10 lbs. Winter cereal straw $3 \mathrm{lbs}$. Peanut cake ...... 2 lbs. Rye meal ........ 4 lbs.

8.

Potatoes ........ 8 lbs. Carrots ........... 6 lbs. Meadow hay II....10 lbs. Clover hay ....... 3 lbs. Winter cereal straw 2 lbs. Cracked rye ...... 2 lbs. Cracked beans .... 3 lbs. 


\section{B. For Horses at Heavy Work, Per 1,000 Pounds Live Weight, Per Day Per Head}

1.

Oats ..............18 lbs.

Meadow hay II... 6 lbs.

Winter cereal straw $3 \mathrm{lbs}$.

Beans .........2.5 lbs.

\section{2.}

Oats ........... 5 lbs. Corn ........... 8 lbs. Meadow hay .... 8 lbs. Clover hay ...... 4 lbs.
Winter cereal straw $3 \mathrm{lbs}$. Peanut cake ...... 2 lbs.

\section{3.}

Oats ............10 1bs. Meadow hay II...10 lbs. Alfalfa hay ..... 5 lbs. Winter cereal straw 3 lbs. Palm cake ....... 2 lbs. Rye bran ....... $1 \mathrm{lb}$.
4.

Oats ........... 8 lbs. Rye ............ 4 lbs. Meadow hay .... $8 \mathrm{lbs}$. Alfalfa hay ..... 4 lbs. Winter cereal straw 3 lbs. Peanut cake ...... $1 \mathrm{lb}$. Linseed meal ..... $1 \mathrm{lb}$.

\section{Rations for Growing Animals}

In view of the growth requirements of the young organism, the feed for growing animals should be rich in albumen and mineral matter. The growth of young animals is not absolutely inhibited even when the food supply does not exceed the wastes of the body. Under these circumstances growth takes place at the expense of the body organs. Under such conditions life can not, of course, be indefinitely prolonged.

Provided with an abundance of production feed, a suckling calf may make daily gains of 4 pounds or more, per 1,000 pounds live weight, while the mature ox can hardly make gains to exceed 0.6 to 0.8 pounds per 1,000 pounds live weight, per day. Such rapid development of young animals is possible only in connection with an ample supply of easily digestible nutriment of high availability, assisted by the inherent power of the young to assimilate and convert albumens and minerals into body tissue (Fig. 85).

The power to convert digested nutrients into tissue is gradually re-

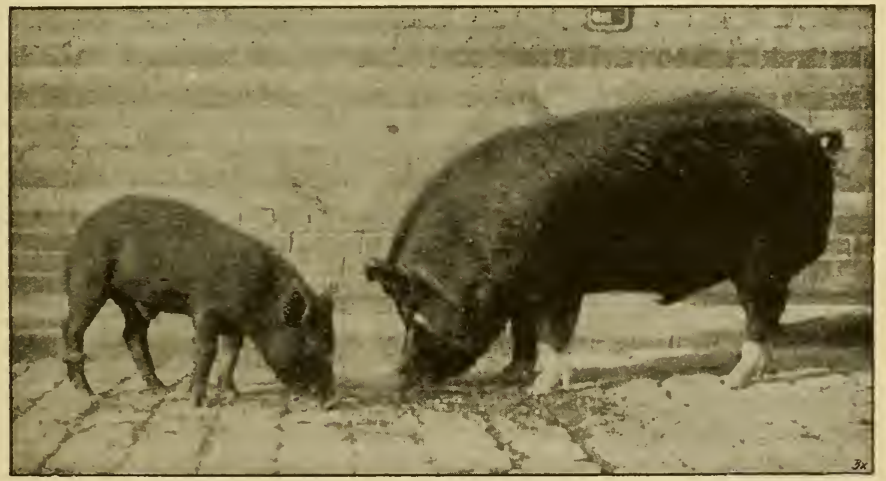

Fig. 85. Pigs of the same litter. Berkshire Boars. The one at the left, starved; the one at the right, properly fed. Farrowed Dec. 9, 1910; photographed May 15, 1911. Weights 29 and 110 lbs. respectively. (From Nathusius.) 
duced with advancing age, and as far as the albuminous tissues are concerned this faculty is all but lost (Fig. 86) in mature animals.

Regarding the nature of the food supply, the suckling has all the advantage as compared with the mature animal. Milk requires no work for mastication, it is readily and completely digested, and contains all the necessary nutrients in just the proper proportions. Compared with these conditions, the food supplied to mature animals always requires more or less work to accomplish proper mastication, and contains a considerable proportion of nutrients difficult to digest and of low availability. In the feeding of young or growing animals it is of the highest importance to provide a sufficient supply of food, so that the natural course of development may in no way be interrupted, particularly since the results of neglect in this matter can never be overcome by subsequent efforts (Fig. 86). The capacity for growth diminishes with ad-

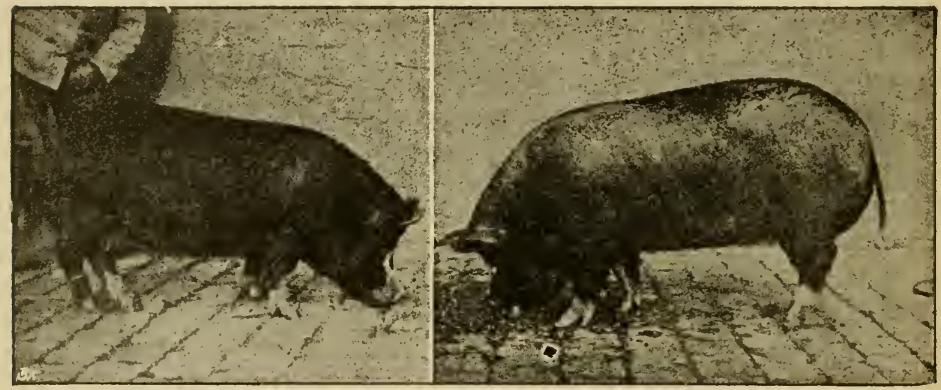

Fig. 86. Pigs of the same litter: Berkshire sows. To the left, starved in youth; to the right, fattened in youth. Farrowed Dec. 9, 1910. Fed under identical conditions from Dec. 9, 1912.

Photographed at same distance from camera Nov. 15, 1912. (From Nathusius.)

vancing age and at a certain period it is completely lost. Futhermore, our methods of feeding must be directed according to the character of work or service expected of the growing animal in the future.

Meat-producing animals must be well fed even in the fetal stage of development, followed by an uninterrupted supply of rich food from the time of birth to maturity. In the feeding of young meat animals the problem is not confined to the question of how to put on a maximum amount of fat (as is the case with fattening mature animals), but rather to the question of how to utilize to the fullest extent the animal's natural capacity to put on flesh. The solution of this problem depends upon an abundant supply of albumen, as demanded in the different stages of growth and development.

Males intended for breeding should be well nourished but not fattened. This applies to a somewhat minor degree to animals intended for milk, muscular energy (work) or wool production. 
The most natural and suitable food for the newborn animal is the milk of its own mother. The milk secreted by the mother during the first few days after parturition (colostrum) is richer in nutrients and on account of its slight laxative action has the effect of removing the meconium (first excrement) more promptly than would otherwise occur. For this reason the newborn animal should not be deprived of the first milk. Since the colostral milk coagulates upon being boiled, it should be administered in the raw or fresh state.

Calves from dams not known to be free from tuberculosis should have boiled milk only (or milk heated to at least $185^{\circ} \mathrm{F}$.-pasteurized), to prevent possible transmission of disease. Milk from other species of animals, when fed to the newborn, should always be boiled or at least pasteurized.

The limited supply of ferments in the digestive fluids of the newborn makes it possible that the foreign albumen in milk of other species can not be properly "denatured" by the digestive fluids before being taken up by the blood. These foreign albumens, when absorbed into the blood, etc., in their unmodified condition, exert a harmful action like any other foreign albumen introduced directly into the blood stream.

There is a prevalent opinion that cooking or boiling milk produces changes in taste, odor, coagulation of the albumen, destruction of ferments, preventing coagulation in the stomach, transformation of soluble into insoluble salts, etc., which make it less agreeable and less nutritious. Investigations of Dammann have shown that boiled milk is entirely harmless.

Feeding experiments with 27 calves, by Hittcher, with reference to the comparative value of boiled or raw milk and the effect of the addition of salts of various nature, are interesting. The table shows the amount of milk, with 11.50 per cent dry matter, necessary to produce a gain of $1 \mathrm{~kg}$. (2.2 pounds). The experiment extended over two periods of five weeks each.

\begin{tabular}{|c|c|c|c|}
\hline & $\begin{array}{l}\text { First period } \\
\text { Kilograms }\end{array}$ & $\begin{array}{l}\text { Second period } \\
\text { Kilograms }\end{array}$ & $\begin{array}{c}\text { Average } \\
\text { Kilograms }\end{array}$ \\
\hline Raw milk, alone. . & . 11.18 & 11.20 & 11.19 \\
\hline Boiled milk, alone $\ldots \ldots \ldots \ldots \ldots \ldots \ldots \ldots \ldots$ & . . 10.36 & 11.25 & 10.80 \\
\hline Boiled milk, with common salt, 2 gm. per liter... & .. 10.17 & 10.75 & 10.46 \\
\hline $\begin{array}{l}\text { Boiled milk, with citrate of lime, } 2 \text { gm. per liter. } \\
\text { Boiled milk, with monocalcium }\end{array}$ & $\therefore 12.28$ & 10.35 & 11.32 \\
\hline per liter $\cdots \cdots \cdots \cdots \cdots \cdots \cdots \cdots \cdots \cdots \cdots \cdots \cdots$ & 13. & 11.3 & 12.41 \\
\hline oiled milk, with calcium chlorid, $0.4 \mathrm{~g}$ & 13.0 & 13.82 & $13.42-2$ \\
\hline
\end{tabular}

According to these results the boiled milk, especially that with an addition of common salt, seems to be superior to the raw.

In contrast to these results Bruening, etc., found that kids thrived better on raw mother's milk than on boiled milk of the same origin. However, when young goats, swine, dogs, rabbits and guinea-pigs were fed on raw and boiled milk, respectively, of another species (cow's milk), the boiled milk produced the best results. Schrape recorded a similar 
experience. In the experiments of Brueckler with foreign milk (cow's milk for kids), raw milk with a low bacterial content was superior to pasteurized or boiled milk for sucklings.

In any event, boiled milk should not be administered to sucklings until the second or third day after birth. The newborn (calves) as a rule do not thrive on boiled milk. It is liable to produce attacks of indigestion and diarrhea (calf scours), frequently of a fatal nature.

\section{Rations for Colts}

Whenever possible, sucklings should have milk from the same species of animal. When this is not procurable, we usually resort to cow's milk. In the latter case newborn colts should have cow's milk with 20 to 30 per cent of water added, blood warm, administered with a bottle, at intervals of two hours. As a rule a teaspoonful of sugar is added per quart of milk, and occasionally from one to three eggs may also be added. In the course of two or three weeks the whole milk is gradually displaced by skim milk ( 6 liters), to which should be added $11 / 2$ liters of pea soup, or broth, and $1 / 2$ liter of linseed tea. At the age of four weeks colts should have some fine soft hay and even a little crushed oats. The milk ration may be withdrawn entirely at the age of 4 to 5 months.

The act of weaning is not without a decided influence upon the mental as well as physical well-being of the colt. It should therefore be so conducted that the nutrition and development of the young animal is interrupted as little as possible. To this end the colt should be isolated in such a manner that it will not be disturbed or made restless by either sound or sight of the dam. The sexes should be separated at the time of weaning or at the latest a few weeks thereafter. Weakly or backward colts that are molested by their companions should at least be kept in separate stalls.

The best place to raise a colt is the pasture. Von Oettingen recommends that yearlings on good pasture be given from 4 to 6 pounds of oats daily, and colts intended for development into draft horses should have from 6 to 8 pounds, in addition to green clover, alfalfa or esparcet. Purebred yearlings should receive from 10 to 12 pounds of oats besides green alfalfa. The extra alfalfa or esparcet is necessary only in case of shortage of grass in the pasture. With regard to the modern tendency to lay great stress upon the value of "contentedness," see chapter on "Pasture" in Klimmer's Veterinary Hygiene.

After the pasture season, according to Von Oettingen, half-bloods should receive 6 pounds of oats and 12 pounds of hay as daily rations, or 8 pounds of oats and 15 to 20 pounds of hay, alfalfa or esparcet, for animals intended for draft purposes.

Two-year-olds and three-year-olds, according to Von Oettingen, should have, in addition to pasture, 0 to 2 pounds of oats, draft horses 4 to 6 pounds, in addition to green alfalfa or clover, and at the end of the 
pasture season 6 pounds of oats and 12 pounds of hay.

A part of the oat ration may be displaced with peas (up to 2 pounds daily). Plenty of exercise should be provided.

High-legged colts with large heads should have extra rations of oats in order to induce rapid growth and early maturity of the bones and thus make a more stocky form.

Colts should be haltered and tied when eating their oat ration. A handful of ground or roasted oil meal ( $1 / 4$ pound daily) added to the ration is excellent. (See also article on "Pasture" in the author's work on Veterinary Hygiene.) When changing from pasture or soiling crops to hay (10 pounds meadow hay or fine alfalfa or clover), daily additions of about 6 liters of chopped carrots for three or four weeks, followed during the entire winter with 2 liters of wheat bran twice a week (mixed with the oats), are recommended. If the hay is of first quality the oat ration may be reduced by one pound. Rock salt in the form of "lick stones" is suitable to supply the necessary sodium chlorid.

Every advantage should be taken to utilize to the fullest extent any available pasturage. Stable feeding should then be confined to the oat ration at midday and to the feeding of extra portions of clover or alfalfa hay in the fall of the year. On very hot days the noon period of stable feeding may be prolonged to three hours and extra rations of soiling crops provided. During the cold of winter and the raw weather of late fall and early spring when pasturing is impracticable or impossible, daily exercise should be provided for $1 \frac{1}{2}$ to 2 hours daily, under shelter or in the open according to circumstances and weather conditions.

\section{Rations for Calves}

Newborn calves should receive whole milk for from three to six weeks, up to 5 quarts daily, and this should be gradually increased to 10 quarts, the amount varying with the type of animal to be developed. For the first few days, in order to prevent digestive troubles (scours), the amount should be considerably less, 3 pints daily. After this period one pint may be added daily until the total reaches 9 or 10 quarts. The exact amount depends upon the live weight of the animal and upon the type. Calves of the milk-producing type, or males intended for work, should have from one-seventh to one-eighth of their live weight of whole milk daily for about four, but at least three, weeks. Bull calves intended for breeding purposes and calves intended for beef should receive from onesixth to one-fifth of their live weight in the form of whole milk for a period of about six weeks. For the first week the amounts of milk indicated should be divided into from three to five parts and fed as many periods, after which three feeds per day, carefully measured and regularly dispensed, will suffice. The milk should be administered freshly drawn and blood warm. Cold milk is liable to produce diarrhea.

Calves may be raised with the dam or the milk may be drawn by hand and administered strictly fresh while still blood warm. Hand feeding, 
which is practically confined to calves, has the advantage of enabling the feeder to regulate the exact amount of nutriment taken (according to purposes in view); the act of weaning is simplified, and the total yield of the dam can be utilized to better purpose. It is well known that newborn animals rarely consume the entire milk yield of the dam. Frequently the dam stubbornly resists all attempts to remove the remainder, even repeated milkings failing in this attempt. This has an unfavorable effect upon the future milk yield. This objectionable feature may be avoided by hand-rearing the calves from the beginning.

It is a simple matter to teach the young calf to drink from a pail. Gently forcing its mouth into the milk and letting it suck a finger usually starts it off with little further trouble. Patent calf-feeders offer the advantage of less trouble at the beginning, but are hard to keep clean and consequently more or less insanitary. In the end the calves have to be weaned from these, and on the whole, the method is not recommended. The vessels in which the milk is fed should be so constructed as to facilitate cleaning. Enameled ware is the best. Wooden vessels are objectionable for evident reasons. The vessels may be set in specially constructed frames to prevent upsetting.

Veal calves are more commonly raised on the dam, this being attended with less trouble than hand feeding. They should be permitted to suck three, four, or better, five times a day, at regular intervals. Between meals they should be kept tied up short, or confined in narrow stalls. The enforced rest favors fat accumulation. On the other hand, calves intended for breeding or dairy purposes should have abundant opportunity for exercise.

Calves intended for hand raising had best be removed from the presence of the dam at once, before the latter has had an opportunity to lick them. They should be placed in a warm, clean, well-bedded stall, free from draft, rubbed dry with a handful of dry, soft straw gently manipulated, and the mouth and nostrils wiped clean of mucus.

The production value of 10 liters of milk (about 10 quarts, equal to $1.2 \mathrm{~kg}$. milk dry matter) if properly administered amounts to $1 \mathrm{~kg}$. increase in live weight.

At the age of from 3 to 6 weeks the whole milk ration is withdrawn. This must be done gradually in order to avoid a sudden interruption of development. The best substitute for whole milk is sweet, boiled, lukewarm skim milk, which may be supplied by adding $2 / 3$ to 1 pint to the daily whole-milk ration, a proportionate amount of whole milk being deducted from day to day.

The resulting loss of fat may be replaced at first with crushed flaxseed or oatmeal (25 to $30 \mathrm{gm}$. for each pint of skim milk). Wilsdorf recommends as a substitute for the milk fat the addition of from 2 to 4 per cent of finely emulsified fat of animal or vegetable origin.

Pigs as well as calves are said to have thrived much better after feeding on "homogenized" fat and skim milk than when fed in the usual man- 
ner with skim milk and flaxseed meal, oats, barley, etc. Peanut oil, cocoanut oil and oleonargarin were used as the sources of the homogenized fat. On the other hand Podbieski observed that fat of this character is excreted after a brief time and that pigs and calves thus fed did not thrive properly.

Schuppli recommends for economic reasons that calves be started on "vegetable fat-emulsion milk" at the end of the second or third week. Vegetable fat-emulsion milk consists of skim milk with 3.5 per cent of emulsified vegetable fat (e. g., palmatin). Special machines for making these emulsions are on the market and can also be used as centrifuges. Only one-fifth of the milk to be emulsified need be run through the emulsifier. Both milk and fat should be at a temperature of $140^{\circ} \mathrm{F}$. The product thus obtained is diluted by the addition of four parts of skim milk. The emulsion must be freshly prepared for each feed and cooled to $95-105^{\circ} \mathrm{F}$. before feeding. After a certain time the emulsion milk is replaced by skim milk.

Schuppli suggests the following table.as an outline of procedure:

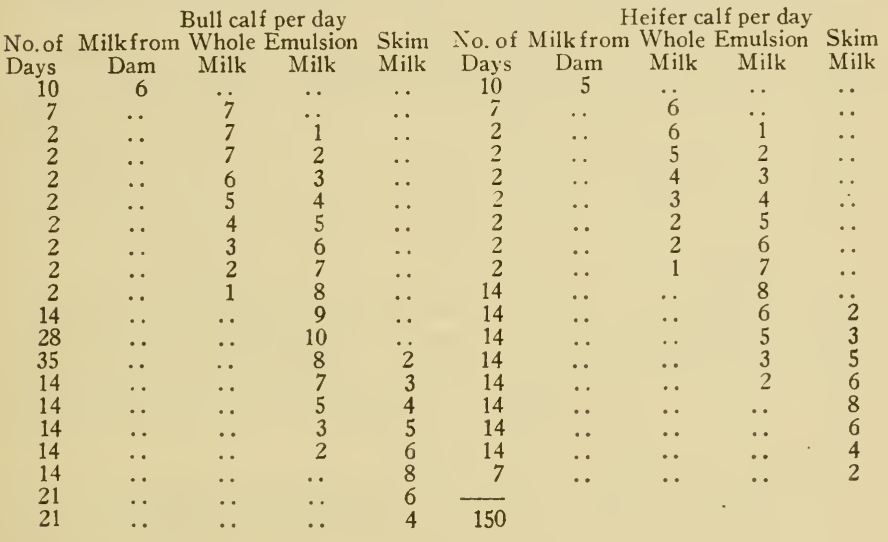

222

After the eighth day a little hay is given following the milk. While the milk is being reduced in quantity, a little water should be given after the hay, $11 / 4$ quarts of water for each quart of milk deducted. Twice a week 10 to 12 grams (a little more than one-third of an ounce) of salt should be given. When the calves are put on pasture the hay ration is decreased. In wet, cold weather the hay ration is increased.

Later on, linseed cake may be added to the ration, or other oil cakes like palmseed, cocoanut and peanut. Rapeseed cake and cottonseed cake, however, should be avoided. Barley, pea meal, bran and malt sprouts 
may gradually be introduced in the form of gruels or soups until they completely displace the skim milk. By the time the whole milk is entirely withdrawn concentrates of the above character should amount to one pound daily in addition to 5 grams of phosphate of lime or prepared chalk. By the time that the skim milk also is entirely withdrawn (at age of 6 months) the concentrates should amount to 3 pounds per day for heifers and 4 pounds per day for bull calves.

As with all other animals calves should not be fed according to general rules but rather according to individual requirements. General rules, of course, are useful as guides, but should not be closely adhered to. It would be a serious mistake to feed a stunted calf less merely because it was lighter in weight. On the contrary, such an animal would require additional nourishment to enable it to make up for past losses.

In order to increase the digestibility and availability of starchy feeding stuffs it has been suggested that they be treated with diastase (diastosolin) or with barley malt (which is more economical) and thus convert the starch into sugar. Animals eat "saccharified" starch readily and utilize it to good advantage. Compared with milk it reduces the cost of calf feeding about 33 per cent.

Probst recommends a mixture composed of 65 parts of wheat meal, 30 parts of coarsely ground linseed (flaxseed) and 5 parts of barley malt meal. One pound of this mixture is added to 9 liters of skim milk. In the absence of skim milk, the same author recommends the following: 40 parts wheat flour, 25 parts coarsely ground flaxseed, 10 parts each of peanut, cocoanut and palmseed meal and 5 parts of malt meal, 3 pounds per calf per day.

The objection to saccharified starch, according to Pflugradt and Gutbrod, is that its preparation involves too much trouble and loss of time. While saccharified skim milk has been recommended for calves from the time they are a few days old, the author is of the opinion that some whole milk is practically indispensible for the first 4 to 6 weeks. Saccharified milk is hardly to be recommended as the basal feed except under special circumstances or for more mature calves.

At the age of 6 months skim milk may gradually be displaced entirely by buttermilk or sour milk. When a week old, calves should have access to a little soft, fine meadow hay so that they can gradually become accustomed to solid food. The amount of hay can be increased gradually to from 2 to 4 pounds per day. By the end of the first month thoroughly crushed beets or carrots mixed with chaffed straw, crushed oats or corsely ground peas or barley, oil meal, malt sprouts and sweet grasses (no clover) may be given. In the marsh districts of Germany coarsely ground beans are a favorite supplementary or "by-feed" for calves. Distillery slops, brewers' grains, beet pulp (unless dried) rapeseed cake and cottonseed cake should be avoided for young calves.

The temperature of the milk or fluid substances may be gradually lowered upon the approach of warm weather. 
At 6 to 8 weeks, or even before, the best place for calves is on a good pasture. It goes without saying that there should be an ample supply of grass.

To enable the feeder to regulate the food supply in a rational and profitable manner, young growing animals should be weighed from time to time. Whether or not additional concentrates should be given when animals are on pasture depends upon conditions. If the pasture is good and the food supply abundant, the addition of concentrates is not only unnecesary but adds to the cost of keep without giving adequate returns. Not only this, but it actually spoils the disposition of animals to such as extent that they no longer profitably utilize the farm grown crops, especially the forages, and demand continued rations of expensive concentrates.

Between the fourth and sixth months the beet and dry roughage rations may be increased, and the concentrates increased to 3 or 4 pounds for heifers and 4 to 8 pounds for bulls. In certain districts calves that are fed for market are given as high as 10 to 12 pounds of concentrates per day.

After the first year calves may be fed in the same manner as mature animals. The future purpose of the animal should, however, never be left out of mind. While future dairy and breeding stock should be well nourished, it should not be fattened. Animals intended for slaughter should receive heavier rations. General hints for feeding this class of animals are furnished by Kellner's tables on page 165 .

In view of the delicate and sensitive structure of the organs of young animals special importance should be attached to the question of providing faultless feeding stuffs. With reference to mineral nutrients, see page 154 , etc. The following rations are practical in themselves and will serve as guides for the construction of others.

Rations for Growing Cattle, Dairy Breeds (Daily Rations per Head) A. Age, 2 to 3 Months. Average Live Weight, 140 Pounds

1.

Skim milk ......8.0 lbs. Meadow hay I...2.0 lbs. Oats ............ 10.0

Peanut oil ........ $0.16 \mathrm{lb}$.
2.

Pea meal ........ $1.0 \mathrm{lb}$.

Meadow hay I...2.5 lbs.

Rice feed meal... $0.5 \mathrm{lb}$.

Flaxseed ........ $0.5 \mathrm{lb}$.
3.

Coarsely ground barley ......... 1.5 lbs. Meadow hay I...2.0 ibs.

Pea meal ........ $1.0 \mathrm{lb}$.

Flaxseed ........0.6 $1 \mathrm{~b}$.

\section{B. Age, 3 to 6 Months. Average Live Weight, 280 Pounds}

1.

Meadow hay I...4.0 1bs. Oats ...........

Rye bran ........ 1.01b.

Flaxseed .......1.6 lb.
2.

Meadow hay I....4.0 lbs.

Oats .........2. lbs.

Malt sprouts .....1.0 Ib.

Linseed cake .....1.4 lbs.
3.

Meadow hay I ...4.0 lbs

Beets .........6.0 lbs

Rice feed meal..2.0 lbs

Palmseed cake $\ldots 2.0 \mathrm{lbs}$. 


\section{Age, 6 to 12 Months. Average Live Weight, 460 Pounds}

1.

Beets ........... 8.0 lbs.

Meadow hay II ...6.0 lbs.

Spring cereal

straw .......4.0 lbs.

Oat chaff ........2.

Malt sprouts .....1.0 lb.

Peanut cake ....0.5 lb.
2.

Potatoes ........6.0 lbs.

Meadow hay II ...8.0 lbs.

Spring cereal

straw ........4.0 lbs.

Rape cake ........ 1.5 lbs.
3.

Meadow hay II...6.0 lbs.

Clover hay .....4.0 lbs.

Spring cereal straw .......2.0 lbs.

Coarsely ground

barley meal ....4.0 lbs.

D. Age, 12 to 18 Months. Average Live Weight, 640 Pounds 1.

Potatoes ........18.0 lbs.

Meadow hay II.. 8.0 lbs.

Oat straw ..... $8.0 \mathrm{lbs}$.

Rape cake ..... 2.0 lbs.

\section{2.}

Beets ........... 10.0 lbs.

Meadow hay II. . 8.0 lbs.

Spring cereal

straw ....... 8.0 lbs.

Rape cake ..... 2.0 lbs.

Oat feed meal.... $1.0 \mathrm{lb}$.
3.

Potato waste....40.0 1bs.

Meadow hay II. . $8.0 \mathrm{lbs}$.

Winter cereal

straw ...... $8.0 \mathrm{lbs}$.

Malt sprouts .... $0.5 \mathrm{lb}$.

Rations for Growing Cattle, Beef Breeds (Daily Rations per Head)

A. Age, 2 to 3 Months. Average Live Weight, 150 Pounds

1.

Whole milk ......6.0 lbs.

Meadow hay I....2.0 lbs.

Oats $\ldots \ldots \ldots+1.0 \mathrm{lb}$.

Flaxseed ........0.6 lb.
2.

Whole milk .....8.0 lbs. Meadow hay I...2.0 lbs.

Peanut cake ....0.5 lb.

Rye feed meal...0.66 lb.
3.

Whole milk ......6.0 lbs. Meadow hay I...2. $2.0 \mathrm{lbs}$.

Pea meal ........1.5 lbs.

\section{B. Age, 3 to 6 Months. Average Live Weight, 300 Pounds}

\section{1.}

Meadow hay I....4.0 lbs.

Oats $\ldots . . . \cdots, 2.0 \mathrm{lbs}$.

Rye bran ......2.0 lbs.

Linseed cake ....1.0 lb.
2.

Carrots ........6.0.0 lbs.

Meadow hay I...5. 5 lbs.

Palmseed cake ...2.0 lbs.

Linseed cake ....1.0 lb.
3.

Beets ..........6.0 lbs. Meadow hay I...6.0 lbs. Malt sprouts .....1.0 lb.

Oats $\ldots \ldots \ldots \ldots 1.0 \mathrm{lb}$.

Linseed cake ..... $0.5 \mathrm{lb}$.

\section{Age, 6 to 12 Months. Average Live Weight, 460 Pounds \\ 1. \\ 2. \\ 3.}

Beets $\ldots \ldots \ldots . .8 .0 \mathrm{lbs}$. Meadow hay II... 8.0 lbs. Spring cereal straw .......4.0 lbs. Palmseed cake ...1.0 lb. Linseed cake $\ldots .2 .0 \mathrm{lbs}$.

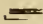

Flaxseed …...0.26 lbs.
Ensilaged beet pulp $\ldots \ldots \ldots .20 .00 \mathrm{lbs}$.

Meadow hay II. $8.00 \mathrm{lbs}$.

Spring cereal straw ...... $4.00 \mathrm{lbs}$

Oats $\ldots \ldots \ldots .2 .00 \mathrm{lbs}$

Sesame cake ... $1.00 \mathrm{lb}$.
Potatoes .......6.0 lbs.

Meadow hay II...6.0 lbs.

Pea or bean straw $\ldots \ldots . .4 .0 \mathrm{lbs}$ Oats $\ldots . . . \ldots .1 .01 \mathrm{lb}$.

Linseed cake ...2.0 lbs. Rice feed meal...1.5 lbs.

\section{Age, 12 to 18 Months. Average Live Weight, 680 Pounds}

\section{1.}

Beets ........20.0 lbs.

Meadow hay II.. $6.0 \mathrm{lbs}$.

Pea or bean

hay $\ldots \ldots \ldots \ldots 6.0 \mathrm{lbs}$.

Winter cereal

straw ....... $4.0 \mathrm{lbs}$.

Rape cake ...... 2.0 lbs.

2.

Ensilaged beet pulp .........20.0 lbs.
Meadow hay II. $8.0 \mathrm{lbs}$. Spring cereal straw $\ldots \ldots \ldots, 6.0 \mathrm{lbs}$.

Oats $\ldots \ldots \ldots \ldots 2.0 .01 \mathrm{lbs}$.

Malt sprouts .... $1.0 \mathrm{lb}$.

Palmseed cake .. $1.0 \mathrm{lb}$.

Sesame cake ... $0.5 \mathrm{lb}$.

Dre

3.

Potatoes .......8.0 lbs.

Meadow hay II...4.0 lbs.
Clover hay ...... $4.0 \mathrm{lbs}$.

Pea or bean hay $\ldots \ldots \ldots \ldots .2 .0 \mathrm{lbs}$.

Spring cereal

straw $\ldots \ldots \ldots .2 .0 \mathrm{lbs}$.

Oats .............2. $2.0 \mathrm{lbs}$.

Rapeseed cake ...2.0 lbs.

Barley feed meal..1.0 lb.

\section{Rations for Lambs}

For the first three or four weeks the food for lambs consists exclusively of the mother's milk. For breeding stock this period should be 
extended to from 10 to 14 weeks. After this, for a period of from 6 to 8 weeks they are permitted access to the dam during the day only. At first they should be permitted to suck several times a day, then twice a day and finally only once a day. During the weaning period they should have tender meadow hay, soon followed with crushed oats, and later, cracked peas, linseed, palmseed or peanut meal and fresh, pure water, not too cold. Like all young stock, lambs thrive best in mild weather on pasture. But this change also should be made gradually and light feeds of hay and grain continued.

The daily feed requirements per 100 head in the weaning period consist of from 40 to 60 pounds of hay and from 12 to 20 pounds of oats; after weaning and until the age of one year, 100 pounds of hay and 20 to 40 pounds of grain. During the second year, 100 to 150 pounds of hay, 20 to 30 pounds of grain and some beets as a by-feed and straw to provide bulk. Slops and watery waste products may be used as supplementary feeds in small quantities at the most. The character of feed suggested will give a sufficient supply of salts or mineral matter. However, when the hay is displaced with straw and the grain feed with poorgrade by-products, additional mineral matter, as suggested on pages 155 etc., is absolutely essential. In regard to standard nutrient requirement see page 165 .

\section{Rations for Growing Sheep, Mutton Breeds (Daily Ration per 100 Head)}

\section{A. Age, 4 to 6 Months. Average Live Weight, 60 Pounds}

1.

Meadow hay I ............ 90 lbs.

Young clover hay .............

Oats .......................

Peas ........................ 30 lbs.

Linseed cake ................ 20 lbs.

Peanut cake ................

B. Age, 6 to 8 Months. Average Live Weight, 76 Pounds 1.

Beets .................200 lbs.

Young meadow hay .......... 60 lbs.

Clover hay .............. 40 lbs.

Corn .................... 30 lbs.

Barley feed meal ........... 20 lbs.

Coarse wheat bran ........ 40 lbs.

Peanut cake ............. 20 lbs.
2.

Beets ..................... 150 lbs.

Young meadow hay ........ 40 lbs.

Clover hay ............. 40 lbs.

Oats ................... 40 lbs.

Corn ...................... 30 lbs.

Linseed cake ............. 16 lbs.

Peanut cake ............ 20 lbs.
2.

Potatoes ...................150 lbs.

Young meadow hay ........... 60 lbs.

Bean or pea hay .......... 20 lbs.

Cracked beans ........... 20 lbs.

Linseed cake ............... 30 lbs.

Wheat feed meal .......... 20 lbs.

\section{Age, 8 to 11 Months. Average Live Weight, 92 Pounds}

\section{1.}

Ensilaged beet pulp .......200 lbs. Meadow hay II .............

Bean or pea hay .......... 40 lbs.

Oat chaff .............. 20 lbs.

Linseed cake ............. 30 lbs.

Rapeseed cake ............. 30 lbs.

Rve feed meal ........... 20 lbs.

Wheat feed meal
Potatoes ................... 100 lbs.

Meadow hay if $\ldots \ldots \ldots \ldots \ldots \ldots$ lbs.

Pea or bean hay ........... 40 lbs.

Rapeseed cake ............ 30 lbs.

Corn .................. 40 lbs.

Palmseed cake ............ 20 lbs.

Peanut cake ............... 10 lbs. 


\section{Rations for Pigs}

During the first month after birth the food for pigs should consist of the milk of the dam. For pigs intended for early market this period should be extended to two months, and to ten weeks for weakly individuals. If the milk of the dam is insufficient, a common practice in Germany is to provide a goat for wet nurse (Fig. 87), care being observed to select one adapted for the purpose (low hanging udder). Bottle feeding is also practiced under such circumstances.

As soon as the pigs show a tendency to gnaw foreign objects, which usually occurs at the age of two or three weeks, they should have crushed oats or whole wheat or barley, and this should be followed later with cracked peas and beans. In addition they should have access to prepared chalk, (one-third ounce per head per day), as well as soft coal,

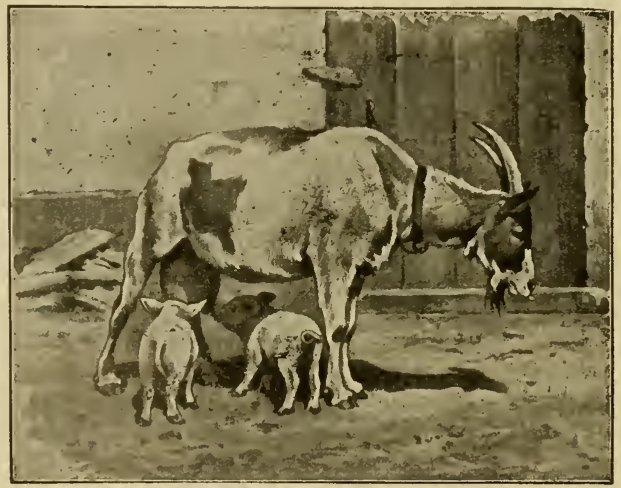

Fig. 87. Goat as wet nurse for pigs. (From Landwirtschaftliche Zeitung.)

earth, sand, pitch, wood ashes, bone meal or charcoal. The lime containing materials favor bone development, while the other substances stimulate digestive activity, thus favoring feed utilization and effecting an actual saving of feed. According to trials at the Wisconsin Experiment Station the saving thus affected amounts to as much as 28 per cent.

By the end of the third or fourth week the milk of the dam may be displaced to the extent of one-half with cow's milk. The latter should be fresh, warm, and slightly diluted with water. Later on skim milk, thin gruels, etc., may be gradually substituted. The latter should be given sparingly at first, one-quarter of a pint, and gradually increased to 1 quart. According to Klein, saccharification of the starchy gruels which are gradually substituted for the milk (pp. 33 and 186) is not followed by better assimilation in pigs, as is the case with calves. As they become accustomed to solid food the pigs are gradually weaned. They are sepa- 
rated from the sows and the intervals between nursings are lengthened from time to time.

Pigs intended for breeding purposes should have chopped beets by the time they are three months of age, or cooked or steamed potatoes, dried potatoes, ground corn and tender green feed, especially red clover. The males should have somewhat more nitrogenous food than the females. One hectare of clover furnishes sufficient pasture for 25 to 40 shoats (one acre for 10 to 16 shoats). Soil and weather conditions must of course be suitable. Stubble fields and potato and beet fields, after the main crop has been harvested, are also suitable runs for young pigs. In addition to the latter, extra rations should of course be supplied. A mere run for young pigs is only a makeshift.

Young pregnant sows should have gradually increased rations of ground oats or barley, and later on, especially after farrowing, they should have wheat bran and linseed cake.

The following table contains hints for combinations of feeding stuffs suitable for breeding stock. They are based on 1,000 pounds live weight. The values in parentheses apply to fattening pigs of early maturity.

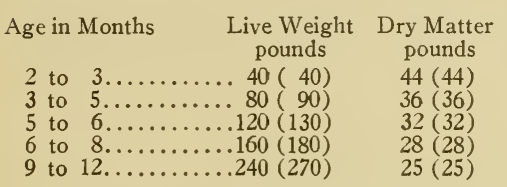

\begin{tabular}{ccc} 
& \multicolumn{2}{c}{ Digestible } \\
Albumen & Fat & Carbohydrates \\
pounds & pounds & pounds \\
$6.2(6.2)$ & $1.0(1.0)$ & $28.0(28.0)$ \\
$4.0(4.5)$ & $0.8(0.9)$ & $23.5(24.0)$ \\
$3.0(3.5)$ & $0.5(0.7)$ & $21.0(22.0)$ \\
$2.3(3.0)$ & $0.3(0.5)$ & $19.0(20.0)$ \\
$1.7(2.5)$ & $0.2(0.3)$ & $15.0(19.0)$
\end{tabular}

Since most of the feeding stuffs commonly fed to swine are deficient in lime (potatoes, beets, grains), it is advisable to give daily rations of from one-sixth to one-third of an ounce of prepared chalk, and in case of phosphorus deficiency, like abount of precipitated calcium phosphate.

Pigs intended for fattening at the age of 6 months should have more proteids from the beginning than breeding stock (for nutrient standards see p. 165). If it is not intended to fatten the pigs until they are mature ( 12 to 18 months) they should have rations with somewhat less protein, in the form of whey, wheat bran, feed meal, corn, beet pulp, distillery slops, chaff and soiling crops, unless for some reason it is preferred to give the run of a pasture.

For intensive feeding of growing pigs, easily digestible, highly available feeding stuffs, like cracked grains and leguminous seeds, feed meals, potatoes, meat meal, blood meal and fish meal, creamery by-products, etc., are necessary. The more digestible the feed and the more available the nutrients, the more rapidly will the animals accumulate muscle and fat. Special care is necessary in the selection of the proper feeding stuffs for the last 7 or 8 weeks of the fattening period. The consumption of large quantities of feeding stuffs rich in the various oils and fats 
(com, rice feed meal, fish meal, certain oil cakes, etc.) has a tendency to produce soft, oily, bacon (p. 153). These objections may be overcome by limiting the fatty and oily feeding stuffs to one-third of the total concentrates, or better still displacing them entirely with barley, or by adjusting or counteracting their effect with feeds of an opposite character like palmseed cake and cocoanut cake.

When feeding heavily with Indian corn the substitution of palmseed meal for one-fifth of the corn ration has proved very effective. The quantity of watery or succulent feeding stuffs like beets, beet pulp, the by-products of starch manufacture and distilleries, creamery by-products, etc., should be limited during the last four or five weeks of the fattening period. In any event, swine should not have food that is too watery. They should not be fed on thin slops exclusively.

Potatoes should be cooked or steamed for swine. Hard grains and chaff, as well as creamery by-products, distillery slops, etc., not strictly fresh, and all feeding stuffs of a suspicious nature which are liable to contain bacteria in large numbers, should also be steamed or cooked before feeding. These materials should be administered in the form of a thick, warm gruel. If slops are used, excessive dilution should be avoided. Grains should be fed either coarsely ground or rolled or crushed, but not cooked. The daily ration should be distributed over three regularly observed feeding periods. Troughs and all utensils should be kept scrupulously clean.

\section{Rations for Growing, Fattening Pigs (Daily Ration per 10 Head)}

\section{A. Age, 2 to 3 Months. Average Live Weight, 40 Pounds}

1.

Skim milk ..............40 lbs.

Crushed barley ............. 8 lbs.

Corn $\ldots \ldots \ldots \ldots \ldots \ldots \ldots \ldots .4$ lbs.

Peas $\ldots \ldots \ldots \ldots \ldots \ldots \ldots \ldots \ldots \ldots+4$ lbs.
2 .

Whole milk ................. $30 \mathrm{lbs}$.

Ground barley ............. $8 \mathrm{lbs}$.

Peas ..................... 6 lbs.

Rye bran $\ldots \ldots \ldots \ldots \ldots \ldots \ldots \ldots \ldots \ldots \ldots$ lbs.

\section{B. Age 3 to 5 Months. Average Live Weight, 100 Pounds}

1.

Skim milk ..............60 lbs.

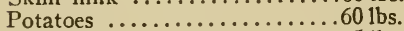

Rye bran $\ldots \ldots \ldots \ldots \ldots \ldots \ldots \ldots \ldots \ldots \ldots \ldots \ldots \ldots \ldots$ lbs.

Corn $\ldots \ldots \ldots \ldots \ldots \ldots \ldots \ldots \ldots \ldots \ldots \ldots \ldots \ldots \ldots$ lbs.

Ground barley ............. 6 lbs.
2.

Potatoes .................. 80 lbs.

Pea meal .....................

Barley feed meal ............... 10 lbs.

Meat meal (tankage) ........ $1 \mathrm{lb}$.

\section{Age, 5 to 6 Months. Average Live Weight, 130 Pounds}

\section{1.}

Skim milk .............. 80 lbs.

Potatoes $\ldots \ldots \ldots \ldots \ldots \ldots \ldots \ldots \ldots \ldots \ldots \ldots$ lbs.

Rye bran $\ldots \ldots \ldots \ldots \ldots \ldots \ldots \ldots \ldots$. 8 lbs.

Rice feed meal ............. 4 lbs.
2.

Beets ..................60 lbs.

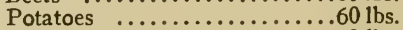

Pea meal $\ldots \ldots \ldots \ldots \ldots \ldots \ldots .6 \%$ lbs.

Rye bran $\ldots \ldots \ldots \ldots \ldots \ldots \ldots \ldots \ldots \ldots \ldots \ldots \ldots$ lbs.

Barley feed meal ............ 6 lbs.

Peanut cake .............. 2 lbs. 


\section{Age, 6 to 8 Months. Average Live Weight, 180 Pounds}

1.

Skim milk ............. 80 lbs.

Potatoes .................150 lbs.

Rye bran ............... 10 lbs.
2.

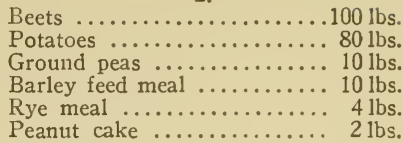

Rations for Nursing Sows. (Per Day per Head)

Approximate Live Weight 300 Pounds, With 8 Pigs More or Less 1.

Potatoes .................6 lbs.

Oats $\ldots \ldots \ldots \ldots \ldots \ldots \ldots \ldots \ldots \ldots \ldots \ldots \ldots$ bs.

Rye bran ................ 2 lbs.

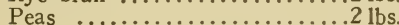

3.

Sour milk ...............12 lbs.

Dry beet pulp ............. 4 lbs.

Barley .................... 2 lbs.

Palmseed cake ............. $1 \mathrm{lb}$.
2.

Skim milk ...............10 lbs.

Potatoes ............... 8 lbs.

Barley ................. 3 lbs.

Linseed cake ............. $1 \mathrm{lb}$.

4.

Beets ...................16 lbs.

Corn .................... 3 lbs.

Oat chaff $. . . \ldots \ldots \ldots \ldots \ldots \ldots \ldots \ldots \ldots \ldots . .1 \mathrm{lb}$.

Sesame cake .............. $1 \mathrm{lb}$.

Rice feed meal ............ $1 \mathrm{lb}$.

\section{Fattening Rations for Mature Animals}

The fattening of mature animals is mainly a matter of putting on so much fat in the shortest possible time, consistent with health. The addition of flesh is insignificant. In young or growing animals, however, as well as in animals that are run down in condition from overwork or starvation, flesh or muscle production is desired and is attained by administering feeds with higher protein content. It is necessary that the muscle tissue be well developed so as to form a basis for the accunulation and deposit of fat. Fattening rations for mature emaciated or lean animals should be preceded by a preparatory feeding period of from two to four weeks during which animals should receive from 12 to 15 pounds of digestible nutrients daily per 1,000 pounds live weight, albumen ratio $1: 6$. This ratio is gradually widened until the desired fattening ration is obtained. The change from the narrow to the wide ration should extend over a period of about one week, the last week of the preparatory period.

The chief fat-forming feeds in use for this purpose are the cheaper carbohydrates. One hundred grams of digestible, fully available carbohydrates will, under favorable conditions, produce 24.8 grams of body fat. The fat nutrients contained in the feed, and which are capable of producing 2.2 times as much animal fat in the ox as the same weight of starch, can not, however, be administered in quantities exceeding certain limits without seriously affecting the appetite and digestion. The outside limit of fat in a fattening ration, per 1,000 pounds live weight, is from one-third to one-half pound. Emulsified fat is less injurious. The best way to administer fat is in the form in which it occurs naturally in oil seeds, oil cakes, etc. Even in this form 0.7 to 0.8 and exceptionally 
as much as 1 pound constitute the maximum that can be administered daily without harm.

As already indicated, it is possible to influence the character of the fat formed in the body by proper selection of the food fats. Practical experience as well as scientific investigations have shown that carbonaceous grains, poor in fat (rye, barley, peas, beans, lentils) potatoes, beets and palmseed, cocoanut and cottonseed cake produce fat of a high melting point in cattle and swine; in other words, hard lard and tallow. On the other hand, sunflower seed cake, flaxseed cake and rapeseed cake, corn, oats, wheat, bran, rice feed meal, as well as tankage and fish meal, produce fat of a low melting point; in other words, soft or flabby fat. Thus the character and quality of pork is improved by the former, while the quality of beef is improved by the latter group of feed concentrates.

Expensive albumen nutrients do not enter into fattening rations to any extent. The cheaper carbonaceous feeding stuffs cannot be surpassed as fattening feeds. The albumens do not even indirectly influence fat formation from the carbohydrates. It is necessary merely to provide sufficient albumen to prevent loss of the albuminous tissues already present in the body. Feed combinations with ratios of $1: 10-12$ are amply sufficient for this purpose. On the other hand, when large amounts of albuminous feeds are at our disposal without extra or excessive cost the ratio may be contracted to $1: 4$ without any fear that the success of our efforts will be interfered with.

As Rubner and Kellner have pointed out, the deposit of fat will proceed at a rate proportional to the excess of the additional albumen; viz., $1 \mathrm{~kg}$. of digested starch will produce $248 \mathrm{gm}$. of fat $(=56.4$ per cent of the heat that was stored up in the digested nutrient), $1 \mathrm{~kg}$. of digested crude fiber will produce $253 \mathrm{gm}$. of fat (= 57 per cent), $1 \mathrm{~kg}$. cane sugar produces $188 \mathrm{gb}$. (= 45.2 per cent), $1 \mathrm{~kg}$. of albumen $235 \mathrm{gm}$. (=38.7 per cent), and $1 \mathrm{~kg}$. fat 474 to $598 \mathrm{gm}$. (= 64.4 per cent) of fat in the ox. Swine utilize the productive portion of the digested food to the extent of 20 to 25 per cent above that utilized by the ox. The statement made above that "the deposit of fat will proceed at a rate proportional to the excess of the additional albumen" must of course be interpreted with limitation. When the total nutriment taken up is excessive, the digestive functions become abnormal and the rule laid down ceases to apply.

1. Fattening rations for mature ruminants, according to Kellner, under ordinary conditions should contain, per 1,000 pounds live weight, per head and per day, the following:

1.6 pounds digestible albumen ( 2.0 pounds for $2-3$ year olds), 0.7 pounds digestible fat, 13-16.0 pounds digestible carbohydrates (nitrogenfree extract and crude fiber), 24-32 pounds of dry matter, 12.5-14.5 pounds starch value, $1: 10-12$ nutritive ratio.

In constructing feeding rations, the daily amount of hay and straw which the available supply will permit for each animal (12 to 15 pounds 
per 1,000 pounds live weight, or only 5 to 10 pounds for fattening animals in order to keep the appetite keen) and the cheaper root crops and tubers (beets, carrots, beet pulp, brewers' grains, slops, potato fiber, molasses, lupines, etc.) are supplemented with the deficient nutrients in the form of concentrates.

Pasturage alone, as a rule, will not complete the fattening process, but it constitutes an excellent preparatory period. Some dry feed administered before driving the animals out to pasture is a wise precautionary measure for preventing digestive troubles. Furthermore, the feed furnished by the pasture should be supplemented with a suitable by-feed. If the pasture consists of clover, alfalfa, serradella, vetches or other plants rich in albumen, the by-feed should consist of feeding stuffs rich in fat and starch, like cracked grains, rice feed meal, dry beet pulp, etc., while forage like corn, timothy, orchard grass, sorghum, millet, etc., should be supplemental with nitrogenous concentrates like oil cake, cracked peas or beans, dried brewers' grains and dried distillery slops.

The water content is an important consideration in the fattening ration. Rations for sheep should contain about 2 or 3 parts of water (either in the form of drink or as water content of the ration itself) and cattle 3 or 4 parts. Care should be observed that animals do not take more water with the feed than the total required. Even the minimum amount required should not all be taken with the feed. If circumstances are such that very watery feeding stuffs must be used, sufficient dry matter should be given in addition.

At all times efforts should be made to keep the appetite at its best, i. e., provide palatable and agreeable feed. Palatability can be increased by careful preparations of the rations, proper combinations and special condimental feeding stuffs. Molasses is a corrective of this nature and a valuable nutrient besides. Common salt is also useful (50-80 gm. $=1 \mathrm{r} / 2$ to 3 ounces).

Fattening animals should be kept contented, comfortable and free from excitement of whatever kind (irregularity in feeding, poor or irregular supply of litter, rough handling, annoyance by other animals, etc.). Every unnecessary muscular effort or nervous excitement tends to reduce the fattening effect of the feed. The comfortable and contented animal helps the feeder reduce his feed bill.

Stable conditions are also of influence; the manner of securing the animals, light supply, temperature, etc. Animals should be so stabled that rest is made compulsory and annoyance next to impossible. For this reason box stalls are less suitable than those of other pattern. Stalls for fattening animals should be kept comparatively dark. This reduces tissue waste and inclines animals to be more restful. The external temperature has a decided influence on the appetite. Highly fed ruminants create more heat than is necessary to keep them comfortable at ordinary temperatures. The excess temperature, above a certain point, no longer serves the purpose of saving fuel. Overheated animals instinctively eat 
less, and fat production is affected. Stalls should therefore be kept comfortably cool $\left(50^{\circ}\right.$ to $55^{\circ} \mathrm{F}$. or less), for intensive feeding. In "extensive" feeding, with smaller rations, low temperatures counteract tissue deposit, and the surrounding temperature should accordingly be kept at a higher level $\left(55^{\circ}\right.$ to $60^{\circ} \mathrm{F}$.).

In some sections of the United States (Missouri, where climatic conditions approach those of central Germany) feeders go even a step farther than has been suggested. Where cattle are undergoing intensive feeding in the cold season of the year, open sheds, protected with boards on the sides exposed to the prevailing storms, are the only shelter provided, if any; and it is maintained that animals can be conditioned in this way more economically than when stabled. Waters gives the following summary of results of feeding 3 lots of steers of 36 animals in each lot:

\begin{tabular}{|c|c|c|c|c|c|c|}
\hline \multirow{3}{*}{$\begin{array}{l}\text { Where kept. } \\
\text { In stable ... }\end{array}$} & \multirow{5}{*}{ 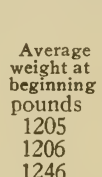 } & \multicolumn{2}{|c|}{ Feed consumed } & \multirow{5}{*}{$\begin{array}{c}\text { Digestible } \\
\text { organic } \\
\text { matter } \\
\text { per head } \\
\text { per day } \\
\text { pounds } \\
19.2 \\
20.2 \\
209\end{array}$} & \multicolumn{2}{|c|}{$\begin{array}{l}\text { Increase in } \\
\text { live weight }\end{array}$} \\
\hline & & Hay & Corn & & Total & $\begin{array}{l}\text { Per head } \\
\text { per day }\end{array}$ \\
\hline & & 3471 & 83 & & $\begin{array}{l}\text { pounas } \\
803\end{array}$ & 1.78 \\
\hline & & & & & 90 & 1.90 \\
\hline lout & & 3935 & 9545 & & 932 & 2.05 \\
\hline
\end{tabular}

According to this experiment the production value of 100 pounds of digestible matter is equal to 92.75 pounds live weight for stable feeding and 98.1 pounds for feeding in the open!

In like manner, clipping stall-fed animals (temperature $55^{\circ} \mathrm{F}$.) favors radiation of heat from the body, stimulates the appetite and promotes fattening. Actual utilization of the feed, however, is not affected by lower temperature, and clipping during cold weather is indicated only for intensive feeding. No advantage can be expected from clipping fattening animals under conditions of low external temperature and short rations.

A part of the fattening ration is needed for the support of the vital processes and is consequently unproductive. Since increase of weight is proportionate to the excess above this requirement, the most profitable feeding is that which produces a given gain in the shortest time, thus eliminating unnecessary maintenance feed. Intensive feeding is, on the whole, more economical than extensive feeding. Unless circumstances demand otherwise, intensive feeding with rich feeding stuffs is the most economical.

In the beginning of the fattening period, as a result of the filling of the digestive canal with food masses and water, animals seem to be making enormous gains. After this abnormal period has passed over and the animals have become accustomed to their increased rations and take their feed and drink regularly, frequent weighings, preferably before the morning feed, arc of great assistance and value to the feeder. Aside from variations due to irregularity in drinking water and voiding excrement and urine, these gains are more or less uniform. Later, when the deposit of watery tissues ceases, the rate of gain becomes less. This is due, in part at least, to the fact that with a gain of live weight the maintenance requirements of the animal also increase. The latter continue to increase as the animal approaches the finished condition. Kellner found that an animal weighing $630 \mathrm{~kg}$. required 21,300 calories per $1,000 \mathrm{~kg}$. live weight for mere maintenance, while one of $748 \mathrm{~kg}$. live weight $\mathrm{rc}=$ quired 23,920; one of $750 \mathrm{~kg}$., 25,280, and one of $858 \mathrm{~kg}$., 25,830 calories.

Since, on the one land, the cost of putting on a pound of gain increases considcrably as the fattening period advances, and, on the other hand, overfat meat docs 
not meet with the approval of the majority of consumers, we have two good arguments against prolonging the fattening period beyond certain limits.

As the fattening process continues, much of the water in the tissues is replaced with fat and the live weight of the animal may actually diminish while it is making real gains in fat. This fact can be practically demonstrated by observing the increase in size and thickness of the external layers of fat. Toward the end of the fattening period when the tissues have become filled with fat to their limit a natural reaction to the formation of fat generally sets in. The animals begin to get particular in their choice, not to say fastidious, and eat less every day.

\section{Rations for Fattening Cattle, Second Period For 1,000 Pounds Live Weight Per Day}

1.

Beets ............50 lbs.

Meadow hay II ...10 lbs.

Winter cereal

straw ........ 5 lbs.

Coarse wheat

bran ......... 4 lbs.

Peanut cake ..... 3 lbs.

Rice feed meal.... 4 lbs.

\section{2.}

Beets ..........75 lbs.

Meadow hay II... 6 lbs.

Clover hay ...... 6 Ibs.

Winter cereal

straw ........ 4 lbs.

Dried rye slops.... 4 lbs.

Rapeseed cake .... 3 lbs.

\section{3.}

Potatoes ........30 lbs.

Meadow hay .....10 lbs.

Clover hay ...... 4 lbs.

Winter cereal

straw ........4 4 lbs.

Dry brewers'

grains ....... 2 lbs.

Peanut cake ....... 3 lbs.
4.

Potatoes .......40 lbs.

Meadow hay II... 8 lbs.

Clover hay ...... 6 lbs.

Winter cereal

straw ......... 3 lbs.

Sesame cake ..... 3 lbs.

Rapeseed cake .... $1 \mathrm{lb}$.

5.

Potato slop .....75 lbs.

Meadow hay ....6 6 lbs.

Spring cereal straw 5 lbs.

Winter cereal straw 5 lbs.

Wheat chaff .... 3 lbs.

Rye feed meal ....6 6 lbs.

Sesame cake .... 3 lbs.

Cracked corn ....2 2 lbs.

\section{6.}

Potato slop .....100 lbs.

Meadow hay II... 6 lbs.

Spring cereal straw 5 lbs.

Winter cereal straw 7 lbs.

Rapeseed cake .... $11 \mathrm{~b}$.

Rice feed meal ... $3 \mathrm{lbs}$.

Palmseed cake ... 5 lbs.
7.

Pressed beet pulp. $60 \mathrm{lbs}$.

Meadow hay .... 5 lbs.

Spring cereal straw $7 \mathrm{lbs}$.

Molasses ...... 3 lbs.

Rye bran ....... 3 lbs.

Peanut meal .... 2 lbs.

8.

Ensilaged beet pulp ..........50 lbs.

Clover hay ...... 6 lbs.

Alfalfa hay .....6 6 lbs.

Barley straw ....6 6 lbs.

Fresh brewers'

grains .......20 lbs.

Cracked corn .... 3 lbs.

Peanut cake ...... $1 \mathrm{lb}$.

9.

Corn ensilage ...44 lbs.

Meadow hay II... 5 lbs.

Clover hay ...... 5 lbs.

Barley straw ....6.6 lbs.

Rice feed meal.... 2 lbs.

Malt sprouts ....2 2 lbs.

Linseed cake ..... 2 lbs.

Palmseed meal ... 2 lbs.

Rapeseed meal ... 2 lbs.

\section{Rations for Fattening Sheep, Second Period}

1.

Meadow hay II...10 1bs. Clover hay ....6.6 lbs. Straw ${ }^{9}$

(picked over)...6 $6 \mathrm{lbs}$.

Field beans ..... 9 lhs.

Corn .......... 3 lbs.

\section{2.}

Potatoes ........30 lbs. Meadow hay II...12 lbs. Pea or bean hay.. 9 lbs. Peanut cake .... 5 lbs.
3.

Beets ..........40 lbs. Meadow hay ......10lbs. Lupine hay .....10 lbs. Straw 9

(picked over) .. $4 \mathrm{lbs}$.

Rye bran ...... 4 lbs.

Sesame cake .... 3 Ibs.

\section{4.}

Pressed beet pulp. 50 ibs. Alfalfa hay .....12 lbs.
Straw ${ }^{9}$

(picked over)..8 8 lbs. Rye feed meal. .5.5 lbs. Rapeseed cake ...4 $4 \mathrm{lbs}$.

5.

Potato pulp ......40 lbs. Meadow hay ....8 8 lbs. Spring cereal straw 4 lbs. Bean or pea hay.. 8 lbs. Lupine (yellow).. 4 lbs. Sesame cake ....2 2 lbs. Rapeseed meal ... $1 \mathrm{lb}$.

9. Straw designated "picked over" is estimated as used un to the extent of 75 per cent and of the samic composition as "yery good summer cereal straw," 


\section{Fattening Ration for Mature Swine, 1 to $1 \mathrm{x} / 2$ Years Old For 1,000 Pounds Live Weight Per Day}

Feed $\begin{gathered}\text { First } \\ \text { fattening } \\ \text { period }\end{gathered}$

Digestible albumen ............ 3 lbs.

Digestible fat ................ 0.7 lbs.

Digestible carbohydrates .........26-30 lbs.

Dry matter ................... 35 lbs.

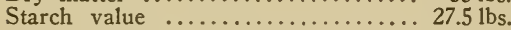

Albumen ratio ................... 1:10

\section{Second \\ fattening \\ period}

2.8 lbs.

$0.5 \mathrm{lbs}$.

$25.0 \mathrm{lbs}$.

28-33 lbs.

$26.1 \mathrm{lbs}$.

$1: 10.8$
Third
fattening
period

2.0 lbs.

$0.4 \mathrm{lbs}$.

19.0 lbs.

24-28 lbs.

19.8 lbs.

$1: 10$

If the swine are in a poor state of nutrition at the beginning of the fattening period, or in case they are not full grown, more nitrogenous feed should be given for the first 2 to 4 weeks ( 4 pounds digestible protein). In the further course of the fattening period, which should terminate in $31 / 2$ to 4 months, the amount of digestible protein is gradually reduced to 2 pounds. It is also advisable, in order to keep up the appetite, that the fat be reduced to about 0.4 pounds in the course of time. In order to give the bacon the desired consistency, care should be observed in the selection of the fat concentrates. The carbohydrates should also be reduced in the course of the fattening period to about 20 pounds toward the end of the period.

\section{Rations for Dairy Animals}

Rations for dairy cattle should be adjusted to the milk yield. The reverse process, that of adjustment of the milk yield to the rations, occurs to a less extent than is commonly supposed. This is possible only within limits set by the capacity of the udder. Only those portions of the digested ration which the udder is capable of converting into milk can be expected to be thus converted. The nutrients which are finally converted into milk seem to constitute an integral part of the cellular tissue before the latter is broken down through the means of a complicated chemical process, finally to be excreted as milk. The capacity to secrete milk is at its height in the early part of the lactation period, i. e., soon after calving. As time advances this capacity diminishes, and no kind or quantity of feed can restore it.

The food supply remaining the same, that portion which can no longer be used for conversion into milk is, under these conditions, deposited as fat in the body or udder. But abnormal fat deposits in the udder lessen its efficiency and besides constitute a waste of nutrients in animals intended solely for milk production. It is evident, therefore, that for practical purposes animals should be fed individually with due consideration for their general condition of nutrition. The general condition of nutrition should be good but the animal should not be fat. This rule has a very general application and its observance should not be confined to the lactation period only. 


\section{The Influence of Feed on Milk Secretion}

When fresh cows are underfed it may be observed that more nutrients are excreted with the milk than are supplied in the feed, or, in other words, that a part of the milk is formed from the tissues of the body and that the latter is gradually losing weight. A certain degree of emaciation is frequently observed in fresh cows. The question whether, as a result of intensive breeding, the cow's udder has been developed to such an extent that the digestive organs are unable to keep pace with it, may be an open one. However, milk secretion can not be continued indefinitely at the expense of body tissues and is bound to suffer sooner or later both as to quantity and quality (Kuehn). If the food supply is relatively deficient in phosphate of lime the phosphorus content of the milk may be reduced to the extent of 30 per cent (Weiskes). Weiskes was unable to discover an analogous deficiency of lime.

A decrease in the milk yield occurring in the course of lactation as a result of deficient food supply may to some extent be corrected by liberal feeding, and both solids and fat content, the latter in particular, can be increased. Concomitant with this there is an improvement in the animal's general condition. The influence of nutrition or food, on the milk yield, as already emphasized, is confined within certain limits. A number of factors that influence milk yield, like individuality, breed, natural lactation period, etc., can not possibly be overcome by feeding. Within certain limits, however, in which the food supply affects the milk yield, there seems to exist a zone in which the yield is in proportion to the food supply. Beyond this zone every increase in milk yield requires greater amounts of food until a stage is reached where increases are no longer profitable.

The proteins, of all the nutrients, have the greatest influence upon milk secretion. This is especially true as to quantity. The quality on chemical composition is less affected by the proteids. On the other hand, the effect of the nonalbuminous nitrogenous compounds like asparagin, ammonium acetate, etc., is not very marked.

The effect of the nitrogen-free nutrients on milk secretion is subject to the influence of the proteids. When feed that is rich in albumen but deficient in nitrogen-free nutrients is given, the milk yield suffers and, vice versa, if nitrogen-free nutrients are added, the yield is increased, especially quantitatively. On the other hand, if the feed administered has been deficient in proteids and the discrepancy is widened by the further addition of carbonaceous nutrients, the result may be a depression of the digestive functions and a further decrease of the milk yield. This may not occur if the rations are somewhat less deficient in proteids. As a matter of fact, if the animals in question are otherwise good producers but in a poor or run-down condition, the addition of carbohydrates may result in an actual increase of yield, due to the improved physical condition of the animal. Thus it may not seem strange that numerous ex- 
periments and observations along this line have given conflicting results.

If equivalent amounts of carbohydrates and albumens are replaced by easily assimilable fats, provided that the amount of fat does not exceed 0.5 to 1 pound per 1,000 pounds live weight, per day, the milk yield will not only be increased in amount but in fat content as well. Larger amounts of fat ( 1.5 to 2 pounds per 1,000 pounds live weight) will only occasionally have the same effect; frequently their effect is negligent or less than that of smaller amounts. The nutrient fat of the ration, as such, enters into the composition of the milk to a very limited extent. It seems that a direct transfer of the nutrient fat into milk occurs only in so far as the presence of stearin, palmatin and olein is concerned. According to investigations of Henriques and Hansen and others, it is known that certain other fats (salicinic and linoleic acids) are not excreted with the milk.

A few words should be added with reference to the effects of so-called specific milk-producing feeding stuffs. These effects would be assumed to be independent of the digestible nutrient content of the substances in question, but due rather to their effect upon palatability and on the activity of the digestive glands. It has been found that palmseed cake, as compared with ground corn and peanut meal of equal starch value and digestible albumen content, actually possesses this property to some degree. Cocoanut cake, and corn distillery slop and, to a moderate degree, linseed cake, cottonseed meal and dry brewers' grains, as well as the leguminous seeds (vetches and peas), increase the fat content of the milk without affecting the amount. Maizena and, in a more moderate degree, corn and oats, increase the quantity of milk secreted, but the percentage of fat is reduced so that the total remains practically the same. Camelina sativa (false flax) and poppy-seed cake, as well as rice feed meal, have an unfavorable effect in this respect. The ethereal oils and bitter principles are also classed with the specific milk-producing substances (galactopoietics), e. g., fennel, anise, caraway, coriander, juniper berries, calamus root, gentian root, jaborandi leaves (pilocarpin). Certain sulphur preparations, flowers of sulphur, antimony sulphid and bicarbonate of sodium also belong to this class.

Morgen and his co-workers, as well as Fingerling, have shown that a certain content of aromatic substances (ethereal oils) in feedings stuffs actually influences milk secretion. In an experiment conducted with two lots of sheep and goats, the one receiving good quality aromatic meadow hay, the other straw, starch, gluten, tropon by-products, sugar, prepared lime and hay ash, while the rations for each lot contained the same amount of digestible nutrients and had practically the same starch values, the meadow hay ration produced the largest yields of milk. After adding condimental feeding stuffs, fennel, anise, hay distillate or hay extract and malt sprouts to the second ration, and subtracting a corresponding amount of digestible nutrients, the milk yield and fat production almost equalled that from the meadow hay ration. The same favorable effects 
of the ethereal onls was observed on addition of small quantities of fennel to rainsoaked or weathered hay. The effects, however, were not noticeable when good meadow hay was used as the basal feed. The addition of fennel in the latter instance resulted in an increase of hardly 2 per cent in the total milk yield, 0.5 per cent of the dry matter, 3 per cent of the fat, 2 per cent of the sugar and $11 / 2$ per cent of the ash. The conclusion evident from this experiment, as well as that of many similar trials, is that sound, normal feeding stuffs when fed to healthy animals are not materially improved by the addition of condiments. However, in the feeding of leached, insipid, or slightly spoiled feeding stuffs, their moderate use is indicated.

\section{Standardization of Rations for Cows}

Rations for dairy cattle, as already emphasized, should be adjusted to the milk yield, i. e., individual feeding should be practiced as much as possible. In general the quantity of feed should be so regulated that the animals are kept in good condition and neither starve nor get too fat. The only exceptions to this rule are animals going dry and intended for future slaughter. Kellner gives the following feeding standards:

Daily milk yield per $1000 \mathrm{~kg} .{ }^{10}$
live weight
Liters $^{1}$
10
20
30
40

\begin{tabular}{|c|c|c|}
\hline \multicolumn{3}{|c|}{ Per day per $1000 \mathrm{~kg}$. live weight. } \\
\hline Albumen & Fat & Starch value \\
\hline Kilograms & Kilograms & Kilograms \\
\hline $1.0-1.3$ & 0.3 & $7.8-8.3$ \\
\hline $1.6-1.9$ & 0.5 & $9.8-11.2$ \\
\hline $2.2-2.5$ & 0.6 & $11.8-13.9$ \\
\hline $2.8-3.2$ & 0.8 & $13.9-16.6$ \\
\hline
\end{tabular}

Dry matter, $20-30 \mathrm{~kg}$; ; roughage, $12-20 \mathrm{~kg}$., per 1,000 kg. live weight. The albumen ratio is $1: 6-10$. More proteids (or a narrower ration, $1: 4$ ) are not economical unless an unusual price is obtained for the milk.

The more important classes of feeding stuffs for dairy cattle are as follows :

Green feed (pasture and soiling crops, which are most conducive to health and milk yield): Grass, clover, leaves of beets, etc.; green corn and other grains in their green state, like oats and rye; buckwheat, white mustard, rape, turnips, spurry, etc.

Tubers and root crops: Beets; potatoes in limited quantity; industrial by-products like beet pulp, slops, bran, oil cake, molasses; grains (chiefly and preferably coarsely ground); roughage, hay, straw, chaff, etc.

\footnotetext{
10 For the sake of accuracy the kilogram weights given in the German table have not been converted into pounds, as this would involve the use of complicated fractions. For practical purposes pints may be substituted for liters and pounds for kilograms, as has been done by the translator in most of the text, whenever such changes did not affect proportions.-Translator.
} 
In the selection of feeding stuffs, palatability and agreeability should always be sought and the effect on the taste and other properties of milk and butter kept in mind. The feeder is cautioned against the use of moldy or otherwise spoiled feeding stuffs, silage, soiling crops, etc., and against excessive rations of beets of any kind, beet leaves, cabbage stems, potatoes, distillery waste and pulps, fresh or ensilaged pulps, lupines with bitter principles not properly removed, leek, chamomile, corn cockle seed in bran, rapeseed cake (above 1 pound per head per day), etc. Long-continued consumption of watery feeding stuffs produces watery milk. The feeding to excess of common beets, beet leaves, beet pulp, potatoes, vetches, peas and beans, palmseed cake, cocoanut cake, cottonseed cake or meal, straw, overripe grass and hay, or the latter mixed with sour grasses, makes hard butter. The opposite effect, or "greasy" butter, results from excessive feeding of ground oats or corn, rice feed meal, and rape seed, sesame seed and sunflower seed cake or meal, and wheat bran. Good grass and clover, carrots, oats and rice feed meal are correctives for palatability. As already stated, palmseed cake and cocoanut and cottonseed cake have a tendency to make the butter hard, while rapeseed cake, ground corn and rice feed meal have the opposite effect.

For pregnant cozes the daily ration of digestible albumen should be increased during the $5 \mathrm{r} / 2$ months preceding parturition. The increase should amount to from $11 / 2$ to 3 ounces (average 2 ounces) per day per 1,000 pounds live weight. The amount of straw should be reduced during this period, or withdrawn completely and replaced with hay (10 pounds per 1,000 pounds live weight). Heating, bloating and constipating feeding stuffs like ground legume seeds, rank clover and wet green forage, as well as frosted or frozen, fungus infected, musty or soiled feed of any kind, should be avoided. Green forage, especially good pasture, and good hay, oats, crushed barley, bran, and linseed, palmseed, cocoanut and peanut cake or meal, dry beet pulp, dry distillers' slop and $d r y$ brewers' grains, as well as beets and potatoes, are indicated for pregnant cows.

Rations for dry cows per 1,000 pounds live weight should contain 0.74 pounds of digestible albumen and 6 pounds starch value. In many instances this low ration is reduced to from $1 / 2$ to 1 pound one month before calving. It is said that the danger from milk fever can in this way be much reduced. Immediately after calving it is customary in many places to administer a warm gruel or bran mash. For a few days immediately following calving light, easily digestible feed is advisable on account of the relaxed condition of the abdominal muscles.

As already discussed in detail on page 156 etc., an abundant supply of mineral matter is necessary for all milk-producing animals. This ap- 
plies in particular to the bone-forming salts which occur in milk in large amount. Cows giving a daily yield of 10 quarts of milk suffer a loss of 18 grams of lime and 15 grams of phosphoric acid. Unless a sufficient amount of these minerals is provided in the feed, the body will suffer the loss. In providing for this loss in building the ration, the requirements of the animal itself should also be kept in mind. A cow of 1,000 pounds live weight requires for its maintenance $12 / 3$ ounces of lime and fivesixths of an ounce of phosphoric acid. Since these two minerals, when combined or mixed with the feed, can be utilized by the animal to the extent of only 33 to 50 per cent, a cow giving 10 liters ( $21 / 2$ gallons) of milk per day should have at least $31 / 3$ ounces of lime and $2 \frac{1}{3}$ ounces of phosphoric acid in its ration per day. Cows giving over 10 liters per day should have correspondingly more. Where an abundance of good green forage, hay and clover are furnished, the requirements for these minerals will be met. On the other hand, if the ration consists of leached material or stuffs deficient in lime and phosphoric acid from the beginning, like slops, pulps, brewers' grains, straw, feed meal, etc., then these minerals must be added in one form or another.

\section{Rations for Milk Cows}

A. Daily Milk Yield, 15 Pounds (For 1,000 Pounds Live Weight Per Day)

\begin{abstract}
1.
Beets .......... 30 lbs.

Meadow hay I....8 $8 \mathrm{lbs}$.

Winter cereal straw 5 lbs.

Barley straw ..... 7 lbs.

Wheat bran ..... 2 lbs.

Palmseed cake ...2 2 lbs.

Cottonseed meal .. $1 \mathrm{lb}$.
\end{abstract}

\section{2.}

Beets ..........40 lbs.

Meadow hay II... 6 lbs.

Winter cereal straw 3 lbs.

Barley straw .... 8 lbs.

Wheat chaff .... $3 \mathrm{lbs}$.

Decorticated

cottonseed meal. 2 lbs.

Malt sprouts ....1.5 lbs.

\section{3.}

Beets ..........50 lbs.

Clover hay .....6 lbs.

Spring cereal straw 8 lbs.

Wheat chaff ..... 2 lbs.

Dry brewers'

grains ....... 2 lbs.

Hulled peanut cake 2 lbs.

\section{4.}

Potatoes ........10 lbs.

Meadow hay II... 5 lbs.

Clover hay ...... 5 lbs.

Winter cereal straw 4 lbs.
Spring cereal straw 4 lbs.

Fresh brewers' grains .......20 lbs.

Palmseed cake .... $1 \mathrm{lb}$.

5.

Potatoes .......20 lbs.

Meadow hay I.... 8 lbs.

Alfalfa hay ..... 5 lbs.

Barley straw .... 2 lbs.

Spring cereal straw 4 lbs.

Palmseed cake.... 2 lbs.

6.

Potatoes ........15 lbs.

Clover hay ........

Meadow hay I.... 5 lbs.

Spring cereal straw $3 \mathrm{lbs}$.

Fresh brewers'

grains .......20 lbs.

\section{7.}

Potato slop .....50 lbs.

Meadow hay II...10 lbs.

Spring cereal

straw .......... 10 lbs.

Rye feed meal .... 3 lbs.

Peanut cake meal. $1 \mathrm{lb}$.

\section{8.}

Ensilaged beet pulp 30 lbs. Clover hay ..... 5 lbs. Meadow hay II... 5 lbs.
Oat straw ...... 5 lbs.

Wheat chaff ..... 3 lbs.

Malt sprouts ..... 2 lbs.

Oat bran ........ $1 \mathrm{lb}$.

Molasses palmseed meal ........ 2 lbs.

Rice feed meal...1.5 lbs.

Tankage ....... $0.5 \mathrm{lbs}$.

\section{9.}

Ensilaged beet pulp $50 \mathrm{lbs}$.

Clover hay ...... 5 lbs.

Spring cereal straw 8 lbs.

Coarse wheat bran 2 lbs.

Cottonseed cake..0.5 lbs.

Palmseed cake ...2.0 lbs.

\section{0.}

Ensilaged beet pulp $50 \mathrm{lbs}$.

Clover hay ..... 5 lbs.

Spring cereal straw 8 lbs.

Palmseed cake ...2 2 lbs.

Peanut meal ....1.5 lbs.

\section{1.}

Corn ensilage.....30 lbs.

Clover hay ......8 $8 \mathrm{lbs}$.

Barley straw ..... $5 \mathrm{lbs}$.

Wheat chaff .... $3 \mathrm{lbs}$.

Rye bran ....... 2 lbs.

Linseed meal ..... 2 lbs.

Palmseed meal ...2 2 lbs. 


\section{B. Daily Milk Yield, 20 Pounds (For 1,000 Pounds Live Weight Per Day)}

\section{1.}

Beets ...........50 lbs.

Clover hay ...... 8 lbs.

Winter cereal

straw .........10 lbs.

Sesame cake .....4 4 lbs.

Coarse wheat bran $1 \mathrm{lb}$.

Dry brewers'

grains $\ldots \ldots \ldots 1 \mathrm{lb}$

2.

Beets ............30 lbs.

Meadow hay II... $8 \mathrm{lbs}$.

Spring cereal straw 6 lbs.

Fresh brewers'

grains ........25 lbs.

Rapeseed meal.... 3 lbs.

Rice feed meal ... 2 lbs.

3.

Potatoes .........20 lbs.

Clover hay .......10 lbs.

Wheat straw .... $5 \mathrm{lbs}$.

Wheat chaff ..... $4 \mathrm{lbs}$.

Fresh brewers'

grains ........20 lbs.

Malt sprouts .... I lb.

Tankage ........ $0.5 \mathrm{lb}$.

\section{4.}

Potatoes ........25 lbs.

Meadow hay II... 6 lbs.

Winter cereal straw $5 \mathrm{lbs}$.

Bean or pea hay.. $8 \mathrm{lbs}$.

Cracked beans ... 2 lbs.

Sesame cake .... 3 lbs.

\section{5.}

Potato slop .....50 lbs.

Meadow hay II... 8 lbs.

Spring cereal straw $5 \mathrm{lbs}$.

Winter cereal straw 6 lbs.

Rice feed meal.... $3 \mathrm{lbs}$.

Cracked beans ... 2 lbs.

Malt sprouts .... 2 lbs.

6.

Molasses beet pulp $5 \mathrm{lbs}$. Meadow hay .... 5 lbs.

Spring cereal straw 5 lbs.

Chaff .......... 2 lbs.

Field beans ...... 2 lbs.

Cocoanut cake .... 2 lbs.

Peanut cake .....1.5 lbs.

7.

Ensilaged beet pulp $35 \mathrm{lbs}$. Meadow hay II... $4 \mathrm{lbs}$.
Clover hay ...... 6 lbs.

Oat straw ....... 4 lbs.

Wheat chaff $\ldots \ldots 3 \mathrm{lbs}$.

Fresh brewer's

grains ........20 lbs.

Malt sprouts .....2 2 lbs.

Rapeseed cake ...2.5 lbs.

\section{8.}

Ensilaged beet pulp $45 \mathrm{lbs}$.

Clover hay ..... 9 lbs.

Spring cereal straw $6 \mathrm{lbs}$.

Wheat chaff .... 3 lbs.

Winter cereal straw $2 \mathrm{lbs}$.

Peanut cake ....2.5 lbs.

Palmseed cake... 3 lbs.

\section{9.}

Dry beet pulp.... 6 lbs. Meadow hay II... 6 lbs. Clover hay ...... 6 lbs. Spring cereal straw 6 lbs. Wheat chaff ....2 2 lbs Coarsely ground

beans $\ldots \ldots \ldots \ldots 1 \mathrm{lb}$.

Rapeseed cake ... $3 \mathrm{lbs}$.

Sunflower seed cake $1 \mathrm{lb}$.

\section{Rations for Goats}

A few words in regard to the feeding of goats are in order. The best and most natural feed for goats is green forage obtained from meadows that have not been heavily manured or fertilized. The leaves or green shoots of blackberries and of the hazel, birch, linden, oak and the grape vine are also suitable and well liked. In a general way, goats should be fed according to the same principles laid down for the feeding of cattle. A common error consists in feeding goats on kitchen refuse and thin soups or gruels. This is wrong.

The nutrient content of the feed should be in accord with the requirements of the animal and its work or product. Concentrates, root crops and tubers should be fed in a more or less dry state. Above all, sufficient quantities of green forage and hay should be provided. Weekly additions of prepared chalk or feed-lime, 3 to 4 teaspoonfuls for kids and 3 to 4 tablespoonfuls for mature goats, are recommended as minimum quantities.

The feeding of kids is much along the same line recommended for lambs.

- The author has calculated the following values as standards for mature goats : 
Maintenance feed for 1,000 pounds

Digestible albumen

live weight per day................

Or for 100 pounds live weight per day........ to $0.12 \mathrm{lbs}$.

Production ration per 1,000 pounds

live weight per day, milk yiẹld...20 lbs. 2.0 to $2.2 \mathrm{lbs}$.

$100 \ldots \ldots \ldots \ldots \ldots \ldots \ldots \ldots \ldots \ldots \ldots \ldots \ldots \ldots \ldots$ lbs. 0.2 to $0.22 \mathrm{lbs}$,

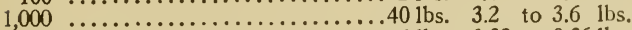

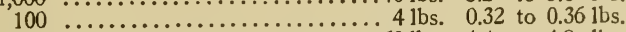

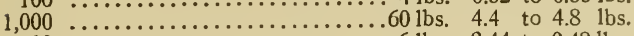

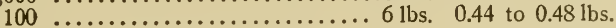

A few rations for goats follow.
Starch value

8.3 to $9.0 \mathrm{lhs}$.

0.83 to $0.9 \mathrm{lbs}$.

12.0 to $14.0 \mathrm{lbs}$.

1.2 to $1.4 \mathrm{lbs}$.

16.4 to $19.0 \mathrm{lbs}$.

1.64 to $1.9 \mathrm{lbs}$.

20.6 to $24.0 \mathrm{lbs}$.

2.06 to 2.4 lbs.

\section{Rations for One Goat (Milk Yield, 3 to 4 Pounds)}

1.

Morning: Good hay..........

Noon: Leaf hay.............

Turnip cabbage ........... 3.0 lbs.

Evening: Chaffed green forage.3.0 lbs. Good clover hay............. 1.0 b.

In addition: Common beets or potato peelings ........... 0.5 lb.

Malt sprouts and wheat bran,

of each ................... $0.25 \mathrm{lb}$.

With a milk yield of 4 pounds, 0.6 to

1.2 pounds of oats should be added to the above ration. Young growing animals should also have additional oats.

\section{2.}

Morning and evening: Hay, root crops, oats or bran.

Noon: Kitchen or farm refuse.

Hay ................... 3 lo lbs.

Root crops ............2 lbs.

Oats or bran............. 1.5 tos. Milking goats should have, in addition, mornings and evenings, $1 \mathrm{lb}$. coarsely ground grain, noon 1 quart oats and potatoes or beets, the amounts to be varied slightly according to milk yield.

3. Summer ration for 100 -pound goat, per day; milk yield 3 quarts.

Medium quality meadow hay .............................

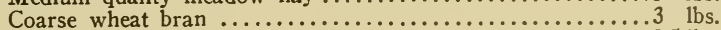

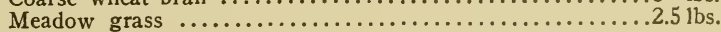

4. Winter ration for 100 -pound goat, per day; milk yield 3 quarts.

Common beets (average) .............................

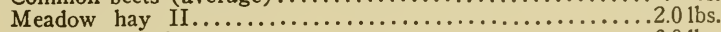

Coarse wheat bran....................................

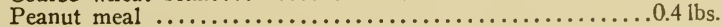

5. Ration for 100 -pound goat, per day; milk yield 1 quart.

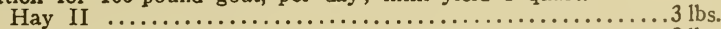

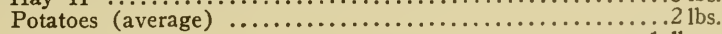

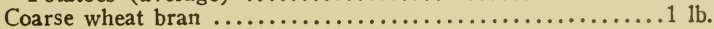

6. Ration for 30 goats per day; total milk yield 30 quarts.

Wheat feed meal ..................................... 30 lbs.

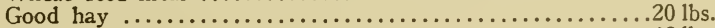

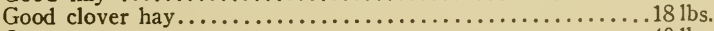

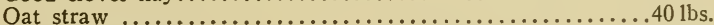

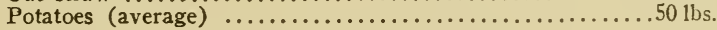

\section{Rations for Dogs}

Although the dog is a carnivorous animal, he will thrive better on the more economical mixed rations than on meat alone. The ordinary family dog is usually nourished with the wastes of the table and kitchen. In this connection it should be noted that salt is to be avoided and that strong spices like pepper, paprika, ginger, etc., are harmful. It is well also to avoid the feeding of the brittle and splintery bones of poultry: game and mutton. 
The following foods are in common use:

1. Meat of any kind, unspoiled, raw or cooked. Horse meat is just as wholesome as any other kind. Slaughterhouse offal like portions of the genital organs (scrotum), the stomachs of cattle, intestine, spleen, lungs, tankage, etc., are suitable.

2. Milk, for young, weak, old, pregnant or nursing dogs.

3. Cooked rice. Rice mixed with a little meat is considered the most wholesome food for the dog.

4. Oat flour, oatmeal and ground oats, boiled or scalded; favorite food for hunting dogs.

5. Bread. This is in very common use but much less wholesome than the feeding stuffs given under 3,4 and 6 .

6. Cooked legume seeds and meals. Objectionable for watch dogs and lap dogs, on account of tendency to cause constipation, obesity and laziness. Very suitable for draft dogs, however, especially when mixed with rice ( 1 pound rice and about two-thirds of a pound of peas for a large dog).

7. Potatoes and vegetables should be used merely as by-feeds for dogs at rest. They are not suitable as an exclusive diet and should not be fed at all as a basal feed to growing or working dogs or nursing bitches.

8. Dog biscuits (p. 127) are usually soaked in warm water (broth or soup), seldom fed dry. Dog biscuits of proper composition may be used as exclusive feed, but are not economical.

One feed per day is sufficient for dogs at rest or doing light work. Two feeds per day are necessary for dogs at hard work. If the dog is kept in the house, a light evening meal and a heavier morning meal are best. The food should never be given hot, but always lukewarm or cold.

By-feeds of bones (calf bones, calf feet and cartilage) or prepared chalk are indispensable for growing dogs and occasionally necessary for mature animals.

Pregnant bitches should have concentrated, easily digestible food (meat with some fat as well as rice and oatmeal or milk with oatmeal or cornmeal, etc.). The ration should be rather short for one or two days after whelping. After this time nutritious food in the form of whole milk, oatmeal and rice should be given.

Young dogs (pups) thrive best on the mother's milk during the first two months of their existence. After this the food for the smaller breeds is usually much the same as that for man, but this is hardly sufficient for the larger breeds. Lime and albumen should be increased from four to five fold. Cow's milk does not constitute a complete ration for the young dog. Milk, rice and bread are equally unsuitable. These foods contain too little lime and albumen and predispose to rachitis. The food of young dogs should approach the bitch's milk in chemical composition. The latter is composed of about 7.5 per cent albumen, 9.5 per cent fat, 3 per cent milk sugar and 1 per cent mineral matter. In order to grow 
a good bony frame, especially in dogs of the large breeds, an abundance of bone-forming salts must be furnished. The growing dog thrives best on animal nutrients, raw meat, bones and blood. Food of a vegetable nature should of course be added to these; peas, beans, lentils, also ground oats, corn and barley. In addition to this character of food the young dog should always have a supply of ground raw bones, in as fresh condition as possible. Transition foods, to be given in the weaning period should consist of cow's milk (goat's milk is better), with a little chopped meat added. The milk may be discontinued in the eighth to tenth week. Pups should be fed four times a day until 8 weeks old, then three times until 5 or 6 months old, when two feeds a day will suffice.

\section{Poultry Feed}

\section{Feeding Chickens}

Freshly hatched chicks are provided with a sufficient food supply for the first 24 to 48 hours in the form of the unused portion of the yolk which has become enveloped in the abdominal cavity. Beginning with the second or third day they should have as much cracked buckwheat, cracked oats or hulled millet every two or three hours as they will eat up clean in half an hour. Toward the end of the first week they may have soft feed consisting of old wheat bread and finely chopped greens. Ants' eggs (larvæ) are an excellent addition in this stage (easily obtained by a little search under old boards, wood, etc.). This feed should be alternated with the grain, feeding every three hours as before. The soft feed, bread, may be improved by addition of finely chopped hard-boiled eggs or scrambled eggs, with cheese, etc. The scrambled eggs are prepared by mixing equal parts of eggs and fresh milk and finely broken eggshells, stirring and heating. One egg per day is sufficient for 15 chicks.

Beginning with the second week, mixed dry or soft feed (mash) is suitable. The latter is prepared by mixing oat, barley, corn or buckwheat meal with sufficient water or milk to make a moist, crumbly (not pasty) mass. The addition to this of greens, like finely chopped clover, notchweed (Atriplex), spinach, entrails of fowls, grass, nettles, dandelions, cress, yarrow, etc., or grated carrots, sprouted grains, or finely chopped meat, soft cartilage from veal, tankage or fish meal, blood meal, hard curd or cottage cheese, finely ground bone, etc., is a common and commendable practice. Estimated amounts per head per day consist of meal, 2 to 5 grams for the first three weeks and 10 grams thereafter: ground bone or bone meal, 5 to 10 grams or phosphate of lime, $1 / 4$ to 2 grams, in place of the bone meal. Meat fiber chick feed, "Spratt's patent" and other similar preparations have proved very satisfactory. The commercial preparations are usually fed as complete rations, exclusively or alternating with other feed.

The feed is strewn out on little boards, put in galvanized boxes or troughs, etc. All paraphernalia of this sort should be kept clean. Only 
so much feed should be given at a time as will be picked up clean. Young chicks should be fed every two or three hours until a few weeks old, then four times a day.

Hulled millet seed, oatmeal or cracked buckwheat should be fed mixed or alternated with the soft feed. Sand and charcoal should at all times be accessible to the little chicks.

Beginning with the third week the cracked grains are gradually displaced with wheat bran, the fresh milk with sour, and the quantity of curd is increased. Cracked or broken rice, barley, wheat and corn are suitable at this stage.

When the chicks are 5 weeks old, malt sprouts and water-soaked bread (with surplus water expressed), and occasionally boiled potatoes and larger grains, are good. At 8 or 9 weeks the chicks may have the same feed as the older fowls.

Pure water, not too cold, should always be accessible. Many poultry raisers add 3 grams of copperas to each quart of water as a preventive for diarrhea. Drinking vessels should be kept clean. Automatic "fountains" are much in use; they serve to keep the water free from dirt and protect the chicks from getting wet by being immersed in larger vessels.

Dry feed consists of ground grains of all kinds-buckwheat, oatmeal, oats, barley, corn, bran, linseed meal, hulled millet, canary grass seed, etc. This may be mixed with fish meal or tankage, greens, etc. Dry feeding is most practicable, attended with less work than the use of soft feeds, and has the advantage that the feed is less apt to spoil before being used.

According to the age of the chicks, the grains fed may be millet, cracked or broken rice, cracked corn, whole wheat, etc., in the order named. The following plan has been found successful:

For the first week or two, millet seed and oatmeal, strewn on a clean board in the runs; chaffed straw added to make the chicks scratch.

For the third and fourth weeks, an automatic feeder containing a mixture of 4 parts oatmeal, 2 parts cracked corn, 1 part fish meal and onehalf part finely chopped clover. In addition, three times a day, strewn in the run, a mixture of equal parts of millet, rice and dari.*

For the fifth and sixth weeks, a mixture of oatmeal, ground oats and finely cut clover, 2 parts of each; cracked corn, wheat bran and fish meal, 1 part of each. In addition, broken rice, dari* and cracked corn.

For the seventh to tenth weeks, a mixed feed consisting of 4 parts each of oatmeal and clover hay, finely chaffed, and 2 parts each of bran and fish meal. In addition, grain feed composed of wheat and cracked corn.

Later on barley and oats may be added and the quantity of wheat bran increased.

In connection with all of the above rations a supply of green stuff is very desirable. In the absence of green stuff, grated carrots and kohlrabi (turnip cabbage) are good.

\footnotetext{
*Sorgh. tart.
} 
In the absence of an opportunity to roam about on a pasture or stubble field, chicks are deprived of many dainty morsels in the form of worms, caterpillars, insects, etc. A manure pile is a good substitute. This can be improvised by making a hole one yard or more square and 18 to 20 inches deep and filling it with fresh horse dung and occasionally sprinkling this with blood to attract flies.

Rations for chickens 3 months of age may be compounded according to the rules outlined on page 169 . The nutritive ratio should be narrow, $1: 3-4$.

Among the possible feeding stuffs to select from may be mentioned tankage and fish meal, blood meal or dried blood, cracklings, dried May beetles, shrimps, fresh ground bone (Fig. 88), horse meat, curds, sour milk, buttermilk, linseed cake, sunflower seed cake and other oil cakes, peas, malt sprouts, dried brewers' grains, bran, feed meals, grains of all kinds, acorns, horse chestnuts (dried and ground like acorns) pota-

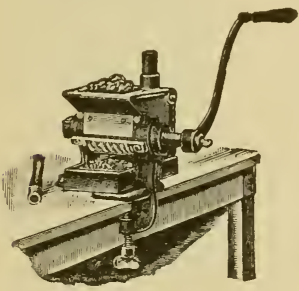

Fig. 88. Bone grinder.

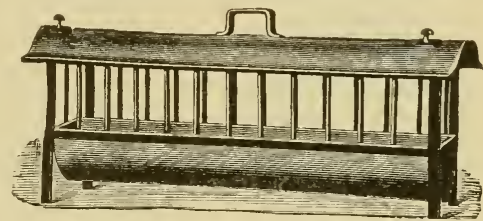

Fig. 89. Soft-feed trough.

toes, sugar beets, artichokes, hempseed, flaxseed, poppy seed. Chickens, as a rule, will not eat the seeds of legumes, beans, peas, etc.

Finally, a good supply of green feed is at all times desirable. Chickens kept in pens should be given green stuff like nettles, notchweed, dandelions, sweet grasses, clover, alfalfa, serradella, vetches, spinach, mangels, spurry, rape, buckwheat, corn, artichokes, comfrey, beet and cabbage leaves. Beets, cabbage, sprouted grains (oats), chaffed clover and meadow hay, etc., etc., may be given in the absence of the more suitable and succulent plants mentioned above.

Laying hens should also have access to sand, charcoal, gravel, crushed stone (grit), oyster shells, etc.

The grains are fed whole and raw, preferably in the evening. Very large grains of corn should be crushed. Barley and oats are improved by sprouting. Feed for fattening purposes-corn, barley, rice, milletshould be boiled or soaked in water. Potatoes should be cooked or steamed. Beets should be fed raw, green stuff fresh and not chopped, or chopped fine and mixed with chaffed hay. Oil cake or meal and tankage are usually mixed with other feed without any further preparation and may be fed as soft feed (slightly moistened) or dry. 
The estimated requirement for a large laying hen consists of 120 to 130 grams of feed per day with a dry matter content of 80 grams, digestible albumen 14 to 15 grams, fat 4 to 5 grams, and 50 grams of digestible carbohydrates. If the hens have an opportunity to pick up insects, worms and other natural feeding stuffs, their rations may be reduced by one-fourth to one-third, according to circumstances. As a rule about 15 to 30 grams ( $1 / 2$ to 1 ounce) of grain, evenings, is sufficient under these circumstances. In the summer confined hens are fed three times a day; in winter twice a day.

\section{A. Soft Feed Ration for Laying Hen, Weight 4 Pounds, Per Day}

1.

Potatoes .........50 gm.

Wheat bran ....25 gm.

Curd ..........15 gm.

Ground bone ...5 $5 \mathrm{gm}$.

Grain:

Oats $\ldots \ldots \ldots \ldots 10 \mathrm{gm}$.

Corn ..........15 gm.

Barley .........20 gm.

\section{2.}

Potatoes ........50 gm. Wheat bran .....25 gm.

Fish meal .......10 gm.

Grain :

Oats .........25 gm.

Corn ..........25 gm.

\section{3.}

Potatoes .......45 gm. Malt sprouts …20 gm. Dried blood ......50 gm. Bone meal ......10 gm. Grain:

Wheat $\ldots \ldots \ldots 20 \mathrm{gm}$.
Oats ..........10 gm.

Corn ..........20 gm.

4.

(For Summer)

Potatoes or beets. $30 \mathrm{gm}$.

Wheat bran ....60 gm.

Tankage ....... $5 \mathrm{gm}$.

Grain:

Barley .........30 gm.

Wheat …......

5.

(For Winter)

Potatoes or beets. $50 \mathrm{gm}$. Wheat bran ......40 gm. Fish meal ......10 gm. Grain :

Corn, oats and Wheat .......40 gm.

6.

Potatoes .......70 gm. Crushed barley ...10 gm. Sesame meal ....10 gm. Clover sweepings .. $7 \mathrm{gm}$. Fish meal ..... $5 \mathrm{gm}$.
Tankage ....... $5 \mathrm{gm}$. Grain :

Oats .......... $30 \mathrm{gm}$.

Beets ad libitum

$$
7 .
$$

(For Winter)

(Hens out on run)

Potatoes .........40 gm.

Serradella sweepings or chaffed clover $8 \mathrm{gm}$. Wheat bran .....10 gm. Fish meal ......10 gm. Or ground bone...15 gm. Grain:

Oats ..........45 gm.

Beets ad libitum

\section{8.}

(For Moulting Period)

Potatoes ........40 gm.

Cracked corn ...15 gm.

Wheat bran ...110 gm.

Cracklings ......15 gm.

Fish meal or tankage ....... $5 \mathrm{gm}$. Grain:

Corn .........40-50 gm.

\section{B. Dry Feed Ration for Laying Hen, Weight 4 Pounds, Per Day}

1. (For Winter.) Dry Feed, in Automatic Feeder, Consisting Of:

Cracked corn .....1 qt. Ground oats $\ldots . .1$ qt. Wheat bran .......2 qts. Clover (chaffed). .2 qts.
Tankage .........1 qt.

To be taken ad libitum

(About $5 \mathrm{gm}$. daily)

In addition:
Beets ad libitum and

Mornings-oats. $.20 \mathrm{gm}$. Evenings-corn. $.30 \mathrm{gm}$.

2. (For Summer, With Free Run.) Dry Feed, in Self Feeder, Consisting Of:

Ground oats .......1 qt. Ground barley ....1 qt.
Wheat bran ......4 qts.

In addition:
Mornings-oats. $.20 \mathrm{gm}$. Evenings-barley $30 \mathrm{gm}$.

3. (For Summer, Limited Run.) Dry Feed, from Self Feeder, Consisting of:

Ground barley .....2 qts.

Wheat bran $\ldots . . .2$ qts.

Chaffed clover ....1 qt.
Fish meal ....... T/2 qt.

In addition:

Green stuff ; kitchen offal
Mornings-oats. $.20 \mathrm{gm}$. Evenings-wheat. . $30 \mathrm{gm}$. 
Vessels for soft feed should consist of troughs with wire grating to prevent waste, and galvanized iron or wooden tops (Fig. 89).

Lettuce heads and cabbage or beets may be placed in little open racks where they are accessible, or suspended on a string or wire to prevent waste from soiling.

Dry feed can be supplied in self feeders.

Water may be supplied in automatic water bottles (Figs. 91, 92). Flat, open vessels are too liable to become filled with dirt. Feeding and drinking vessels should be cleaned daily. Fresh water should be provided at least once every day. About 2 quarts of water are required daily for 10 hens on dry feed.

Hens and chicks thrive best on open ranges, pastures and stubble fields, etc. Even under these conditions extra feed should be supplied.

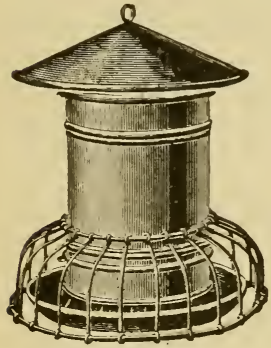

Fig. 90. Self feeder.

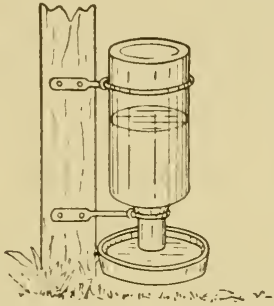

Fig. 91. Automatic water bottle. Fig. 92. Automatic drinking fountain.

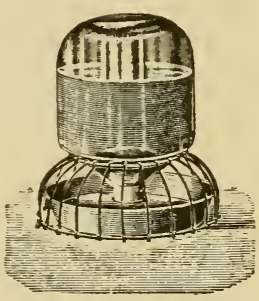

For fattening young chickens or "fries," porridges made of ground barley or buckwheat, or barley meal with milk, are suitable. The birds" should be kept in subdued light.

For fattening chicks, give buckwheat gruel with sweet milk, beginning on the second or third day after hatching, followed with barley meal or ground buckwheat after one or two days, or a mixture of 4 parts ground buckwheat and 1 part of cracked corn with sour milk made into a thin porridge. On the following four or five days some oatmeal mush may be given. Beginning with the seventh day, finely chopped little fish, including scales and entrails (cooked), about 1 pound daily for 100 chicks until three weeks old ( 2 pounds from 3 to 6 weeks old), or fish meal (fat extracted), or a mixture of ground dried shrimps and fresh ground bone. No water. Feed every few hours from 6 a. m. to 10 p. m. Keep feeding vessels clean!

So-called "masting" (fattening) consists in part of "free mast" (voluntary feeding) and in part of "cramming." Lean birds are prevented from taking exercise and subjected to a preparatory process of feeding with nitrogenous food (ground buckwheat and barley, or barley meal and oatmeal with curdled milk or curd, meat scraps and potatoes). In 
addition to these, crushed wheat or oats, oatmeal or barley, etc., are fed every evening. After this treatment they are placed in "mast cages" and kept in semi-darkness at a temperature of $12^{\circ}$ to $15^{\circ} \mathrm{C} .\left(53.6^{\circ}\right.$ to $59^{\circ}$ F.).

In "voluntary masting" from 6 to 15 fowls are kept in one cage $11 / 2$ meters long, $1 / 2$ meter wide and 50 to $60 \mathrm{~cm}$. high. The mast feed consists of coarsely ground buckwheat or buckwheat meal with fresh milk, or buckwheat meal mixed with barley meal oatmeal or cornmeal, bran, sour milk or buttermilk, with a little salt, charcoal and sand, fish meal or finely ground egg shells, oyster shells or other shells. During the last four or five days or the last week a teaspoonful of oil or 10 grams of lard is added to the ration. To impart a spicy taste to the meat 0.1 to $0.15 \mathrm{gm}$. of cinnamon or 0.25 to $0.3 \mathrm{gm}$. of juniper berries are added to the morning and evening feed of each fowl. Feeding times, $8 \mathrm{a} . \mathrm{m}$. and 4 p. m., must be regularly observed, feeding vessels cleaned before each meal, fowls kept free from vermin (by use of insect powder), and the droppings removed daily or covered with ground muck in a quiet manner so as not to disturb or excite the fowls. The entire process requires about two or three weeks.

\section{Feeding Ducks}

From 24 to 36 hours after hatching, young ducks receive feed composed of a mixture of milk, wheat bread, weighed amounts of green stuff (nettles, yarrow) and grated carrots or soaked rice. Beginning with the second week they receive coarsely ground buckwheat, barley or wheat. Beginning with the third week, wheat bran and feed lime or ground bone, shrimps or fish meal, and chopped raw or cooked horse meat or tankage. Rye bran and wheat bran, greens (chopped nettles, duckweed [Lemna] etc.), equal parts of each, and 5 per cent of meat and sand are mixed prior to feeding.

Beginning with the sixth week young ducks receive crumbs of soft feed composed of 3 parts corn meal, 5 parts bran, 4 parts feed meal and $1 / 2$ part fish meal. Curds, sour milk, earthworms, crushed snails or May beetles, lettuce and comfrey are favorite by-feeds. When the feathers begin to develop, soaked ground oats, followed a little later with dry ground oats and whole grains, are given.

At first the young ducklings should be fed every two hours, then four times a day, and beginning with the sixth week three times a day. After they have access to pasture and ponds, morning and evening feeds are sufficient.

Rations for older ducks, in pens, per head and per day, are as follows: Boiled potatoes $100 \mathrm{gm}$. with bran $60 \mathrm{gm}$.; evenings, $75 \mathrm{gm}$. of oats or barley; at noon, greens, worms, chopped meat or tankage, 15 gm., beets $50 \mathrm{gm}$., or the following ration: 


\section{Ration For Laying Duck, Per Day}

Potatoes .................300 gm.

Wheat bran ................. $65 \mathrm{gm}$.

Fish meal ................. $30 \mathrm{gm}$.
Crushed corn or oats.........100 gm.

Greens (thistles, nettles, etc.)..200 gm.

Sand ...................... $100 \mathrm{gm}$.

Grain, twice a week, at night.

Free range with access to ponds or streams is most conducive to good results. By-feeds, in addition to the above, are usually desirable.

The fattening of young ducks should be completed at the end of the ninth to eleventh week. The usual feed is given from the second to the tenth day. After this time wheat bran, buckwheat meal, rye meal or barley meal, bone meal or fish meal, charcoal, coarse sand and chopped greens are added.

The fattening proper begins about the fifth week. The feed then consists of wheat bran and barley meal or rye meal, 1 part of each; steamed mashed potatoes and greens (comfrey), fish meal and coarse sand, 2 parts. Beginning with the eighth week the greens are displaced with cracklings.

Until the beginning of the fourth week feed should be given five times a day, then four times, and finally three times. Water should be provided with each feed. For forced fattening, ducks are fed as above outlined until 6 weeks old, are then penned up and gradually restricted in voluntary exercise by closer confinement in semi-darkness. In the course of two or three weeks the process should be completed.

They are fed two or three times a day with malt meal, barley meal or bean meal (coarse), wheat bran, steamed potatoes and some cracklings in the form of soft feed in addition to beets and greens. At night they get soaked barley and always plenty of water, sand and some charcoal. The addition of oil-cake meal, skim milk or sour milk is a common practice.

\section{Feeding Geese}

The first feed for goslings consists of crumbs of stale bread with finely chopped nettles, thistles, lettuce leaves or the tips of blades of grass, and occasionally some finely chopped boiled egg. ${ }^{11}$ At the age of 2 weeks wheat bran, coarse barley meal or oatmeal with boiled potatoes or mashed beets and greens are given. When the feathers begin to develop the feed is changed to bran and potatoes, with sour milk and scalded cracked oats or a mixture of oats, barley, buckwheat or corn.

Older geese are given grass, clover and various herbs gathered up in meadows, fields, waysides, etc., also grains (stubble pasture) and the seeds of legumes, beets and beet leaves, boiled potatoes, scalded chaffed hay and scalded bran. A daily grain ration of from 100 to 150 grams is sufficient for one breeding fowl during the winter. A free range is desirable for geese as well as for other fowls.

\footnotetext{
11Young geese may be successfully raised on good bluegrass pasture and green dandelions, with out any other feed whatever. An ample supply of fresh water should be provided. Grain may be offered when the goslings have attained a weight of 3 to 5 pounds.-(Personal experience of transiator.)
} 
For fattening, geese are usually penned up in September or October after spending the summer on pastures and stubblefields. When operating on a large scale, about 100 geese are placed in an inclosure of about 100 square meters, so located that the prisoners can not see nor hear their companions that are still roaming at large. The real fattening is usually preceded by a preparatory period of two weeks during which they are fed on chopped carrots. Owing to the watery nature of carrots, drinking water is usually withheld. A certain amount of sandy clay is administered to stimulate digestive activity. The fattening proper begins with the third week. If the stubble pasture has been very good, the preparatory period is sometimes omitted. Oats and barley are the chief or only feeds. They are fed either in the form of a mixture throughout the process, or oats are fed exclusively at the beginning and corn alone at the closing period. Barley, as compared with oats, produces a firmer quality of fat, which is very desirable in geese. It is absolutely necessary to make the change from the vegetable to the grain diet very gradually. Every week one additional feed of vegetables or beets is withdrawn and grain substituted. Sometimes corn or boiled potatoes and peas with or without barley meal or crushed carrots are substituted for the full grain method of fattening. To stimulate the appetite $2 \mathrm{gm}$. of common salt and $1 \mathrm{gm}$. of ground black pepper are added to each feed, per individual goose. The addition of $1 / 2 \mathrm{gm}$. of antimony to favor the development of fatty livers is a common practice. Water and sandy clay are provided to be taken ad libitum. The fattening period should be completed in one month.

\section{Rations for Rabbits}

During the first three weeks the newborn rabbits are nourished with the milk of the dam. After this period they should have sweet skim milk, green stuff with the addition of hay, followed with carrots and beets. Grass ranges, inclosed with wire, are recommended. At the age of 3 months the sexes should be separated. Males should be kept singly or in pairs. They may be bred at the age of 6 to 8 months.

Young. rabbits should be fed four times a day; later on only three times, and when mature two feeds may suffice. The usual feed consists of green stuff, carrots, boiled potatoes, and potato pealings with bran. The addition of prepared chalk, phosphate of lime and common salt is recommended. Hay should be provided in addition to grass and other green stuff. The evening meal should be a little heavier than the morning feed. Grain (oats and barley) is necessary for pregnant or nursing females only. Skim milk and water may also be given during the nursing period. Otherwise the supply of water is adjusted according to the water content of the rations. If green feed or other succulents are fed exclusively, water is usually dispensable. To avoid waste of feed, hay racks are convenient. 


\section{Feed for Fish}

Among the cultivated or artificially reared food fish, the carp is the most important. It is used as the basis in the following discussion.

Fish feeding is conducted along two distinct lines:

A. Indirect feeding, or so-called "fertilization," which has for its object the providing of favorable conditions, including food material, for the growth and development of the forms of life which constitute the natural food of fish, or, to go a step farther, to provide these condtions for the still lower forms of life upon which the latter are dependent.

B. Direct or artificial feeding, as for instance, supplying lupines or fish meal, which are consumed directly by the fish.

\section{A. Fertilization}

The object of fertilization is to favor or encourage the development of the natural animal or vegetable food material.

1. Plankton, or pelagic life, constitutes a very important group of these natural foods. For practical purposes this is divided into two subgroups.

\section{Group 1.}

a. The lower plants, of which the most important representatives are: $\mathrm{a}^{1}$. Bacteria, which, as everywhere in nature, live on waste animal and vegetable matter, convert it into carbonic acid, water and ammonia, which in turn serve as food for algæ and higher plants. Bacteria also serve as food for Infusoria and similar minute forms of life.

$\mathrm{b}^{1}$. Alga.-These are the most important oxygen generators in the water, and, like the bacteria, serve as food for low, minute forms of life. Among this group the common green fresh-water algæ are the most common. They occur on the bottom of ponds in long, thick masses of interlaced threadlike forms or entwining higher plants. The gases which they liberate tend to raise them to the surface in the form of brownish layers or scum. The diatoms should also be mentioned here. They are unicellular algæ with a delicate silicious covering. Large masses of bacteria live on the surface of the algæ and serve in their turn as food for Infusoria, etc.

b. Infusoria, Amebce and Rotalia. These live on bacteria and themselves serve as food for higher forms.

\section{Group 2.}

\section{a. Small Crustaceans, or Entomostracans}

$a^{1}$. Daphniida, Daphnids, or water fleas, characterized by their marvelous power of reproduction (according to Rahmdohr one individual may produce one thousand million offspring in 60 days). In the spring of the year the single hard-shelled winter egg hatches into a female, in the dorsal brood organ of which a large number of small fertile summer eggs develop in the course of two days. In a few days the latter 
hatch into females, which again lay fertile summer eggs (Fig. 93). This process of unisexual reproduction (parthenogenesis) continues during the entire summer. In the fall of the year the summer eggs develop into males and females. The female now develops one large winter egg in its dorsal brood organ (Fig 94), which requires fertilization before it can develop. The winter egg is protected by a hard shell against external influences. It remains dormant throughout the winter and is not affected by freezing temperatures. It seems, in fact, as though the exposure to the cold of winter gives additional vigor and power of reproduction. This is one of the beneficial effects of draining fishponds for the winter.
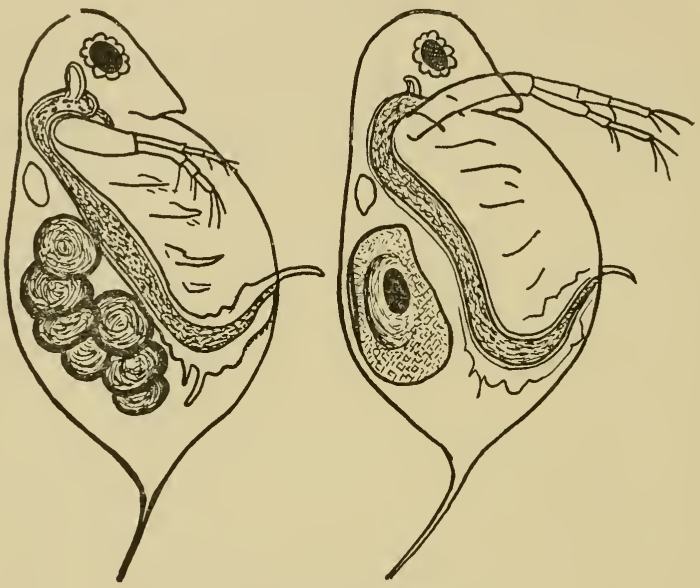

Figs. 93 and 94. Water flea (Daphnia pulex.)

$a$, Female with summer eggs; $b$, female with one winter egg.

\section{Feed for Fish}

Water fleas live on unicellular plant and animal life and prefer warm, shallow ponds rich in organic matter. They often occur in enormous numbers and impart a distinct color to the water.

$\mathrm{b}^{1}$. Cyclops or hoppers.-Jurine has estimated that a single pair can produce $45,000,000,000$ offspring in a single season. They feed and develop in a manner similar to that of the daphnids.

$c^{1}$. Ostracoidea.-These are entomostracans with hard bi-valve shells. Their habits, etc., are similar to those of the cyclopses.

$\mathrm{d}^{1}$. Amphipoda or sand fleas.-Numerous species of various sizes and habits. Those in question are characteristic of this form of life in pure cold water. 
$\mathrm{e}^{1}$. Asellus aquaticus, water louse.-Occurs in moderate numbers in ponds, especially cool trout ponds.

Waterfleas and cyclopses are easily reared in little side pools connected with larger ponds. In the winter and early spring these are covered with layers of manure, clay and compost to favor their propagation. With the advent of warm weather, when the organisms have multiplied sufficiently, they are admitted into the main pond by a connecting channel. Since all of these lower forms of life, but especially the water fleas, are injured by even slight acid reaction of the medium in which they are found, this danger should be averted by regular "working" of the pond bottoms.

\section{b. The Larvae of Insects}

$a^{1}$. Culex pipiens (stinging gnats) and several species of Anopheles (mosquitoes). The larvæ live among the vegetation of shallow pools and ponds. They float just under the surface of the water with their backs exposed to the air, breathing oxygen. When the water is agitated they may be seen wriggling to the bottom.

$b^{1}$. Coretha.-The larvae are recognized by their transparent bodies. They may be observed floating around in the water, apparently quite motionless.

$c^{1}$. Chironomus.-This larva, recognized by its red color, lives in the mud and slime of foul streams.

$d^{1}$. Ephemera, Clö̈ (day fly).-The mature insect often makes its appearance in enormous swarms. The larvæ require from two to three years for development.

$e^{1}$. Phryganeides.-The larva of the caddis fly inhabits a variety of stagnant and flowing waters and secretes itself in structures which it builds of sand, fragments of plants, stones, etc.

To encourage the development of these insects and their larvæ, Susta had already recommended the planting of vegetation (basket willows) on the borders of ponds. Gnats like to swarm in warm air but not in direct sunlight.

II. Spawn and the young progeny of Mollusca, among which might be mentioned the small bivalves which are usually found attached to sticks, stones and similar obects; Limnæa or pond snails, which are a favorite food of fish; Planorbis (snails with discoidal shells), and Paludina (pond snails with operculated shell). They subsist chiefly upon vegetation and slime and do not molest other animal life which serves as food for carp. When not present in carp ponds they should be introduced. Lime spread over and worked into the bottom of ponds favors their rapid development.

To promote the development of the lower forms of life which serve as food for fish, pond fertilization is practiced. The primary object of fertilization is to furnish food for the lower pond flora, although some 
of the organic fertilizers used supply enormous numbers of bacteria which serve as food for Infusoria, etc., and even the Mollusca.

The character of the fertilizers used is much the same as that of the manures applied to fields and meadows. Since the supply of natural manures is usually limited, chemical manures are resorted to, much the same as in agricultural operations, viz., lime, potash, nitrogen (ammonia) and phosphoric acid. The other elements, like sodium, iron, magnesia, sulphur, silicic acid, etc., are usually present in sufficient quantity and need not be supplied artificially. Carbon, which is necessary for the support of all life, is usually supplied in abundance, when nature is not interfered with, but when artificial fertilization is practiced this important element may be reduced below the minimum required, as compared with the proportion of other available food, and thus counteract the benefits of fertilization (Zuntz, Gensny). When artificial fertilization is practiced care must be observed that all the nutrient elements or substances are supplied in sufficient quantity, or rather in the relative proportions required, thus maintaining the chemico-physicobiological equilibrium, or restoring it, as the case may be (Demol). Practical pond or laboratory experiments may be conducted to obtain the necessary information upon which to proceed with the fertilizing operation, much the same as in agriculture.

According to Zuntz-Knanthe, the laboratory experiments for "honitizing" fish ponds are conducted as follows: The pond water in question is filtered through Daper filters and one-half liter of the filtered water placed in each of 14 flasks of $3 / 4$ liter capacitv. These flasks are inoculated with one-celled green algæ (e.g., Bacillus protococcus), which are easily obtained from ponds with the aid of dipping nets. After inoculation the flasks are treated with various solutions of nutrient salts, etc., combined in definite proportions. Zuntz uses twelve different solutions, ${ }^{12} 4$ drops of each solution being added to a flask. All flasks are then placed under the same conditions of temperature and light and kept under observation. After determining which of the flasks produces the most rapid or luxuriant growth, further trials are made to determine the proper concentration of the solution in question. After the algæ have reached a certain degree of develonment, 2 daphnids are placed into each flask. to test the effect of the fertilizers on the development of these very important food organisms. In the course of from 8 to 10 davs several generations of daphnids will have developed and the effects of the different solutions become very apparent.

Zuntz's method above described, while not without certain imperfections, gives results that constitute a valuable basis for practical work. The manifold and complicated conditions that influence the biological processes in ponds (light, temperature, precipitation, currents, carbon dioxid and bacterial content) cannot be reproduced in the laboratory.

In the artificial fertilization of ponds it is necessary to have knowledge of the minimum, optimum and maximum amounts of fertilizing

12The following solutions, with the excentions noted. are all of 5 ner cent strength (No. 9, 2 per cent; Nos. 11 and 12 are used undiluted. prepared according to directions): 1 . Glauber salts (sodium sulnhate). 2. Di-hasic sodium phosnhate. 3. Chile saltpeter (sodium nitrate). 4. Common salt (sodium chlorid). 5. Potassium snlphate. 6. Ammonium sulphate. 7. Calcium chlorid.
8. Ensom salt (magnesium sulphate). 9. Conperas (ferro-sulphate). 10. Milk of lime (caustic 8. Ensom salt (magnesium sulphate). 9. Cnnperas (ferro-sulphate). 10. Milk of lime (caustic
lime). 11. Decomposed urine of animals (liquid manure). 12. Straw infusion (10 grams of straw treated with 100 grams of boiling water, supernatant liquid poured off after twenty-four hours and preserved for use). 
elements that can be applied to advantage, or with safety, as the case may be. An excess of certain nutrients may result in actual harm (poisoning). It is known, however, that the potash salts are the only ones that are dangerous in this respect. Even excesses of nitrogen and phosphorus salts do no harm, while such an eventuality is partly guarded against by the high cost of these elements.

Sewage, also, can be used with the best success for the fertilization of fish ponds. This practice is attended with the additional virtue of saving artificial manures and assisting in water purification (Hofer, Strell and R. Demoll).

To avoid putrefaction processes, sewage used for this purpose should previously be clarified and thus freed from 50 to 60 per cent of sediment and suspended matter.

Any method of sewage disposal which does not require retention of the sewage in the settling tanks longer than 24 hours is suitable for this purpose, provided that the settling tanks are so constructed that daily removal (or removal at two or three day intervals at the most) is practicable. This is necessary to prevent putrefaction of the pond water. In the pond fish industry at Strassburg, where sewage is utilized as the fertilizing element, the preliminary clarification is conducted successively with a coarse rake, a Geiger screen paddle wheel, and a Neustadt settling basin 12.5 meters long and 3.6 meters wide with a capacity of about 100 cubic meters. A similar plant in Amberg employs 3 Kremer apparatuses for each 10,000 inhabitants.

After the sewage has been subjected to the processes above outlined it is diluted with about two parts of pure water from streams. Thus diluted, the sewage is discharged into the ponds by means of a number of wooden conduits. In Strassburg, these conduits are arranged horseshoe fashion around approximately one-third of the front shore line of each pond. They are placed about 10 meters apart and discharge their contents through fan-shaped distributors about $2 \frac{1}{2}$ meters long. To favor oxygenation the distributors are so arranged that the water is discharged in the form of cascades or against so-called splashboards. On hot summer nights and during sultry periods preceding storms the diluted sewage supply is shut off and fresh water is admitted according to needs.

A water area of one hectare (2.471 acres) is required for the sewage from every 2,000 population, estimating 100 liters per inhabitant per day. The rate of discharge into the fishponds is so regulated that the sewage water remains in the ponds about 6 days. During this time, even in winter, the water is purified to a degree that approaches ordinary river water. The nitrogenous substances present in the "clarified" sewage water are reduced to the extent of from 60 to 70 per cent and the bacteria from 85 to 92 per cent.

The ponds in Strassburg are 100 to 150 meters long, 40 to 50 meters wide and 0.5 meter deep. Before they are filled with water they are 
planted with aquatic plants (Ceratophyllum or hornwort, Myriophyllum or water milfoil, Ranunculus or crowfoot). These are started in pure water which is inoculated with the necessary lower forms of plant and animal life. The clarified sewage water is not added for several weeks.

In the management of sewage fishponds putrefaction processes must be kept in absolute check by suitable supplies of pure water and oxygen. The oxygen content of the pond water must also be controlled. For carp the water should contain 3 c.c. of oxygen per liter of water. The presence of only 0.5 c.c. per liter causes asphyxiation of the carp.

According to Hofer, the approximate oxygen content of water is easily determined in the following simple manner:

Take a flask with accurately fitted ground stopper and $1 / 4$ liter capacity and fill to overflowing with the water to be examined. Insert immediately (closed and downward) a 2 c.c. glass tube filled with a 25 per cent solution of manganous chlorid. In a similar manner insert a second tube filled with a 30 per cent solution of caustic soda containing 10 per cent of potassium iodid. Keep the water flask stoppered at all times except at the moment when each tube is inserted. Observe care that no air bubbles are retained in the flask! Shake the flask for several minutes so that the contents of the glass tubes become thoroughly mixed with the water in the flask. A dirty white precipitate of manganous hydroxid is formed. The latter has the property of combining with oxygen and forming a brown precipitate of pyrolusite $\left(\mathrm{MnO}_{2}\right)$. According to the amount of oxygen in the water, this precipitate assumes different shades of brown. If the water contains only 0.5 c.c. of oxygen per liter (carp asphyxiate under this condition) the precipitate remains white. If the water contains only 3 or 4 c.c. of oxygen per liter (this is just sufficient to prevent asphyxiation of Salmonidæ-trout and allied species) the precipitate becomes yellow. If the water contains 7 to 8 c.c. of oxygen to the liter (normal oxygen content) the precipitate becomes a pronounced brown. The Bavarian Biological Experiment Station for Pisciculture, in Munich, has issued a color scale to aid in recognizing and valuing the different shades of color in this test. This simple method of oxygen determination can, of course, also be applied successfully in the problem of live fish transportation, wintering fish under ice, etc.

Two-year-old carp are best adapted for stocking sewage ponds where table fish are desired. In Strassburg, Koenigsbrunn and Bruenn the gain per hectare of pond surface is estimated at 1,200 pounds. Demoll also recommends stocking with younger carp and artificial breeding. Rainbow trout and tench (Tinca vulgaris-European species allied to carp) may be planted as secondary crops. These fish are exceedingly palatable, but tench should be placed in fresh water ponds or traps for some time before marketing, which should also be done under other conditions.

The extensive establishments at Strassburg and Amberg, in addition to the sewage ponds above described, are provided with fresh-water ponds, spawning ponds, reservoirs, etc., with all facilities for convenient access in winter. An extensive duck-breeding establishment is also maintained and considered of great importance in connection with fish culture in sewage ponds. These ponds become infested with duckweeds (species of Lemna) which multiply rapidly and often cover the entire water surface with their growth, shutting out light and air, and keeping the water too cold. These plants are a favorite food of ducks. 
Sewage fishponds serve the additional function of purifying the water. They accomplish this more effectively than any other method, especially the irrigating system of sewage disposal, and require considerably less area than the latter. One hectare of sewage pond area suffices for the disposal of the sewage of a population of 2,000, while one hectare of irrigation surface is required for every 250 inhabitants (Darmstadt 180, Berlin 240, Magdeburg 440). All other systems of sewage disposal have the objectionable feature of being unproductive or unremunerative.

The annual sewage water of the city of Munich, after preliminary clarification, contains-

$3,200,000 \mathrm{~kg}$. of nitrogen,

$577,000 \mathrm{~kg}$. of phosphoric acid, $637,000 \mathrm{~kg}$. of potash.

It has been planned to conserve this waste by means of fish culture. The fresh suspended matter or sludge contains-

$$
\begin{aligned}
& 400,000 \mathrm{~kg} \text {. of nitrogen, } \\
& 224,000 \mathrm{~kg} \text {. of phosphoric acid, } \\
& 110,000 \mathrm{~kg} \text {. of potash. }
\end{aligned}
$$

It has been proposed to mix this sludge with the coarser rubbish or "mull" and use it for fertilizing, and thus reclaiming, the worthless heath regions and moors of the country surrounding Munich (Garchung, Froettmaning, Dachau, Schleissheim, Erding, Aubing) and converting them into valuable agricultural land.

It is evident that the utilization of sewage in fishponds has a promising future.

\section{B. Artificial Feeding}

An increase in the yield of fish from ponds, by means of artificial feeding, is possible or practicable under certain conditions only. Feeding pays only in cultivated ponds with a deficient flora. Ponds overrun with weeds cause too much loss of feed. Again, densely shaded ponds with low water temperature may affect the results of artificial feeding to the extent of 50 per cent. Warm water and an abundant supply of oxygen favor the effects of artificial feeding. Artificial feeding should not be practiced with the water temperature below $57^{\circ}$ or above $77^{\circ} \mathrm{F}$. Hence the maxim, when feeding for high production, to "feed with thermometer in hand." Carp practically stop feeding at a temperature of $8^{\circ} \mathrm{C}$. $\left(46.4^{\circ} \mathrm{F}\right.$.). In winter, therefore, food should be given sparingly and only sufficient to prevent starvation, or as much as they will eat. Excess of food, beyond what is actually consumed, only serves to befoul the water. The warmer the water, the more active is metabolization in the body of the carp, more food is consumed and more digested. At the same time the requirement for oxygen is raised. This is an important point to consider. In order to avoid losses from lack 
of oxygen, fish should not be fed in the evening, because plants cease giving off oxygen into the water on the approach of darkness. The oxygen supply in water also tends to become less on the approach of storms. The carp will instinctively refuse to feed and the food supply will spoil (Knauthe).

As a rule only "storiers" or "fries" are fed. Smaller fish are fed very limited amounts or not at all. Fish intended for breeding should receive natural food as far as this is possible.

Fishponds are stocked with carp one year old, of 80 to 100 grams weight. The addition of tenches, especially in mud-bottomed ponds, is recommended. Tenches are more industrious scavengers than carp, searching the bottom of the pond for the leavings of the latter.

Ponds supplied with artificial food may be stocked from three to four times as heavily as under natural food conditions. All fish, however, require natural food in addition to that supplied artificially.

In general, fish are fed during the summer only, but daily. Weather conditions being favorable about 20 per cent of the entire summer, allowance is given during the month of June, 30 per cent during July, 35 per cent during August and 15 per cent during September. The food should be distributed over moderate sized areas of the pond. For hygienic reasons and as a precaution against poaching, the feeding areas should be changed frequently. Overfeeding should be avoided; the practice is wasteful and may be detrimental.

Feedingstuffs for carp are:

1. Vegetable. The most important of these are:

$a$. Lupines, especially the yellow species. These are cracked and slightly soaked before feeding, but not treated for removal of the bitter principle. From 300 to 400 pounds of lupines are necessary to produce 100 pounds of carp meat (feed coefficient 3-4);

$b$. Other leguminous seeds (peas, vetches, beans, lentils, etc.). Their effect and value is similar to that of lupines.

c. Indian corn, which is fed in the same manner as lupines. Its high fat content leads to excessive fat deposit in the carp, which is generally regarded as objectionable, making them more susceptible to attack by disease, especially in winter ponds. From 400 to 500 pounds of corn are required to make 100 pounds of carp meat.

$d$. Other grains (barley, wheat, oats, rye, etc.). They resemble corn in effects produced, and in value.

$e$. Potatoes. These are fed raw or steamed. Their food value is low, from 20 to $30 \mathrm{cwt}$. being required to produce $1 \mathrm{cwt}$. of carp meat. They are usually supplied only as by-feeds.

$f$. Brewers' grains, malt sprouts and molasses. Usually supplied as by-feeds only.

g. Fungi. Even those that are toxic for human beings may be consumed by fish without harm (Klimmer). 
2. Animal feedingstuffs:

a. Meat meal or tankage. American tankage is rather deficient in lime (p. 124); the addition of 5 per cent of feed lime or 10 to 20 per cent fish meal is recommended. German tankage (meat meal) contains more lime, and additional mineral matter is unnecessary. Meals of good quality should be soft, mealy, and light brown in color. Dark, granular meals have been overheated; they are hard to digest and are apt to produce intestinal trouble. From $1 \frac{1}{2}$ to $2 \mathrm{cwt}$. of tankage will produce 2 cwt. of carp meat.

b. Fish meal. Fish meals of good quality have high nutritive value and contain every necessary element for the building up of the tissues of the fish. value.

c. Blood meal. This closely resembles fish meal in properties and

d. Dairy by-products (sour milk, whey, curd) serve as by-feeds.

e. May bugs or cock chasers (Melolontha vulgaris), caterpillars, the larvæ of flies, etc. These also serve as by-feeds.

3. Feed mixtures. The various meals can not be fed as such; they would be carried away by the wind. They must be worked up into solid masses before feeding. Favorite mixtures follow:

1.

Tankage ................ 1 part

Fish meal .............. 1 part

Rye meal or flour.......... 1 part

These ingredients are mixed, stirred up with water, cooked to make a thick gruel or paste and molded into little balls.
2.

Fish meal .............. 1 part

Tankage ................ 1 part

Boiled mashed potatoes......4-5 parts

or

Fish meal and tankage, of each 1 part

Corn meal ................ 2 parts

Prepared as directed under No. 1. 


\section{APPENDIX}

By way of appendix a few dietetic feed mixtures are given below. They are intended for horses at hard work, for pregnant and nursing mares, stud horses during the breeding season, and for intestinal weakness.

$1 \mathrm{~kg}$. bran and $2 \mathrm{~kg}$. oats thoroughly mixed with $\mathrm{I} / 4$ liter of boiled flaxseed and a little salt, then scalded with 1 to 2 liters of boiling water; let stand for 12 hours. Feed for one horse. Or:

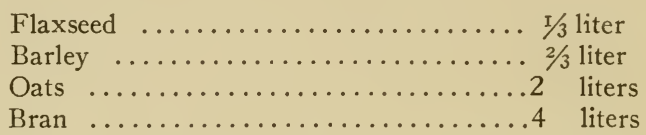

Boil the barley and flaxseed in 3 liters of water and while still hot add the oats and bran, stir thoroughly, let stand for 12 hours and feed to one horse. To retain the heat, protect vessel with woolen cloth.

This mixture should be given once a week.

For run-down animals or convalescents:

Wheat or rye.................. liters

Linseed meal ................. $1 / 2$ liter

Cooked beans $\ldots \ldots \ldots \ldots \ldots \ldots \ldots \ldots \ldots \ldots$ r $/ 2$ liter

Add three liters of boiling water and soak for 12 hours. Or:

Boiled oats ................... liters

Linseed meal .............. $1 / 2$ liter

Barley meal ................ $1 / 2$ liter

Chopped carrots ...............

Add 4 liters of boiling water, etc.

For anemic conditions:

Yellow oxid of iron........10 gm. in 1 liter

Rye soaked in water 24 hours,

Crushed oats.................... liters

Potassium carbonate..........1 tablespoonful

For chronic gastric or intestinal catarrh, tendency to colic, etc.:

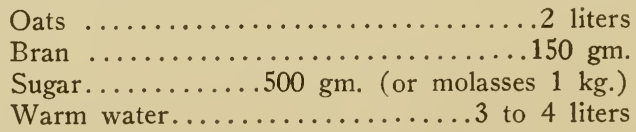

If necessary, laxatives (Glauber salts) diuretics or tonics may be added. 


\title{
Table I.
}

Composition, Value, Digestible Albumen Content, Starch Value and AlbumenStarch Value Ration of Feeding Stuffs. ${ }^{13}$

(Copyrighted)

Feeding Stuffs $\begin{gathered}\text { Crude } \\ \text { Nutrients }\end{gathered}$

\section{Green Forage}

\author{
a. Grasses
}

Per Cent

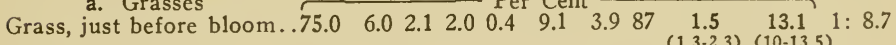

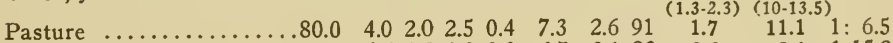

Corn, European seed....88.6 $5.6 \begin{array}{lllllllll}1.2 & 1.0 & 0.3 & 6.7 & 3.1 & 83 & 0.6 & 9.1 & 1: 15.2\end{array}$

b. Clovers and Legumes.

Red Clover,

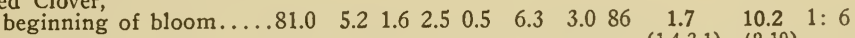

Alfalfa, before bloom.....76.0 $6.8 \quad 2.3 \quad 3.20 .4 \quad 6.3 \quad 2.979 \begin{array}{cccccc}(1.4-2.1) & (9-10) & 9.1 & 1: 5.4\end{array}$

c. Other Forage Plants.

$\begin{array}{lllllllllll}\text { Buckwheat, in bloom.....88.7 } & 4.3 & 1.1 & 1.6 & 0.3 & 5.2 & 2.5 & 87 & 1.1 & 8.1 & 1: 7.4\end{array}$

d. Leaves and herbs.

$\begin{array}{llllllllllll}\text { Sugar-beet tops and leaves } & 83.8 & 1.6 & 4.8 & 1.7 & 0.1 & 6.6 & 1.2 & 84 & 1.4 & 8.7 & 1: 5.1\end{array}$

II. Silage.

$\begin{array}{llllllllllll}\text { Sugar-beet tops and leaves } & 77.0 & 3.4 & 7.4 & 1.5 & 0.3 & 7.2 & 2.5 & 91 & 0.2 & 9.5 & 1: 47.5\end{array}$ III. Hay.

a. Meadow Hay and Grasses.

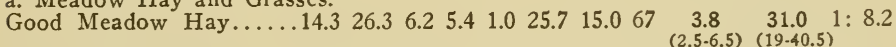

b. Clovers and Legumes.

Good red clover...........16.5 24.0 $6.08 .51 .726 .011 .370 \underset{(4.0-7.0)}{5.5} \underset{(25-35.6)}{31.9} 1: 5.8$

c. Foliage, herbs, leaves.

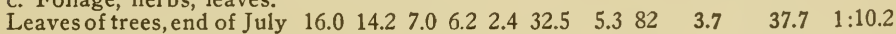

13With the permission of the publishers, Paul Parey, Berlin, these tables have been copied from Kellner, "Die Ernaehrung der Landwirtschaftlichen Nutztiere," 8th edition, 1919. The author takes this opportunity to express again his sincere thanks for this privilege. For the sake of convenience the author has added the ratio of the digestible albumen to the starch value. 
Table I.

Composition, Digestibility, Starch Value, etc., of Feeding Stuffs.-Continued. Crude
Nutrients

Feeding Stuffs

Digestible
Nutrients

IV. Straw.

a. Cereal straw.

$$
\text { Nutrients }
$$

$\begin{array}{llllllllllllll}\text { Oat straw } \ldots \ldots \ldots \ldots .14 .3 & 28.7 & 5.7 & 1.3 & 0.5 & 16.5 & 20.9 & 43 & 1.0 & 17.0 & 1: 17.0\end{array}$

Spring cereal straw,

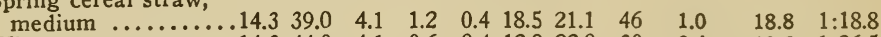

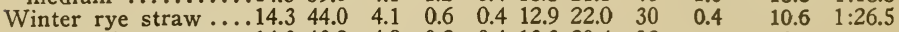

$\begin{array}{llllllllllll}\text { Winter wheat straw..14.3 } & 40.8 & 4.8 & 0.2 & 0.4 & 13.3 & 20.4 & 32 & \ldots & 10.9 & \ldots\end{array}$

b. Legume straw.

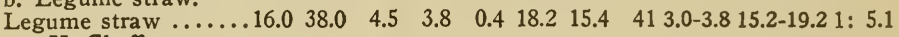
V. Chaff.

a. Cereals.
Oats $\ldots \ldots \ldots \ldots \ldots \ldots$
Ry...

Rye $\begin{array}{lllllllll}\ldots \ldots \ldots \ldots \ldots \ldots & 14.3 & 44.1 & 7.7 & 1.1 & 0.4 & 11.3 & 22.0 & 63\end{array}$

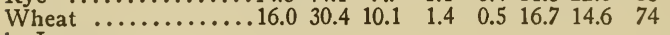

$1.4 \quad 28.6 \quad 1: 20.4$

$0.7 \quad 22.0 \quad 1: 31.4$

b. Legumes.

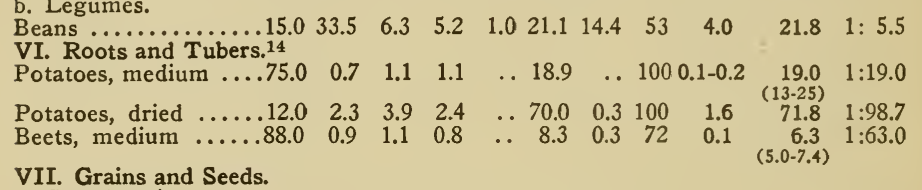

\section{Cereal grains.}

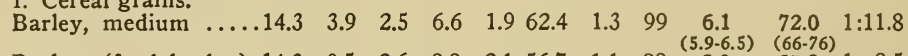

Barley (feed barley).14.3 $\begin{array}{lllllllllll} & 0.5 & 2.6 & 8.8 & 2.1 & 56.7 & 1.1 & 98 & 8.0 & 67.9 & 1: 8.5\end{array}$

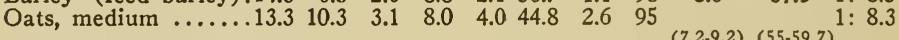

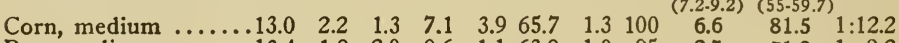

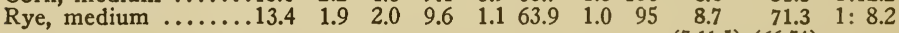

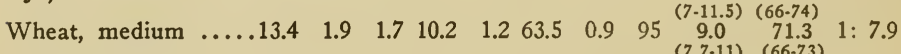

\section{Legume seeds.}

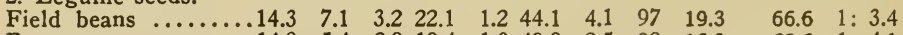
$\begin{array}{llllllllllll}\text { Peas } \ldots \ldots \ldots \ldots \ldots \ldots & & \end{array}$ $\begin{array}{lllllllllll}\text { Lupines, yellow } \ldots \ldots \ldots 14.0 & 14.1 & 3.8 & 34.4 & 3.8 & 21.9 & 12.7 & 94 & 30.6 & 67.3 & 1: 2.2\end{array}$

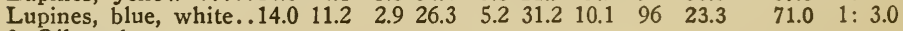
3. Oil seeds.

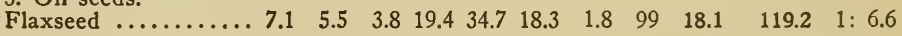

\footnotetext{
14For the sake of uniformity with the other feeding stuffs, the sugar content of the sugarcontaining root crops has not been converted into the usual nitrogen-free extract. The sugar content is expressed merely in its starch value and in its "value" number, which latter indicates its lower "production value."
} 
Table I. Composition, Digestibility, Starch Value, etc., of Feeding Stuffs.-Cont'd

$$
\begin{gathered}
\text { Crude } \\
\text { Nutrients }
\end{gathered}
$$

Feeding Stuffs

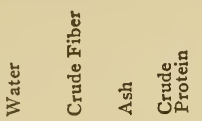

Digestible

Nutrients

VIII. Commercial Products

\section{a. Milling by-products}

10

Barley bran .............

Rice feed meal........... 12.6
Rye bran $\ldots \ldots \ldots \ldots \ldots .12 .5$

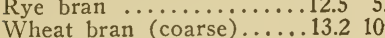

b. By-products from the manufacture of starch and sugar.

Potato pulp, dry........ $14.0 \quad 8.8 \quad 5.5 \quad \ldots \quad \ldots 56.6$
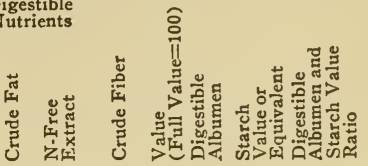

c. By-products from the

manufacture of sugar.

Beet pulp, fresh. . .

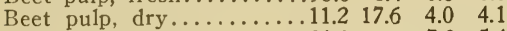

Molasses, ${ }^{15}$ common ......21.9 $\quad$. $7.2 \quad 5.4$

d. By-products of brewing and distilling industries.

Brewers' grains, fresh.....76.2 5.1

Brewers' grains, dried..... 9.016 .0

Distillery grains, dry..... 7.214 .6

Yeast residue, extracted...12.1

$\begin{array}{ll}3.2 & 13.8 \\ 5.2 & 42.7\end{array}$

$\begin{array}{ll}1.2 & 3.7 \\ 0.6 & 15.1\end{array}$

4.615 .1

Potato slop, fresh........994.3 $0.6 \quad 0.7 \quad 0.6$

Potato slop, dry........... $10.0 \quad 9.5 \quad 11.7 \quad 12.2$

Corn slop, dry .......... $8.6 \quad 10.2 \quad 2.2 \quad 18.2$

Malt sprouts (light color). $12.0 \quad 12.3 \quad 7.5 \quad 18.5$

e. Oil cakes.

Linseed cake and meal.....10.5 $25.0 \quad 7.2 \quad 18.1$

Linseed cake and meal, decorticated ............ $8.0 \quad 7.5 \quad 7.0 \quad 39.7$

$\begin{array}{lllll}\text { Peanut cake meal rufisque. } & 9.0 & 4.4 & 4.5 & 46.7\end{array}$

Hemp cake .............. 12.020 .2

Cocoanut cake............... 10.514 .7

Linseed cake ............11.0 $8.7 \quad 6.5 \quad 28.8$

Poppyseed cake ..........11.5 11.211 .028 .2

Palmseed cake ............ $9.7 \quad 23.8 \quad 4.013 .5$

Palmseed meal, extracted..10.9 $25.4 \quad 4.3 \quad 13.8$

Rape cake ..............10.0 $11.1 \quad 7.727 .4$

Sesame cake ......................

Soy-bean cake meal........ $11.2 \quad 7.0 \quad 6.1 \quad 39.2 \quad 4.4 \quad 25.6$

Soy-bean cake meal,

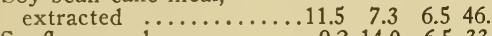

Sunflower cake .......... $9.2 \quad 14.0 \quad 6.5 \quad 33.5$

Animal Products.

Fish meal, poor in fat.....12.8

Cadaver meal ........... 7.0

Meat meal (tankage).....10.8

Cow's milk, separated.....90.3

$$
\begin{array}{rrrrrrrrrrr}
2.7 & 32.6 & 47.3 & 1.6 & \ldots & \ldots & 100 & 43.6 & 44.0 & 1: & 1.0 \\
22.0 & 39.5 & 15.8 & \ldots & \ldots & 100 & 24.6 & 69.8 & 1: & 2.9 \\
\ldots & 3.8 & 67.2 & 12.5 & \ldots & \ldots & 100 & 63.6 & 89.9 & 1: & 1.3 \\
\ldots & 0.8 & 3.8 & 0.2 & 4.7 & \ldots & 100 & 3.8 & 7.6 & 1: & 2.0
\end{array}
$$

15The crude protein of molasses consists almost exclusively of nitrogenous substances of nonalbuminous nature. 
Table II

The Salts in Feeding Stuffs

Average Content in 1,000 Parts of Fresh or Air-Dried Substance

\section{Feeding Stuffs}

I. Green Forage.

a. Meadow Crops and Grasses.

Meadow crops in bloom.......7750 20.3 unfertilized moor pastures.....750 15.1

in fertilized moor pastures....880 12.0

Rich pasture ................780 21.5

Grass, young and second crop...800 18.0

Rye grass $\ldots \ldots \ldots \ldots \ldots \ldots \ldots 70020.4$

Orchard grass ..................700 17.8

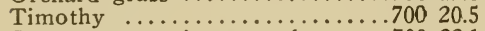

Sweet grasses in general......700 22.1

Feed rye .................760 16.3

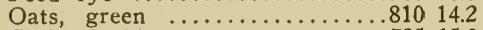

Grains in bloom ...............785 15.0

Corn, green ................ 82010.4

Sorghum in bloom ............770 14.0

Italian millet, beginning bloom...750 17.4

b. Clovers and legumes.

Alfalfa, beginning bloom .......740 17.0

Red clover, very young........8.860 13.8

Red clover, in bud...........8.820 13.1

Red clover, in bloom ..........800 13.7

Swedish clover ............. $820 \quad 8.5$

White clover, bloom ..........800 14.2

Carnation clover, bloom .......815 11.2

Kidney vetch ...............830 10.9

"Clover grass" ..................750 16.4

Esparset, in bloom ...........850 11.0

Serradella, in bloom .........800 19.6

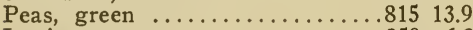

Lupines, green ...................... 650

c. Other forage plants.

Rape, beginning of bloom......870 10.5

Mustard, white, before bloom....870 10.2

Buckwheat, in bloom .........850 12.4

Field spurry ...............8 80013.5

d. Leaves and tops of root crops.

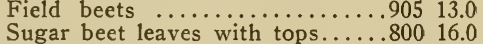

Turnips ...................8 89012.0

Kohlrabi $\ldots \ldots \ldots \ldots \ldots \ldots \ldots \ldots \ldots .68019 .6$

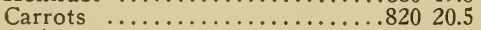

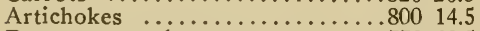

Potatoes, nearly mature ........770 20.5

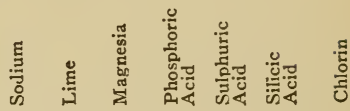

$\begin{array}{llllllll}5.8 & 0.6 & 2.7 & 1.2 & 1.2 & 0.9 & 7.9 & 1.0\end{array}$

$\begin{array}{cccccccc}5.8 & 0.6 & 2.7 & 1.2 & 1.2 & 0.9 & 7.9 & 1.0 \\ 2.4 & \ldots & . & \ldots & 1.1 & \ldots & \ldots & 0.9\end{array}$

$\begin{array}{llllllll}4.3 & \ldots & \ldots & \ldots & 1.2 & \ldots & \ldots & 1.2\end{array}$

$\begin{array}{llllllll}8.7 & 0.3 & 2.5 & 1.1 & 1.9 & 0.7 & 3.4 & 1.7\end{array}$

$\begin{array}{lllllllll}5.3 & 0.7 & 1.6 & 1.2 & 1.4 & 0.9 & 4.6 & 1.0\end{array}$

$\begin{array}{llllllll}7.1 & 0.7 & 1.5 & 0.4 & 2.2 & 0.8 & 6.5 & 2.1\end{array}$

$\begin{array}{llllllll}5.9 & 0.8 & 1.1 & 0.5 & 1.3 & 0.5 & 5.9 & 1.3\end{array}$

$\begin{array}{llllllll}7.1 & 0.4 & 1.7 & 0.7 & 2.4 & 0.6 & 6.6 & 1.1\end{array}$

$\begin{array}{llllllll}7.1 & 0.6 & 1.7 & 0.7 & 1.8 & 0.9 & 8.1 & 1.3\end{array}$

$\begin{array}{llllllll}6.3 & 0.1 & 1.2 & 0.5 & 2.4 & 0.2 & 5.2 & 0.6\end{array}$

$\begin{array}{llllllll}5.6 & 0.5 & 0.9 & 0.4 & 1.3 & 0.5 & 4.4 & 0.6\end{array}$

$\begin{array}{llllllll}4.4 & 0.3 & 0.9 & 0.4 & 1.4 & 0.4 & 6.2 & 0.6\end{array}$

$\begin{array}{llllllll}3.7 & 0.5 & 1.4 & 0.1 & 1.0 & 0.3 & 1.9 & 0.5\end{array}$

$\begin{array}{llllllll}3.9 & 1.9 & 1.3 & 0.6 & 0.8 & 0.5 & 4.0 & 1.1\end{array}$

$\begin{array}{llllllll}6.3 & 0.4 & 1.8 & 1.6 & 1.0 & 0.6 & 4.9 & 0.9\end{array}$

$\begin{array}{llllllll}3.0 & 0.3 & 7.8 & 0.9 & 2.0 & 1.1 & 1.8 & 0.7\end{array}$

$\begin{array}{llllllll}4.9 & 0.3 & 3.9 & 1.2 & 1.6 & 0.3 & 0.4 & 0.5\end{array}$

$\begin{array}{llllllll}4.8 & 0.2 & 3.9 & 1.4 & 1.3 & 0.3 & 0.3 & 0.4\end{array}$

$\begin{array}{llllllll}4.4 & 0.2 & 4.7 & 1.5 & 1.3 & 0.4 & 0.3 & 0.4\end{array}$

$\begin{array}{llllllll}2.3 & 0.2 & 2.9 & 1.0 & 0.8 & 0.3 & 0.3 & 0.4\end{array}$

$\begin{array}{llllllll}3.0 & 0.8 & 3.5 & 1.1 & 1.8 & 0.8 & 0.6 & 0.6\end{array}$

$\begin{array}{llllllll}2.5 & 0.9 & 3.5 & 0.7 & 0.8 & 0.3 & 1.8 & 0.3\end{array}$

$\begin{array}{llllllll}3.0 & 0.1 & 5.7 & 0.5 & 1.0 & 0.2 & 0.4 & 0.1\end{array}$

$\begin{array}{llllllll}7.6 & 0.3 & 1.7 & 0.7 & 1.6 & 0.8 & 3.3 & 0.3\end{array}$

$\begin{array}{llllllll}3.1 & 0.4 & 4.0 & 0.7 & 1.1 & 0.3 & 0.9 & 0.4\end{array}$

$\begin{array}{llllllll}7.7 & 0.4 & 4.3 & 0.7 & 2.2 & 0.8 & 1.7 & 0.5\end{array}$

$\begin{array}{llllllll}5.2 & 0.5 & 3.5 & 1.4 & 1.5 & 1.1 & 0.2 & 0.4\end{array}$

$\begin{array}{llllllll}1.5 & 0.5 & 1.6 & 0.6 & 1.1 & 0.4 & 0.4 & 1.1\end{array}$

$\begin{array}{llllllll}3.5 & 0.4 & 2.3 & 0.4 & 1.2 & 1.5 & 0.5 & 0.8\end{array}$

$\begin{array}{llllllll}4.0 & 0.4 & 2.5 & 0.4 & 0.5 & 1.0 & 0.5 & 0.8\end{array}$

$\begin{array}{llllllll}3.8 & 0.3 & 5.0 & 1.6 & 0.8 & 0.5 & 0.1 & 0.1\end{array}$

$\begin{array}{llllllll}4.7 & 1.1 & 2.6 & 1.6 & 2.0 & 0.5 & 0.2 & 1.1\end{array}$

$\begin{array}{llllllll}2.5 & 3.5 & 1.6 & 1.4 & 0.8 & 0.8 & 0.5 & 2.5\end{array}$

$\begin{array}{llllllll}3.5 & 3.0 & 1.5 & 1.1 & 1.0 & 0.5 & 0.8 & 1.0\end{array}$

$\begin{array}{llllllll}2.9 & 1.1 & 3.9 & 0.5 & 0.9 & 1.1 & 0.5 & 1.2\end{array}$

$\begin{array}{llllllll}2.8 & 0.8 & 6.5 & 0.8 & 2.0 & 2.3 & 2.1 & 1.5\end{array}$

$\begin{array}{llllllll}2.5 & 2.0 & 7.9 & 0.8 & 1.0 & 1.8 & 2.4 & 1.5\end{array}$

$\begin{array}{llllllll}3.1 & 0.2 & 5.0 & 1.3 & 0.7 & 0.2 & 3.6 & 0.4\end{array}$

$\begin{array}{llllllll}4.5 & 0.9 & 6.4 & 3.3 & 1.6 & 1.3 & 0.9 & 1.5\end{array}$ 
Table II.

The Salts in Feeding Stuffs.-Continued.

Feeding Stuffs

II. Hay.

a. Meadow hay and grasses.

Meadow hay ........................... 740.020 .0

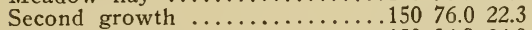

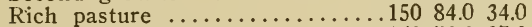

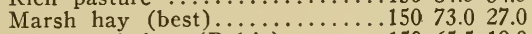

Salt marsh hay (Baltic) ............

Meadow grass, irrigated with liquid manure .........150 80.035 .0

Alpine hay ..........................

Rye grass (English) . . . . . . . . 140 58.020 .0

Orchard grass .............

Meadow hay from unfertilized moor meadows ............. $150 \quad 51.0 \quad 8.0$

Meadow hay from moor meadows fertilized with potassium

phosphate .............. 15054.019 .0

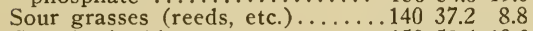

Cereals, in bloom ................ 59.419 .3

b. Clovers and legumes.

Alfalfa, beginning bloom........160 63.015 .0

Red clover, very young...................

Red clover, in bud.............................

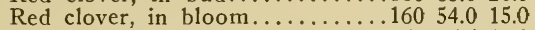

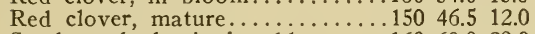

Sand vetch, beginning bloom....160 69.020 .0

White clover in bloom..................

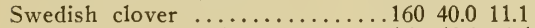

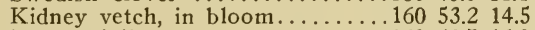

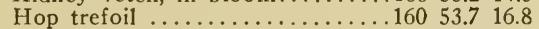

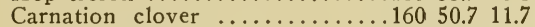

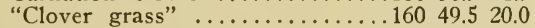

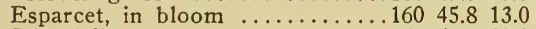

Serradella ................ $160 \quad 54.010 .0$

Vetches, green, in bloom .......160 45.510 .0

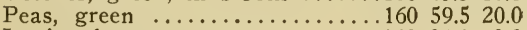

Lupine hay ................. $16034.2 \quad 8.0$

c. Other forage plants.

Rape, beginning bloom .......160 68.022 .6

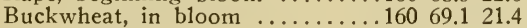

Field spurry .............. $167 \quad 56.319 .7$

III. Root crops.

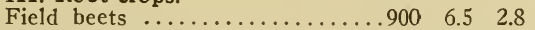

Sugar beets (new varieties

rich in sugar) ...........750 5.32 .3

Turnips $\ldots \ldots \ldots \ldots \ldots \ldots \ldots \ldots \ldots \ldots .920 \quad 6.4 \quad 2.9$

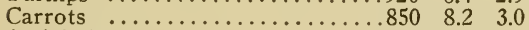

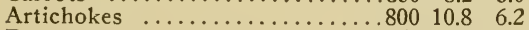

Potatoes $\ldots \ldots \ldots \ldots \ldots \ldots \ldots \ldots \ldots \ldots .750 \quad 9.5 \quad 6.0$

Kohlrabi $\ldots \ldots \ldots \ldots \ldots \ldots \ldots \ldots \ldots \ldots .670 \quad 7.5 \quad 3.5$

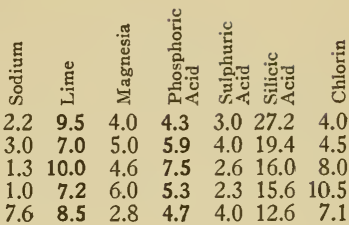

$\begin{array}{lllllll}2.5 & 9.5 & 3.2 & 9.3 & 4.6 & 6.9 & 9.8\end{array}$

$\begin{array}{lllllll}0.4 & 7.4 & 2.4 & 2.7 & 1.4 & 7.2 & 0.7\end{array}$

$\begin{array}{rrrrrrr}2.0 & 4.3 & 1.3 & 6.2 & 2.3 & 18.5 & 6.0\end{array}$

$\begin{array}{lllllll}2.2 & 3.1 & 1.4 & 3.6 & 1.3 & 16.7 & 3.6\end{array}$

$\begin{array}{llll}3.8 & \ldots & \ldots & 3.0\end{array}$

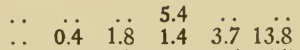

$\begin{array}{lllllll}1.0 & 3.4 & 1.7 & 5.6 & 1.5 & 24.7 & 2.3\end{array}$

$\begin{array}{lllllll}1.1 & 25.2 & 3.1 & 6.5 & 3.6 & 5.0 & 2.5\end{array}$

$\begin{array}{lllllll}1.9 & 23.5 & 7.6 & 10.0 & 1.8 & 2.5 & 3.3\end{array}$

$\begin{array}{lllllll}1.4 & 20.7 & 7.6 & 6.9 & 1.7 & 1.8 & 2.4\end{array}$

$\begin{array}{lllllll}1.1 & 20.1 & 6.3 & 5.6 & 1.9 & 1.6 & 2.2\end{array}$

$\begin{array}{lllllll}1.4 & 15.8 & 6.9 & 4.4 & 1.4 & 3.0 & 1.3\end{array}$

$\begin{array}{lllllll}0.8 & 18.1 & 5.7 & 9.7 & 4.3 & 7.3 & 2.5\end{array}$

$\begin{array}{lllllll}4.4 & 18.4 & 5.8 & 7.8 & 4.5 & 2.7 & 2.6\end{array}$

$\begin{array}{lllllll}1.2 & 13.6 & 5.0 & 4.1 & 1.6 & 1.6 & 2.2\end{array}$

$\begin{array}{lllllll}0.7 & 27.7 & 2.5 & 4.7 & 0.7 & 1.7 & 0.6\end{array}$

$\begin{array}{lllllll}4.4 & 14.9 & 4.5 & 4.4 & 2.2 & 1.9 & 4.8\end{array}$

$\begin{array}{lllllll}4.3 & 16.0 & 3.1 & 3.6 & 1.3 & 8.2 & 1.8\end{array}$

$\begin{array}{lllllll}0.9 & 5.6 & 2.3 & 5.3 & 2.8 & 11.1 & 1.2\end{array}$

$\begin{array}{lllllll}1.5 & 16.8 & 6.3 & 4.6 & 1.4 & 3.7 & 1.8\end{array}$

$\begin{array}{lllllll}1.7 & 18.2 & 2.8 & 9.1 & 3.1 & 7.0 & 2.1\end{array}$

$\begin{array}{lllllll}2.4 & 16.3 & 4.6 & 6.2 & 3.4 & 1.1 & 1.4\end{array}$

$\begin{array}{lllllll}2.3 & 15.6 & 6.3 & 6.8 & 5.1 & 0.8 & 2.0\end{array}$

$\begin{array}{lllllll}2.5 & 8.8 & 3.3 & 5.8 & 1.9 & 2.4 & 0.6\end{array}$

$\begin{array}{lllllll}2.3 & 15.0 & 2.7 & 7.6 & 9.5 & 3.2 & 5.0\end{array}$

$\begin{array}{lllllll}1.6 & 27.9 & 9.2 & 4.2 & 2.5 & 0.8 & 0.5\end{array}$

$\begin{array}{lllllll}4.5 & 10.8 & 6.8 & 8.3 & 1.9 & 0.8 & 4.4\end{array}$

$\begin{array}{lllllll}1.5 & 0.3 & 0.4 & 0.6 & 0.3 & 0.2 & 1.0\end{array}$

$\begin{array}{lllllll}0.7 & 0.6 & 0.5 & 0.8 & 0.2 & 0.2 & 0.2\end{array}$

$\begin{array}{lllllll}0.6 & 0.7 & 0.2 & 0.8 & 0.7 & 0.1 & 0.3\end{array}$

$\begin{array}{lllllll}1.5 & 0.9 & 0.4 & 1.1 & 0.5 & 0.2 & 0.4\end{array}$

$\begin{array}{lllllll}1.0 & 0.3 & 0.3 & 0.6 & 0.6 & 0.2 & 0.4\end{array}$

$\begin{array}{lllllll}0.2 & 0.3 & 0.5 & 1.2 & 0.6 & 0.2 & 0.4\end{array}$

$\begin{array}{lllllll}0.4 & 0.9 & 0.3 & 1.1 & 0.7 & 0.1 & 0.5\end{array}$ 
Table II.

The Salts in Feeding Stuffs.-Continued.

Feeding Stuffs

IV. Grains and Seeds. a. Grains.

Winter rye .................140 18.9

Winter wheat $\ldots \ldots \ldots \ldots \ldots \ldots \ldots \ldots \ldots 14017.8$

Winter barley .................140 21.5

Summer rye ................140 19.0

Summer wheat $\ldots . \ldots \ldots \ldots \ldots \ldots \ldots 14019.9$

Summer barley .................140 25.5

Oats .....................140 26.5

Spelt without glumes ..........140 15.0

Spelt with glumes .............140 37.0

Corn ........................140 12.8

Sorghum .....................140 16.0

Millet ......................140 29.5

Sugar millet ..................140 23.4

b. Legume seeds.

Peas .......................140 27.512 .5

Field beans ..................... 14031.012 .9

Garden beans ..................150 27.412 .1

Soy beans $\ldots \ldots \ldots \ldots \ldots \ldots \ldots \ldots \ldots \ldots+10028.312 .6$

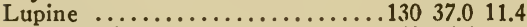

Feed vetch .....................140 $26.6 \quad 8.0$

c. Oily seeds.

Rape .....................120 39.29 .6

Mustard ....................130 $36.5 \quad 5.9$

Summer turnips ...............120 38.010 .0

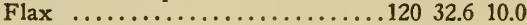

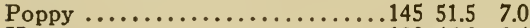

Hemp .....................120 46.39 .4

Beechnuts ...................150 $27.0 \quad 8.3$

Peanuts $\ldots \ldots \ldots \ldots \ldots \ldots \ldots \ldots .6532 .012 .7$

Cocoanut ....................460 $9.7 \quad 4.3$

d. Other seeds and fruits.

Buckwheat ..................140 $11.8 \quad 2.7$

Horse chestnut (fresh).........490 $12.0 \quad 7.1$

Acorns (fresh) ...............550 $9.8 \quad 6.3$

Fruit and berriesApples, whole fruit ........830 $2.2 \quad 0.8$ Pears ....................8.830 $3.3 \quad 1.8$ Plums ......................8

V. Straw.

a. Cereal straw.

Winter rye ...................140 40.010 .0

Winter wheat $\ldots \ldots \ldots \ldots \ldots \ldots \ldots \ldots .14048 .5 \quad 9.0$

Winter spelt $\ldots \ldots \ldots \ldots \ldots \ldots \ldots \ldots 140 \quad 50.8 \quad 7.2$

Summer rye .................140 $41.5 \quad 7.5$

Summer wheat $\ldots . . . \ldots \ldots \ldots \ldots . .1140 \quad 35.0 \quad 7.5$

Barley ......................140 48.012 .0

Winter barley ..................140 48.012 .0

Oats .......................140 63.315 .0

Indian corn ................150 45.316 .4

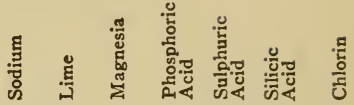

$\begin{array}{lllllll}0.6 & 0.5 & 2.0 & 8.5 & 0.2 & 0.3 & 0.6\end{array}$

$\begin{array}{lllllll}0.6 & 0.5 & 2.0 & 8.0 & 0.2 & 0.3 & 0.5\end{array}$

$\begin{array}{llllllll}0.7 & 0.1 & 2.0 & 6.6 & 0.5 & 4.9 & 0.8\end{array}$

$\begin{array}{llllllll}0.6 & 0.5 & 2.0 & 9.2 & 0.2 & 0.2 & 0.6\end{array}$

$\begin{array}{lllllll}0.5 & 0.5 & 2.2 & 8.5 & 0.2 & 0.3 & 0.5\end{array}$

$\begin{array}{lllllll}1.0 & 0.6 & 2.0 & 8.0 & 0.4 & 6.0 & 1.5\end{array}$

$\begin{array}{llllllll}0.5 & 1.0 & 1.3 & 7.0 & 0.5 & 10.5 & 0.5\end{array}$

$\begin{array}{llllllll}0.7 & 0.6 & 1.0 & 6.5 & 0.2 & 0.1 & 0.3\end{array}$

$\begin{array}{llllllll}0.4 & 1.0 & 2.6 & 7.6 & 1.1 & 17.1 & 0.2\end{array}$

$\begin{array}{lllllll}0.1 & 0.3 & 1.9 & 5.7 & 0.1 & 0.3 & 0.2\end{array}$

$\begin{array}{lllllll}0.5 & 0.2 & 3.4 & 8.1 & . . & 1.2 & \ldots\end{array}$

$\begin{array}{lllllll}0.4 & 0.2 & 2.8 & 6.5 & 0.1 & 15.6 & 0.1\end{array}$

$\begin{array}{lllllll}2.0 & 0.2 & 3.1 & 5.8 & 0.2 & 8.6 & \ldots\end{array}$

$\begin{array}{lllllll}0.2 & 1.1 & 1.9 & 10.0 & 0.8 & 0.2 & 0.4\end{array}$

$\begin{array}{lllllll}0.3 & 1.5 & 2.2 & 12.1 & 1.1 & 0.2 & 0.5\end{array}$

$\begin{array}{lllllll}0.4 & 1.5 & 2.1 & 9.7 & 1.1 & 0.2 & 0.3\end{array}$

$\begin{array}{lllllll}0.3 & 1.7 & 2.5 & 10.4 & 0.8 & \ldots & 0.1\end{array}$

$\begin{array}{lllllll}0.3 & 2.8 & 4.5 & 14.2 & 3.2 & 0.1 & 0.3\end{array}$

$\begin{array}{lllllll}2.1 & 2.2 & 2.4 & 9.9 & 1.0 & 0.3 & 0.7\end{array}$

$\begin{array}{lllllll}0.6 & 5.5 & 4.6 & 16.6 & 0.9 & 0.5 & 0.1\end{array}$

$\begin{array}{lllllll}2.0 & 7.0 & 3.7 & 14.6 & 1.8 & 0.9 & 0.2\end{array}$

$\begin{array}{llllllll}. . & 5.2 & 4.7 & 14.9 & 2.3 & \ldots & \ldots\end{array}$

$\begin{array}{lllllll}0.7 & 2.6 & 4.7 & 13.5 & 0.8 & 0.4 & \ldots\end{array}$

$\begin{array}{lllllll}0.5 & 18.2 & 4.9 & 16.2 & 1.0 & 1.7 & 2.4\end{array}$

$\begin{array}{lllllll}0.4 & 10.9 & 2.6 & 16.9 & 0.1 & 5.5 & \ldots\end{array}$

$\begin{array}{lllllll}0.4 & 6.2 & 2.5 & 6.3 & 1.4 & 0.2 & \ldots\end{array}$

$\begin{array}{lllllll}0.9 & 1.3 & 0.6 & 12.4 & 3.4 & 0.1 & \ldots\end{array}$

$\begin{array}{lllllll}0.8 & 0.5 & 0.9 & 1.7 & 0.5 & 0.1 & 1.3\end{array}$

$\begin{array}{lllllll}0.7 & 0.5 & 1.5 & 5.7 & 0.2 & \ldots & 0.2\end{array}$

$\begin{array}{llllllll}. . & 1.4 & 0.1 & 2.7 & 0.3 & 0.3 & 0.8\end{array}$ $\begin{array}{lllllll}0.1 & 1.0 & 0.5 & 1.5 & 0.4 & 0.1 & 0.2\end{array}$

$\begin{array}{llllll}0.6 & 0.1 & 0.2 & 0.3 & 0.1 & 0.1\end{array}$

$\begin{array}{llllll}0.3 & 0.3 & 0.2 & 0.5 & 0.2 & 0.1\end{array}$ $\begin{array}{lllll}0.3 & 0.2 & 0.4 & 0.1 & 0.1\end{array}$

$\begin{array}{lllllll}1.0 & 3.1 & 1.2 & 2.8 & 1.6 & 18.8 & 1.5\end{array}$ $\begin{array}{lllllll}0.6 & 2.7 & 1.1 & 2.0 & 1.1 & 31.0 & 1.0\end{array}$ $\begin{array}{lllllll}0.3 & 2.9 & 1.2 & 1.6 & 1.2 & 36.0 & 1.0\end{array}$ $\begin{array}{lllllll}0.6 & 4.0 & 1.2 & 2.0 & 1.5 & 25.2 & \ldots\end{array}$ $\begin{array}{lllllll}0.6 & 2.6 & 0.9 & 2.0 & 1.8 & 18.2 & 1.2\end{array}$ $\begin{array}{lllllll}3.0 & 3.3 & 1.2 & 1.8 & 1.8 & 23.4 & 3.0\end{array}$ $\begin{array}{llllllll}\ddot{4} 0 & \ddot{4} . \dot{3} & \ddot{2 . j} & 1.8 & 1.0 & 2.0 & 30 . \dot{0} & 4.0\end{array}$ $\begin{array}{lllllll}0.5 & 4.9 & 2.6 & 3.0 & 2.4 & 13.1 & 0.8\end{array}$ 
Table II.

The Salts in Feeding Stuffs.-Continued.

Feeding Stuffs

b. Other plants.

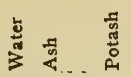

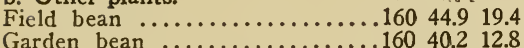

Pea .................... $16038.0 \quad 5.0$

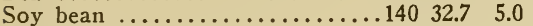

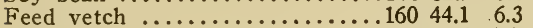

Lupine ...................160 42.617 .7

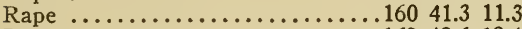

Poppy ...................160 48.618 .4

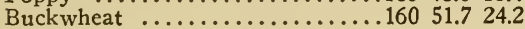

VI. Chaff.

a. Of the grains.

Winter rye ................ 14082.75 .2

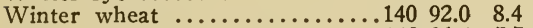

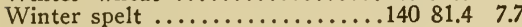

Oats ..............................

b. Other plants.

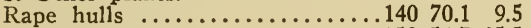

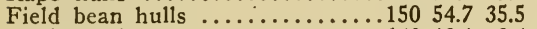

Lupine hulls .................140 19.19 .4

VII. Commercial Products

and Refuse.

a. Milling by-products.

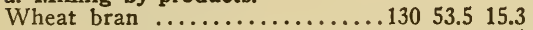

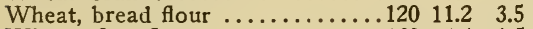

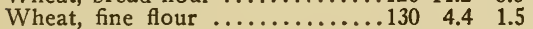

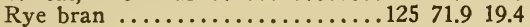

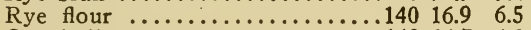

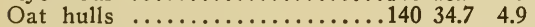

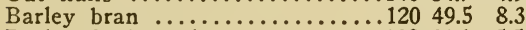

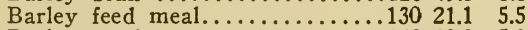

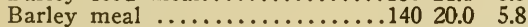

Buckwheat bran .............. 14029.89 .7

Corn meal ................. $140 \quad 5.9 \quad 1.7$

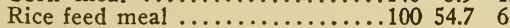

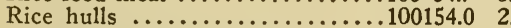

b. Refuse from the distilling

and brewing industries.

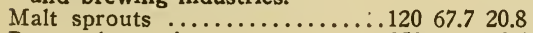

Beet pulp, moist .............950 2.80 .4

Beet pulp, dry ..................... 35.0

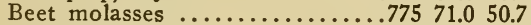

Molasses slump ..............800 27.015 .0

Potato fiber ...............850 1.10 .2

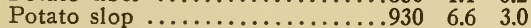

Grape or wine refuse........650 $36.7 \quad 17.2$ c. Oil cakes.

Cottonseed cake .............110 66.415 .8

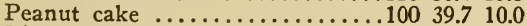

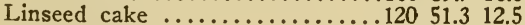

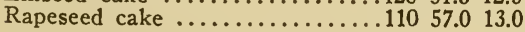

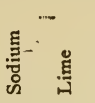

$\begin{array}{lll}0.8 & 12.0 & 2.6\end{array}$

$\begin{array}{lll}3.2 & 11.1 & 2.5\end{array}$

$\begin{array}{lll}1.8 & 15.9 & 3.5\end{array}$

$0.7 \quad 14.6 \quad 5.0$

$\begin{array}{lll}6.9 & 15.6 & 3.7\end{array}$

$\begin{array}{lll}1.3 & 9.7 & 3.4\end{array}$

$\begin{array}{ll}3.9 & 11.7\end{array}$

0.614 .7

1.19 .5

2.5

3.1

1.9

告

을웜

نี.

몬

$\begin{array}{llll}2.9 & 1.8 & 3.2 & 2.0\end{array}$

$\begin{array}{llll}3.9 & 1.7 & 1.9 & 3.1\end{array}$

$\begin{array}{llll}3.5 & 2.7 & 2.9 & 2.3\end{array}$

$\begin{array}{lll}3.1 & 2.1 & 1.8\end{array}$

$\begin{array}{lll}2.7 & 3.3 & 3.6\end{array}$

$\begin{array}{lll}2.5 & 3.4 & 1.2\end{array}$

i.j

$\begin{array}{llll}2.5 & 3.1 & 2.6 & 3.5\end{array}$

$\begin{array}{llll}1.6 & 2.5 & 5.5 & 1.3\end{array}$

$\begin{array}{llll}6.1 & 2.7 & 2.9 & 4.1\end{array}$

\section{$0.3 \quad 3.5$}

$\begin{array}{llllll}3.5 & 1.1 & 5.6 & 0.1 & 66.4 & 0.4\end{array}$

$\begin{array}{lllllll}1.7 & 1.7 & 1.2 & 4.0 & \ldots & 74.7 & \ldots\end{array}$

$\begin{array}{lllllll}0.3 & 2.0 & 2.0 & 5.9 & 1.9 & 60.4 & \ldots\end{array}$

$\begin{array}{lllllll}2.9 & 4.0 & 1.5 & 1.3 & 3.5 & 50.4 & 0.8\end{array}$

$\begin{array}{lllllll}3.0 & 3.1 & 5.8 & 3.7 & 6.4 & 0.8 & 3.5\end{array}$

$\begin{array}{lllllll}1.3 & 6.8 & 6.0 & 2.7 & 1.2 & 0.3 & 1.0\end{array}$

$\begin{array}{lllllll}1.3 & 4.4 & 0.8 & 1.0 & 0.4 & 0.9 & 0.3\end{array}$

$\begin{array}{llll}0.3 & 1.5 & 9.0 & 26.9\end{array}$

$\begin{array}{llll}0.1 & 0.6 & 1.4 & 5.6\end{array}$

$\begin{array}{llll}\text {. } & 0.3 & 0.4 & 2.2\end{array}$

$\begin{array}{llll}0.5 & 2.1 & 11.4 & 34.4\end{array}$

$\begin{array}{llll}0.3 & 0.2 & 1.4 & 8.2\end{array}$

$\begin{array}{llll}0.3 & 1.4 & 1.0 & 1.6\end{array}$

$\begin{array}{llll}0.7 & 1.9 & 3.1 & 9.1\end{array}$

$\begin{array}{llll}0.4 & 0.7 & 2.8 & 10.8\end{array}$

$\begin{array}{llll}0.5 & 0.6 & 2.7 & 9.5\end{array}$

$\begin{array}{llll}0.6 & 2.9 & 4.0 & 10.7\end{array}$

$\begin{array}{llll}0.2 & 0.4 & 0.9 & 2.7\end{array}$

$\begin{array}{llll}1.2 & 1.2 & 9.5 & 23.8\end{array}$

$\begin{array}{llllllll}0.5 & 0.8 & 0.1 & 4.1 & 0.2 & 0.3\end{array}$

. $0.2 \quad \ldots$

.

$\begin{array}{llll}\cdots & \cdots & \cdots\end{array}$

$\therefore \ldots$

$\begin{array}{lll}1.3 & 23.2 & 0.5\end{array}$

$0.924 .1 \quad 0.6$

$\begin{array}{ll}0.3 & 0.3\end{array}$

$0.6 \quad \ldots \quad \cdots$

$\begin{array}{llll}0.9 & 0.6 & \cdots\end{array}$

$0.210 \ddot{3}$

$0 . \dot{2}$

$\begin{array}{lllllll}1.2 & 1.9 & 1.9 & 18.2 & 2.7 & 14.9 & 4.7\end{array}$

$\begin{array}{lllllll}0.1 & 1.1 & 0.2 & 0.2 & 0.1 & 0.7 & 0.1\end{array}$

$\begin{array}{lllllll}1.0 & 14.0 & 2.0 & 1.5 & 0.2 & 9.0 & 1.0\end{array}$

$\begin{array}{lllllll}9.1 & 3.1 & 0.3 & 0.5 & 1.6 & 0.3 & 6.2\end{array}$

$\begin{array}{lllllll}3.0 & 0.1 & 0.1 & 0.1 & 0.2 & 0.1 & 0.4\end{array}$

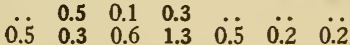

$\begin{array}{lllllll}0.2 & 4.0 & 1.5 & 4.6 & 1.8 & 3.8 & 0.2\end{array}$

$\begin{array}{rrrrrrr}0.9 & 2.9 & 10.1 & 30.5 & 0.8 & 5.5 & \\ 0.8 & 4.3 & 8.1 & 11.6 & 0.9 & 1.2 & 0.9 \\ 0.8 & 4.3 & 8.1 & 16.2 & 1.7 & 6.4 & 0.4 \\ 1.9 & 7.1 & 7.3 & 20.0 & 3.4 & 2.9 & 0.4\end{array}$ 
Table II.

The Salts in Feeding Stuffs.-Continued.

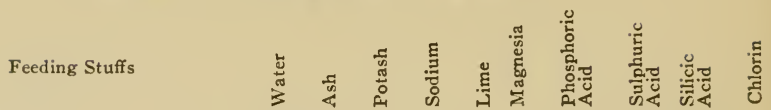

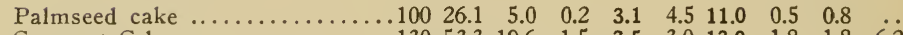

Cocoanut Cake ....................

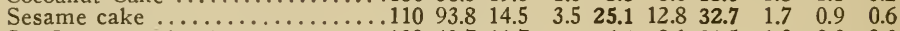

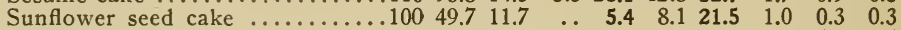

Poppy-seed cake ...............

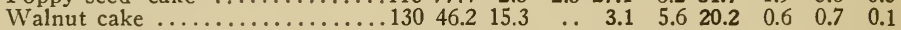

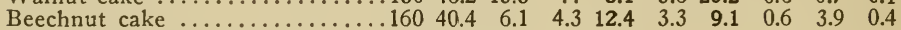

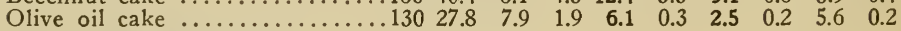

VIII. Animal Products.

a. Dairy products and wastes.

\begin{tabular}{|c|c|c|c|c|c|c|c|c|c|}
\hline olostrum & 11.8 & 0.9 & 0.7 & 4.1 & 0.2 & 3.3 & & & 1.3 \\
\hline Cow's milk & 7.2 & 1.7 & 0.4 & 1.7 & 0.2 & 2.0 & 0.1 & & 1.0 \\
\hline Skim milk & 7.9 & 2.1 & 0.5 & 1.7 & 0.2 & 2.2 & 0.3 & & .9 \\
\hline Whey (cow's milk) .. & 5.4 & 1.7 & 0.7 & 1.0 & & 0.9 & 0.2 & & 8 \\
\hline heep's milk ..............815 & 7.3 & 1.6 & 0.3 & 2.1 & & 2.6 & 0.1 & 0.2 & \\
\hline $\begin{array}{l}\text { Goat's milk ..................... } 920 \\
\text { b. Other animal waste products. }\end{array}$ & 5.9 & 2.3 & 0.6 & 0.4 & 0.3 & 0.8 & 0.2 & . & \\
\hline age $\ldots \ldots \ldots \ldots \ldots \ldots \ldots \ldots \ldots \ldots$ & & 0.9 & 0.5 & 3.6 & & 6.9 & 0.2 & 0.1 & \\
\hline lay bugs (fresh & 13 & 5.0 & 0.8 & 0.4 & 1.1 & 5.6 & 0.2 & 0.2 & \\
\hline$\ldots \ldots \ldots \ldots$ & & 0.6 & 3.6 & 0.1 & & 0.4 & 0.2 & 0.1 & \\
\hline
\end{tabular}




\section{INDEX}

Absinthin, 16.

Acetic acid, 15.

Aconite, 44.

Acorns, 97, 98, 230.

Actinomycosis bovis, 47, 68 .

Adenin, 9.

Advantages, 45 .

Agglutination, 45.

Age of oats, 85 .

Age of plants, 44 .

Agreeability of foods, 166 .

Agrostis, 36, 37, 41.

Aira, 41.

Air dry feeding stuffs, 147.

Albumen, 118.

Albumen index, 130, 134.

Albumen ratio, 172 .

Albuminous substances, 4, 5, 151.

Aleuron layer, 77.

Alfalfa, 51, 52 .

Algae, 218.

Alkaline solution, 13.

Alkaloids, 9.

Allantoin, 9.

Almond seed cake, 123.

Alopecurus, 35, 41 .

Alpine hay, 60 .

Aluminum, 4.

American meat meal, 125.

Amido compounds, 9.

Amids, 6.

Ammonia, 3, 9, 218.

Ammophila, 42.

Amygdalin, 9.

Anaphylaxis, 51 .

Anemia, 64, 159, 160, 224.

Angelicin, 16.

Anis seed by-products, 123.

Anthroxanthum, 36, 41 .

Anthrax spores, 101.

Anthyllis, 50.

Appetizer, 3, 151.

Apples, 75, 220.

Arabin, 14.

Arabinose, 11, 12.

Arginin, 8.

Arrow grass, 43.

Arsenic, 4.

Artichoke, 14, 16, 69, 209, 229

Artificial fish feeding, 221.

Arundo, 43.

Ash, 4.

Ash analysis, 134 .

Assimilation, 150, 161.

Automatic feeders, 211.

Avena brevis, 81 .
Avena sativa, 81 .

A vitamins, 8 .

Avitaminoses, 8 .

Avenin, 83

Awns, 77.

Bacon, 92, 192.

Bacteriological examination, 147.

Baking, 34.

Barite, 134

Barley, 87, 89, 130, 222, 223, 230.

bran, 99, 227, 231.

by-products, 102.

feed, 226, 231.

French, 102.

green, 47.

hulls and chaff, 68 .

malt, 104.

meal, 102, 231.

slop, 89.

sprouted, 103

straw, 60 .

winter, 230.

Basal feeding stuffs, 148

Beans, 93, 226, 230.

Bean straw, 68 .

Beckmann's method, 32 .

Beechnuts, 98, 230.

Beechnut cake, 122, 232.

Beets and roots, 74, 228.

Beet leaves, 54, 55.

leaf silage, 63 .

pulp, 107, 108, 195.

pulp, dry, 108.

pulp disease, 111 .

ferment, 108.

Beet sugar, 107.

Bent grasses, 37.

Benzine, 112.

Betain, 9, 109.

Biogenic elements, 155.

Biological examination, 135.

Bitter principles, 16.

Blue grass, 38.

Blood corpuscles, 15.

Blood feed, 87. meal, 127, 223.

Boiled milk, 183.

Bone feed meal, 128. diseases of, 155 .

by feed of, 206.

Bonnet grass, 37.

Buckeye Ohio, 98.

Buckwheat, 53, 81, 85, 93, 225, 229, 230 , 231. 
Buckwheat bran, 101, 102, 231 crushed, 76.

disease, 53.

green forage, 225, 228.

seeds, 230.

seed hulls, 54 .

straw, 68 .

Bulkiness of rations, 166, 171.

Buttermilk, 125.

Butyric acid, 15.

Brachypodium, 36, 41.

Bran, 99, 102.

buckwheat, 102.

coarse, 102.

corn, 103.

made from tips, 102.

moistened for horses, 101.

rye, 102.

wheat, 102.

Bread, 34.

Breed, 151.

Brewer's grains, 104.

Briza media, 41.

Bromus, 36, 41, 42.

erectus, 39 .

racemosus, 39 .

Cadaver meal, 125, 126.

Caffein, 9.

Cajanus, 94.

Calamagrostis, 41, 42.

Calcium, 4. chloride, 158, 157.

Calculations of rations, 165 . of money value of. feeding stuffs, 129.

Calf feed, 183.

Calluma vulgaris, 65 .

Calorimeter, 149.

Camelina cake, 122. straw, 68 .

hulls, 69. chaff, 69.

Canary grass, $41,4 ?$.

Cane, 43. sugar, 11, 14.

Candlenut cake, 122.

Cannery refuse, 126.

Capronic acid, 14.

Caraway seed, $51,123$.

Carbohydrates, 5, 11, 13, 152, 153.

Carbonic acid test, 134.

Carex, 43.

Carp feeding, 221.

Carrot, 74, 229.

Castor oil bean cake, 122 .

Cellulose, 11, 13, 33, 34 .

Centrifuging, 107.

Cereal, 66.

straw, 66 .

grains, 76, 79.

Cerebritis, 115 .
Chaff and hulls, 67, 68, 226.

Chaffed hay, 67 . straw, 66, 68 .

Chamomile, true, 46.

Change of feed, 167.

Charcoal, 4.

Charlock, 94.

Chemical constituents of feeding stuffs, 2 . examinations of feeding stuffs, 134 . latitude, 132.

Chess, meadow, 39, 41 .

Chicken feeding, 207. masting, 212.

Chives, 46.

Chloride manganous, 220.

Chloroform test, 134.

Chlorophyl, 10, 47.

Cholesterins, 10.

Cholin, 9,83.

Chufa, 75.

Cibus, 110.

Cider press, 107.

Cirsin, 9.

Citric acid, 15.

Cleanliness, 168.

Climate, 44.

Clover, 48, 225, 228.

species, 49. disease, 51 .

Cochineal, 6.

Cock chasers, 128.

Cockle, 79, 89, 134.

Cocoa shells, 131. nut molasses feed, 109. nut by-products, 121, 230. nut oil cakes, 123.

Colic flatulent, 68 .

Colostral milk, 181.

Colsmann's method, 32 .

Combustibles, 149.

Comfrey, 56.

Commercial feeding stuffs, 126, 128.

Compensating indegredients, 132.

Complement fixations, 135.

Composition of forage, 45.

Concentrates, 149.

Condimental, 2.

Conglutinins, 135.

Conservation of feeding stuffs, 16.

Control association, 163.

Control of feeding stuffs, 31 .

Cooking, 28.

Copper, 4.

Coretha, 217.

Corriander seed, 123.

Correctives of by-feeds, 148 .

Corn, 86, 91, 92, 222, 226. bran, 103. cob, 92 .

cockle, 106.

fodder, sweet, 49.

germ cake, 112 . 
Corn gluten meal,112. glucose cake, 111. green, 48, 225, 230.

lean, 80,82 . meal, 231.

oil cake, 86 .

plump, 80,82 .

screenings, 80,82 .

slop, 106, 227.

smut, 92.

straw, 230.

Cotton seed cake, 117, 231.

meal, 118.

oil, 117.

Cow wheat, 134.

Crude fiber, 12.

Curd, 223.

Cynosurus, 37.

Cyclops, 216, 217.

Darnel, poisonous, 101.

Dayfly, 217.

Dead ripe grains, 85 .

Determination of moisture content, 3 .

Devil toad stool, 57.

Dextrin, 11, 13, 102.

Dextrose, 11, 13.

Diarrhea, 107.

Diastose, 33, 34, 103, 186.

Diastasolin, 33, 34, 186.

Dietetic effects, 167

Dietetic feed mixtures, 223.

Diuretics, 224.

Digestibility, 151.

Digestion, 150.

Dioxid, 4.

Disaccharids, 11.

Diseases from grass feeding, 46.

Distillery, 105. slops, 106.

Dog biscuit, 128, 206.

Dog food, 206.

Dolichos, 95.

Dry brewers grains, 104. feed for hens, 210 .

feed for chickens, 207.

matter, 3 .

potatoes, 86

slop, 107.

Drying, 19. artificial, 21.

Duck food, 212.

Duck weed, 220.

\section{Eggs, 7.}

Embryo, 77.

Emulsified milk, 185.

Endosperm, 77, 144.

Energy conversion, 149.

Ensilaged, 107.

Ensilage bacteria, 27.
Ensilaged beet pulp, 108 .

Enzymes, 7, 17,29, 169.

Eosin, 89.

Ergot, 134, 142.

Erica tetralis, 65.

Esparcet, 50, 182, 228.

Ethereal oils, 10.

Ether soluble non-fatty substances, 10.

Examination, of by-products, 141 . of feeding stuffs, 131. of starch grains, 137.

Exanthema, 51 .

Exercise, 151.

Extract, 11. meal, 113. product, 13.

Fagopyrum, 53.

False flax, 69, 200.

Fats, 5, 10, 152, 153 .

Fattening growing pigs, 192.

Fattening rations, 194.

Fat tissue, 152.

Feces, examination of, 161.

Feed cakes, 87. sugar, 111.

Feeding calves, 181. chickens, 207.

ducks, 212.

for profit, 1 . growing animals, 179. lupine hay, 63. molasses, 109. periods, 168.

Feeding stuff, conservation of, 16. of animal origin, 124.

Feeding stuffs, 149, 299.

Feed utilization, 163.

Fennel, 123.

Ferments, 7.

Fermentation, 23, 29 acetic acid, 24. butyric acid, 24. lactic acid, 24.

Ferns, 65.

Fertilizer, 44.

Fertilization of fish ponds, 215.

Festuca, 36, 41.

Festuca rubra, 40.

Field beans, 93, 226, 230.

Field beets, 74, 228 .

Field pea, 50, 86, 93, 94, 95.

Field rushes, 43.

Field spurry, 9, 35, 53, 98.

Fish feeding, 221.

Fish food, 216.

Fish food meal, 216.

Fish meal, 126.

Flag oats, 81.

Flax seed meal, 98.

Flax seed, 69, 223, 230, 226.

Flesh forming food, 153. 
Florin grass, 37.

Fluid feeding stuff, 149.

Fluorophyll-Koefeld, 54.

Fly toadstool, 57.

Food-

agreeability of, 166 .

palatability of, 166.

dietetic effects of, 167.

Food for goats, 204

Food for pregnant bitches, 206.

Food influence on milk secretion, 199.

Forage, green, 35 .

disadvantages of, 46 .

advantages of, 45 .

practical use of, 46 .

Forage plants, 44.

Formic acid, 15.

Foot and mouth disease, 124.

Foxtail, 36.

Freezing, 17.

Fruit sugar, 11, 13.

Fructose (fruit sugar), 11, 13.

Fucus, 128.

Fucus serratus, 128.

Fucus vesiculosis, 128.

Fungi, 57, 222.

Galactose, 11, 14.

Garlic, 46.

Gawalowsky's test, 134.

Geese, food for, 213.

Gentopicrin, 16.

German cadaver meal, 125, 126.

Germination, 17.

Giant cheat, 41.

Githagin, 16

Glauber salts, 224, 218.

Glove factory waste, 126.

Glue concentrate, 127.

Glutamin, 9.

Gluten, 111.

mean, $111,112$.

Glyceria aquatica.

s. spectabilis, 41 .

Glyceria fluitans, 41.

Glycogen, 11, 153.

Glycosids, 9, 16.

Goats, milk yield of „204.

Golden oats, 38, 40.

Good herbs, 59.

Grain prematurely ripened, 85 .

Grain, 90.

lean, 80 .

slop, 105 .

straw, 65 .

Grape sugar, 11, 13.

Grape vines, 65 .

Grass, 3, 41, 225.

cultivated field, 47.

fescue, 43.

florin, 37.

honey, 38, 40, 41 .
Grass, manna, 41

meadow, 45 .

pasture, 47.

sour, $35,43,58$.

sweet, 35,39 .

Grease, 109.

Green barley, 47.

rye, 47 .

wheat, 47.

stuff, 208.

feed for chickens, 207

Grits, 13.

Grits and groats, 131.

Group feeding, 163.

Guanin, 9.

Guanidin, 9.

Gum, 11, 51.

Hansa blood meal, 110

Hay, 44, 57, 62, 229.

aftermath, 57.

air dried, 19.

baked, 23.

bean, 63 .

brown, 23 .

buckwheat, 63 .

clover, 63 .

fresh, 59,60 .

heather, 65 .

judging, 58 .

leaf, 64,66 .

lupine, 63 .

meadow, 57, 59, 186, 229.

pea, 63 .

to prepare, 19.

rations, 171 .

twig, 65 .

uses of, 62 .

Heather, 65.

meal, 65 .

Heat production, 150.

Henneberg's method, 11.

Hexones, 11.

Hulls and chaff, 67, 68, 226.

Humic acid, 160.

Holcus, 38, 40, 41 .

Honey grass, 38 .

Hops, 103, 105.

trefoil, 229.

Horse chestnut, 98, 99.

Horses, feed for, 178 .

Hybrid clover, 48, 49.

Hygiene, 2.

Hygienic examination, 133.

Hypholoma fasciculare, 59.

Hypoxanthin, 9.

Iceland moss, 65 .

Icterogen, 63.

Incrustated, 11

Individuality, 151.

Individual feeding, 162. 
Influence of feed on milk secretion, 199.

Infusorial earth, 134.

Infusoria, 215.

Inorganic salts, 155 .

Insufficient nutriment, 148.

Inulin, 11.

Iodin, 13.

Iodin starch reaction, 4, 134 .

Iron, 4, 160.

Iron salts, 5, 161.

Irrigated meadows, 59.

Java bean, 95 .

Judging hay, 58.

Juncus, 43.

June grass, 38.

Kapok cake, 123.

Klimaxmelasse, 110.

Kjeldd's method, 5.

Lactarius rufus, 57.

Lactic acid, 14.

Lactic acid fermentation, 24.

Lactose (milk sugar), 11,14.

Laminaria, 128.

Lathyrus sylvester, 54 .

Leaching, 30.

Lead, 4.

Leaves of, beets, 54 . cabbage, 54 . car rot, 54 . kohlrabi, 54 . fall turnip, 54 .

Lecithin, 10.

Lees of wineries, 107.

Legumes, 93, 222, 226.

Legume seeds, 76.

Lehmann's method, 32 .

Leguminosæ, 50 . hulls of, 69,144 . straw of, $68,226$.

Lemna, 220.

Levulose (fruit sugar), 11, 14.

Licking disease, 159.

Liguin, 11.

Lime, 4, 134, 155, 157.

Lime salt, 5 .

Linamarin, 9.

Linseed, cake, 9, 114, 135, 231. meal, $98,114,135$. by-products, 114 . or flax hulls, 69.

Lodging of grain, 76.

Lolium, 36, 38, 41 .

Lucerne, 51, 228, 229.

Lumpy jaw, 47.

Lupines, 8, 52, 93, 222, 231.

Lupine alkaloids, 9, 63.

Lupine, green, 228.
Lupine hay, 63, 96, 229.

hulls, 231 . seed, 11.

Lupine, toxic properties of, 63,96 .

Lupinosis, 62, 64.

Lupinotoxin, 63.

Luzula, 43.

Lysin, 8 .

Machine threshed straw, 67 .

Madia cake, 122.

Magnesia, 4, 160.

Magnesium salts, 5 .

Mahwa nut oil cake, 122

Mahwa or bassia meal, 131.

Maintenance ration, 149.

Maintenance ration for oxen, 173 .

Maizena, 112

Malic acid, 15.

Malt, 103. crushed, 34 sprouts, 103, 104, 110,149, 222, 227, 231. sugar, 11, 14.

Maltose, 11.

Mangel wurzel, 14.

Manganese, 4.

Manna grass, 41 .

Mash, 87.

Mastication, 150.

May bugs, 182, 223.

Meadows, 47, 218.

Meadow oats, 37 .

Meadow grasse's, 45, 218.

Meadow peas, 44 .

Meal cakes, 112.

Meal flat cakes, 86 . gruel, 141. mite, 85. testing, 134.

Meat meal, 125, 126, 223, 227.

Medicago lupulina, 48, 49.

Medium grain, 80 .

Melelotus, 50.

Mercury, 5.

Meteorological conditions, 45.

Microscopic examinations, 136.

Middlings, 90, 100, 101, 102.

Mielitz hay, 60 .

Milk, 122, 124, 182, 183, 184, 185. butter, 125, 186.

by-products, $223,232$.

cows, $121,227$.

for young dogs, 206.

fungi, 57 .

molasses, 110.

plant influence on secretion of, 46 .

powders, 151.

producing foods, 200.

ripe grain, 85 .

secretion, 1.

skim, 124, 186. 
Milk, sour, 186.

sugar, $11,13,14$.

transition to other feed, 183, 185 , $187,191$. whole, 124, 184.

Milking cows, after feeding, 168 . before feeding, 168 .

Millet, 54, 92. bran, 102. hulls, 102. meal, 102. shells, 131.

Milling by-products, 99 .

Mineral acid, 134. admixture, 133. matter, 4, 134, 154, 155. substances, 136.

\section{Mites, 147.}

Moistening food, 29.

Molasses, 108, 109, 222, 227, 231. blood, 110 . cakes, 110 . for feeding, 109. peat meal, 110. pulp, 109.

Mold, 147. fungi, 3 .

Money value of feeding stuffs, 129 .

Monosaccharids, 11.

Moon bean, 95.

Mother peas, 94.

Muscular energy, 153.

Mustard ,54, 123. seed cake, 123. oil, 115.

Nardus, 36, 37, 43.

Neurin, 9.

Nobbe's compound sieve, 136.

Nonesuch, 49.

Nonproteid nitrogenous compounds, 8.

Niger cake, 123.

Nitrates, 10.

Nitric acid, 9.

Nitrogen, 5, 6, 10. free extract, 11, 12, 151, 152 . free organic substances, $5,10$.

Nitrogenous bodies, 5 . glycosids, 9.

Nutrient assimilation, 150 . requirements, 150, 151 . salts, 155. ratio, 49,170 .

Nutritive value of leguminosea, 50 .

Oats, 81. bran, 102. flag, 81 . freshly harvested, 83 . musty, 85 .
Oats, panicled, 81 . purr, 81 . straw, 102. wild, wind, 81 .

Oat grass, 37.

Odor, 10, 81, 84, 104.

Oexmann's method, 31 .

Oil cakes, 85, 113, 144, 227.

Oil production, 112 .

Oleic acid, 10.

Olive cake, 123.

Onion, 44, 46.

Onobrychis sativa, 50 .

Orchard grass, 38, 40, 228 .

Organic acid, 14. bases, 9 . material, 5 . nutrients, 154 substances, 149.

Ornithopus sativus, 50 .

Osteomalacia, 100.

Ostracoidea, 216.

Ovagsolan, 174.

Over feeding, 51 .

Oxalic acid, 15.

Oxen, feed for, 176, 177.

Oxygen, 220.

Palatability, 166.

Palmatin, 10, 185.

Palmseed cake, 115. molasses, 109.

Paludina, 217.

Paralytic symptoms, 109.

Pasteurization, 124.

Pasture, 183. grass, 47.

Paxillus, 55.

Pea, 87, 93, 222, 226, 228, 231. chick, 94.

chickling, 95.

meal, 86. sugar, 93 .

Pears, 75, 230.

Peanuts, 230. by-products, 116 . hulls, 116, 131 . meal cake, 147, 220, 227, 231. shelled, 117.

Peat ground, 65.

Peat meal molasses, 110.

Pebbles, 110.

Pectin, 14.

Pelagic life, 215.

Pentones, 11.

Pentosanes, 11, 13, 14.

Peptone, 103. feed, 110.

Peptonization, 34 .

Petroleum ether, 112.

Phalaris 41, 44.

Phaseolus lunatis, 95. 
Phleum, 36.

Phleum pratense, 41.

Phosphate of lime, 126, 127.

Phosphoric acid, 4, 5, 157, 160.

Photodynamic substance, 51 .

Pigs, rations for fattening, 192.

Pitting, 16.

Pisum sativum, 50,93.

Pisum arvense, 93.

Plankton, 215.

Planorbis, 217.

Plums, 75, 230.

Poa, 36, 38, 40.

Poisonous plants, 1.

Polygonaceæ, 93.

Polysaccharids, 93.

Polygonum fagopyrum, 53.

Pomace, fruit, 107.

Poppy seed cake, 121, 227. feeding stuffs, 121, 230.

\section{Potash, 4.}

Potash salts, 5, 159, 160.

Potassium, 4.

Potatoes, 56, 69, 226, 229. desiccated, 22, 226.

fiber, 111.

flakes, 73, 78.

for dogs, 206.

for ruminants, 71 .

pits, 18.

pressed, $22,73,86$.

puff ball, 57 .

pulp, 111.

rot, 18.

shavings, 22,86 .

slop, 105, 227.

sprouted, 17,70 .

storage, 16.

tops, $18,56,64$.

Poultry feed, 207.

Powders,

appetizer, 151.

cattle, 151.

fattening, 151 .

milk, 151 .

Predigestion, 34.

Precipitation, 135.

Preparation of food, 28, 168. for preliminary tests, 136 .

Premature ripening, 76.

Press feed, 26.

Prickly dyers broom, 56.

Principles of feeding, 148. of nutrition, 148.

Productive rations, 149.

Propionic acid, 14.

Protein, 5, 151. pure, 6 .

Prussic acid, 49.

Pumpkin, 75, 123.

Pure water, 208.

Purity of grain, 79.
Purr oats, 81 .

Quaking grass, 41 .

Qualitative tests, 133,135 .

Quick grass, 74.

Rabbit feeding, 214.

Racks, 19, 162.

Raffinose, 11, 14.

Rainbow trout, 220.

Rangoon or moon bean, 95 .

Rape, 54, 229.

hulls, 69 .

seed, 98 .

seed cake, 114, 115, 122, 227, 231.

straw, 68.

Rations, 169.

Rations for

breeding pigs, 191.

calves, 183.

carp, 222.

cattle fattening, 197.

chicks, 209.

chickens, 207.

fattening chicks, 211.

colts, 182.

cows, 201.

dry cows, 202.

milk cows, 203.

pregnant cows, 202.

dairy animals, 198.

dogs, 205.

ducks, 212.

fish, 215, 216.

growing animals, 179.

pigs, 191.

sheep, 189.

geese, 213.

goats, 204.

hog fattening, 191.

lambs, 188.

laying hens, 210.

mature ruminants, 194.

swine, 198.

military horses, 177.

mutton breeds, 189 .

nursing sows, 193.

poultry, 207.

pups, 206.

rabbits, 214.

sheep fattening, 197.

wool sheep, 175 .

work horses, 177.

work oxen, 176.

young dogs, 206.

Raw meat, 8.

Red top, 37.

Reeds, 35, 43, 65.

Reindeer lichens, 65.

Resin, 33.

Respiration, 16.

Rice, 92, 93, 134. 
Rice, bran, 103.

chaff, $68,131$.

feed meal, 101, 103, 227.

gluten, 112.

refuse, 104 .

slop, 111.

wash, 112 .

Ricinus communis, 122, 135.

Roasting, 30.

Roborin concentrate feed, 110.

Rock salt, 159.

Rolled grain, 29.

Roots, 68, 69, 94.

Rotalia, 215.

Roughage, 57, 59, 149

Rules for purchase of commercial feeding stuffs, 131.

Rutabago, 74.

Rushes, 43.

Russula, 57.

Rye, $87,90,91$.

bran, 102 .

chaff, $68,226$.

cracked, 90.

flour, $90,231$.

grass, $37,38,41$.

meal, 99.

slop, 106.

straw, $67,226,230$.

Saccharification, 33, 34 .

Saccharified starch, 186.

Saccharose, 11, 14.

Saline, 58.

Salt, common, 4, 158.

fed animals, 192.

hay, 60 .

in feeding stuffs, 160, 230, 231, 232.

marsh hay, 60 .

potash, 219.

Salts, $2,4$.

ammonia, 9 .

epsom, 218.

inorganic, 155.

lime, 93 .

phosphorus, 155.

Sampling feed stuffs, 132 .

Sand, 133, 134, 208.

Sand fleas, 216.

oats, 81 .

reed, 43

vetch, 50 .

Saw dust, 33, 64, 65 .

Saw dust or meal of fir tree, 33.

Scalding, 29.

Scavengers, 222.

Schaffnit's method, 137.

Sea algea, 128 .

Sedge, 43 .

Seed hulls, 68 .

Sedges, 35, 43.

Serradella, 93, 209, 228, 229.
Sesame by-products, 121 .

Sewage, 219.

Sewage in fish ponds, 221.

Shavings, 65.

Shells, hulls and skins, 141

Silage, 24, 60.

Silica, 4. sweet, 24,62 .

Silicic, 4.

Silo, 25.

Silo filling, 26.

Silver grass, 43.

Sinalbin, 9.

Sinigrin, 9.

Slimy residue, 124.

Slop eczema, 70, 106.

Slop,

rye, 106.

corn, 106.

cough, 106.

dry, 107.

rye, 106.

sugar refinery, 106.

Slops, 3, 105, 106.

Smut, 68 .

Smut spores, 133, 143.

Soaking, 29.

Sodium, 4, 160.

Sodium salts, 5 .

Sodium cellulose, 33, 34 .

Soft feed for chickens, 207.

Soil, 45.

Solanin, 9.

Solanin poisoning, 70.

Solanidin, 9.

Sorghum, 49, 230.

Sorghum saccharatum, 135.

Sour grasses, 35, 43, 58.

Sour silage, 63.

Soy bean, 50, 93, 97.

Soy bean cake, 122.

Spawn, 217.

Spear grass, 38, 41.

Spelt chaff, 69, 87, 230.

Spent hops, 104.

Spergula arvensis, 53 .

Spoiled feeding stuffs, 134 .

Spurry, 53.

Squash, 75.

Stable conditions, 195.

Stall mangel, 159.

temperature, 196.

Starch, 11, 13.

Starch grains, 137, 138.

Starch value of food, 130, 169.

Starchy gruels, 190.

Steaming, 28, 29.

Steffen process, 111.

Stems, 76.

Stinging gnats, 217.

Stock salt, 159.

Storage, 16, 17. 
Storiers, 222.

Straw,

barley, 67.

bean, 68 .

buckwheat, 68 .

chaffed, 32 .

concentrate, 31 .

false flax, 68 .

flail, 67.

grain, 65 .

legume, 68 .

millet, 67 .

pea, 68 .

pulp, 33 .

rape, 33 .

rye, 67.

spring cereal, 178.

summer, 65, 230.

turnip, 33 .

vetch, 68 .

wheat, 66 .

Suberin, 11 .

winter cereal, 178.

Sugar, 13, 107.

beet, 14, 74 .

by-products, 107 .

cane, $11,14$.

fruit, 11,13 .

grape, 11, 13.

malt, 11, 14 .

milk, 11, 14.

Sugar pulp, 107, 109.

Sugar refinery slops, 106.

Sulphite, 33.

Sulphite cellulose, 33.

Sulphite lye, 33 .

Sulphuric acid, 4, 11, 143, 218.

Sunflower seed cake, 121, 227.

Swedish clover, 49, 228.

Sweet mashes, 34 .

Sweet press feed, 158.

Sweet silage, 24, 26, 62 .

Sweetening in potatoes, 17.

Symphytum asperrimum, 56.

Tankage, 125, 223. meat meal, 227.

Tannic acid, 15, 94, 99.

Temperature of food, 167.

Tench, 220.

Testing spoiled feeding stuffs, 134 .

Theobromin, 9 .

Thermo precipitation, 135.

Timothy grass, 36, 38, 41, 228.

Toadstools, 57 .

Torulin, 8.

Toxic laminitis, 109.

Tricholoma, 57 .

Trieur, 80.

Trifolium, 49.

Triglochin, 43.
Tricicum, 38.

Trisitum, 38.

Tropon waste, 126.

Tryptophan, 8.

Tubers, 69.

Tubercle bacilli, 124 .

Tuberculosis, 124. alimentary, 124. feeding, 124.

Tumelin, 110.

Turnip, 54, 74, 229. seed cake, 114, 115.

Turpentine, 33 .

Tutolin, 110.

Tyrosin, 9 .

Ulex europeus, 56.

Urinary calculi, 100.

Utilization, 150, 161.

Vacuum tank, 126.

Valerianic acid, 14.

Vegetable fat emulsion milk, 185. mucilage, 11, 14. wax, 10. oil, 112.

Vetch, 14, 15, 43, 50, 52, 93, 134, 223. chickling, 94 . common, 135. feed, 230, 231.

fence, 44 .

kidney, 16, 229.

sand, 135, 229.

straw, 68 .

tufted, 44 .

winter, 135 .

wood chickling, 54 .

Vicia sativa, 50, 135 .

Vitamins, 7, 8, 152.

Vogl's reaction, 134.

Volume of feed ration, 166.

Water, 3

Water chess, 42. content, 165 .

fleas, $215,217$.

pepper, 44.

plantain, 44. pure, 208.

Waxy stage of grain, 85 .

Weaning, 183, 185, 187, 191.

Weed seeds, 136, 146.

Weender, method, 11.

Weingaertneria, 43.

Wheat, 47, 90, 91, 111, 134.

bran, 101, 102.

chaff, 68.

middlings, 102.

straw, 66 .

Whey, 125.

Wild forage plants, 44 . 
Wild or wind oats, 81 .

Xylan, 14.

Wine preparations, 107.

Xylose, 11.

Wood cellulose, 33 .

gum, 14.

meal, 33 .

rushes, 43 .

Work, shavings, 65 .

consumption of nutrients in different kinds of, 154 .

Wormwood, 16.

Worthless herbs, 44.

Xanthin, 9.

Yarrow, 51.

Yeast, 7, 105, 227. beer, 105 .

cooking, 105.

dried, 105.

dry, 1,87 .

mineral, 105.

residue, 227.

Yellow rattle, 134.

Zink, 4 





